\title{
Envisioning Equity: Coalition and Partnership Strategies of Ottawa's Equity and Inclusion Lens
}

\author{
by \\ Yumi Kotani
}

A thesis submitted to the Faculty of Graduate and Postdoctoral Affairs in partial fulfillment of the requirements for the degree of

\author{
Master of Arts \\ in \\ Political Economy
}

Carleton University

Ottawa, Ontario

(C) 2014, Yumi Kotani 


\begin{abstract}
This thesis examines the development process of the Equity and Inclusion Lens, a guidebook on inclusive practices designed for City of Ottawa employees, created by a coalition of eleven local community-based social movements in partnership with the City. It analyzes the political strategies pursued by these actors at three interrelated but distinct scales: the City-community partnership, the intersectional coalition of movements, and the individual movements themselves. While the shared strategies adopted by both the coalition and the partnership were generally effective in achieving their common goals, as well as those specific to each movement, this study argues that the multiple priorities they had to address sometimes contradicted one another. The strategies adopted at the higher scales also played out differently at the scale of the individual movements, as some movement-specific strategies aligned more readily with the shared strategies of the coalition and the partnership, while others ran counter to them.
\end{abstract}




\section{Acknowledgements}

I would like to express my sincerest thanks to so many people who contributed to the completion of this thesis. I am particularly grateful to all the participants of this study for their generosity in sharing their thoughtful reflections, insights, knowledge and memories, as well as their hopes and frustrations with me. I hold in great respect all those who have worked countless hours to make our city a more inclusive and equitable place over the years, some of whom are part of this study and others not. I am deeply inspired by all of your work, for this is what has made it possible for me to do my part, and I look forward to contributing to what we can accomplish in the future. Within the university my deepest gratitude goes to my thesis supervisor Justin Paulson, who provided me with unwavering support and encouragement throughout this process, and knew when I need it the most. Without your support I would not have persisted through the difficulties I encountered along the way. I also thank my secondary reader Teresa Healy, who helped me appreciate the joy of the reflexive process I had the privilege to go through as a researcher, a member of the community I was studying, and as a living human being trying to make sense of it all. Donna Coghill at the Institute of Political Economy has supported me from day one, and I am ever so grateful for what you do for all the students who come through this program. Special thanks to many faculty members at Carleton University and elsewhere who taught me the true meaning of equity through their actions and the work that still lies ahead of us. I also thank Aha Blume for working hard to transcribe the interviews. I am most indebted to my partner Matt, who has been my strongest supporter and always helped me meet the challenges and learn from the mistakes along the way. And to all those I have not mentioned yet - thank you. 


\section{Table of Contents}

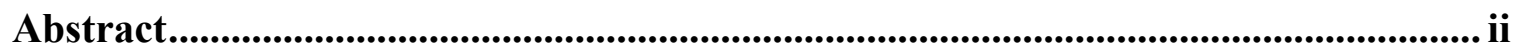

Acknowledgements ...............................................................................................................ii

Table of Contents …......................................................................................................... iv

List of Appendices..................................................................................................................... $\mathrm{x}$

1 Chapter: Introduction ........................................................................................................ 1

1.1 Divergent Processes within the Coalition and the Partnership .................................... 4

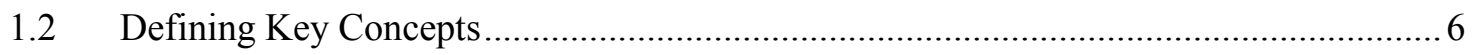

1.2.1 Movements, Coalition, and Partnership ......................................................... 7

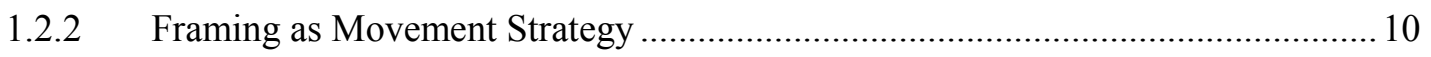

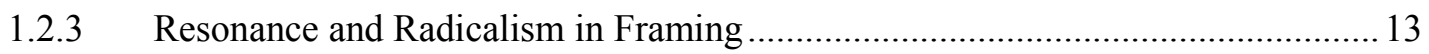

1.2.4 Frame Alignment: Vertical across Scales and Horizontal across Movements....... 16

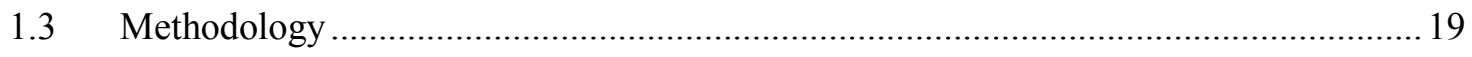

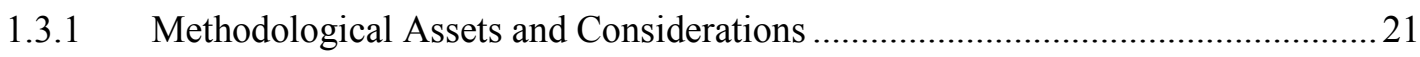

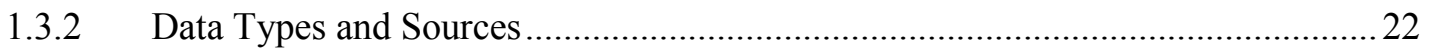

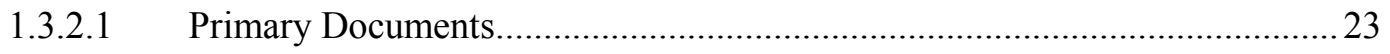

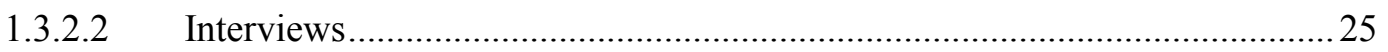

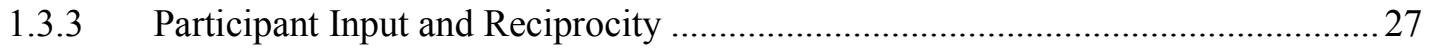

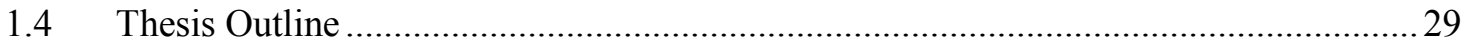

\section{Chapter: Historical Background of the E\&I Lens: Origins of the Coalition and}

Partnership Strategies ............................................................................................................... 32

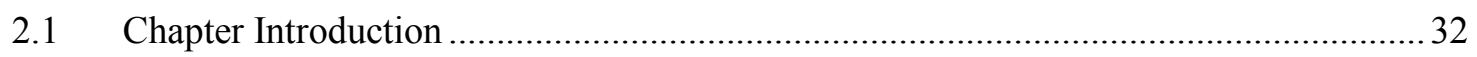

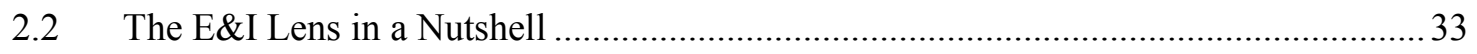

2.3 Emerging Strategic Priorities: Basis for the Coalition- and Partnership Frames ............36

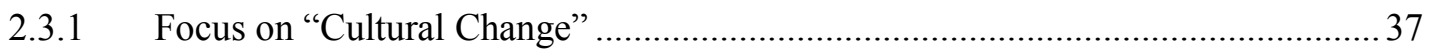


2.3.3 Broad Engagement and Direct Representation ................................................ 43

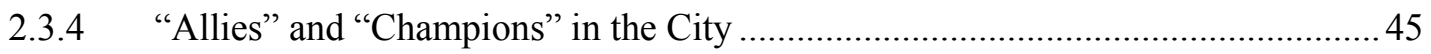

2.3.5 From Advocacy to Partnership to Resonance: Prioritizing City Employees ......... 47

2.3.6 From Separate Communities to an Intersectional Coalition ............................... 49

2.4 Local History: Equality Framework and the Gender Equality Lens ............................51

2.4.1 The Ottawa Equality Framework: An Early Articulation of an Intersectional

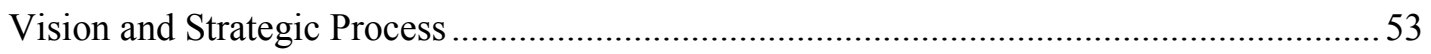

2.4.1.1 Beginnings of a Coalition, and a Partnership ..............................................5

2.4.1.2 Tie-in: Alignment with the Official Frame(s) ............................................59

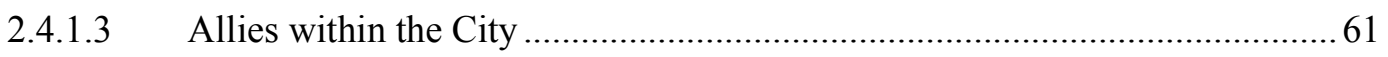

2.4.1.4 Strategic Framing for Resonance (and Radicalism) ...................................6 65

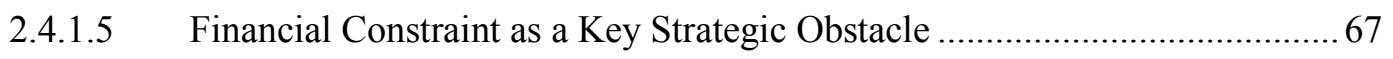

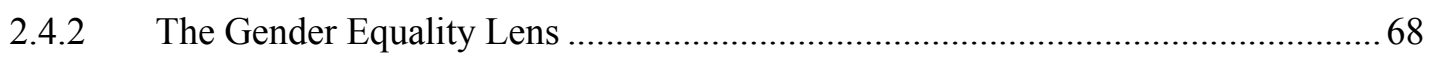

2.4.2.1 The Early Lobbying Effort for Gender-specific and Broad-based Equality .. 69

2.4.2.2 Achieving Concrete Implementation through Allies within the City ............71

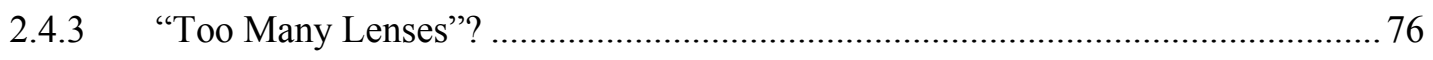

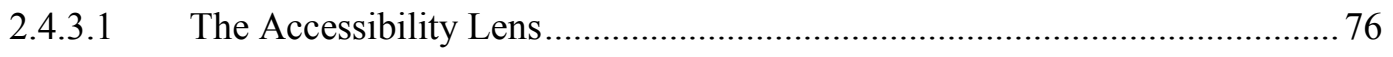

2.4.3.2 The Equity and Diversity Lens: From Competition to Collaboration............. 80

2.4.3.3 CAWI's Strategic Framing to Secure Management Buy-in............................ 84

2.4.3.4 The Continuing Challenge of Securing the City's Financial Commitment ... 86

2.4.4 Equity and Inclusion Lens Development Approved ........................................ 92

2.4.4.1 Recruitment of the Equity and Inclusion Lens Reference Group ..................97

2.4.4.2 Concerns Raised by the Advisory Committees........................................... 98

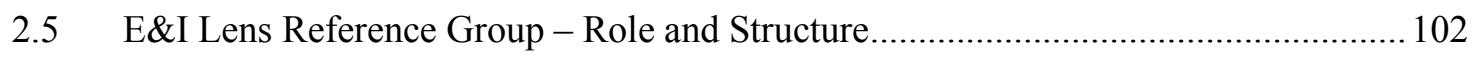

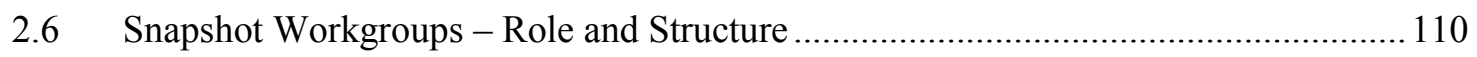




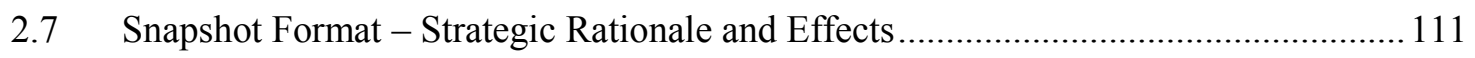

2.8 Snapshot Development Process - Strategic Rationale and Effects............................. 113

3 Chapter: People with disabilities and GLBT Snapshots Subcases.................... 117

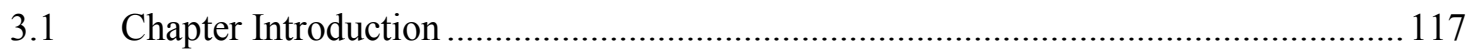

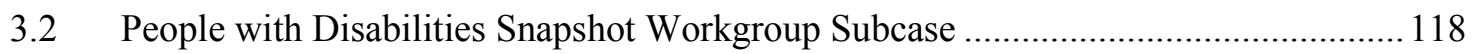

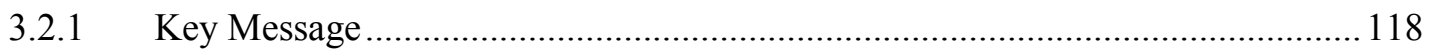

3.2.2 Key Debates and Discussions at the Workgroup ............................................... 120

3.2.2.1 Breaking Down the Label "Disability" .................................................... 121

3.2.2.2 Balancing the 'Positive' and 'Negative' Content........................................ 127

3.2.2.3 Wishes of the Community vs. Needs of the City Audience.......................... 129

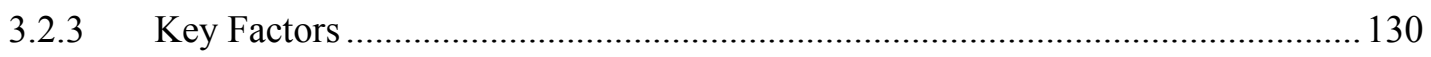

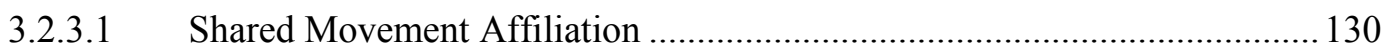

3.2.3.2 Strategic and Frame Alignment with the Reference Group ......................... 134

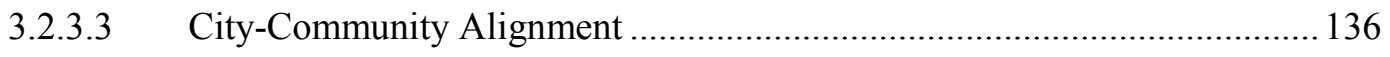

3.2.4 People with Disabilities Case Summary ....................................................... 141

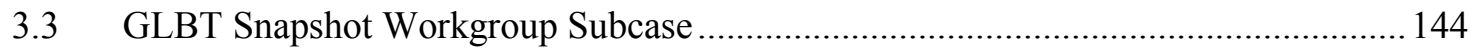

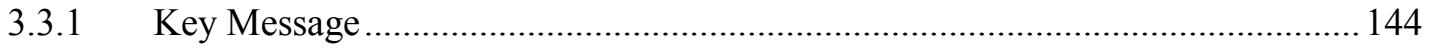

3.3.2 Key Debates and Discussions at the Workgroup ............................................... 149

3.3.2.1 Definitions and the Language Debate within the Community ..................... 149

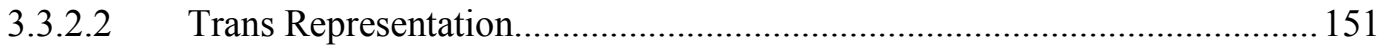

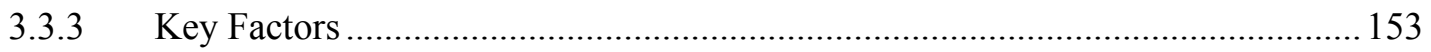

3.3.3.1 A Safe, Open, and Welcoming Space .................................................... 153

3.3.3.2 Internal Discussion and Strategic Framing for the External Audience........ 155

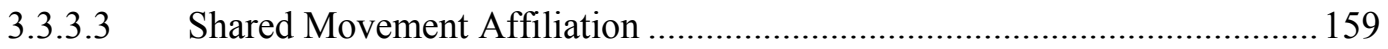

3.3.3.4 Discursive Strategic Repertoire of Affiliated Movements.......................... 162

3.3.3.5 Alignment with the Institutional Framework ......................................... 167 


\section{Chapter: Immigrants and Visible Minorities Snapshots Subcases ................... 175}

$4.1 \quad$ Immigrants Snapshot Workgroup Subcase ….......................................................... 175

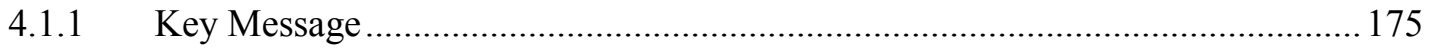

4.1.1.1 Overarching Frame: Immigrants as Resources and Opportunity ................. 175

4.1.1.2 Diverse Settlement Processes: Racism as Part of the Barriers ..................... 178

4.1.2 Key Debates and Discussions at the Workgroup .............................................. 180

4.1.2.1 Limited Scope of Official Definitions: "Recent" and "Skilled" Immigrants180

4.1.2.2 Labour Market Exclusion as 'Missed Opportunities' .................................. 185

4.1.2.3 We Are More than Just the Economy …................................................ 187

4.1.2.4 Naming Racism as the Societal Barrier ................................................... 189

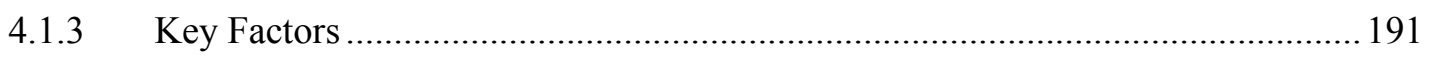

4.1.3.1 A Partially Transformative Frame as the Official Frame............................. 191

4.1.3.2 Alignment with the Coalition, Partnership and the City's Official Frames . 195

4.1.3.3 Frame and Resource Convergence in Broader Society .............................. 197

4.1.3.4 Strategic Resonance and the Risk of Reinforcing the Dominant Frame(s).. 199

4.1.3.5 Combining, Extending, and Modifying Frames........................................201

4.1.3.6 Strategic and Forced Resonance: Letting Go of the Radical by Necessity .. 203

4.1.3.7 Workgroup Composition and Strategic Awareness ..................................2 210

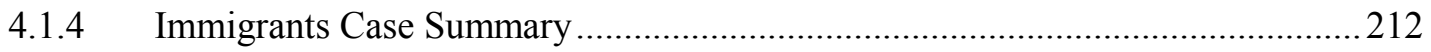

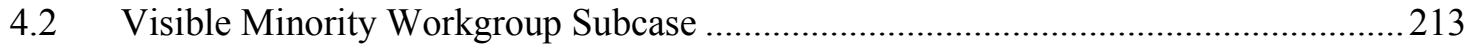

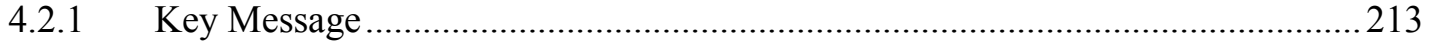

4.2.1.1 Key Message(s) of the Workgroup: Getting Racism on the City's Agenda 219

4.2.1.2 The Term 'Visible Minority' as Laden with Problems ................................221

4.2.2 Key Debates and Discussions at the Workgroup ..............................................224

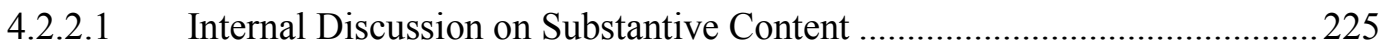


4.2.2.2 Internal Strategic Deliberation 228

4.2.2.3 Negotiation with the City: Prioritizing Resonance and Vertical Frame

Alignment 230

4.2.2.4 Recalibrating the Strategy..... 231

4.2.3 Key Factors .234

4.2.3.1 Strategic Priorities in a Bind .234

4.2.3.2 Polarized Discourse: 'Radical' and 'Oppositional' Message against the

Dominant Frame(s) 236

4.2.3.3 Lack of a Clear, Coherent, Alternative Movement Frame 239

4.2.3.4 Frame Dis-Alignment: Contesting the Official Discourse and the Institutional Framework 245

4.2.3.5 Partial Alignment with the Coalition and Partnership Frames...... 248

4.2.3.6 Clash of Priorities across Scales: Lack of An Ally in Key Position 250

4.2.4 Visible Minorities Case Summary .252

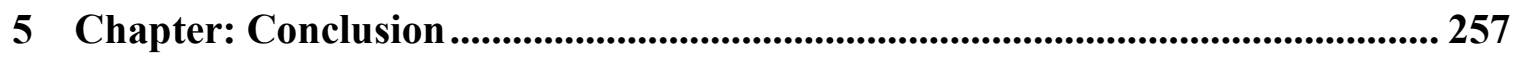

5.1 Dis/Alignment of Strategies and Priorities between Scales ......................................2257

5.2 Resonance, Radicalism, Dominant Frame, and Transformative Frame......................258

5.3 Radicalism as a Higher-Risk Strategy within the Multi-scale Context of the Coalition and Partnership 261

5.4 Radicalism at the Workgroup Scale: Varied Movement-Specific Conditions.............263

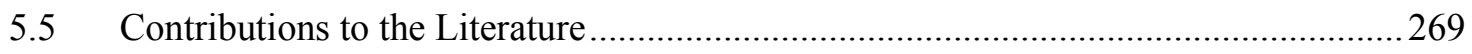

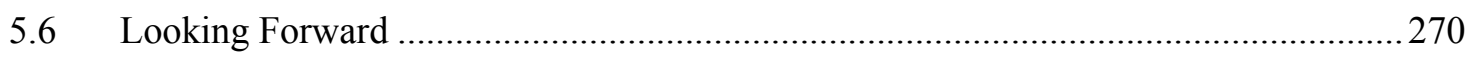

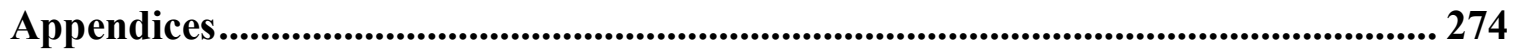

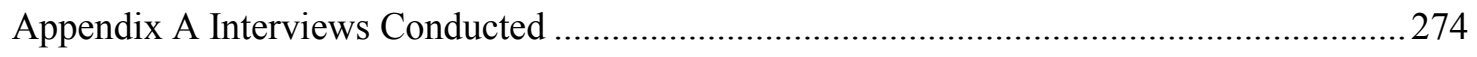

Appendix B Documentary Data: Non-Publicly Available Sources ......................................22 
Bibliography .................................................................................................................... 280 


\section{List of Appendices}

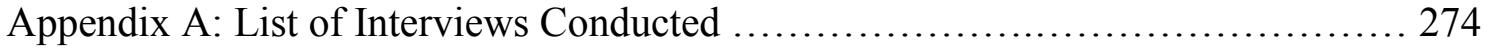

Appendix B: Documentary Data: Non-Publicly Available Sources ................ 276 


\section{Chapter: Introduction}

This thesis tells the story of a local community-City partnership initiative in Ottawa called the Equity and Inclusion Lens ("the Lens" or "the E\&I Lens"), a tool that was developed by an emerging coalition of eleven diverse local communities, in partnership with the City of Ottawa between 2008 and 2010. In the broadest sense, this is a story about pathways to social change at the local municipal level, and the strategic choices and challenges that these social actors encountered in the process. It traces the visions, goals, and strategies of these diverse communities as they came together to cocreate a tool to bring their city a little closer to their budding vision of an inclusive, welcoming, and equitable place for all segments of the local population - and not just their own - as expressed in the Lens's tagline "A City for Everyone" (CAWI and City of Ottawa 2010a). This was the first time in Ottawa's local history that these diverse marginalized communities came together under one banner, shared explicit goals, and worked systematically and consciously to think and act intersectionally - i.e., to ensure that the issues, perspectives and aspirations of each of these communities were heard and taken seriously not only by the City, but also by one another as they endeavoured together to develop the E\&I Lens.

The E\&I Lens was designed to be a hands-on, user-friendly handbook to assist City employees in identifying, reducing and removing systemic barriers that reproduce inequities and exclusion among Ottawa residents in their everyday work context, which included both the Corporation of the City of Ottawa as their workplace ("the City") and the broader public they serve ("the city" or "Ottawa") (CAWI and City of Ottawa 2010a: 34). The Lens highlighted the eleven communities that the City and community leaders 
came to identify over the years as "(most) at risk of exclusion in Ottawa", which are, in alphabetical order, Aboriginal peoples, Francophones, GLBT (Gay, Lesbian, Bisexual, Trans), Immigrants, People living in poverty, People with disabilities, Rural residents, Seniors, Visible minorities, Women, and Youth. ${ }^{1}$ The main advisory body called the "Reference Group" guided the overall development process of this Lens, made up of representatives from the eleven communities and the City who contributed their expertise, as well as lived and professional experiences, to the project. Their collective effort is reflected in the final product of the Lens, which consists of two parts: the "User's Guide" addresses intersecting systems of inequalities and identities, and eleven background documents called "Diversity Snapshots" convey a narrative by each of the eleven groups on their specific experience of marginalization in Ottawa.

This 16-month project to develop the Lens was funded through a partnership grant by Status of Women Canada and the City of Ottawa, whereby the two governmental entities from the federal and the municipal levels each contributed fifty percent of the financial cost to reduce their respective burden of promoting social inclusion at the local level. ${ }^{2}$ The project was coordinated by CAWI, an Ottawa-based feminist civic engagement NGO aimed at involving women from diverse backgrounds in municipal decision making, which established an official partnership with the City of Ottawa in

\footnotetext{
${ }^{1}$ Of course, eleven communities or population groups do not stand for all residents in Ottawa nor all marginalized or excluded groups in the city, and this is acknowledged in the Lens, as the users are encouraged to identify for themselves who else may be excluded or negatively affected and what other factors of exclusion may be salient in a specific work context they are operating in (CAWI and City of Ottawa 2010a: 7, 8, 26, 28). Chapter 1 will discuss the process by which these eleven groups came to be identified as most excluded in Ottawa's local context.

${ }^{2}$ I was part of this process most intensely between September 2008 and September 2009 when I joined the coordinating team for this project as a full time employee for the City for All Women Initiative (CAWI), a local feminist organization that acted as the project coordinating body. See the methodology section below for more detail about my role vis-à-vis the case.
} 
2005. ${ }^{3}$ CAWI took on this coordinating role because of their previous experience in having co-developed a similar, but more limited, planning tool in partnership with the City between 2006 and 2008, called the "Gender Equality Lens", which was designed to promote equality between women and men of diverse backgrounds in Ottawa (CAWI and City of Ottawa 2008a). This "Gender Lens" became a model for the Equity and Inclusion Lens, viewed as an "expanded" and more broadly "intersectional" version of the original, when the City moved away from issue- or population-specific lenses to a single consolidated lens for multiple marginalized groups in early 2008 (Interviews: a, d, e, g, i, j).

The decision to create the Diversity Snapshots came halfway through the project out of the concerns of the Reference Group members that the specific focus on each community may be lost in the intersectional approach of the Lens. To develop the Snapshots, the Reference Group struck eleven separate subcommittees called "Workgroups". Each Workgroup was comprised of a broader representation of community leaders and City employees who were recruited for their specific subject expertise on each marginalized community. The Reference Group set the general purpose, structure and format of the Snapshots to provide consistency across the board, but the substantive content of each document depended wholly on the input from each respective Workgroup. The Snapshots thus created a space for each community to tell their own narrative to the users of the Lens about who they are, their vision of an inclusive city, the contributions they make, and the barriers and challenges they face.

\footnotetext{
${ }^{3}$ Initially this partnership grant between SWC and the City of Ottawa was approved as a one-year project from 2008 to 2009. However, when the actual process of developing this Lens went beyond the originally proposed timeline and budget, the City's Human Rights and Employment Equity branch provided additional funding to CAWI on an ad hoc basis to complete the development of the Lens in 2010 (SWC 2009; Interview: a).
} 


\subsection{Divergent Processes within the Coalition and the Partnership}

All of these Workgroups pursued very similar strategic paths within each of their movement-specific space in developing their respective Snapshots. However, the actual processes that each Snapshot Workgroup took to arrive at the final version, and their experiences of this process, were by no means homogeneous. For example, while some Snapshots progressed relatively quickly and smoothly, others experienced noticeable delays in the process. In particular, the Visible minorities Snapshot involved a more complicated process of negotiation within the Workgroup, especially between what the community members felt should be said in the document, and what some of the City representatives perceived the target audience to be ready to hear. This posed such a difficulty in reaching common ground halfway through the process that it almost led to the dissolution of the Workgroup. Additional emergency discussions outside of the regular process were held in order to redefine their main objective and how they could get there, before they were able to resume their original task of developing the draft of the Snapshot. Meanwhile, advanced drafts on "GLBT" and "People with disabilities came to be used as a model for the rest of the Snapshots to follow, and even though the document on "Women" was started the last of all eleven it was completed in just under two months. These were less contested processes, and in my own experience of being part of this process at the time, I heard various comments by participants that spoke to their very different experiences in developing these documents.

My research was first inspired by these apparent differences in the processes and experiences of these individual Workgroups. I began to ask what it was that contributed to such differential processes and experiences, when all eleven communities and the City 
had ostensibly chosen to pursue a shared strategic path to get to a shared destination - a City for Everyone - by co-developing this Lens. ${ }^{4}$ More specifically, what did each of these movements desire to convey in their respective Snapshots, and how well were they able to achieve it, and finally, what contributed to their ability to do so?

To answer these questions, I turned my attention to the interaction among the strategic priorities and choices that the actors involved in this project made, especially across the distinct but interrelated scales at which they were formed, negotiated, and executed. I conceptualized these actors as operating at three scales, namely: as eleven 'community movements', one intersectional 'coalition' of these eleven movements, and the official City-community 'partnership' that wove them together in this project to cocreate the E\&I Lens. To facilitate this analysis, I focused on four sub-cases and began to examine the diverse combinations of factors that shaped the dynamic interactions of these multiple - and sometimes contradicting - strategic priorities across these scales, which together shaped the different processes and experiences of each Snapshot Workgroup.

In addition, I began to see evidence that contributors were engaging in the discursive politics of framing in hopes of bringing about a cultural change in how the City conducts its everyday businesses. This overall package of shared strategic priorities and choices that the contributors to the Lens pursued was to form a new intersectional coalition of identity-based movements, which in turn formed the City-community partnership. In turn, these strategies combined to create a tacit need among all the

\footnotetext{
${ }^{4}$ This thesis does not assess the 'outcome' of these processes in terms of success, because what appears to be a win or a loss changes for different parties. Despite the delays and significant compromises, and despite the general consensus I found among the Lens participants that Visible minority Workgroup seemed to have been "most contentious" (Interviews: a, e, f, n) in retrospect many of its members have found the final draft to be one of the most progressive, or most rewarding, or most detailed out of all the Snapshots (Interviews: e, $\mathrm{k}, \mathrm{u}$ ), or have since used this experience to strengthen the advocacy effort about racism (Interview: a).
} 
participating movements and the City to pursue a shared discursive strategy, or more specifically, a shared framing strategy to inform what was to be included in the Lens and how, as well as in each of the eleven Diversity Snapshots.

In part, this strategic package resulted from the previous work done by local social actors who had generated strategic innovations in this area extending over the past decade, though of course these 'choices' were circumscribed by historical path dependency (partly shaped by their own actions as well as of City officials over the years) as well as the increasingly limited resources made available to address inequities in Canadian cities since the 1990s. However, in this new moment, local actors pursued this shared strategic package as a creative effort to manage the diverse priorities of coalition partners to produce a common output that advanced the shared objective. For the most part they were successful, in that at the end of the 16-month process they produced a relatively simple and easy-to-use tool that invited users to consider the differential impact of various systemic barriers on all eleven communities.

\subsection{Defining Key Concepts}

As I continued to examine the complex processes of calibration among the eleven distinct movements and the City at these three scales, it became evident to me that the particular configuration of the strategic choices and priorities that this coalition and the partnership collectively adopted played out differently at the scale of the individual community movements as they developed their respective Diversity Snapshots. This occurred even while all of them, without exception, had to manage these multiple, and sometimes contradictory, priorities spanning across scales. Below, I lay out the key points of strategic contradictions in this package that faced this coalition of movements 
and its partnership with the City. Before I do so, I will discuss some of the basic concepts I use to set the context for my analysis of the Equity and Inclusion Lens development process.

\subsubsection{Movements, Coalition, and Partnership}

First, I call the eleven communities involved in this process 'community-based movements', 'community movements', or 'movements' for short. Each is a population- or identity-based social movement, as they advocate on behalf of a specific marginalized group in society, in this case the amalgamated City of Ottawa. They are a variant of “equality-based special issue movements" in Morris and Braine's classification of social movements (2001), as the cause that makes them a distinct movement is their subjective experience of a systemic oppression in human society. ${ }^{5}$ In short, these are identity-based movements associated with a specific marginalized group - or a specific set of issues affecting that population - for example the experiences of limited accessibility for people with disabilities, of racism for visible minorities, and of homo- bi- and trans-phobia for GLBT people.

These movements are not completely outside of the state or oppositional to it as Gamson (1990[1975]) and McAdam (1992) posited a few decades ago. Rather, they are institutionally embedded in the non-profit, non-governmental community service and/or advocacy groups and organizations at the local level - or civil society. I view these community movements as "state-oriented challengers" in the sense that they seek "to gain

\footnotetext{
${ }^{5}$ Note, however, that the language "oppression" was not the official part of the coalition or the partnership frame for the Lens, but this was instead framed in terms of "systemic barriers" that are responsible for creating "exclusion" and "inequity" for target groups. While several members of the Reference Group and Workgroup members that I interviewed did use the concept and the language of "oppression" as part of the description of their work, as the coalition and as the partnership they did not use this in the Lens mainly because this was deemed too 'radical' and unbefitting for this City-community partnership project (Interviews: c, i, m, n, o, p, u).
} 
collective goods through states" (Amenta et al. 2002: 47, italics mine) and to influence the state structure and function itself to pursue that end (Amenta and Caren 2004). These community movements' demands entail the full inclusion and participation of marginalized groups in the social, cultural, economic, and political life of the city, which includes political representation, labour- and consumer market participation, and active community engagement (City of Ottawa 2010a; 2010b-1). In other words, they claim their own inclusion into the state, market, and civil society, and call for an active state role in facilitating it - rather than rejecting, defeating, subverting, or taking over the state.

These are also an extension of the "new social movements" that seek both material redistribution of resources and symbolic recognition of the disenfranchised within the (welfare) state (Wilde 2007; Fraser 2000). The difference is that the community movements are operating in today's entrenched neoliberal urban governance in Canada, after years of cuts to welfare budget and devolution of responsibilities from the national and the provincial to the local scale of governance since the 1990s have left the municipal governments with mismatched resources and capacities for this role (Boudreau et al 2009; Keil and Mahon 2009; Graefe 2005, 2006; Anheier 2009). This in turn gave rise to a new mode of economic governance called "public-private partnership" (PPP), which seeks to further devolve authority and responsibility from the state to the policy networks in civil society (Bradford 2003). The case of the E\&I Lens fits one variant of PPP, which opts to "address problems of social exclusion in the new economy by encouraging associative dialogue among diverse representative groups" (ibid: 1005).

Second, I call these eleven communities' co-participation in the development of this multi-issue, multi-group and thus intersectional Lens an intersectional coalition of 
identity-based community movements. This is what makes the case of the E\&I Lens particularly interesting, for it is not a single-issue coalition among organizations and groups addressing an already similar or shared set of issues organized solely around gender, race, or sexual orientation, etc., such as a coalition of women's groups (Guenther 2010) and among ethnic minorities (Okamoto 2010), or by a particular combination of a few of them (e.g., immigrant women's groups, Queer youth). This coalition is decidedly cross-movement, crossing over a great number of identity categories that are not commonly brought together under one umbrella. An assumption that these categories are distinct and mutually exclusive can (and does) divide the marginalized communities into compartmentalized silos of their own. In unfortunate cases, a heightened sense of identity politics can drive them into competition against one another. Such competition is salient especially in the context of dwindling resources available to address social exclusion and inequity in entrenched neoliberalism. Such competitive tension between or among participating movements was certainly downplayed by the coalition in the case of the E\&I Lens, although a close examination also shows that there were some inter-movement tensions that this emergent coalition needed to address, especially early on in the process. Third, this coalition of community movements formed the basis of a state-civil society, or a City-community, partnership. In this form of organization, the dividing line between the state and the civil society is increasingly blurred, though it still remains relevant. It is also important to note the dynamic nature of the interaction between the two, as the push to address exclusion and inequity in society comes from both the state and the community movements, and not just from the "challenger" to the state, nor simply is downloaded by the state to the "civil society". Each side relies on the other in 
different ways, but it is still not a one-to-one, equal exchange free of power relations and politics of negotiation. ${ }^{6}$ These dynamics played out most evidently at the Diversity Snapshot Workgroup level, where each of the eleven community movements worked in close collaboration with, and also negotiated with, the City as they deliberated on the appropriate message, and the appropriate framing of it, for the target audience of these documents.

\subsubsection{Framing as Movement Strategy}

Next, I turn to the concepts of "frames" and "framing" as a social movement strategy, which help me analyze the other key aspect of this strategic package. Framing is a useful heuristic for elucidating the interpretive, articulatory, and discursive work of movement actors involved in creating the Lens and the accompanying Snapshots. I take, as a starting point, the American social movement scholars Benford and Snow's contribution to frame theory as a discursive strategy used by social movements. Building on the earlier definition of "frame" by Goffman, they adapted it to explain how and why there was a burgeoning "cycle of protests" following the success of the civil rights movement in the 1950 s and 60 s, despite the seemingly unfavourable political conditions for the flourishing of American social movements at the time. ${ }^{7}$ They defined a frame as

\footnotetext{
${ }^{6}$ While I find the Gramscian (and neo-Gramscian) concepts of "civil society" and "state" to be useful in understanding the very dynamic, interactive, unequal and yet mutually dependent nature of the relationship between these community movements and the City, I do not use the Gramscian approach as the overarching frame of analysis here, because the class-based analysis implied in these concepts do not apply to this particular case. Class struggles and class relations did not figure prominently as a focal point of the interaction between these movements and the City as they negotiated over the purpose, content, and the main beneficiary of this intersectional Lens they were co-developing. In fact, this was not the case even in the "People living in poverty" Snapshot Workgroup, as their focus was primarily on communicating the challenges and the experience of living in poverty in order to combat the negative stereotypes or disempowering attitudes towards this population held by the City as service providers and decision makers - rather than advancing a class analysis or drawing attention to the unequal nature of class relations in the City/city.

${ }^{7}$ At the time, the main theoretical paradigm in the American social movement literature was resource mobilization theory (RMT), which focused on the social movement organizations' (SMOs) access and
} 
"an interpretive schemata that simplifies and condenses the 'world out there' by selectively punctuating and encoding objects, situations, events, experiences, and sequences of actions within one's present or past environment" (1992: 137).

From this Snow and Benford developed the concept of "collective action frame" to apply specifically to social movements' use of frames, defined as "action-oriented sets of beliefs and meanings that inspire and legitimate the activities and campaigns of a social movement organization (SMO)" (2000: 614). They further posited that social movements develop "collective action frames" to amplify and extend extant meanings, transform old meanings, and generate new meanings, in order to identify a problem, what/who is to blame, and what should be done to solve the problem (1992: 136-137). Thus they argued that the sudden burgeoning of social movements in the 1970s was attributable to these movements' ability to develop, adapt, and utilize "a broadly resonant frame" to convey a particular narrative that captures the movement's view of a particular issue. This allowed them to reach the broader public audience in a way that garnered their support for their cause, and to put pressure on the target institutions (such as the government, a corporation, etc.) to take the kind of action the movement saw as necessary or desirable.

Here, I bring in another key concept advanced by Benford and Snow to inform my analysis of the case of the E\&I Lens: "master frames". That is, while a "collective action frame" is specific to individual movements and "limited to the interests of a

ability to utilize material resources to mobilize social action. Political process theory (e.g., McAdam) sought to complement this by paying attention to the environmental conditions within the broader society or "political opportunity structure" and also the movement actors' subjective perception of their environments as an opportunity that sets them up to mobilize themselves to collective action. However, when neither explanation seemed plausible, the broader 'cultural turn' in social movement theory also started in the 1980s, pushing these scholars to examine the more explicitly cultural, symbolic, subjective, and interpretive dimensions of social movements, such as the role of collective identity, sense of solidarity, and discourse in social movements. 
particular group or to a set of related problems", a "master frame" is much broader in scope, inclusivity, flexibility, and cultural resonance that can function as "a kind of master algorithm that colors and constrains the orientations and activities of other movements" (Benford and Snow 2000: 618). Put differently, a master frame is a collective action frame that transcends the particular focus or scope of a particular movement to have a more overarching reach and influence over other social movements' frames. ${ }^{8}$ The examples of such broad-reaching master frames are "rights frame", "choice frame", “equality frame" "injustice frame”, “oppositional frame”, “exploitation frame”, etc. $(1992 ; 2000)$. It can originate in a particular collective action frame (and/or a political philosophy, ideology, or even academic theory) - but once developed, a master frame can serve as a type of discursive resource 'out there', circulating in broader society that individual movements can strategically employ and adapt to convey their own movement's vision or message to their target audience. ${ }^{9}$

Although Snow and Benford used these concepts of frames to explain the discursive mechanism that is spurring the "cycle of protest", I use them instead to shed light on some of the factors that contributed to the differing experiences of the eleven community movements that participated in the creation of the Equity and Inclusion Lens. That is, in the case of the E\&I Lens, the use of mater frames was evident at the Reference

\footnotetext{
${ }^{8}$ In a more recent contribution, Benford (2013) describes a master frame as "a generic type of collective action frame that is wider in scope and influence than run-of-the-mill social movement frames... Whereas most collective action frames are context specific (e.g., drunk driver frame, cold war frame, exploited worker frame, environmental justice frame, etc.), a master frame's articulations and attributions are sufficiently elastic, flexible, and inclusive enough so that any number of other social movements can successfully adopt and deploy it in their campaigns" (n.p.).

${ }^{9}$ Benford (2013) explains how the 'carry over' of frames between movements occurs through a broadly resonant master frame: "Typically, once a social movement fashions and espouses a highly resonant frame that is broad in interpretive scope, other social movements within a cycle of protest will modify that frame, or add something, and apply it to their own cause. For example, once there are a number of successes based on an equal rights and opportunities frame, several other movements, including the American Indian, women's, gay and lesbian, Chicano/a, and Gray Panthers, adopted and proffered a similar frame to their specific movement campaigns" (n.p.).
} 
Group level, as community and City representatives all sought to develop a coherent narrative to convince their target audience - the City of Ottawa employees - to buy into the value of practicing equity and inclusion in their everyday work. This practice was also evident, perhaps more so at the level of individual Snapshot Workgroups, where each of the eleven movement-specific Workgroups variously drew on different extant master frames to help formulate their own frame (for example the rights frame in the case of People with disabilities Snapshot, and the equality frame in the GLBT Snapshot).

In this thesis, I use the expressions 'movement frame' (rather than "collective action frame"), 'coalition frame', and 'partnership frame' to refer to the frames operating at these three scales. Within the context of the E\&I Lens, movement frames most closely corresponded to the frames used by the community movement actors, though in some cases also by the City members at the scale of the individual Snapshot Workgroups where they supported the community movements in developing the narrative for their Snapshots. The coalition frame and the partnership frame corresponded most closely with

the Reference Group, and the narrative conveyed in the main User's Guide portion of the E\&I Lens. In practice, the scalar distinction between the coalition and the partnership frame is sometimes not too evident, because in the organizational structure of the Lens development, the Reference Group was the scale at which both of these frames were expressed, developed, negotiated, and hammered out.

\subsubsection{Resonance and Radicalism in Framing}

In addition to the above, in order for these frames to be effective, movements must achieve frame "resonance" with the prevailing cultural and discursive context within which their target audience(s) is situated. In other words, such a movement's 
frame must make sense to the movement audience so it relates and appeals to how they view the world or the particular issue at hand, if it is to inspire them to support or join the movement's cause and adopt its worldview. Achieving resonance with the existing, and even dominant discourse, attitude, perspective, or culture in a given society is thus a prerequisite for social movements trying to utilize framing to their advantage. And yet, Ferree (2003) argues that achieving resonance alone in not sufficient as a social movement strategy, because their mission involves challenging or changing the status quo, and this includes the existing dominant culture and discourse that support the systemic inequity among people in society. This is where I also draw on contributions from other scholars like Oliver and Johnston (1999) who highlighted the distinctly "political" aspect of framing as linked to the concept of "ideology" as "a system of ideas" that support relations of domination in society, and the element of "resistance" that social movements with progressive political orientation bring in to their frames. ${ }^{10}$

In this context, Ferree (2003) highlights the notion of "radicalism" as the opposite of "resonance", and point out the explicitly strategic and selective use of these two

\footnotetext{
${ }^{10}$ This is what Oliver and Johnston (1999) saw was lacking in Benford and Snow's initial treatment of frames. They critiqued Benford and Snow's for overlooking the role of "the older, more politicized concept of ideology" as rooted in Hagel's historical idealism and Marx's historical materialism. (Oliver and Johnston characterize frame theory to be rooted the study of symbols, and ideology as rooted in the study of politics.) To this, Benford and Snow (2000) responded by admitting that they indeed did "gloss over the difference between frame and ideology" in their initial work, although they defended their position stating that they never suggested that frame and ideology to be the same nor to disregard the importance of ideology as an analytical category. Benford and Snow clarified that the heuristic value of studying frames is rather that they are the more empirically observable expressions of ideologies. My use of frames in my research incorporate both insights, in the sense that I treat frames as the discursive manifestations that contain the movement's ultimate vision and an ideology for how we should organize our society. However, I also add an explicitly strategic nature of frames to this, as the movement actors also seek to incorporate elements of resonance and radicalism in their frame in their effort to reach their target audience. And as such, as a strategic tool, a movement frame may not necessarily express their ultimate vision or core ideology directly, but may contain other strategic considerations and trade-offs given the immediate purpose to appeal to - and convince - their specific audience to buy in to their message. In short, I do not take the particular frames conveyed by a movement at a given point in time 'at face value', for there are many strategic considerations, as well as constraints, that went into that particular frame.
} 
elements in a frame by social movement activists. She argues that some activists intentionally opt for radicalism rather than resonance, even though it may not be a popular choice, precisely because they seek to challenge the "dominant discourse" and the "dominant ideology" in society that is propping up the status quo. This is useful concept to understand the strategic considerations that went into the development of the E\&I Lens and the Snapshots. These actors had to achieve enough resonance with the dominant culture and the discourse within the City in order to increase the receptivity of their message by the City employees, while at the same time challenging the ways they currently 'do business' in the City that is leading to the status quo of systemic inequity and exclusion of these eleven groups in Ottawa. ${ }^{11}$

Thus, in this thesis I use the terms 'dominant frame' and 'dominant culture' to refer to the discourse and the cultural outlook that reinforce the existing systemic inequity or exclusion in the City/city. In the context of the Diversity Snapshots, dominant frames are expressed in the form of commonly held negative stereotypes or assumptions about a given marginalized community or group among the dominant groups in society, many of whom are part of the City's workforce. These dominant stereotypes or assumptions often serve as an explanation or justification for the way things are, often by attributing the problem to the characteristics of these groups themselves and thus naturalizing the systemic inequity and exclusion. These are often built into the existing and commonsense "way of looking at things" and of "doing business" in the City, which is precisely what the E\&I Lens and the Snapshots aim to shift (CAWI and City of Ottawa 2010a), by

\footnotetext{
${ }^{11}$ While the explicit language of "power", "domination", or "ideology" was not used outright in this project and especially in the final text of the Lens or the Snapshots, some participants did use these terms and concepts in their interviews to describe their work, because these are implicit in their long-term vision to make Ottawa (more) equitable, inclusive, and fair(er) for all people (Interviews: a, e, b, c, d, i, j, l, m, o, p, r, $\mathrm{u}, \mathrm{v})$.
} 
emphasizing the systemic nature of the problem and getting City employees to see how they can remove these systemic barriers causing this problem. I use the term resonance to refer to these movement actors' effort to align with and appeal to such an outlook in an effort to garner support from the City staff as the target audience, and radicalism to refer to their effort to challenge, critique, and ultimate change such outlook.

Here lies one of the most fundamental sets of contradictory strategic priorities facing all of the actors involved in developing the E\&I Lens and the Snapshots: to find the right balance between enough resonance, but to do so without losing sight of the radical element so that they do not end up simply legitimating the status quo through their narrative. While this is not impossible to achieve, it is often difficult for movements unless many factors support them. I use the expression transformative frame to refer to a frame that manages to do just that by combining just enough resonance and just enough radicalism in a way that allows the movement actors to shift the perspective of their audience to take a positive action or solution to promote the equity and inclusion of a given community. I also introduce the expressions 'strategic resonance' to denote a conscious use of resonance by movement actors by choice, and 'forced resonance' to denote the situation in which they do so more out of necessity or because of external constraints, whether it is the set of priories at another scale, or the discursive environment surrounding them, or a pressure from another actor or institution.

\subsubsection{Frame Alignment: Vertical across Scales and Horizontal across Movements}

Moreover, as a newly emerging intersectional coalition of eleven community movements, the creators of the E\&I Lens had additional tasks ahead of them in working with frames. Here I draw from the literature on social movement coalition dynamics, and 
build on Croteau and Hicks' finding that new coalitions face a unique and fundamental task of developing consistent frames at the coalition and individual movement levels (2003: 251). As a recently formed coalition, the eleven movements needed to develop a new overarching frame to be adopted by all of the participating movements to create cohesion and solidarity within the coalition. This alignment was important to increase the clarity and cohesion of their collective voice, and to leverage it more effectively to reach and affect change in the target audience, i.e., City's managers and employees. Put differently, however, by choosing to form a coalition, the eleven movements also had to align their disparate frames, and in some cases conform to the shared frame of the coalition as a whole if it did not match well with their existing movement-specific frame. This was thus another set of contradictory strategic priorities spanning across scales that the creators of the Lens and the accompanying Snapshots had to manage.

At the same time, however, there was another contradictory priority associated with aligning frames within the coalition, also because this was an emerging and an explicitly intersectional, cross-movement coalition. Many of the participating movements raised concerns about "losing specificity" and "erasing differences and uniqueness" of the issues, perspectives, and experiences of each community, as well as the nature of barriers affecting them, by virtue of participating in an "all in one Lens" (Interviews: a, b, $e, d, p, t)$. Making this room for differences, even while forging a shared intersectional vision of a city, was partly a strategic necessity for this young coalition, as it needed to obtain buy-in and commitment from the participating movements to co-produce this Lens. This was also important as a principle - such diversity among movements needs to be respected and embraced as part of the spirit of inclusion - one of the central themes of 
this Lens. Unlike a coalition of groups within a single-issue movement, this fledging cross-identity and multi-issue coalition had to establish commonality and uniformity (solidarity and cohesion) among the eleven movements, while still creating enough room to acknowledge and express differences among themselves.

Furthermore, in addition to being a newly formed coalition, these actors were also forming a new official partnership between the City of Ottawa and the coalition of these eleven community movements. This created an additional layer of vertical frame alignment at an even higher scale of City-community partnership, where the two sides needed to align their frames with each other. More specifically, the movement actors often needed to align their frames with those of the City's. On the one hand, this opened up opportunities to increase legitimacy of the movements' claims in the eyes of the target audience of the City. By partnering with the City, and by aligning their frames with the official discourse upheld by the Corporation of the City, the movements who would otherwise be located far 'outside' of the polity could sound more like an 'insider', more official, and more legitimate, and thus increase their ability to gain the audience's receptivity and buy-in for their message.

And yet again, the added strategic contradiction here is that partnering up with the City, and pursuing alignment with its official discourse made it more difficult for the movements to choose radicalism more freely. Combined with the previous sets of priorities about the necessity to align frames within the coalition, and to align frames with the City's official frame at the partnership level, all while ensuring to achieve resonance to obtain the audience buy-in, radicalism quickly came to be viewed as a higher risk and thus a less desirable option that might not serve the interest of the coalition. This was also 
the case especially at the scale of the partnership, where the City also held strong influence over its direction. Here, I draw on the insights from the coalition dynamics literature to posit that coalitions may put additional pressure on the participating movements that represent a more radical element if it poses a threat to the success or the existence of the coalition as a whole. ${ }^{12}$

\subsection{Methodology}

My research primarily focuses on the roughly 16-month period between the summer of 2008 and fall of 2009, in which the Lens coalition was formed and the Lens completed. ${ }^{13}$ Specifically, I use four subcases within this coalition to allow for an indepth comparative analysis of the specific Snapshot Workgroups: GLBT, People with disabilities, Immigrants, and Visible minorities. I identified these four based on several grounds of comparison to 'measure' how contentious and prolonged vs. how smooth and quick the process was. I considered the timeframe it took a given Workgroup to complete the final draft, and the presence of contention over how to frame the document, as it is useful for teasing out the distance between the movement frame (radicalism) and the dominant frame (resonance) that had to be bridged to produce a transformative frame. I first identified Visible minorities based on my direct experience of the case, knowing that this took the longest time to complete and was the most contentious of the

\footnotetext{
${ }^{12}$ For example, Berry (1997) found that movements choose to form coalitions to pool their resources together that any one of them would not be able to access individually, but Barkan (1986) found that "scarcity of resources can lead to conflict if some coalition members perceive that the actions or rhetoric of more radical groups threatens funding sources" (cited in Van Dyke and McCammon 2010: xvi). Here, I am adapting these insights to the context of the E\&I Lens, in which the definite, short-term, and one-time project funding to develop this Lens was secured by the partnership grant between the City and the Status of Women Canada, but the discursive resources by which they needed to secure the longer-term buy-in and commitment from the City employees to implement and continue using this Lens was not yet guaranteed at the time.

${ }^{13}$ With individuals who had been involved in related initiatives that predated this time period, I asked them to share their historical knowledge as well, for example on the precedent The Gender Equality Lens and Ottawa Equality Framework.
} 
eleven. ${ }^{14}$ For points of comparison I included other subcases that had a shorter and 'smoother' process than these two (i.e., GLBT, Immigrants, People with disabilities), which I knew progressed with less contention or delays in the process. I also looked to the Workgroups that demonstrated a degree of contention or debate over the language used for the title of the Snapshot, thus the name used to describe the group of people, which was important in framing the entire document. Focusing on key concrete items like the name of the group was useful in tracing the discursive negotiation process between the City officials and the community members of the Workgroup. The fact that these four Workgroups arrived at differing level of changes to the language used made it a good ground for comparison, and I used this as a starting point for my inquiry. "Immigrants" and "People with disabilities" reflected what the community members of the Workgroup preferred; "GLBT" settled on a partial change or an alternative arrangement, and "Visible minorities" did not change at all despite the preferences expressed by community members.

In addition, given this was an explicitly intersectional coalition of eleven different community movements, I was interested in comparing differences based on the nature of the core issue or the basis of exclusion that the broader social movements to which the community movements were affiliated addressed, and to consider how these issues were received in the dominant culture in the City. Put differently, I was interested in the

\footnotetext{
${ }^{14}$ Initially I had identified Aboriginal peoples as another more 'contentious' subcase, but I decided to exclude it from my case selection. This was primarily because the four Snapshots mentioned above were composed by the same author (myself), except for Aboriginal peoples which was composed entirely by the other key coordinator of the project. Using the first four provided an effective ground for comparison among them, as the final product better reflected the differing input from each of the movements, in a sense making my role as the writer a 'control variable'. Including the Aboriginal peoples in this particular mix would not yield the same methodological advantage, however. The second reason was more logistical in nature, in the sense that I was unable to schedule interviews with the individual members of the Reference Group whose expertise was on Aboriginal peoples.
} 
distance between what a given community movement frame wished to address, and what the currently existing dominant frame of the City would say on the matter. These core issues were: 1) accessibility and ableism, 2) homo-, bi- and transphobia and heteronormativism, 3) racism and racialization, and 4) xenophobia. The last two would allow me to compare between variant manifestations of racism in Canada, while the other two would offer a point of comparison across different bases of exclusion. In addition, I decided to include the case on Immigrants as what Flyvbjerg (2001) calls a "critical case", for this is a 'race-related' case, but one that seemed to have experienced shorter and less complicated process in arriving at its final draft compared to Visible minorities.

\subsubsection{Methodological Assets and Considerations}

The fact that I bring direct personal experience with the case to my research presented unique methodological assets as well as challenges, and as such required special considerations. My unique position as one of the central coordinators of the Lens development process as a whole has provided me with deep knowledge of the entirety of the case as opposed to one particular movement. At the same time, I needed to be reflexive about the changing and overlapping roles that I was playing in relation to the case as my role shifted from a coordinator to that of a researcher. While I expected, and found, many of the interviewees to be willing to share their thoughts frankly with me given my known commitment to this project, ${ }^{15}$ I needws to be mindful of the fact that some of them might not want to disclose controversial issues because of my existing relationship with them, and because of the relationship among the participants themselves. After all, this Lens is a living project that continues to carry strategic

\footnotetext{
${ }^{15}$ That is, to ensure the successful implementation of the Lens, and to improve its efficacy to realize its main goals: to promote equity and inclusion of multiple marginalized groups in our city, which requires an honest reflection on what worked well and what did not.
} 
interests of various stakeholders, and the interviewee pool was a closed one with a relatively small number of individuals, many of whom continue to work and interact with each other in their work in the community and the City.

Throughout the research process, I made a conscious effort not to rely on my own memory as data source or the framework for my analysis, but instead drew on it to identify the starting points for inquiry, as well as gaps in my knowledge or perspective. For instance, in some cases I used my memory to adapt and target interview questions to different individuals, or to ask follow up questions to dig deeper during interviews. During the data gathering and analysis stages, I made a very conscious effort to remain open to, and actively look for, information that differed from my initial memory, whether from interviewees or from documentary evidence, while noting the instances where the data confirmed my memory. In addition, I incorporated other methodological precautions into my research process. Keeping a reflexive journal helped me articulate and work through my concerns, as well as record key methodological decisions and the rationale for them as I went through the research process. Open conversations with research participants and other academic researchers, and staying connected to current developments surrounding the case in the City and the community allowed me to check and validate my questions, insights, interpretations and assumptions, and to make adjustments to my research design as necessary.

\subsubsection{Data Types and Sources}

In this study I used multiple sources of data: 1) in-depth interviews with participants who contributed to the development the User's Guide and the Snapshots, 2) primary documents that recorded their discussions and decisions over the course of the 
Lens development process, such as meeting minutes and reports, 3) the actual text of the draft- and final versions of the User's Guide and the Snapshots that captured the outcome of such negotiation process; 4) and other key documents that captured the broader political, economic and social context in the City of Ottawa within which these negotiations were taking place. By triangulating these multiple data sources I was able to locate and contextualize my memory with other participants' perspectives, as well as to ground others' and my own memories (that inevitably fade over time or leave strong impressions about some events over others) with documented events and comments at the time.

\subsubsection{Primary Documents}

I gathered two types of primary documents: publicly available materials from the City and community organizations with which the contributors of the Lens were affiliated, and semi- or non-publicly available documents that I obtained from research participants with their permission. Initially I gathered over 7,000 documents, which I whittled down to 1,300 , and eventually down to approximately 400 key documents. I continued to gather publicly available documents over the course of the research process on an as-need basis as I identified gaps in my sources. The sources for these documents included the meeting minutes from, and reports and presentations to: the Reference Group, the subcase Workgroups, Citizens Advisory Committees, City Council and its Standing Committees, City management team, and the funder(s), as well as other reports and communiqués to the wider communities in Ottawa during the 16-month period. I also relied on the documentary sources to trace the historical background on the Equity and 
Inclusion Lens, building on and going beyond the initial input from the interview participants.

I analyzed the text in the final versions of the User's Guide and the Snapshots of the subcases as the outcome of the development process (City of Ottawa 2010a-1). This allowed me to get at the subtle nuances and meanings of the text and to analyze them relationally in the specific context in which each of them was developed. To supplement the interview data, I used the written records documenting the development process of the Lens to identify the key debates and key moments in the development process, such as when important decisions regarding specific language use and framing of the issues were made, and the rationale for them.

In order to identify the goals and priorities of the City as a political and bureaucratic institution and how they are framed, I examined the official documents by the City, such as its policies and frameworks, Council mandates, strategic plans, Service Excellence vision statement and annual reports, as well as relevant legislation at the provincial and federal levels that the City had to comply with. This allowed me to delineate the dominant frame and the official frame in the City. Finally, I supplemented the above with relevant background information on Ottawa's local history, including the City and the community leaders' efforts that led to the creation of this Equity and Inclusion Lens since the 2001 amalgamation. Together, these various sources helped me identify the discursive pressures as well as the discursive opportunities that the coalition and each of the movements sought to respond to and take advantage of as they worked and negotiated with each other and with the City. All of publicly available documentary data I cite in this thesis are referenced in the bibliography, and all of the non-publicly 
available documentary data I cite, which I obtained from research participants, are presented in the Appendix B: Personal Communications.

\subsubsection{Interviews}

I conducted in-depth interviews with as many members as possible of the Reference Group (which included the community and the City staff members), and of the Snapshot Workgroup of the selected subcases (which included the Reference Group members, respective Citizens Advisory Committee member(s), as well as an expanded pool of community and City staff members). Between July 2012 and June 2013, I conducted a total of 42.5 hours of in-depth interviews, 33.5 hours of which were recorded, with a total of 22 respondents. Of these, 15 were community participants and seven (7) were City employees, thus capturing the diversity of positions, perspectives, and interests of those who were involved in creating this Lens. 16 were members of the Reference Group, which meant that they also sat on at least one Snapshot Workgroup, thus giving me a wide coverage of Workgroups through these individuals. Six (6) remaining respondents were members of the sub-case Snapshot Workgroups but not of the Reference Group.

There were 25 separate interviews in total; four (4) of which were follow-up interviews with key respondents. One (1) of these three (3) was a group interview with two (2) informants at the same time, which I arranged upon explicit request by one of the key informants, who strongly believed in the act of sharing knowledge through the research process. Each interview lasted about an hour to an hour and a half on average, though some were longer or shorter depending on the respondents' availability. 20 interviews were conducted in person, four (4) by phone, and one (1) individual responded 
in written format by email, as this individual was unable to participate in an interview in person or by phone at that time. When the interview was not audio-recorded, I took notes by hand. The interviews were transcribed after they were completed.

I set out my interview plan so that I would interview the Reference Group members first, then expand out to the Snapshot Workgroup contributors, in order to cluster similar types of participants closer together in time. I deemed it important to interview the Reference Group members first because of their longer, wider, and deeper scope of engagement with the development process of the Lens as a whole, including the User's Guide and the Snapshots; whereas the non-Reference Group members of the Snapshot Workgroups had a task that was more specific both in timeframe and scope, for their involvement started later in the project timeline. Put differently, this distinction was important for understanding the different scales of frames. This timeline was roughly followed, although the actual scheduling was based on the availability of the individual interviewees. (See Appendix A for the list of the interviews I conducted for this study.)

These interviews provided rich data on the individual participants' own perspective on their goals, strategic considerations, any potential trade-offs, and their rationale for making them. I asked them to reflect on their initial hopes and expectations for the Lens (and/or the Snapshot(s)), motivation for taking part in this project, the key messages they wanted to convey to their audience, and the strategic considerations that went into their framing effort. I also asked them about the key debates or disagreements that occurred at the Reference Group and/or the Snapshot Workgroup(s), and how they were resolved and their rationale. I also asked them to reflect on the factors that made the development process of this tool successful or challenging, and what they thought about 
the final version of the Lens (and/or the Snapshot(s)). I asked them to consider what they would do differently to make the process of even more effective, and the final product more effective, given what they experienced. I also asked them to consider these questions at the distinct scales of the movement, the coalition, and the City-community partnership. In addition to personal in-depth interviews, I also conducted several key informant interviews with the key coordinators of the Lens development process, who, like me, had a more comprehensive perspective on this process because of their role within this project, compared to individual members of the Reference Group or one of the Workgroups.

\subsubsection{Participant Input and Reciprocity}

I sought to create two-way communication between myself as the researcher and the contributors to the Lens as research participants. For example, I offered to send out research updates to participants who wished to receive it and actively encouraged them to contact me any time during the research process. I exchanged emails and phone conversations with some participants as a result, which contributed to better methodological decision-making as to how to use research data in my writing. Based on the preliminary conversations that I had with key informants, I offered to disseminate the research findings in multiple/alternative formats as a way of sharing the fruit of the work of this research with those who contributed to it. I asked for the participants' feedback on how they would like to receive/access it - e.g., read the thesis, executive summary in plain language, non-academic report, community forum or presentation, and one participant requested that I share the findings online alongside the links to the actual the E\&I Lens to help promote it and to share good practices with the wider community of 
practice in Canada. When I asked what the participants wished to get out of this research, this sharing of findings with the community in short, plain format was the most common response I received.

In addition, I asked for the participants' feedback on how they'd like to be addressed or not addressed in my writing (e.g., by name, by position titles, by organizational affiliation, by sectoral affiliation, by role in relation to the case, etc.). While I explained that complete anonymity was impossible in this case due to the already public nature of their contribution to the Lens, I strived to incorporate their wishes as much as possible within the requirements of thesis writing, especially when they felt that they disclosed potentially sensitive or controversial points. For this reason, throughout this text I do not name the interviewees when citing them. Instead, I cite them by interviewee code which I assigned, and I chose not to make public which interview corresponds to which code. ${ }^{16}$

I also offered to give back the interview data in its full and unedited format for them to keep in order to give them control over their own interview material. In several cases, I provided the interview recording file to the interviewee immediately following the interview, or at a later date at their request. In one case, I arranged to share the interview data that I conducted with this individual, to be used for another communitybased research project in which this interviewee was participating, which was aimed at recording the local history of their particular movement.

\footnotetext{
${ }^{16}$ In cases where the interviewee made a specific request to dissociate their name from a particular comment they made during the interview, but still gave me permission to use that material in this research, I cite that portion as "(Interview(s): anonymized)". The code key is maintained confidentially by the author.
} 


\subsection{Thesis Outline}

This thesis traces the ways in which one set of strategic priorities and decisions made at one scale interacted with a different set of strategies at other scales, in complex and often unforeseen ways, in order to explain the differences in the Snapshot development processes experienced at the individual Workgroup level. To this end, I use each chapter to pinpoint the different components of these strategic priorities and decisions made, by different actors on multiple scales, over the course of the E\&I Lens development process.

In Chapter 1, I present the local historical background on the Equity and Inclusion Lens, including its two parallel predecessors the Gender Equality Lens and the Ottawa Equality Framework, in both of which CAWI played a coordinating role. I use this history also to trace the particular set of strategic paths that the contributors to these two projects came to adopt over time, which in turn set the broadest parameters of the strategic paths available to the creators of the E\&I Lens a few years later. In a sense, the 'strategic package' adopted at the partnership and the coalition scales of the E\&I Lens was mostly informed by these historical initiatives. In the second half of this chapter, I move onto the details of the development process of the E\&I Lens itself between 2008 and 2009 (2010). This includes the project timeline as it unfolded over the 16-month period. It explains the role, structure, and makeup of the Reference Group, and how they came to the decision to develop eleven Diversity Snapshots as an additional component of the E\&I Lens based on the feedback from these community representatives - i.e., to respond to the unforeseen strategic need for the intersectional coalition building in its early stage. Here I lay out the overall strategies that guided the development process of 
the Lens as a whole at the Reference Group level in light of the strategic priorities that had become evident to them over time, and situate the hopes, intentions, and strategies of the individual Snapshot Workgroups within this context.

Chapters 2 and 3 are case chapters, in which I zoom in on the lowest scale of this study: the individual Workgroups. Here I examine the details of how the Snapshot development process occurred at each of the four Workgroups as subcases. In Chapter 2, the People with disabilities and the GLBT cases are grouped together as a) their drafts were finalized relatively quickly, b) both arrived at a transformative frame that resonated with, but challenged, the dominant discourse, and c) both Workgroups featured participation of at least one City representative whose perspective corresponded closely with those of the community members. The chapter presents each case in order, addressing the key messages that the Workgroup sought to convey in their Snapshot, as well as the key debates that occurred among its members, highlighting the points of correspondence and disagreements, and how those were negotiated over the course of its development process. It highlights each Workgroup's decisions about which ideas and key terms to include, leave out, or modify - ultimately leading to the framing used in the final version of the document. Each subcase concludes with a brief summary.

Chapter 3 follows the similar structure, and discusses the Immigrants and the Visible minority cases. These two are presented together because of the significant overlap in both the membership of the Workgroup and the substantive content in the two Snapshots. ${ }^{17}$ In fact, prior to establishing the Snapshot Workgroups in 2009, the two

\footnotetext{
${ }^{17}$ That is, while not all immigrants experience racism as the primary barrier in their lives, for racialized immigrants, who represent a growing proportion of this population, racism is a core issue. For Visible minorities, racism is the core issue affecting them, and while not all of them in Ottawa are immigrants, many of them are, and many others are (erroneously) assumed to be because of racism.
} 
Reference Group members who acted as the lead members of the Immigrant and the Visible minority Workgroups met with the writer to discuss and coordinate the points of correspondence and distinction between these Snapshots in order to maximize the limited space available to convey the messages about these communities to the target audience (CAWI 2008-11-27). Although there is much similarity between the two subcases, the process for each Workgroup was quite different, for the former was much less protracted and contentious than the latter.

In the Conclusion, I bring together these four cases in a comparative framework to consider how these contributing factors played out differently at the individual movement level. Here, I compare the specific framing strategy(ies) adopted by each Workgroup, and the different factors that shaped what was available (and what was not) to each of them in arriving at a particular framing - even while they all pursued the similarly structured goal of developing an effective Snapshot document. In other words, I highlight the points where the strategic pursuit at the scale of the Workgroup aligned with, and supported, the strategic priorities at the coalition and the partnership scales, and where it did not. From the empirical findings from these cases, I pull together what constituted the key ingredients of a transformative frame within this particular project context, and what came to be considered less desirable, riskier, or too radical to include in the Snapshot - especially given the strategic priorities and decisions made at the higher scales of the project. Finally, the chapter concludes with some practice-oriented lessons that can be gleaned from this case, as well as future lines of inquiry that emerge out of this study. 


\section{Chapter: Historical Background of the E\&I Lens: Origins of the}

\section{Coalition and Partnership Strategies}

\subsection{Chapter Introduction}

This chapter sets the historical context out of which the Equity and Inclusion Lens emerged. I tease out the key strategic components of the Lens by tracing some of the recent local history behind it, namely its precedent initiatives over the last ten years: the "Ottawa Equality Framework" ("the Equality Framework") and the "Gender Equality Lens” ('the Gender Lens' or 'the GEL'). In both of these initiatives, CAWI, as a newly emerging organization, played a coordinating role alongside other local community groups and leaders as it established its 'official partnership with the City of Ottawa' in 2005. These two parallel initiatives cast light on the early articulations of the vision of equity, equality, diversity, and inclusion as intersectional concepts circulating among community leaders in Ottawa. These two initiatives also shaped the key strategic paths and processes that the creators of the Equity and Inclusion Lens adopted, both deliberately and serendipitously, to help make this emerging vision a more concrete reality a few years later. Here, these strategic paths involved the formation of an intersectional coalition of diverse communities, whose specific experiences or interests may not overlap, and of a partnership between the community and the City. This coalition and partnership in turn pursued a common strategic path to develop an expressly handson tool that the City employees can easily (and would want to) use in their everyday work setting, to remove existing systemic barriers in the ways in which the City conducts its business. 


\subsection{The E\&I Lens in a Nutshell}

The Equity and Inclusion Lens is a social inclusion tool developed by the City of Ottawa in joint partnership with members of the local community between 2008 and 2010, intended explicitly to be a practical and user-friendly handbook for City staff. The Lens is comprised of two parts: a 37-page long User's Guide, and eleven separate accompanying documents called "Diversity Snapshots" ('Snapshots') that profile the eleven communities or the population groups that the local community and the City had come to identify over the years as most at risk of social exclusion in Ottawa.

The User's Guide describes a vision of what "A City for Everyone” would look like under ten headings: "A place of belonging", "Barrier free", "Equitable", "Accessible", "Respectful”, "Innovative", "Diverse", "Representative", "Participatory", and "Safe", and each of these is described in more detail with a concrete statement (CAWI and City of Ottawa 2010a:3). From here, the Guide walks the user through an ongoing, four-step process of self-reflection, application, learning, and self-evaluation about how one's way of thinking, decision-making and actions can help remove the systemic barriers that get in the way of achieving an equitable and inclusive experience of the city by all residents. The User's Guide covers ten "areas of work", each containing a series of questions that prompt the user to detect unintended barriers in their specific work contexts, and a concrete example of a good practice that already exists within the City. ${ }^{18}$ At any point in this four-step process, users are encouraged to consult any of the eleven Snapshots to learn more about the particular challenges (and contributions) of

\footnotetext{
${ }^{18}$ The ten areas of work are: Working with people, Designing communications, Developing policy, Engaging the community / consultation, Evaluating, Gathering information / research, Leading and supervising (staff and volunteers), Planning projects / programs, Recruiting and interviewing (staff and volunteers), and Training (staff and volunteers) (CAWI and City of Ottawa 2010a).
} 
people belonging to each of these communities. At the end of the User's Guide is an appendix that contains definitions of four key concepts which serve as the guiding principles or values, i.e., "Diversity", "Equity”, "Social inclusion”, and "Systemic barriers" (ibid: 34$).{ }^{19}$

The development process of the Lens was coordinated by City for All Women Initiative (CAWI), a local feminist organization established as an official partnership with the City of Ottawa in 2005 to promote the civic engagement of women from diverse communities and women-friendly municipal decision-making. ${ }^{20}$ The one-year project funding to develop this Lens was provided through a partnership grant between Status of Women Canada ('SWC') and the City of Ottawa (Status of Women Canada 2009). ${ }^{21}$

\footnotetext{
${ }^{19}$ Equity here is defined as "Treating everyone fairly by acknowledging their unique situation and addressing systemic barriers. The aim of equity is to ensure that everyone has access to equal results and benefits". While these are simple (simplified) definitions, together they underscore a philosophical break from the classic liberal notion of equality as often defined in terms of equality of opportunity and procedural equality, sameness, and the individual as the basic unit. Instead, they focus on substantive equality or equality of outcome and benefits of social life, and systemic inequity that disadvantages groups of people as a collective. Here, "differences" are taken into consideration - both as a positive value to be embraced as in "diversity" and "inclusion", and in terms of vertical difference, or inequality, that needs to be corrected in order to create "a city for everyone". The other three concepts are defined as follows: "Diversity - A wide range of qualities and attributes within a person, group or community. Diversity celebrates the richness that occurs when people with a variety of experiences, perspectives and skills all contribute to a community or a workplace (See Diversity Wheel, p. 8); Social inclusion - Acknowledging and valuing people's differences so as to enrich social planning, decision-making and quality of life for everyone. In an inclusive city, we all have a sense of belonging, acceptance and recognition as valued and contributing members of society"; and "Systemic barriers - Obstacles that exclude groups or communities of people from full participation and benefits in social, economic and political life. They may be hidden or unintentional but built into the way society works. Existing policies and practices can reinforce them" (City of Ottawa 2010a: 34).

${ }^{20}$ It should also be noted that CAWI's partnership is not only between the community women and the City, but also includes academics. The co-founders of CAWI and its forerunner "The Working Group on Women's Access to Municipal Services" were academics from the University of Ottawa and Carleton University (Arnold 2002; CAWI 2011c; WGWAMSO 2001:1-3; 2002:i). These two academic members have been the only permanent and continual voting members serving on CAWI's central governance body the "Steering Committee", while the City and the community members on it have changed over the years, although there is no public record explaining why these two seats are reserved as permanent (CAWI 2011a; $\mathrm{b} ; \mathrm{e})$.

${ }^{21}$ The basic structure of the partnership for the Equity and Inclusion Lens and the Gender Equality Lens can also be traced to CAWI and its forerunner the Working Group on Women's Access to Municipal Services, whereby a partnership was established among community women, two academics, and City representatives which included a mix of female members of City Council and employees - supported financially by Status of Women Canada and by in-kind by the City (WGWAMSO 2001; 2002:i; Arnold
} 
CAWI first obtained \$74,506.00 from Status of Women in May 2008, and the City matched these funds by contributing the remaining fifty percent (Interviews: a, g). With this funding, the E\&I Lens Reference Group developed the pilot version of the Lens ('Pilot Version') between the summer of 2008 and the fall of 2009 (CAWI and City of Ottawa 2009). This version was then rolled out in a pilot implementation between late 2009 and early 2010 in select departments within the City. Based on the findings from this pilot, further revisions and edits were made by CAWI and a small team of City staff, ${ }^{22}$ which became the final version currently circulating in the City and the local community ('Final Version') (CAWI and City of Ottawa 2010).

According to the City-appointed project lead for the Lens development at the time, the only condition that the City's Executive Management Committee ('EMC') $)^{23}$ required for approving the development of the Lens at the time, at least officially, was that CAWI first obtain the fund from SWC, which it did in May 2008 (Interviews: g). In sum, a lack (perceived and real) of financial resource on the part of the City's executive management was the only real obstacle to moving this initiative ahead in the City at that time, and this continued to carry strategic significance for the creators of the E\&I Lens at

2002; CAWI 2011c). Many of the same individuals who were involved in CAWI and its forerunner continued to play a role in the Equality Framework, the Gender Equality Lens, and Equity and Inclusion Lens over the years, including members of City Council, City employees and the community leaders, and many of them sat on the Reference Group and the Snapshot Workgroups for the E\&I Lens (WGWAMSO 2001: 1-3; 2002:i).

${ }^{22}$ The key coordinators of the Lens from CAWI, the City, and an additional City official led this final editing process, in close collaboration with an employee from the City's Communications department (Interviews: a, e).

${ }^{23}$ The City's Executive Management Committee ('EMC'), or the Executive Committee, is comprised of the City's most senior managers, though the exact composition of it changes with each cycle of organizational restructuring that the City undergoes. In 2008, Kent Kirkpatrick held the position of the City Manager and Steve Kanellakos the Deputy City Manager heading the Department of Community and Protective Services ('CPS'). As of 2013, the committee consists of City Manager (Kent Kirkpatrick), two Deputy City Managers (Steve Kanellakos and Nancy Schepers), City Clerk and Solicitor (M. Rick O'Connor), and City Treasurer (Marian Simulik) (City of Ottawa 2013). 
all scales of the partnership, coalition, and the individual Snapshot Workgroups

throughout the process. $^{24}$

\subsection{Emerging Strategic Priorities: Basis for the Coalition- and Partnership}

\section{Frames}

It is significant to note here that securing funding as a one-time financial cost was the only official condition imposed by the Executive Management Committee of the City in approving the development of this Lens. As my analysis in the following chapters will show, this seemingly small detail shaped many of the subsequent strategic choices and decisions that the contributors of the E\&I Lens and the Snapshot were able to or had to make. The key coordinators of the E\&I Lens as well as the other contributors came to identify many other unofficial, but what they saw as necessary, conditions or priorities to ensure that this Lens would actually be used by City staff down the road, and eventually (and hopefully) to change the status quo.

These strategic insights were initially derived from the local community leaders' previous experiences in trying to move forward similar initiatives inside the City over the years, namely the Ottawa Equality Framework and the Gender Equality Lens, as well as

\footnotetext{
${ }^{24}$ The importance of the economic restrictions placed on municipal budget is evident in the City's annual reports as well. Since 2008, the negative impact of "the global recession", "the global economic downturn", and "the global economic uncertainty" on the health of the local economy has been a consistent priority addressed at the very beginning of the City's annual report each year since then (City of Ottawa 2009a, 2010, 2011a, 2012a, 2013c). The 2008 report opens with: "Entitled Taking Action in Demanding Times, the 2008 annual report provides highlights of key initiatives that the City undertook during a year in which a global recession created additional challenges for the city, residents and businesses." In the following year, it opens with: "Entitled Strengthening the Foundation. Building the Future, the 2009 annual report provides highlights of key initiatives and accomplishments that the City undertook during a year in which global events continued to affect economies and communities across Canada and around the world". In 2010, as the City's budget continued to tighten, the focus shifted more explicitly to "fiscal responsibility" and finding "savings": "In an effort to cultivate a culture of fiscal responsibility and to get the most out of taxpayers' dollars, the City of Ottawa will be presenting this and future annual reports on the City's website and will no longer publish printed hard copy booklets. By taking this decision, we have saved approximately $\$ 45,000$. This is but one example of cost cutting measures that the City of Ottawa is taking to find savings which will help us secure a sustainable and affordable future" (City of Ottawa 2009a, 2010, 2011a).
} 
the insights provided by their allies within the City. Over time, these became the key strategic priorities for the key coordinators and the contributors to the Lens. This process of identifying the key strategic priorities continued after the development of the E\&I Lens was officially approved by the City in 2008 , as the key coordinators continued to seek strategic input from the community leaders from the eleven equity groups, from the City's Citizens Advisory Committees, as well as from the City representatives who acted as inside allies or champions.

These strategic priorities provided the main organizing principles or rationales for much of the development process of the Lens going forward, and in turn formed the basis of the coalition frame adopted by the coalition of eleven community movements, then by the partnership between the community and the City as a whole. ${ }^{25}$ And, in turn, over the course of the development process, this coalition frame came to carry more strategic weight over the coalition. This became evident in the later stages of this process, especially when the eleven different Snapshot Workgroups started to flesh out and present their own movement frames in their respective Diversity Snapshot.

\subsubsection{Focus on "Cultural Change"}

One of the most important strategic priorities articulated by the key coordinators and the contributors of the Lens at large was to focus on "cultural change" within the Corporation of the City. This was because they believed, based on previous experience

\footnotetext{
${ }^{25}$ Two documents that recorded the initial consultations with the Advisory Committees during the summer of 2008 capture much of these strategic concerns and priorities that the Advisory Committees identified prior to the development process of the Lens (CAWI 2008-08-02, h). The key coordinators of the Lens shared this input with the Reference Group in September 2008 when they first convened to commence this process. The Reference Group further fleshed out their strategic priorities as a new coalition and a partnership over the fall of 2008, when they identified "potential risks and mitigating factors" to the successful development and implementation of the Lens. This one-page document identifies the need to counter the various excuses that the City and/or the audience might use to justify not using this Lens, such as overwork, lack of resources, economic recession, and the claim that the City has already achieved equity/inclusion (CAWI 2008-12-01).
} 
that the formal, institutional or legal changes that were imposed upon an organization or bureaucracy tended not to translate into actual change in practice, in terms of how the City staff operate their everyday businesses or interact with the public. That is, the interviewees in this research variously raised that formal or legal change in and of itself would not necessarily lead to real, substantive "systemic change" towards a more equitable and inclusive Ottawa if it was not also accompanied by an internally-embraced or voluntary motivation on the part of the City employees to change the status quo. That is, when people do something only "because they have to", and not because they "want to" or "understand or embrace the value" of doing it (whether intrinsically as a principle, or out of self-interest of some sort), these formal structures remain superficial (Interviews: $\mathrm{b}, \mathrm{d}, \mathrm{g}, \mathrm{p}, \mathrm{u}, \mathrm{t}$ ).

Some of the interviewees were concerned that this may result in individuals going through a simple "checklist" merely to fulfill the minimum requirements, and no other action or change in attitude beyond it. Or, these formal initiatives may not get implemented at all and "sit on the shelves and collect dust" (Interview: a, p, q, t). Or worse, they could be used to "window-dress" the government to "make them look good" by having a lofty, elaborate and official structure in place, even though in reality these do not change anything substantively (Interviews: a, b, e; CAWI 2008-02, 2008-08-18).

These historically and experientially generated insights on the part of various contributors of the Lens thus converged to their focus on creating a 'cultural change' by creating this Lens that would actually be used by City employees. 


\subsection{2 "Buy-In" and "Tie-In"}

However, this strategic focus on cultural change rather than imposed formal or legal change through the institutional structure of the City still required a mechanism to generate voluntary motivation and incentive on the part of the intended users of this Lens. This is why "obtaining buy-in" from the City staff, and in particular from the managers across the Corporation, became a key priority for the key coordinators of the Lens (Interviews: a, g). The reason why they targeted the managers was based on their knowledge of the structure and the culture of the City as a bureaucratic organization, where hierarchy matters in setting the direction. That is, it is these managers in various departments that hold the practical power in the everyday operational sense to decide whether and how this tool would be implemented - or not. Within the bureaucratic hierarchy of the City, it is these managers who set the directions for their employees in their respective departments, branches, units, and teams, all the way down to the front line staff. This is also why the very first page in the User's Guide portion of the Lens contains "A message from the City Manager", in which he sends a strong endorsement for all staff to use this Lens, as his position is the highest within the entire hierarchy of this bureaucracy (CAWI and City of Ottawa 2010a: 2).

The manager of Diversity and Employment Equity who was the City-designated project lead for developing the E\&I Lens explains that she had to combine various kinds of incentives to interest the target audience (the managers), and it was her role to "sell" the Lens to them through her consistent "marketing effort" (Interview: g). A corollary strategy for this was to combine "soft" and "hard" incentives - or what she calls "carrot" and "stick" - to get the managers to see the value of using this Lens, but a strong 
emphasis was placed on appealing to the immediate self-interest of these managers and their job responsibilities (ibid). This mix of various kinds of motivations is reflected, for example, in the final text of the User's Guide, which asks the reader "Why this Lens?". Here, the main reason given is "Because we believe in a city for everyone" - the intrinsic value of equity and inclusion in and of itself. It further adds three more sub-reasons: 1) "It's the Right Thing to Do"; 2) "It's Good Business"; 3) "It’s Required" (CAWI and City of Ottawa 2010a: 5). In other words, it appeals first to the moral argument, then an economic incentive and self-interest, followed by the legal compliance required of the municipality and its employees.

The other corollary strategy utilized to achieve "tie-in" is related to this incentive mechanism. As a non-mandatory tool, the Lens had to be 'tied into', or grafted onto, the existing institutional framework and strategic priorities of the Corporation in order to increase the relevance and legitimacy of this Lens to the target audience. Many of the local community leaders had tried this over the years in their 'lobbying' effort leading up to the approval of this Lens as a City-endorsed project, and the City's key coordinator also saw this as her responsibility to ensure the successful uptake of the Lens by the target audience. The coalition frame of the Lens as an "efficiency tool" for the City combined both kinds of incentives (self-interest and legal mandate), as it was advertised as a "one-stop shop" that "consolidated" multiple mandates and priorities for which the City staff had to comply - everything from federal and provincial legislation, to council mandates and municipal policies, to corporate strategic priorities. Using this Lens would "simplify work", "reduce duplication", "save cost", "save time and effort", and overall "help them do their work more effectively" and "more efficiently" (Interviews: a, d, e, g, 
i, m; CAWI 2008-12-03). Here, the appeal to the (legal or otherwise) institutionallymandated priorities for the managers worked as the 'hard' incentive, and the appeal to work performance enhancement and efficiency was used as 'soft' incentive.

The two main institutional pillars to which the key coordinators 'tied' this Lens were the Equity and Diversity Policy of the City ('E\&D Policy' or 'EDP') ${ }^{26}-$ which has the 'legal' power within the municipal structure, as it is officially approved by Council and the "Service Excellence" vision, as approved by the senior management team of the City's bureaucracy in $2008 .^{27}$ These two pillars thus derived institutional authority from the fact that they were issued by the top positions of the Corporation: Council (political government) and the City Manager's Office (top bureaucrat). Therefore a substantial part of the 'marketing frame' used by the key coordinators and the promoters of this Lens within the Corporation were taken from, and thus aligned with, these two City mandates. In addition, the text in "A message from the City manager" is the condensed version of

\footnotetext{
${ }^{26}$ This policy was created by the Human Rights and Employment Equity Unit and the Equity and Diversity Advisory Committee upon amalgamation in 2001 (Interview: g).

${ }^{27}$ The City's senior management team approved Service Excellence in 2008 as a key driver for its largescale organizational cultural change strategy as released in the "service excellence vision and guide called, We See a City", a document which "established a goal of achieving a service excellence culture within five years" (Patwell, Gray, Kanellakos 2012b). The Deputy City Manager of City Operations and then-Director of Organizational Development and Performance, together with a "Senior Organizational Development and Change Consultant", have co-published in organizational development journals and a professional conference on the City of Ottawa's (successful) experience in creating a cultural shift under the aegis of Service Excellence between 2007 and 2010 (Patwell, Gray, Kanellakos 2011; 2012a; 2012b). These publications reveal a remarkable level of alignment between the partnership frame of the E\&I Lens and the official frame of Service Excellence as an organizational change management strategy. It is evident in terms of the pointed focus on "large-scale cultural change" or "culture shift throughout all levels of their organization", which need to "become embedded in the way people worked, incorporated into the city's culture, and be sustainable in the future". However, even these senior bureaucrats realized that they had to ensure this resonated with their employees if this were to take root, and they also needed to "motivate people to embrace change" or to secure buy-in from their own employees. To do so, they need to celebrate and "build on a level of existing successes", especially "given the tight restrictions on budget, resources, and technology" that limit what their employees can do (ibid 2011;2012a; 2012b). These senior City officials also speak about the challenge and the necessity of achieving "alignment" among all managers and employees at all levels and in all parts of the Corporation to work towards a shared vision, value, and goal of Service Excellence. This is somewhat a parallel to the emerging intersectional coalition of disparate movements working in silos to align themselves towards the coalition's common vision and a goal of intersectional equity and inclusion for all.
} 
this marketing frame, as it contains the lines, phrases, and certainly ideas taken from the E\&D Policy and Service Excellence mandate (CAWI and City of Ottawa 2010a: 2). ${ }^{28}$ Another related corollary strategy here is the dual focus of the Lens on the "inside and outside" of the Corporation, or promoting equity and inclusion among all employees within the City as a workplace, and promoting it among all residents in Ottawa. This dual focus was explicitly embedded into the E\&D Policy itself, as well as in the Service Excellence vision, which aimed at enhancing the "client satisfaction" or "customer satisfaction" of residents, and the "job satisfaction" of the employees who work for the City (City of Ottawa 2009b; Interviews: f, s). ${ }^{29}$

On the other hand, such marketing efforts were necessary precisely because the Lens was not 'legally' mandated by the City. This was partly because of the coalition and the partnership's strategic decision to facilitate informal cultural change towards equity and inclusion with a strong commitment from the City employees themselves. However, this was also partly because of the lack of institutional and resource investment by the City to support this type of change and practice in the City on an ongoing basis, at least at that point in time. Again, the only official condition for approving the development of this Lens was that CAWI obtained partnership funding from elsewhere so that the City

\footnotetext{
${ }^{28}$ This "Message from the City manager" was in fact co-drafted mostly by the City members of the Reference Group, which was then approved and signed by the City Manager (CAWI City Manager letter Drafts 2009). The fact that the City Manager did endorse this powerfully written message in support of the Lens is important, but the fact that the City staff members were able to and did draft messages like this is also a testament to the contributions from the creators, facilitators, and supporters and promoters of the E\&I Lens by those who worked within the Corporation of the City, as they brought the internal cultural knowledge, understanding, and the organizational procedural know-how to construct an effective frame that can generate "buy in" from other bureaucrats within the City in various positions within the hierarchy. ${ }^{29}$ Note that in both of these mandates, the residents of Ottawa and the City are framed in terms of "clients" or "customers" who receive services, with the municipality as the service provider, and not in terms of 'citizens' and the City as a democratic 'government'. Some Reference Group members challenged this customer service provider frame that the City uses to portray itself, though such push back against this official (and dominant) frame in the City did not become the central thrust of the message conveyed in the E\&I Lens.
} 
would not have to bear the financial burden entirely, and the marketing pitch made to the City by the community was that this would be a "one time cost" (c.f., CAWI and City of Ottawa 2007-03-22; EDAC 2007d). The discourse used to 'market' and 'sell' this Lens to the target audience, and to get their 'buy in', also emphasized that this would help reduce the financial and human resources required to do this work - hence less money, less human resources, less effort, and less time. And while efficiency is not a bad thing in and of itself, creating a meaningful, wide-reaching and truly systemic change in a large bureaucratic organization does require the investment of resources and time in a sufficient, consistent and sustainable manner.

Many contributors of the Lens and the Snapshots I interviewed identified this non-mandatory nature of the Lens to be one of the fundamental weaknesses of this tool, as it "has no teeth" and without being mandatory, the City staff won't use it. Many of the interviewees, especially those from the community, commented on the fact that City staff "are busy", "don't have time" and "probably will not read all these documents". Many community members wondered to what extent this tool was "actually being implemented" in the City now that it had been developed because they believed it has the potential to "create good change if it is properly used". And some, while still hoping it would be, indeed doubted that it would lead to concrete positive change in the lives of those in the community (Interviews: anonymized).

\subsubsection{Broad Engagement and Direct Representation}

And of course, obtaining buy-in, support, and the ongoing participation from the contributors of this Lens was another key strategic priority that the key coordinators of the Lens needed to achieve before this Lens could be co-developed as a collaborative 
effort among them. This required an active coalition building process, such as outreach to key community leaders, organizations, and the City's Citizens Advisory Committees whose mandates related to the eleven designated groups in the Lens. This was particularly important during the earliest phase of the E\&I Lens development process, for the key coordinators needed to convince all eleven groups that being part of a multi-lens was a good idea for their respective community (movement), and not a loss. Relationships of trust also needed to be established among these contributors, as well as the credibility of the key coordinators to be able to create a truly intersectional Lens that reflected all eleven communities' concerns, realities, experiences, barriers, and issues without overlooking some, or without having a strong 'bias' for their own specialty (i.e., gender and women).

For example, the key coordinators started the systematic outreach to all the Advisory Committees immediately after CAWI secured the federal and the municipal funding for the project during the summer of 2008, assisted by a few additional key individuals who had been closely involved in the two preceding projects, the Ottawa Equality Framework and the Gender Equality Lens. They also recruited the Reference Group members who had the subject expertise, public credentials and profile, and organizational affiliation, as well as membership or "lived experience" in the given community (CAWI 2008-05-27, 05-29). The intention was that these individuals could serve as direct representatives of these communities wherever possible, ensuring that relevant knowledge and expertise would be provided to inform the content of the Lens, while also serving as an ongoing conduit or liaison between the E\&I Lens project and their broader community through their organizational affiliation and network. 
Having the visible presence of a 'community representative' for each of the eleven groups was also essential to ensure that the E\&I Lens would be viewed as a legitimate tool by the broader public, especially those belonging to these eleven groups. Ensuring broader public support for this Lens would also be an important strategic consideration for forming a coalition, as a means of increasing their collective leverage vis-à-vis the City. And of course, all of this was important not only for these explicitly strategic and instrumental reasons, but also for the inclusive and participatory process it implied, ensuring that the project indeed reflected the views, voices, experiences, and visions of these often excluded communities.

\subsection{4 "Allies" and "Champions" in the City}

For similar reasons, the key coordinators also needed to obtain the buy-in, support, and ongoing participation from various representatives of the City of Ottawa to codevelop this Lens. Just as the excluded communities would need to be able to see this Lens as something that includes, reflects, and is relevant to their lived experiences, the Lens had to offer the same to potential users of the Lens inside the City. Having the substantive input from City representatives who know the everyday needs of their peers, supervisors, and employees within the organizational culture, and having their direct participation in the process, were both essential. This also added another important strategic implication down the road in anticipation of the implementation stage of this Lens once it had been developed.

Moreover, based on the previous experiences with the Equality Framework and the Gender Equality Lens, the key coordinators knew very well the strategic importance of having an "ally" or a "champion" within the institution of the City (Interviews: a, e, g, 
i). They could be a member of Council or the City's senior management team who helps in the official approval process for an objective or a project. They could also be a manager or a staff person in a key ally department, who could act as an operational "point person" to help community actors move their initiatives up and down the bureaucratic decision-making channels in the Corporation, first to get senior-level endorsement, then to follow up and to operationalize such endorsements into concrete actions. They could provide strategic advice to community actors based on their internal knowledge of the Corporation's institutional structure and processes, and also of its culture. ${ }^{30}$ In addition, these allies from the institution of the City also derived additional authority and legitimacy from their position within the institutional structure and its hierarchy, which benefited the community actors.

Such collaborative relationships can be mutually beneficial for both the City and the community as collectives, as well as the individual actors from these two groups. That is, those who operate within the Corporation as allies can also gain added legitimacy for their case when backed by this 'external', public support from the community (Interview: s). This of course allows for greater access and leverage on the part of the often excluded community groups to the City's decision-making and operational processes. Indeed, the City of Ottawa and these allies use the expression "community partners" to refer to community-based groups such as those involved in creating this Lens, reflecting this recognition of mutual benefit and respect (Interviews: e, g, s; SPC and CAWI 2006a: 5). Through collaboration with these community partners, the City can also benefit greatly

\footnotetext{
${ }^{30}$ For example, the strategic advice to "market" and "sell" to the "target audience" in the City to get "buy in" by appealing to their "self-interest" as well as "the greater benefit to the City as a whole" came to CAWI from an insider ally, during the early 'lobbying' effort by community leaders trying to push the City to adopt the Equality Framework (CAWI 2005-09-06).
} 
from their subject expertise, insights about the lived experience of constituents, and through the volunteered - and hence unpaid - work and time of community leaders and participants.

Many community participants of this Lens also appealed to this concept of 'partnership' as a way to make claims on the City as a democratic government that is accountable to them. They variously expressed that as citizens the members of these often excluded communities have the right to have a say in the way that the City is run (Interviews: a, b, d, h, i, l, o, q, r, t, u, v). This includes the development, implementation, and evaluation of tools like the E\&I Lens, as well as the broader governance and operation of the City as their municipal government. This is where the line demarcating the boundary of the polity is highly salient but blurred, especially within the context of an officially proclaimed and practiced "partnership" (See p. 61 for further discussion on modification to the concept of 'polity').

\subsubsection{From Advocacy to Partnership to Resonance: Prioritizing City Employees}

Although the idea of polity was blurred, we can still see a broad pattern in the dynamics between what everyone involved in the partnership called 'the community' and 'the City' over time. Here, we see a gradual shift from a stronger advocacy role that community leaders played in the early years, to a growing emphasis on a 'partnership' between the City and the community in moving concrete initiatives forward inside the Corporation. This was visible in the earlier period between 2004 and 2006, when the community leaders were still trying to push the City from the outside (with broader community support behind them) to get it to take action to promote the related values of equality, equity, inclusion, diversity, etc. This took the form of trying to get the City to 
endorse the City-wide Equality Framework as an overarching set of values and principles for the City, or to establish CAWI as an official partnership with the City and, after that, to develop and implement the Gender Equality Lens as a concrete tool for City staff to use to promote gender equality. This gradual move towards more concrete projects like the Gender Equality Lens and then to the Equity and Inclusion Lens came with these community actors' transition to its official partnership status with the City.

With it came a heavier reliance on frame 'alignment' and resonance with the dominant and official frames and the existing organizational structure and culture of the City. In particular, in my analysis I noted the increased weight the community and City stakeholders placed on resonance coincided with the formation of 'partnership' with the City. Initially, the use of resonance was an explicitly and strictly strategic move made by some of these community leaders, as well as the Citizens Advisory Committee members, who sought to make a strong "business case" to the City's senior management team and/or the Council at different points in time in order to obtain their approval for the initiatives they were proposing, including the creation of the E\&I Lens (c.f., CAWI 2007$03-22,2007-07-09) .{ }^{31}$

A similar set of discourses were articulated by their allies working inside the City as well, who helped them make a strong case to sell this to the senior management who had to approve this Lens. This strategic resonance over time also fed into the dominant frame of the City - especially the economic bottom line and the lack of financial

\footnotetext{
${ }^{31}$ As described earlier, such a business case drew from the language of "cost reduction", "cost saving", "efficiency", "efficacy", "increased revenue generation" and "economic growth" (from the greater economic participation of the currently excluded) to incentivize the City to adopt a Lens like this. Another key component of the marketing discourse featured the Lens as "user-friendly", "short", "simple", "quick and easy to use", or that it "saves time", and would be a "one-stop shop tool" that "consolidates" multiple mandates that the "busy City staff" had to fulfill as part of their job into one (CAWI 2007-03-22, 2007-0709; Interviews: a, c, d, e, g, i, j, p, r, t).
} 
resources available to the municipality to invest into various social initiatives like equity and inclusion - which in turn put added restrictions on the range, extent, or the kind demands that the community groups could place on the City. This included restrictions on how and to what extent a "radical" challenge to the status quo or the dominant frame of the City could be included in the Lens and the Snapshots.

\subsubsection{From Separate Communities to an Intersectional Coalition}

Another broad shift was the gradual transition from separate communities working in isolation from each other to the formation of an intentionally and explicitly intersectional coalition, which required the "frame alignment" of the coalition partners. Again, during the earlier stage of coalition building, the key coordinators and community leaders engaged in a heavy outreach and courting effort to community coalition partners. This was evident during the conception stage of the Equality Framework that would include multiple excluded target groups, as well as the very initial stage of the Equity and Inclusion Lens development process, when the key coordinators needed to bring all eleven communities on board.

During the middle stage of the E\&I Lens development process, the key coordinators engaged in a heavy parallel outreach and engagement of both community and City stakeholders into the development process of the Lens, especially when the Snapshot Workgroups were being established. ${ }^{32}$ In the later stage of the Lens development process, there was a stronger emphasis on catering to the needs of the intended users or the target audience of the Lens, primarily the managers of the City and then their employees. This strategic focus on the target audience's needs increased as the

\footnotetext{
${ }^{32}$ Here, the key coordinator from the City took the lead on the outreach to representatives from the City, and the key coordinator from CAWI led the outreach to community participants, yet another example of the partnership at work (CAWI 2009-04-03).
} 
Lens progressed from a broad conceptual form and its development stage towards its concrete form, and ultimately to its implementation stage in the City. ${ }^{33}$ The contributors of the Lens also generally describe the development process of this tool to be "community-driven", "community-based", "community-led", and a "grassroots effort" often with a sense of pride on the part of both the community and the City contributors for having adopted this progressive approach ${ }^{34}$. In contrast, the current implementation stage is described by those who are privy to this process as more "City-driven", "done by the City", and "in the hands of the City", which has left some of the community members of the development process out of the loop (Interviews: a, e, c, d, e, h, i, l, n, o, p, q, t). ${ }^{35}$

\footnotetext{
${ }^{33}$ This is evident in the shifting makeup of the E\&I Lens Reference Group over the course of the 16-month period. Initially, it was made up mostly of the community members from the eleven groups highlighted in the Lens. Over time, a greater number of City representatives joined the Reference Group as the focus shifted from the community-driven development of the Lens to the City-led implementation of it. Similarly, during the initial stage, the key coordinators held consultations with all the Citizens Advisory Committees to seek input from these Committees associated with the eleven groups. During the middle stage, the City key coordinators held consultations with managers from various City departments to seek input on how useful the draft Lens would be for the target audience. And towards the final stage, the key coordinators held focus groups to test the pilot version of the Lens and the Snapshots with City managers, nonmanagement staff, as well as the Advisory Committees. With each round of consultations, the key coordinators placed greater emphasis on resonance to make this tool as appealing, simple, and user-friendly for the target users as possible (Interviews: a, e, g).

${ }^{34}$ For many of the community contributors to the Lens, the fact that they were able to develop this Lens as a "truly grassroots" effort is a great accomplishment to be proud of. Many of these contributors also acknowledge the openness to and the trust of the local community(ies) that the City - and in particular the City-designated project lead/manager for the Lens development - displayed through action by allowing the process of making this tool to be so strongly community-driven. This is often cited by the community participants as a sign of a positive and sincere "partnership" between the two, and likewise by many of the City contributors of this Lens as well. Indeed, many members of the Reference Group and the Workgroups commented that they viewed the very presence of this manager to lead this process as a very strong indicator that the City and its senior management was indeed serious about making equity and inclusion a priority (Interviews: a, c, e, d, g, h, i, j, l, n, o, q, v).

${ }^{35}$ This in itself was an example of yet another contradictory strategic priority, for it was strategically deemed necessary by the key coordinators of the Lens implementation (comprised mostly of the City allies) to build the internal capacity for the City to train staff to implement this Lens on an ongoing basis, rather than relying solely on external expertise from the community. However, many of the community contributors to the Lens that I interviewed were not informed of the status of the Lens after its development was completed. With the expiration of the funding which was a one-time investment to develop this tool, some feel 'the community' has been left out of this process as the responsibility and the focus of the project shifted over to the City (Interviews: anonymized).
} 


\subsection{Local History: Equality Framework and the Gender Equality Lens}

In this subsection, I trace some relevant aspects of Ottawa's local history in order to set the stage for the creation of the Equity and Inclusion Lens as a result of a collaborative effort by both a newly formed intersectional coalition and a Citycommunity partnership. The origins of this Lens are therefore multiple, coming out of the convergence and accumulation of various preceding initiatives emerging from both the broader community (community leaders, activists, organizations and movements) and the Corporation of the City of Ottawa (employees and decision-makers, both elected officials and bureaucrats). ${ }^{36}$ Out of these, two parallel initiatives fed most directly into the creation of the Equity and Inclusion Lens, in which CAWI played an active role: the Ottawa Equality Framework and the Gender Equality Lens.

Earlier articulations of a vision of a city for everyone- a vision for a broadly inclusive city that was not confined to one social issue or population group - were formulated through discussions that took place among local community leaders between 2005 and 2007 on how to push the City to adopt the Ottawa Equality Framework. It is here that the concept of highlighting multiple 'at risk' or 'excluded' groups emerged and were fleshed out - and the eleven communities featured in the Lens are found in this framework, though worded or scoped slightly differently. The idea to work in partnership with the City to change the ways in which it conducts its own businesses as a workplace, as a public service organization, and as a local democratic government is also found here,

\footnotetext{
${ }^{36}$ For example, one Workgroup member recalled hosting a series of round tables in previous years with another member of the Reference Group on the state of the City's service delivery in light of the rapid demographic changes occurring in Ottawa. This shows that long before the Equity and Inclusion Lens was created, the organizers and the participants of these round tables were engaging in the broader discussions in search of new tools and solutions to assist the City to become more responsive to and inclusive of its changing and increasingly diverse population (Interview: $\mathrm{u}$ )
} 
though this also flowed (both naturally and strategically) from the fact that CAWI was created as a partnership with the City in 2005 .

Between 2005 and 2008, another tool called the Gender Equality Lens was being developed by CAWI, also in partnership with the City of Ottawa. ${ }^{37}$ This provided a tangible, concrete, user-friendly tool that City employees could (and did) use in their everyday work to promote gender equality in Ottawa. While this tool focused specifically on "gender" and "differences and inequalities between women and men" in particular, it established an analytical foundation for the development of an intersectional social inclusion planning tool for the City (CAWI and City of Ottawa 2008a). In addition, the practical lessons learned from the development, pilot implementation, and the evaluation of the Gender Lens served also as a concrete model for a new, "expanded" lens that succeed it, the Equity and Inclusion Lens (Interviews: a, d, e, g, i, s). This expanded lens was initially called the "multi-lens", "multi lens", "Multi-Focal Lens" or "Multi-focal Lens" (and other similar ways of spelling it) to signal its emphasis on multiple categories of analysis or social groups in contrast to the singular focus on gender. On a practical level, the basic structure and composition of the Reference Group for the Equity and Inclusion Lens built on those of the Equality Framework and the Gender Lens, which allowed for a broad representation from diverse communities as well as the City officials.

\footnotetext{
${ }^{37}$ The three City departments that contributed to the development of the Gender Equality Lens included Community and Protective Services (CPS), the City Manager's Office, and Business Transformation Services (CAWI and City of Ottawa 2008a: 2). This formed an institutional foundation for the ally departments and ally City staff for CAWI for years to come, as one employee from BTS, and another employee from CPS, were appointed by the City to sit on CAWI's Steering Committee as City representatives. The former was later appointed by the City to be the "project lead" for the development process of the E\&I Lens, and the latter for its implementation (Interviews: a, e, g, s).
} 


\subsubsection{The Ottawa Equality Framework: An Early Articulation of an Intersectional Vision and Strategic Process}

The Ottawa Equality Framework was an initiative that emerged as an informal yet organized effort among a small group of community leaders and activists in Ottawa. One inspiration for this came when this group of community activists came across the extensive Equalities Framework that was already in place in the City of London, UK (see: Greater London Authority 2009), and consulted the documents and resources available on the City of London's website (Interviews: a, e). Coordinated by CAWI and the Social Planning Council of Ottawa ('SPC') they formed an informal "reference group" to brainstorm what Ottawa's own equality framework should look like, and developed strategies for realizing it. This informal group started to push Ottawa's City Hall to adopt a similar framework - though less extensive than that of London, and locally adapted to Ottawa - as a way to commit the City to work towards ensuring the same quality of life for all residents, especially the communities they were starting to identify as most at risk of exclusion. This effort was thus a precursor to Ottawa's Equity and Inclusion Lens, and both the 'Pilot' and the 'Final' versions of the Lens acknowledge London's Framework for inspiration, and as a model (CAWI and City of Ottawa 2009; 2010a).

While an overarching Equality Framework still has not been adopted by the City of Ottawa as a concrete policy to date, significant patterns for the future development of the Equity and Inclusion Lens were set by the work of this group, both in terms of an intersectional vision for an equitable city and the strategic paths/processes taken to get there. First, what is most notable is the fact that the vision for the Equality Framework 
started out not from the perspective of one particular social group (such as 'women'), but from those of multiple target groups (CAWI 2006-06-15; SPC and CAWI 2006-01-25). In fact, it is out of these early discussions under this Framework that the eleven communities highlighted in the Lens came to be identified as most adversely affected by exclusion in Ottawa. This was an early effort among these community leaders to try to define what it means to adopt an 'intersectional' lens of the world and of how inequity affects society as a whole. A new, yet-to-be defined vision of Ottawa was being articulated and rearticulated among these community leaders and some individuals from the City.

Second, new strategic paths were being searched for and tested to pursue this emerging vision. One characteristic strategy common to the Equality Framework and the Lens was the formation of a core reference group, primarily made up of community leaders. This core group actively sought broad outreach to, consultation with, and direct representation from, diverse communities or "target groups", in order to ensure that their perspectives were appropriately incorporated into this emerging vision and processes early on (CAWI 2006-06-15; SPC and CAWI 2006-01-25). Another key strategy they chose was to "tie in" this initiative to the existing policies and priorities/practices of the City as much as possible, and to collaborate with representatives of the City, both bureaucratic and elected, to move things within the Corporation. ${ }^{38}$ This informal reference group thus actively sought input and participation from any of the vulnerable or marginalized population group members, as well as the Citizens' Advisory Committees

\footnotetext{
${ }^{38}$ The Equity and Inclusion Lens almost exclusively focused on working with the City's bureaucracy, as the Key coordinators decided not to go through Council especially given Mayor Larry O'Brien's political position at the time - he was not seen as an ally but an 'enemy' to these communities' advocacy efforts (Interviews: $a, d, e, g, j$ ).
} 
for the City, which was made up of volunteers who brought the residents' perspectives and advice to City officials and Council. These practices were important both to live out the principle of inclusion they were striving for, and to garner necessary support from key stakeholders in the community and the City. In other words, a foundation for a new intersectional coalition among diverse communities and a City-community partnership to achieve a "city for everyone" was already being laid down.

\subsubsection{Beginnings of a Coalition, and a Partnership}

How the informal reference group came to settle with this particular set of eleven communities is a case in point. Between 2005 and 2006, the Equality Framework reference group repeatedly asked the question of who are the most excluded groups in Ottawa, and refined and updated the list of the target groups. They kept this question as open, broad and flexible as possible at the outset, so as not to limit the discussion to the perspective of a small segment of Ottawa's diverse communities. The City's Equity and Diversity Policy was used as the basis for such discussions, both as a starting point and a legitimating force for their choice. The policy identifies five "designated groups" "women, Aboriginal persons, persons with disabilities, members of visible minority groups and gay, lesbian, bi-sexual and transgendered (GLBT) individuals" - though it qualifies this by adding that the selection "does not preclude the possibility of addressing systemic discrimination for other identifiable groups" (City of Ottawa 2001). Following the discourse in this policy, the Equality Framework reference group came to present the "target groups" they identified in two categories: those "designated groups" in the policy and "other groups that also risk exclusion in Ottawa" (ibid). Marginalized or vulnerable 
population groups highlighted in other City-led strategic initiatives and programs were added as 'other groups'. ${ }^{39}$

During this period, different numbers of groups were counted, under different names as the informal reference group was still in the process of identifying and naming them, and the rationale for the selection came both from the discussions within the community as well as from the existing policies and practices of the City. For example, documents dated September 20 and November 14, 2005 identify a total of nine "target groups" - five from the E\&D Policy, and an additional four that are named in the "equality statement" of the City's Community and Protective Services Strategic Plan and the Corporate Plan: "people living on low income, new immigrants, francophones, and people living in rural communities" (CAWI 2005-09-20, 11-14; SPC and CAWI 200506-16). This was still an open question at that time, however, as the first meeting of this reference group on November 16, 2005 included a brainstorm on "who is not here who have equity concerns?" The answers here included seven communities:“[s]eniors, youth, low-income, francophone, people with disabilities, people living in rural areas", and labour unions. ${ }^{40}$ In addition, they identified key committees from the City such as “Advisory Committees (EDAC, PIAC, Accessibility, Seniors, Francophone), COMPAC

\footnotetext{
${ }^{39}$ The selection of which communities should be highlighted in this Framework was, to a significant degree, guided by the existing policy in the City, especially the Equity and Diversity Policy. Here, the policy includes five designated groups, four of which are "legally" designated by the federal Employment Equity Act (e.g., Aboriginal persons, persons with disability, visible minorities, and women, and one was added voluntarily by the City (e.g., GLBT). (The local history behind this voluntary addition of GLBT to the City's own Equity and Diversity Policy is discussed in chapter 3 under the subcase on the GLBT Snapshot Workgroup.) The 'other' non-designated groups that were included in this Framework at the time, and eventually in the E\&I Lens, reflected "vulnerable" or the "marginalized population" in Ottawa (Interview: s) that the City had identified and had policies, strategies, initiatives and programs in place to support, such as youth, seniors, poverty, Francophones, etc. In either case, however, these groups could be 'tied in' to the existing policies and initiatives within the City.

${ }^{40}$ While labour unions were not included in the Lens as one of the eleven communities that risk exclusion, "union affiliation" came to be incorporated into the User's Guide as one of the "organizational" factors that influence individual City employees' experiences of the City as their workplace (CAWI and City of Ottawa 2010a: 8).
} 
(police- visible minority community), Impact Council [from United Way], Transport Advisory Committee from the City and related bodies" (SPC and CAWI 2005-11-16). By June 2006, this has expanded again to a total of eleven - five from the E\&D Policy, and six others, namely "people living on low income", "new immigrants", "francophones", "people living in rural communities", "children and youth", and "senior citizens" (CAWI 2006-06-15).

Likewise, some community activists and City employees used key words such as "equity", "inclusion", "equality", "diversity", and "quality of life for the full diversity of residents" more or less interchangeably between 2005 and 2009 as they continued to experiment these concepts and terminology. Similar kinds of experimentation and evolution of language occurred in relation to the names to refer to the target groups. These phases included, for example, "equity-seeking groups" (CAWI 2005-04-22, 09-20, 2007-03-22; SPC and CAWI 2006-01-25), "target groups" (CAWI 2006-06-15; SPC and CAWI 2006-01-25), "equality target groups" (SPC and CAWI 2005-12-01, 2006-01-25), "target groups concerning equality and social inclusion" (CAWI 2005-11-14), "other groups whose inclusion is important to ensure quality of life for the full diversity of citizens" (CAWI 2005-09-20) or "other groups whose inclusion is important for ensuring quality of life for the full diversity of residents" (SPC and CAWI 2005-06-16,12-21; 2006-01-25), "groups who risk social exclusion in our city" (CAWI 2005-11-14), “groups who risk exclusion" (2008-02-06), "groups who experience exclusion" (2008-0528), “designated groups" (2007-03-22), “equity groups” (2008-05-28, 2009-04-08), “11 groups most affected by social exclusion in the community of Ottawa" (2008-05-28), “equity/inclusion group" (2008-09-05), "specific groups of people at risk of exclusion or 
facing inequities" (2009-02-09). Eventually, these settled with the expression used in the very final version of the Lens in 2010 , i.e., "people who are at risk of exclusion" and "people who face systemic barriers and inequities" (CAWI and City of Ottawa 2010a: 4, 7). ${ }^{41}$

As part of the refinement process of this emerging intersectional vision of an inclusive city, and the new words to express it, the reference group also sought to cultivate close working relationships with these diverse communities themselves. The formation of a cross-community or intersectional coalition under the Equality Framework, and later the Equity and Inclusion Lens, would not have happened otherwise. From the outset, the informal reference group recognized "the need to engage grass roots as much as possible" to make the Equality Framework a reality (SPC and CAWI 200512-01). The community and organizational affiliation of individual attendees at the early reference group meeting included: Aboriginal peoples, GLBT, visible minorities, immigrants, people with disabilities, and they had organizational affiliations with the Health and Social Services Advisory Committee of the City, CUPE local, the GLBT Liaison Committee at Ottawa Police Service, the Coalition of People with Disabilities, Western Ottawa Community Resource Centre, the Social Planning Council of Ottawa, and City for All Women Initiative (SPC and CAWI 2005-11-06, 12-01).

The fact that these minutes explicitly captured the community and organizational affiliation demonstrates their conscious effort to achieve broad community representation. It is also notable that close contacts with key Advisory Committees were already in place by this point. In addition, it was important for this small reference group

\footnotetext{
${ }^{41}$ As I will discuss in Chapter 3 and 4, this evolution of language - especially about the names for groups of people and the reasons behind them - also continued into the development process of the Equity and Inclusion Lens, both at the Reference Group and the Diversity Snapshots Workgroups.
} 
to send a clear message to the City that their work reflected the will and the desire of the broader community, and thus was not easily dismissible as the act of a few individuals. ${ }^{42}$ Finally, the reference group had already identified the need to send a "unified voice... unified message" from this broad cross-section of variously marginalized communities to the City (SPC and CAWI 2005-12-01). This became an important strategic concern in the development process of the Lens as the key coordinators sought to build a sense of solidarity and align the frames among various movements participating in the coalition, as is often necessary for an emerging coalition (Van Dyke and McCammon 2010). ${ }^{43}$

\subsubsection{Tie-in: Alignment with the Official Frame(s)}

The Equality Framework reference group also sought to 'tie in' their emerging initiative with the language used in existing policies, priorities and frameworks in the Corporation of the City of Ottawa. This was chosen as a way to increase their legitimacy and relevance, but also to maximize the "resonance" of the discourse or the "frame" they used to make their case to their target audience, the City (Ferree 2003). For instance, from the very outset SPC and CAWI used the Human Services Plan component of "the Ottawa 20/20" (City of Ottawa 2003) and the City's Equity and Diversity Policy to frame their proposed initiative as a necessary step for the City to live up to their own official

\footnotetext{
${ }^{42}$ For instance, a letter from the Social Planning Council of Ottawa and City for All Women Initiative respectively, sought "community support" to push the City to incorporate "equity" into the Corporate Plan for 2006-2009 (SPC and CAWI 2005-06-16; 2005-06-21). The letter of support from Ottawa Community Immigration Services Organization addressed to the City's Planning Department, and dated August 2, 2005 , is an example of such support coming from the broader community (OCISO 2005-08-02).

${ }^{43}$ Note here that there was a stronger advocacy effort by those from 'the community' around this time, as they were making claims on the City and applying pressure on it from the outside to adopt the Equality Framework or develop and implement the GEL. However, after they finally succeed in getting the City to approve the development of the E\&I Lens, and the official 'partnership' between the City and the community was formed to do so, the key coordinators started to cater more to the City and its employees/managers as their main target audience. For example, the CAWI key coordinator even opened the very first meeting for the Visible minorities Snapshot Workgroup by explaining to the community members that this document would not be an advocacy piece, but rather meant an educational and awareness raising tool for the City employees, which had to be user-friendly (CAWI 2009-04-07).
} 
priorities (CAWI 2005-04-22, 11-14). This proved to be an effective, and indeed indispensable, strategy for the reference group of the Equality Framework to pursue, and for the Reference Group of the Equity and Inclusion Lens a few years later. Although the City's priorities transformed over the intervening years, this core strategy to graft the vision of equality or equity onto the City's internal policy structure as closely and firmly as possible remained central to these community leaders' strategy as they developed the Equity and Inclusion Lens and the accompanying Diversity Snapshots.

For example, starting in December 2008, the Equity and Inclusion Lens Reference Group started to link the Lens to "Service Excellence", which was a new Corporatewide $^{44}$ priority that the City Manager and EMC started to push, with Council mandate, down the City's bureaucratic hierarchy around that time. This is evident in the final text of the Lens, for example, in the very first page of the User's Guide that presents the “message from the City Manager" situating the Lens as a key tool to support the City’s commitment to Service Excellence at Council and all levels of the Corporation (CAWI and City of Ottawa 2010a: 2). "Appendix A" of the User's Guide, titled "City of Ottawa Commitments", is a list of the federal and provincial legislative requirements and the City's own policies, all of which point to the need for the City employees to use the Equity and Inclusion Lens as part of their work at the City. Similarly, each Snapshot includes a section on "Council mandates and legislation" to align the message of the Snapshot and the Lens as a whole with the mandate of the Corporation of the City of Ottawa.

\footnotetext{
${ }^{44}$ The expression 'Corporate-wide' and 'City-wide' is often used interchangeably especially among City officials, but 'Corporate-wide' denotes the institutional structure of the Corporation of the City of Ottawa, especially its bureaucratic component consisting of the City Manager's Office and various departments (all of which ultimately report to the Mayor and City Council). In this thesis I use the terms 'the Corporation' and 'Corporate' to refer to this institutional structure of the City.
} 
The aligning of the words of the community and the City, and the formation of an official partnership between the two, would not have happened without the collaborative relationships between people - those working in the community, and those working inside the City. This was essential to move things inside the Corporation - namely to make a business case to, and obtain buy-in from, senior management and Council. In fact, this was a characteristic strategy taken by the community leaders pushing for equityrelated initiatives, and particularly by CAWI which established itself as an official "partnership" with the City in 2005.

\subsubsection{Allies within the City}

From the outset of the Equality Framework, the reference group identified and worked with what they called key allies within the City. These allies were essential in moving their requests, proposals, deputations and recommendations to develop this framework up the decision making chains inside the Corporation. Later, once Council gave approval - first in 2005 to investigate the possibilities to develop an equality framework, and again in 2008 to develop a concrete tool in the form of the Equity and Inclusion Lens - the community leaders went back to City staff to cultivate relationships with the managers and, through them, down the bureaucratic hierarchy to ensure buy-in from the City staff at large in order to facilitate implementation of the Lens at the ground level. In other words, the community made a point to work with(in) the decision-making and bureaucratic structure of the City - or what social movement theorists call "polity" (Gamson 1990[1975]); McAdam 1992) - rather than opposing it straight-out or working exclusively from outside of it. 
This is where the concept of "polity" as defined in classic social movement theory is useful but needs to be modified for the case of the Equity and Inclusion Lens. Gamson's concept of "polity" and the distinction between its "members" and "challengers" (1990[1975]: 150) offers a useful starting point for my analysis, as the City of Ottawa can be viewed as the polity and its members, whereas the eleven communities - both at the coalition and at the individual community levels - play the role of the challengers. McAdam's description of social movements as "the rational attempts by excluded groups to mobilize sufficient political leverage to advance collective interests (1992: 37-38)" is useful to the analysis of the Equity and Inclusion Lens because the primary target of the tool is the City as an institution, and its employees. However, McAdam's characterization of such groups to be working "through noninstitutionalized means" (ibid) does not strictly apply to this case, for the community leaders have taken an explicit strategy to work through the institutional means within the City, such as submitting a request through staff reports to Council Committees, seeking support from Advisory Committees, obtaining Council approvals, and doing so by tying in their demands to existing legislation and City policies, or even proposing to create a new policy framework for the City altogether, as in the case of the Equality Framework. ${ }^{45}$

The ally-making process between CAWI and the City often started with individual City employees in departments whose portfolios or missions related to equality, equity, inclusion or diversity, or 'ally departments'. As noted earlier, CAWI had worked closely with the Human Rights and Employment Equity (HREE) unit of Human

\footnotetext{
${ }^{45}$ In addition, the community leaders called these City employees and Councilors "allies" within the City, who in turn referred to the community actors as "community partners", signaling they viewed their working relationships to be mutually supportive in moving the City towards what they both viewed as a positive change from their respective positions (SPC and CAWI 2006-01-16).
} 
Resources and Community and Protective Services (CPS), which typically serve "marginalized" or "vulnerable" populations (Interviews: a, e, g, s). CAWI would typically work with these individual allies or 'contact people' to initiate the process to obtain buy-in or support from management (or senior- or executive management), then one of the standing Committees of City Council, then eventually Council itself, the highest decision-making authority within the Corporation. Such incremental process to obtain buy-in and approval from these key decision makers of the City would also be supplemented by additional support from the Advisory Committees and external community agencies.

For example, CAWI submitted an initial request for the City to "investigate London's Equality Program and other programs" as a first step towards creating an equality framework in April 2005. This was done via a report by CAWI's "contact person" in Community and Protective (CPS) at the time. This was then submitted by then-Deputy City Manager of CPS to the Health, Recreation and Social Services (HRSS) Committee of Council. At this Committee, two of the Citizens Advisory Committees provided support for CAWI's request, and CAWI's close ally members of Council ${ }^{46}$ voted in support. This Committee then took it to Council as a whole as a recommendation for Council to approve, which it did. In this way, with the support from key decision makers such as the Deputy City Manager and Council members - and with additional community support from the Advisory Committees and external community agencies -

\footnotetext{
${ }^{46}$ This Committee was made up of the following Councillors: Chair Diane Holmes, Vice Chair Alex Cullen, and Members Georges Bédard, Glenn Brooks, Rick Chiarelli, Clive Doucet, Peggy Feltmate, and Janet Stavinga (City of Ottawa 2005 HRSS Report 21A) and CAWI viewed many of these them as its "allies". In particular, the key coordinators of the E\&I Lens recall Janet Stavinga and Peggy Feltmate as being particularly supportive and instrumental in moving Council's earlier approval of CAWI's partnership with the City forward, and for incorporating the Equality Framework into the Corporate Plan (Interviews: a, e).
} 
CAWI's request was now turned into an approval by Council (City of Ottawa HRSSC 2005 Minutes 21, Report 21A; City of Ottawa Council 2005 Minutes 34).

After this, the cycle of working closely with City's managers and ally Councillors to seek further approval from Council via its Committees continued. In June 2005, CAWI and SPC recommended that the City include "equality" into the Opportunity Agenda of the City's Corporate Plan. This was done first by including this into CPS's departmental strategic and business plan, again through its ally (HRSSC 2005 Minutes 21; SPC and CAWI 2005-06-16). Then in August 2005, one of the members of both CAWI and of Equality Framework reference group, who was also a member of the City' Health and Social Services Citizens Advisory Committee (HSSAC), recommended to this Committee to support SPC and CAWI's earlier recommendation. This Committee voted in support to make this same recommendation to one of the Council's standing committees, the Corporate Services and Economic Development Committee (CSEDC) (City of Ottawa HSSAC 2005; SPC and CAWI 2005). Meanwhile, CAWI followed up on this through another venue, by having one of its community members present the same recommendation to the HRSS Committee of Council (CAWI 2005, September 15). ${ }^{47}$

This persistent effort finally paid off in September 2005, when CSEDC approved "two action steps" to "promote conditions of equality and social inclusion" by: "develop[ing] an equality planning framework to be used in planning corporate wide (2007), drawing upon the experience of London, England and other programs", and "implementing city-wide the gender equality planning tools being piloted in Community

\footnotetext{
${ }^{47}$ This community member later became one of the members of the Gender Equality Reference Group, and eventually one of the City's key coordinators of the E\&I Lens, when she joined the City of Ottawa's Diversity and Employment Equity branch. In this sense, this member acted as a 'bridge' between 'the community' and 'the City' - first as a community leader, then later a City ally (Interview: e).
} 
and Protective Services Department in 2005-2006" (CAWI 2005-09-20). This way, the dual objectives of promoting broad-based equity and inclusion through the "Equality Framework", as well as CAWI's focus on gender equality, both obtained one of the highest directives, within the City's institutional hierarchy: Council approval.

\subsubsection{Strategic Framing for Resonance (and Radicalism)}

It is important to highlight here the essential strategic advice that CAWI and SPC received from one of its ally managers within the City, which later came to form the very core of the strategic package - and framing - of the E\&I Lens and the eleven Diversity Snapshots later on. This manager advised CAWI and SPC on how to "sell" the Equality Framework to City Council and get them to become "champions". In addition, this manager also advised them to "develop a clear communications plan", starting by knowing who one's "target audience" is, and appealing directly to their self-interest ("what's in it for me?"), alongside the "greater benefit" that such equality tools would bring to the city as a whole (CAWI 2005-09-06). Furthermore, this manager also advised them to spell out the "concrete examples" of how the Equality Framework would "translate into everyday benefits for residents", and to tie them to the "hot issues" in the city at the time, and package it as an opportunity for the individual Councillors to "shine before their constituents" (ibid).

This is another example of the ways in which the strategic insights and historical knowledge of the contributors of the Equality Framework and the Gender Equality Lens fed into the strategic package for the E\&I Lens. The intersectional coalition of the eleven community movements and the City-community partnership they formed thus came to pursue this particular framing strategy to create a transformative frame that helped them 
'sell' their case and obtain 'buy-in' from the target audience. As I will show in the following chapters, the individual Snapshot Workgroups also came to follow this common framing strategy in order to sell their cause to the 'average City staff' as the target audience and to obtain their buy-in to read their Snapshots and to use this Lens to promote equity and inclusion in their everyday work.

Meanwhile, the informal reference group for the Equality Framework continued to cultivate this emergent City-community partnership through City officials, both administrative and elected. In December 2005, SPC sent a 'lobbying' letter on behalf of the community to the Chief Corporate Planning and Performance Reporting Officer of the City at the time, CC'ed to a few of its allies such as the Manager of Human Rights and Employment Equity, Deputy City Manager of CPS, as well as one of the ally Council members (SPC and CAWI 2005-12-21). ${ }^{48}$ This letter sought to consolidate the City's commitment so far, reminding the City of the extensive community support behind this initiative, thus putting a subtle pressure or making claims on the City to honour it. ${ }^{49}$ This letter also contained key elements of the strategic package for the E\&I Lens later on, particularly the framing strategy. For example, in moving the discussion to more concrete terms about the actual development and implementation of the Equality Framework, the letter points to the need to coordinate all of the new and existing equity and diversity initiatives within the City to bring about positive results ('tie-in'), and the

\footnotetext{
${ }^{48}$ This former Councillor was one of the allies who supported civil society-based social change; since leaving the position with the City she has served as the Executive Director of the Algonquins of Ontario Consultation Office, and as one of the advisors to the negotiation team for the Algonquin Treaty vis-à-vis the governments of Canada and Ontario (Tanakiwin 2009).

${ }^{49}$ The letter was issued "on behalf of the Ottawa residents, our Boards of Directors and membership, and on behalf of the large number of partner organizations who supported the inclusion of an Equality Framework in our City's Corporate Plan" (SPC and CAWI 2005-12-21). It claimed a very extensive representation of "the community" as the source of its legitimacy and collective leverage against the City, referring to the whole of "the civil society" or "the third sector" outside "the polity" and "the market" (Gamson 1990[1975]; McAdam 1992).
} 
necessary staff time to do so (SPC and CAWI 2005-12-21). At this time, this letter underscores the need for additional resources the City needs to commit to develop and implement it. The reference group was already aware of the potential that lack of resources has to be one of the key sources of resistance from the City, and it immediately mitigated it by offering voluntary 'time' and 'subject expertise' from community organizational and Advisory Committees to guide the City through this process. ${ }^{50}$

\subsubsection{Financial Constraint as a Key Strategic Obstacle}

As we will see, this financial burden was a constant obstacle that the community leaders and their allies had to overcome. At the same time, CAWI and SPC utilized the strategy of 'tie in' to put pressure on the City not to back out of its commitment, by framing this initiative explicitly in terms of the City's own mandate to ensure the equality of all residents, and the willingness and readiness of the community to offer support, guidance and resources to the City along the way to achieve this together (SPC and CAWI 2005-12-21). A delicate framing effort on the part of CAWI and SPC is already evident here, as they push the City to commit action and resources, and use the City's own mandates and priorities to add to their obligation to do so; at the same time, it supports the City to do this together in partnership with the community, who are not criticizing the City nor making demands from it, but seeking solutions together. All of

\footnotetext{
${ }^{50}$ Their decision to adopt the "reference group model" to develop the Equality Framework was for two key reasons. One the one hand, it was a way for them to demand broad community representation and participation in the process and to hold the City democratically accountable to them. At the same time, this reference group was also keenly aware that the added financial and human resources cost to create and implement such framework would be one of the main arguments that the City would use to reject or abandon this initiative. They sought to mitigate this by 'selling' the potential cost-saving effects of collaborating with "community partners who can bring resources" and dissociating this proposed framework from a concrete budgetary cost in discourse by not raising this as part of the City's 2006 budget consultation process. Instead, they decided to "continue our side-line discussions with City staff" to move the idea forward within the bureaucracy while still seeking to secure financial resources by having "EDAC ask Councillors to approve the suggestion in the draft Operating Budget to increase the staff in... HREE [Human Rights and Employment Equity] team", which would then be able to allocate operational budget to develop and implement this framework on an ongoing basis (SPC and CAWI 2005-11-16, 12-01).
} 
these framing efforts in this historical context thus set the parameters of the framing effort that the contributors of the E\&I Lens, and of the individual Diversity Snapshots, had to follow.

SPC and CAWI proactively followed up on these suggestions, and in January 2006 the two organizations gave a joint presentation entitled "Developing an Equality Framework for the City of Ottawa" to the Equity and Diversity Advisory Committee, another Citizens Advisory Committee whose mandate was closely related to the "target groups" for the Equality Framework. Here, they reported that the Chief Corporate Planning and Performance Reporting Officer was now "the coordinating lead for developing and implementing" the Equality Framework and that his office may "seek guidance from the City's Advisory Committees and community partners" in this process, and asked EDAC to appoint a liaison to be part of the Framework's informal reference group (SPC and CAWI 2006-01-16). In this way the informal reference group was incrementally hemming in the City both discursively and materially to join in their goal: the adoption of an Ottawa-specific Equality Framework as one way to move forward their vision of an equitable city for all.

\subsubsection{The Gender Equality Lens}

The Gender Equality Lens was another initiative that developed in parallel with the Equality Framework and laid the groundwork for the Equity and Inclusion Lens. The two initiatives were led by a different core coordinating group and had a different scope. The discussions for the Equality Framework were co-coordinated by SPC and CAWI, while the Gender Equality Lens was more strictly a CAWI initiative. As for scope, the former adopted a broad-based approach to equality by focusing on multiple marginalized 
groups, while the latter had a specific focus on women though with an 'intersectional approach' to explore differences and inequality between and among diverse groups of 'women' ${ }^{51}$ The development process for each of these initiatives were slightly different but closely interwoven, and the coordinating bodies in both of these initiatives sought to use these as parallel initiatives that could inform and feed into each other's success as we will see below.

\subsubsection{The Early Lobbying Effort for Gender-specific and Broad-based Equality}

One significant way in which the two initiatives drew from each other's progress was their incremental effort at 'lobbying' the City in turns. For example, right before City Council approved CAWI's recommendation to investigate London's Equality Program in May 2005, Council had approved the three other preceding recommendations which were focused more specifically on granting CAWI an official partnership status with the City, and endorsing the City's commitment to promoting gender equality in particular. The first two of the four recommendations at this Council meeting in May 2005 officially established CAWI as an ongoing partnership with the City, by renewing what had been set up as a temporary arrangement until that point, and dedicating on a continual basis the staff time of two to three City managers to sit on CAWI's Steering Committee. ${ }^{52}$ The third recommendation designated Community Protective Services (CPS) as the "lead department" to work with CAWI to "to ensure that the goal of implementing practices and strategic plans that increase gender sensitivity and enhance gender equality, is realized" (City of Ottawa 2005 Council Minutes 34). Here, the initial recommendation to

\footnotetext{
${ }^{51}$ McCall classifies this type of intersectional analysis as an "intra-categorical approach" to intersectionality that examines the ways in which identity categories intersect within one category as opposed to the "inter-categorical" approach (2005).

${ }^{52}$ This is the governance body of CAWI, the equivalent of a board.
} 
explore London's Equality Program was at this point tacked onto CAWI's work on gender equality, presented to Council as a way of promoting gender equality through CAWI (ibid).

The organizers for the Equality Framework and the Gender Equality Lens did not view these as completing priorities, but rather as mutually supporting and complementary for each initiative. For one, the recommendation to investigate the London's equality programs might not have reached City Council at that time if CAWI had not obtained its official partnership status, backed with an ongoing working relationship with City managers and an ally department like the CPS. In this sense, CAWI at that time put itself in a position to open doors to the City for itself, as well as for others pursuing similar goals, such as the Equality Framework, and later the Equity and Inclusion Lens. In June 2005, the organizers for the Equality Framework - coordinated under SPC and CAWI were therefore able to use CAWI's partnership status as one channel to access the City's decision-making structure (SPC and CAWI 2005-06-21). The organizers for the Equality Framework also pursued their own 'lobbying' effort to push the City to adopt the Equality Framework, which they always sought to beef up with broader support from the community, as evident in the letters of support from other community organizations and their leaders (SPC and CAWI 2005-06-16; OCISO 2005-08-02). During this time, the direction of 'feeding' between the two continued to shift back and forth as the two initiatives evolved in parallel, until in the long run the Gender lens was replaced by the Multi-lens in the form of the Equity and Inclusion Lens.

Meanwhile, CAWI successfully moved along the gender equality agenda within the Corporation between 2005 and 2008, through a concrete and tangible form of the 
development, pilot implementation, and evaluation of the Gender Equality Lens. In the fall of 2005 City Council first approved CAWI's recommendation to implement "gender equality planning tools" City-wide (CAWI 2005-09-20). Between August 2005 and January 2006 the "Gender Equality Guide" was developed in partnership with CAWI and its ally department Community and Protective Services (CAWI 2005-08-30, 09-13, 0920, 10-12; 11-29). ${ }^{53}$ Like the Equality Framework and the Equity and Inclusion Lens to come later, this Gender Lens chose the reference group model, comprised of both community and City members. The Gender Equality Reference Group included "city staff from three departments [i.e., CPS, City Manager's Office, and Business Transformation Services], gender consultants and community women representing equity-seeking groups in the city" (CAWI and City of Ottawa 2005-10-13; CAWI 2008).

\subsubsection{Achieving Concrete Implementation through Allies within the City}

In order to inform how to roll out this tool Corporate-wide, this original version was piloted in one department, CPS, from February to September 2006, in its twelve "Strategic Projects". CAWI conducted an evaluation of this pilot implementation, which was completed in January 2007 (CAWI 2007; 2011). This pilot implementation and evaluation received a strong endorsement from the Deputy City Manager of CPS, who commended his employees for implementing the Gender Equality Guide in their work, and explicitly encouraged them to provide feedback to CAWI to facilitate its Corporatewide implementation to come (City of Ottawa 2006-08-21). This finding was frequently used by CAWI from here on to boost its case, by emphasizing that this evaluation showed

\footnotetext{
${ }^{53}$ This tool was initially called "Gender Equality Planning Guide" at its inception, and when the first pilot version was created in 2006 it was named "Gender Equality Guide", and was renamed to "Gender Equality Lens" following the evaluation of its first implementation in CPS, to be discussed in the next section. It was implemented and evaluated for the second time in several departments of the City between 2008 and 2009 during the development process of the E\&I Lens, specifically to inform the latter.
} 
that the CPS employees found the tool to be practical and useful in considering the differences between women and men across diversity in the city, and into identifying ways to reduce gender-specific barriers in their everyday work. In fact, CAWI actively used this narrative when seeking the partnership grant to be approved by the Status of Women, then the City in 2008, and almost all interviewees who were involved in both the GEL and the E\&I Lens, either from the community or the City, spoke about it this way (CAWI 2007: 4-5; 2008-n.d.; Interviews). ${ }^{54}$

During this development, an editorial - but significant - change was made to the City's Corporate Plan between 2005 and 2007, however. That is, the reference to the Equality Framework - which CAWI and other community groups had worked hard to have included in the Corporate Plan- was (accidentally) deleted from it during many rounds of editing and re-editing by City staff to condense the document (Interviews: a, e; CAWI 2005-09-20; 2006-01-16 EDAC). As I discussed earlier in this chapter, back in 2005 CAWI and others had managed to have the City incorporate the two-fold goals to promote CAWI's Gender Equality Guide, but also move along the more broad-based or intersectional Equality Framework based on the London model in parallel. ${ }^{55}$ However, the only reference that survived these editorial rounds, and therefore was actually implemented and reported by the City for that year, was the gender-specific pilot of the Gender Equality Lens in CPS - but not the broad-based Equality Framework. ${ }^{56}$ While the

\footnotetext{
${ }^{54}$ One member mentioned that CAWI intentionally played up the success of the GEL strategically in order to generate momentum in support of this project (Interview: anonymized).

${ }^{55}$ The specific wording of this original reference is as followed: "promote conditions of equality and social inclusion", and do so by "implementing city-wide the gender equality planning tools being piloted in Community and Protective Services Department in 2005-2006" and "developing an equality planning framework to be used in planning corporate-wide, drawing upon the experience of London, England and other programs" (CAWI 2005, 2006-01-16).

${ }^{56}$ One of the six goals under the Opportunity Agenda of the City's 2006 Corporate Plan had been switched from "promote conditions of equality and social inclusion" to more gender-focused language to "ensure
} 
Gender Equality Lens was making a concrete headway within the Corporation as it was developed, implemented, and reported in the City's annual report, the Equality Framework had been dropped from sight.

This seemingly small incident actually highlights several important factors that shaped how successful a community-driven initiative could make headway into the City. First, CAWI and its Gender Equality Lens were more firmly embedded within the financial, decision-making and operational structure of the Corporation of the City than the Equality Framework. This particular example also shows the importance of having a dedicated ally staff person who can keep an eye on the initiative so that it would not be lost through the bureaucratic process - and importantly, the fatal cost of not having it. CAWI had officially designated staff people to work with them to promote gender equality in the City, while the Equality Framework did not (yet). ${ }^{57}$ Thus, it was CAWI and its tool that survived during this time, which ultimately opened doors more directly for the Equity and Inclusion Lens as I will present below. In the long run and somewhat ironically, however, the gender-specific GEL was eventually replaced by the multi-focal and more broadly intersectional E\&I Lens, for the reasons of financial and operational cost efficiency and for the vision of broad inclusion as a philosophical principle and strategic need for leverage against the City.

Related to this point is the importance of turning a broad vision into a concrete, tangible and practical tool, and grounding it in the everyday application by City employees in their work settings. Between 2005 and 2006, the discussions on the

that the full diversity of women and men of the community are able to participate in the business of the City and to take advantage of the services the City offers" (City of Ottawa 2007: 26).

${ }^{57}$ As I will discuss in the following chapters, the presence and role of a dedicated ally staff person continued to be a significant factor in the E\&I Lens, especially at the level of the individual Snapshot Workgroups. 
Equality Framework were still very broad and the vision itself was not yet articulated clearly. It was nowhere near reaching concrete design or implementation within the City, while the Gender Lens continued to move quickly yet steadily from the initial Council's commitment to promote gender equality as a principle in spring 2005 , to the development of a tool in the fall of 2005, to its pilot implementation in 2006, and its evaluation completed by early 2007. Having produced tangible and measurable results from this evaluation based on the feedback from the City's very own employees also added to the success of the Gender Lens. The lessons learned from this process were taken seriously by both CAWI and by the Equality Framework organizers, and continued to feed into groundwork leading up to the Equity and Inclusion Lens. Here, the Gender Equality Lens was used as a concrete model for which to base the development of the Equity and Inclusion Lens in 2008. In fact, it was the original plan by both the Equality Framework reference group and CAWI to use the tangible progress of the Gender Lens to inform the development of the Equality Framework. ${ }^{58}$ In this sense, the Equality Framework provided the broad vision for the Equity and Inclusion Lens, while the Gender Equality Lens provided a tangible model for the E\&I Lens as a concrete, user-friendly tool to be used in the City.

One other factor that made the Gender Lens a candidate as the model for the E\&I Lens to come was the fact that the former already engaged with a type of intersectional analysis, and was thus viewed by the key coordinators (and the funders and other

\footnotetext{
${ }^{58}$ The letter from SPC and CAWI to Bob Hertzog on December 21, 2005 states that "The Gender Equality Planning Guide, being piloted in Community and Protective Services Department, to be implemented citywide in 2007 is one tool that could be adapted to form part of the framework" (SPC and CAWI 2005), and on January 16, 2006, the two organizations reported to EDAC that "Equality Framework will build on the experience learned from the Gender Equality Planning Guide Pilot" (e.g. 2006-01-16 PowerPoint_EDAC_Jan16).
} 
participants they convinced) as readily adaptable to form the analytical and practical basis for the Multi-focal or the Equity and Inclusion Lens. Here, gender is used as the primary category of analysis, and the overarching framework of analysis of this tool still rests on a binary comparison of the "differences and inequalities between women and men (girls and boys)" (CAWI and City of Ottawa 2008a: 5). However, the Gender Lens quickly prompts the user to also consider the differences and inequalities among women. The Lens guides the user to appreciate the "full diversity of women" based on multiple factors such as: "Aboriginal ancestry, income, race or ethnicity, language, physical and mental ability, marital status, family status and dependents, age, religion/culture, geographic location, length of time in Canada, sexual orientation or identity". Thus, the eleven "target groups" that were identified in the discussions for the Equality Framework were adopted in the Gender Equality Lens as ten different subcategories of women, i.e., "Aboriginal women, Visible minority women, Women with disabilities, Lesbians, Transgendered, Francophone women, Rural women, Young women, Senior women, Recent immigrant women, Women living on low-income" (CAWI and City of Ottawa 2008a: 7, 12). The Gender Lens thus used gender as the "entry point" into an intersectional analysis of multiple systems of exclusion (c.f. Williams 2002) ${ }^{59}$ From this analytical foundation came the City and CAWI's decision to 'expand' this gender-based tool to a more full-fledged intersectional tool in the form of Multi-focal Lens, which was later named the "Equity and Inclusion Lens", in which all eleven categories could be used as an entry point at any time.

\footnotetext{
${ }^{59}$ Almost all of the contributors of the E\&I Lens who also had participated in developing, implementing, or evaluating the GEL commented on the fact that the GEL was "easier", "simpler", and "more manageable" because it had a single focus on (gender). This allowed them to "go more in depth" to explore the internal diversity among women (and men) more fully, without feeling like it was stretched too thin, making it "too complex", or losing sight of the main focus on gender, and in particular women (Interviews: a, d, e, i).
} 


\subsection{3 "Too Many Lenses"?}

Meanwhile, as the Gender Equality Lens was producing tangible success between 2006 and 2007, two of the Citizens' Advisory Committees in the City were also considering creating their own lenses: an "Accessibility Lens" and an "Equity And

Diversity Lens", proposed respectively the Accessibility Advisory Committee (AAC) and the Equity and Diversity Advisory Committee (EDAC). While neither translated into a concrete tool as they were eventually subsumed under or formed a part of the Equity and Inclusion Lens, these discussions prompted CAWI and City management to make an accelerated move towards "expanding" the Gender Equality Lens to a "Multi-focal" Lens, or "Equity and Inclusion" Lens, or put another way, "consolidating" the multiple lenses into "one Multi-Lens" (Interviews: a, g). In addition, the discursive and other strategic tactics used by these Advisory Committees also set precedents as to what would become the basis of the strategic package pursued by the key coordinators of the Equity and Inclusion Lens. Similarly, many of the strategic priorities that AAC, EDAC, and CAWI came to discover and address during this stage carried into the Equity and Inclusion Lens development process, and some of the differentiating factors that set the individual Snapshot Workgroups apart from one another were also present even at this early stage.

\subsubsection{The Accessibility Lens}

In 2006, the Accessibility Advisory Committee (AAC) was working on a concept to develop and implement an Accessibility Lens City-wide, both to help the City achieve its own goals specified in Ottawa 20/20's section on Caring and Inclusive City (City of Ottawa 2003) and to facilitate compliance with the newly amended provincial legislation, 
Accessibility for Ontarians with Disabilities Act (AODA 2005). On June 13, 2005, Ontario Legislature had passed AODA with the aim of achieving full accessibility for people with disabilities across the province by the year 2025. It set out mandatory "accessibility standards" for public and private organizations - including municipalities to identify, remove and prevent barriers in key areas such as "goods, services, facilities, accommodation, employment, buildings, structures and premises" (AODA 2005: c. 11, 2. 1, 2, 6; OMCPS 2008: 2; City of Ottawa n.d.a). ${ }^{60}$

Unlike the Gender Lens, the concept of an Accessibility Lens already had a legislative backing thanks to AODA, a stronger revision of its predecessor Ontarians with Disabilities Act that had a similar objective, but lacked clear enforcement mechanisms (Lepofsky 2004) ${ }^{61}$ Indeed, AODA required that larger municipalities with a population of over 10,000 establish an accessibility advisory committee, comprised mostly of people with disabilities, to "advise the council about the requirements and implementation of accessibility standards and the preparation of accessibility reports" (AODA 2005: c. 11, s. 29). In this sense, this Advisory Committee was more grounded legally and structurally within the Corporation of the City of Ottawa than other ACs that were created voluntarily on the part of the City, though the Accessibility Lens at this point was not at all in a concrete development stage, and remained as an item in the Advisory Committee's conceptual wish list, unlike the Gender Equality Lens (Interviews: a, g, p).

\footnotetext{
${ }^{60}$ AODA defines "barrier" as "anything that prevents a person with a disability from fully participating in all aspects of society because of his or her disability, including a physical barrier, an architectural barrier, an information or communications barrier, an attitudinal barrier, a technological barrier, a policy or a practice" (AODA 2005: sec 2).

${ }^{61}$ Although, the AODA Alliance - "a disability consumer advocacy group that works to support the full and effective implementation of accessibility standards in Ontario" - was quite vocal as of 2007 and 2008 that the Ontario government was not at all on target to meet this deadline (AODA Alliance 2007; 2008).
} 
The Accessibility Advisory Committee (AAC) followed a very similar process as CAWI in going through the institutional process of obtaining Council's approval for their recommendation by first obtaining it from one of the standing committees of the Council. For example, on October 17, 2006, AAC made a recommendation to the City's Corporate Services and Economic Development Committee (CSEDC) that

City of Ottawa apply an "Accessibility Lens" to all of its work - reports, motions, policies, procedures and decisions. All submissions to council would thereby include a statement or description of the impact on all persons ensuring that any accessibility and inclusion issues or potential barriers have been identified and precluded (City of Ottawa CSEDC 2006).

CSEDC approved the recommendation by AAC that day, which was then sent to the next Council meeting on October 25, 2006, where Council also approved it (City of Ottawa Council 2006). In this way, what was originally 'merely' a "recommendation" by AAC gained official status as a 'hard' directive from Council, which the rest of the Corporation now needed to follow. This directive was quickly incorporated into the 2007 version of the City of Ottawa's annual Municipal Accessibility Plan (COMAP), which was issued on January 16, 2007 by the City's Accessibility Steering Committee in collaboration with AAC. Here, the fact that the "[t]he development and implementation of an Accessibility Lens" was "directed by Council" in October 2006 was cited in the text of COMAP, is a testament to the authority and legitimacy that the status of Council directive carries within the institutional context of the City of Ottawa (City of Ottawa 2007a)

Here we see the early signs of the strategic framing that formed the basis of the coalition- and the partnership frames of the E\&I Lens later on to increase frame resonance by downplaying the financial implication of developing and implementing this type of inclusion "lens" in the City. For example, the member of the AAC who made this presentation to CSEDC explained that they were "not asking for resources, simply a 
frame of mind but it would have great economic impact" for the City (ibid, italics mine) ${ }^{62}$ Here, this AAC member utilized this framing to entice the members of Council to approve their recommendation by pre-empting their target audience's primary concern about budgetary constraint on the City. As I will discuss below, playing down the financial cost to the City in developing and implementing this type of lens, and playing up its economic benefits of doing so to the City became an important part of the common framing strategy used by EDAC as well as by CAWI, and later by various Diversity Snapshot Workgroups as part of the E\&I Lens.

Another important insight into the strategic origins of the Equity and Inclusion Lens, and in particular of the People with disabilities Snapshot is found here. That is, as early as $2006 \mathrm{AAC}$ was seeking to complement such a resonance-based 'business case' with an institutionalized 'hard' directive from Council to make the implementation of an Accessibility Lens mandatory for the City in "all of its work". It thus seems that AAC understood the strategic importance of combining both the voluntary incentive for the City to support this initiative with the mandatory, external motivation or institutionalized requirement so that the City employees and Council members would 'have to' support it. This framing strategy of combining multiple types of motivation to support the use of the Accessibility Lens is reflected in the text of COMAP as well, which elaborates on its merit in "enhance[ing] the City's ability to incorporate accessibility at the front end of projects, programs and policies" and "avoiding costly ramifications of inadvertently

\footnotetext{
${ }^{62}$ This AAC member explained that "as Ottawa is made more accessible, more conventions will be attracted from around the world". He explained also that having an Accessibility Lens in place would help Council identify potential issues before creating a new policy or bylaw. For example, before passing a bylaw prohibiting idling of cars, they would be able to build into the bylaw an accommodation for residents who would need to warm up their cars due to their medical conditions that make them sensitive to severe temperature changes" (City of Ottawa CSEDC 2006a).
} 
introducing new barriers, i.e. non-compliance penalties, or redesign and retrofitting after completion of project" (City of Ottawa 2007a).

\subsubsection{The Equity and Diversity Lens: From Competition to Collaboration}

Around the same time, the Equity and Diversity Advisory Committee (EDAC) was also having their own discussions about the idea of "[a]pplying an equity and diversity lens to the City of Ottawa's policies and program" (EDAC 2007a). Here, the notion of a "lens" was loosely used as a conceptual and procedural "filter", which they would "encourage the City to apply" to ensure that they are weighing all new policy and program decisions against the Equity and Diversity Policy, which this Committee had developed in collaboration with the City upon amalgamation in 2001 (Interview: g). In this sense, this Equity and Diversity Lens was being introduced as an effort on the part of EDAC to normalize and implement the City's E\&D Policy City-wide. However, at this point EDAC was still contemplating what "the intent and different kinds of diversity lenses (accessibility, gay/lesbian/bisexual/transgender/GLBT, minority groups, women and aboriginal)" would look like (EDAC 2007a). That said, EDAC moved ahead with their idea about a Corporate-wide "filter" and built it into its own 2007 annual workplan. ${ }^{63}$ This was approved by CSEDC the following day on May 15, 2007 (City of Ottawa CSEDC 2007), and two months later EDAC presented a "Business Case" report to Council, highlighting the economic benefits of "integrat[ing] equity and diversity

\footnotetext{
${ }^{63}$ This workplan set out that EDAC would "work with all departments, most notably the Employee Services Branch" to facilitate this process; to "develop and present a motion to the Corporate Services and Economic Development Committee to encourage the City to ensure that all policies and programs developed are reviewed against the Equity and Diversity Policy before finalized for implementation", and to "develop a business case report to educate City staff and council on the added value and return on investment of working towards the elimination of discrimination within the City of Ottawa" (EDAC 2007a).
} 
practices as an employer and as a service provider" - and the cost of failing to do so - in an increasingly competitive global economy (EDAC 2007b)

On one level, these early discussions about an Equity and Diversity Lens at EDAC reflected the fact that this Advisory Committee's mandate encompassed multiple designated groups in the E\&D Policy of the City that was not specific to one population group. At the same time, these could be interpreted as referring to the 'other' lenses that were being discussed and developed in different parts of the City, i.e., CAWI's Gender Equality Lens and AAC's Accessibility Lens. In fact, as I discussed earlier in this chapter, individual members of EDAC had been part of the Equality Framework reference group since its very first meeting in 2005 , and this reference group had maintained close communication with, and solicited support from, EDAC to push the City to create an Ottawa-specific Equality Framework as early as January 2006. In this way, EDAC was kept informed on the progress of the Ottawa Equality Framework and this reporting or information-sharing relationship included updates on the progress made on CAWI's Gender Equality lens.

Here, while there was a 'natural' alignment of interests between EDAC and the Equality Framework reference group and thus a relatively easy alliance between them, several interviewees who were associated with CAWI commented that there was a history of tension between CAWI and EDAC, especially during the early years of their interaction as their interests were not always aligned. That is, historically EDAC's primary focus tended to be on visible minorities and immigrants and to a lesser extent GLBT (mostly due to the population groups and perspectives that the membership represented), while CAWI's primary focus since its foundation was on women and 
gender (Interview: a). In fact, early members of CAWI whom I interviewed recall facing resistance from EDAC members - both males and females - to the idea that "gender equality" and a specific focus on "women" were warranted (Interviews: a, d, e, i).

This tension started to be bridged over time between late 2007 and early 2008, partly as a sort of osmosis occurred through the overlapping membership among CAWI, Equality Framework reference group and EDAC as CAWI was engaged in parallel with its Gender Lens and the broader Equality Framework. ${ }^{64}$ Another osmosis may have happened partly when the City manager who had been responsible for implementing the Equity and Diversity Policy and supporting the work of EDAC since Ottawa's amalgamation in 2001, was appointed to serve on CAWI's Steering Committee, and designated as the lead manager for the Equality Framework discussions in 2006, and eventually for the development of the Equity and Inclusion Lens in 2007. However, this tension subsided most noticeably when the alignment of EDAC and CAWI's interests became most evident, as CAWI shifted its focus to the Multi-focal Lens and not just the Gender Equality Guide/Lens in late 2007 to early 2008. This is when EDAC came to view the proposed Multi-focal Lens as a vehicle with a real potential to move along the City-wide championing of the E\&D Policy, which was at the core of this Committee's work since its inception in $2001 .{ }^{65}$ In this sense, at this early stage the manager of HREE,

\footnotetext{
${ }^{64}$ For example, the then-Vice-Chair of EDAC was a member of the Equality Framework reference group since its initial meeting in November 2005. In January 2006, EDAC officially appointed another of its member as a "liaison" for the Equality Framework, and this member had been a strong supporter of CAWI on its work on gender equality (SPC and CAWI 2005; EDAC 2006 Minutes 17; CAWI 2007). Similarly, one of the community members of CAWI who sat on the Gender Equality Reference Group also joined EDAC as part of CAWI's effort to integrate a feminist perspective into the City's decision-making through the civic engagement of women (and this same member became a member of the E\&I Lens Reference Group) (Interviews: a, i).

${ }^{65}$ By March 2008, EDAC had incorporated into its 2008 Workplan that "EDAC participate in the development and implementation of the Equity and Diversity Lens to the City's policies and programs, as part of a multi-focal lens" (EDAC 2008a). CSEDC approved all of the activities specified in this 2008
} 
who later became the City-designated project lead for developing the E\&I Lens, served as a crucial ally and a 'bridger' between the City and the community, between EDAC and CAWI, as well as between the Gender Equality Lens, and the Multi-focal Lens/the Equity and Inclusion Lens.

Meanwhile the requests for the two "other lenses" by AAC and EDAC raised concerns on the part of those promoting the Gender Equality Lens and of CAWI, both from the community and the City perspectives. These interviewees all recalled worrying around that time that there would be "too many lenses" for the City to develop and implement if a separate lens were to be created for every disadvantaged group that was seeking equity. On the one hand, some - though not all - members on the Gender Equality Reference Group feared "losing" their gender focus amid other competing lenses (Interviews: a, d, e, g, i). On the other hand, the City's project lead for the E\&I Lens worried that this would mean a significant increase in the financial cost and human resources for the City, given how much time, energy and resources it took the City to develop, implement, and evaluate the Gender Equality Lens already (Interview: g). In addition, she worried that requiring City managers and employees to use multiple lenses would create a significant addition and/or duplication of similar work, overwhelming and confusing them, and ultimately resulting in the ineffective implementation of all of them (ibid) ${ }^{66}$ In short, having this "many lenses" would create more work for the City managers and employees, and cost more for the City.

workplan, although it remained that there was "no funds available in the City's 2008 Operating Budget for EDAC's 2008 Work Plan items", and Council approved this - again without allocating a concrete budget to it - on May 14, 2008 (City of Ottawa Council 2008a; 2008b).

${ }^{66}$ This reflects the complex and conflicting strategic priorities within CAWI members themselves about pursuing their primary focus on gender (Interviews: a, i) on the one hand, and the desire to also facilitate equity and inclusion in a broader, more 'intersectional' sense on the other, as they had also been part of the parallel effort to promote the Equality Framework for the broad range of marginalized communities in 


\subsubsection{CAWI's Strategic Framing to Secure Management Buy-in}

CAWI and its City staff members started to communicate these concerns to the City's senior management team. They effectively created a new discourse of "multiple lenses" versus "one lens", and pitched the City to "expand" the existing Gender Equality Guide to "consolidate" all lenses under the "Multi-focal Lens", which later became the "Equity and Inclusion Lens". On March 22, 2007, two City officials and the thenCoordinator of CAWI co-submitted a briefing note to the then-Manager of Strategic Initiatives and Business Planning, directing her attention to what they framed as an urgent problem that the Executive Management Committee (EMC) must address by determining "the most effective and efficient way of implementing all the lenses" (CAWI and City of Ottawa 2007-03-22). Here, they framed the issue in light of the fact that the "Gender Equality Guide/Lens" has already been piloted and evaluated successfully in CPS, that the Council recently approved the Corporate-wide application of an "Accessibility Lens" in October 2006, and a proposed "[Equity and] Diversity Lens" from EDAC is forthcoming (ibid).

Upon setting up this frame, this briefing note then recommends two solutions. First, it recommends that the EMC continue the Corporate-wide rollout of the "Gender Equality Guide/Lens" as endorsed by Council and given its success in the CPS pilot, as an "interim solution" until it decides what to do with the 'other' lenses. Second, it

\footnotetext{
Ottawa (Interviews: a, e, n).This was also intertwined with the strategic desire to ensure their continued organizational survival by expanding and building upon their Gender Equality Lens (Interviews: a, g), which was made additionally salient (and viable) by the City's own set of strategic priorities that centered around cost saving and management buy-in, which CAWI knew well through its ongoing working relations with City representatives (Interviews: a, g, i). And pursuing this path in turn meant that CAWI would then need to strategically outreach to other communities to dissuade them from pursuing their own lenses and get them to join CAWI's newly proposed intersectional lens instead. And yet, such an intersectional view was not as a fully developed nor even fully embraced idea within CAWI at that point, as some CAWI members were still concerned about "losing" the a specific focus on gender by doing so (Interviews: a, e).
} 
presents two stark options for the City: 1) "implement separate processes for each lens, thus having three lenses/guides", or 2) "consider one "Equality and Inclusion Lens/Guide" for all groups and individuals", and that "this could be achieved by expanding the existing Gender Equality Guide/Lens.” The note quickly endorses the second option as the most cost-effective path, citing the "current budget pressures" on the City and the amount of effort and resources that were already invested into creating, pilot implementing and evaluating the Gender Equality Guide, ${ }^{67}$ as well as the knowledge experience that was generated from this experience among the City employees and community partners such as CAWI (ibid).

Just like AAC engaged in strategic framing when obtaining Council buy-in by downplaying the cost implication of their Accessibility Lens, and similarly EDAC made a "Business Case" playing up the economic benefits of incorporating Equity and Diversity Lens into all of the City's work (as well as the downplayed cost implication), CAWI also made a business case to the City's Executive Committee, playing up the relative advantage of building on CAWI's Gender Lens, into which the City had already invested money and effort (CAWI 2007-07-09). In June 2007, the City's Executive Management Committee approved both of CAWI's recommendations and decided to 1): “implement Gender Equality Guide city-wide" although without a clear direction on "what that means, money or who is the lead"; and to 2) "[d]evelop a Multi-focal lens

\footnotetext{
${ }^{67}$ Budgetary constraint is the constant factor that set the parameters of what the City perceived as the feasible and desirable range of options, and for the key coordinators as well. In this case, the latter sought to turn this constraint to their advantage, knowing very well that the City did not want to, and was not likely going to, invest much time, financial resources, human resources, or the formal institutional structure dedicated to promoting equity and inclusion in the City. This economic constraint as the bottom line behind almost all decisions made by the City is evident in the City's annual reports, especially since 2008 following the global economic downturn, and this was frequently brought up as an unfortunately reality during the strategic discussions of the Equality Framework reference group, of the E\&I Lens Reference Group, as well as the City's senior bureaucrats leading the organizational cultural change towards Service Excellence (City of Ottawa 2009, 2010, 2011, 2012).
} 
drawing upon the experience of the Gender Equality Guide (ibid) ${ }^{68}$ Thus, CAWI successfully convinced the City's Executive Management to "expand" the Gender Equality Lens into a Multi-focal Lens that would consolidate all other claims for separate 'lenses' once and for all.

\subsubsection{The Continuing Challenge of Securing the City's Financial Commitment}

At this point, much like the AAC and the EDAC had not yet succeed in securing a concrete budget from the City to pursue the development of their respective lenses, CAWI also faced a similar challenge. However, CAWI moved quickly to secure both human and financial resources to put this EMC decision into concrete practice starting in September 2007, again building on their close connections with the internal decisionmaking structure within the City. An internal report by CAWI to its own Steering Committee dated September 18, 2007, records that Deputy City Manager of Business Transformation Services Department (BTS) - which was one of the ally department s for CAWI as I noted above - was tasked with calculating the estimated cost to develop this Multi-Lens in consultation with CAWI (CAWI 2007-07-09). This came to an estimated cost of $\$ 40,000$ to develop the Multi-focal Lens and provide initial training on it for City staff in the first year, which the other two "lenses" had not succeed. Still, this modest amount was not yet built into the City's budget as no department or manager had been assigned to take the lead on this new project. CAWI thus engaged in a strong lobby effort to get this small amount of money approved by the City to move the proposed E\&I Lens

\footnotetext{
${ }^{68}$ The EMC at that time included the City Manager Kent Kirkpatrick and the Deputy City Managers Steve Kanellakos, CPS (Community and Protective Services) and Steve Finnamore, BTS (Business Transformation Services). Here, CAWI benefited from institutional positioning of the ally department and ally individuals, for the two City representatives who were allocated by the City to sit on CAWI's Steering Committee on a permanent basis came from what CPS and BTS (CAWI 2007-09-18).
} 
forward, setting a concrete goal to find funds in the City's 2008 budget so that the development could start later in 2008 (ibid).

Between September 2007 and March 2008, CAWI was able to move quickly to consolidate the City's commitment to develop a new Multi-focal Lens and secure necessary funding for it. Two internal reports by CAWI dated October 2007 still noted CAWI's concerns over the continued lack of actual commitment from the City in terms of a designated "lead" department or manager, as well as lack of any specification of funding especially given the current "budget pressures" in the City (CAWI 2007-10-16, 10-25). CAWI also found this estimated figure of $\$ 40,000$ to be too low considering the even wider range of stakeholders that needed to be brought in to create this new Lens as compared to the Gender Equality Guide (ibid).

To address this, CAWI Steering Committee issued a letter to the City Manager Kent Kirkpatrick on November 5, 2007 to follow up on these outstanding concerns, which also demonstrated various elements of strategic framing on the part of CAWI to push the City to respond to its requests. For example, the letter appealed to the "legislative power" that Council decisions - or directives - have at the municipal scale, to which even the City Manager is officially accountable. ${ }^{69}$ It did so by requesting Council to continue to honour their earlier decisions in 2006 to "implement city wide the gender planning tools" and "develop an equality planning framework", because now "the multifocal lens would be one key aspect of an Equality Framework" (CAWI 2007-11-05). CAWI also complemented this 'hard', institutional directive with a financial incentive to entice the City Manager to respond to CAWI's request, or at least to reduce his resistance

\footnotetext{
${ }^{69}$ The City project lead explained that Council decisions constitute an equivalent of "legislative power" at the municipal level (Interview: g), thus reference to these previous decisions - and directives - by Council added institutional legitimacy and backing to CAWI's claims.
} 
based on the tight municipal budget, for they knew very well by then that financial constraint was a particularly high priority for the City at the time. CAWI did so by informing him of the possibility of obtaining matching funds from Status of Women Canada (SWC) through their new Partnership Grant (ibid). As it turned out, securing this partnership grant from SWC became practically the only condition that the EMC imposed on CAWI when it officially approved the development of the E\&I Lens a few months later.

Meanwhile, CAWI also succeed in bringing EDAC on board for the newly proposed "Multi-focal Lens", and EDAC now played a key role in helping CAWI overcome this budgetary issue with the City by presenting an explicitly economic frame that resonated with the City. In December 2007, EDAC submitted to Council a follow-up report to their earlier "Business Case", which was entitled "Budget Considerations for the Integration of Equity And Diversity Norms within the City of Ottawa". This report made an explicitly and solely economic argument to appeal to the City's bottom line. This added resonance with the City's dominant frame anchored in its organizational interest to manage tight budget restrictions and to find cost saving wherever possible.

In this new report, EDAC no longer pursued its own Equity and Diversity Lens nor competed for the City's limited resources, but instead endorsed CAWI's newly proposed Multi-focal Lens as one of the three key mechanisms to integrate the Equity and Diversity Policy as a norm within the Corporation (EDAC 2007d). EDAC provided direct support for CAWI's effort to obtain the allocation of staff and funding from the City to develop the Multi-focal Lens by presenting a concrete breakdown of the projected "onetime cost" of $\$ 100,000$, which would be necessary to cover "stakeholder consultations, 
training, evaluation, and production of a final tool available for all staff to use" (ibid). It makes a further business case for making this investment by highlighting the "benefit for tax payers" such as the "reduction of costly consultant fees as capacity will be built into the organization... [a]voidance of duplication of expenditures as each department usually manages these issues individually"... and [e]ffective use of resources by building upon the successful pilot of the Gender Equality Guide in CPS" (ibid). All of these provided additional incentives for the City to turn the idea of the Multi-focal Lens into a concrete project backed up with resources. $^{70}$

In the new year, the Multi-focal Lens increasingly gained momentum as CAWI won another key ally in the City's Executive Management team. On January 21, 2008, Deputy City Manager and Executive Director of the BTS responded to CAWI Steering Committee's letter on behalf of the City Manager. Here, he notes that the possibility of obtaining the Status of Women Canada's Partnership Grant pleased him, and he reiterated his interest and commitment to work with CAWI "to move forward the gender equality guide and multi-focal lens" as part of the "broader application of the Equity and Diversity initiatives across all City programs. He informed that the Employee Services Branch would assume the lead role to implement and develop the multi-focal lens, and that staff from his department would set up a meeting between CAWI and this branch to discuss the steps in detail in March 2008 "after Council concludes its 2008 budget deliberations" (City of Ottawa 2008-01-22).

\footnotetext{
${ }^{70}$ However, this business case overplayed this cost efficiency and the short-time cost (and even exaggerating it by calling it "one time" cost). This left out the important question of the City's long-term and ongoing commitment of financial and human resources to implement the Lens as part of its broader effort to promote the principles of equity, inclusion, diversity, etc. across the Corporation. In fact, this was one of the recurring concerns that the Reference Group and the Snapshot Workgroup members raised immediately before, during, and after they developed the E\&I Lens and the Snapshots for the City. Many expressed skepticism and even frustration with the lack of apparent signs of progress or the concrete impact of the City's effort to actually implement it (Interviews: b, d, i, n, o, q).
} 
Thus, between January and May 2008, CAWI proceed immediately to secure funding from SWC and the City, and garnered increased support for the Multi-focal Lens from its allies inside and outside the City. CAWI worked on the SWC grant application process (led by CAWI's Coordinator), while the Manager of BTS sought the City's Executive Management's commitment to match this fund if approved, ${ }^{71}$ and obtained a letter of intent from the City expressing this stance to SWC (CAWI 2008-03-20). ${ }^{72}$ As part of this grant writing process, CAWI fleshed out the project proposal on the development of what was starting to be called the Equity and Inclusion Lens around this time (ibid). On March 20, 2008, CAWI sent a follow-up letter to the Deputy City Manager BTS, this time naming more allies both from within the City as well as the broader local community who supported this project. ${ }^{73}$ Further momentum was added by the Chair of EDAC on April 1, 2008, when he sent an additional letter of endorsement to the Deputy City Manager of BTS, noting that EDAC's new workplan for 2008 included their "enthusiastic support" for the City to develop the Multi-focal Lens, as this tool would champion the City's Equity and Diversity Policy - the implementation of which had been a primary goal of EDAC since its inception in 2001 (EDAC 2008b). ${ }^{74}$ Finally, on May 28, 2008, Status of Women Canada approved \$74,506.00 to develop the 'Equity

\footnotetext{
${ }^{71}$ The City project lead explained in her interview with me in 2012 that the EMC was on board with the proposal to develop the Multi-Focal Lens or the Equity and Inclusion Lens by that point, and the City's commitment to matching funds was only conditional on the SWC grant being approved (Interview: g).

${ }^{72}$ These two individuals thus became key coordinators of the development of the E\&I Lens, one from CAWI and one from the City, and I joined as another one from CAWI in September 2008.

${ }^{73}$ These included the key players from the Equality Framework and "other lenses", such as SPC, EDAC, along with CAWI"s ally City Councilors Peggy Feltmate and Diane Holmes "who share the commitment to this initiative" to buttress their case (CAWI 2008-03-20).

${ }^{74}$ When EDAC first approved its revised workplan for 2008, the wording contained a blurry mix of "the Equity and Diversity Lens" and "a Multi-Focal Lens". It read "[EDAC to] participate in the development and implementation of the Equity and Diversity Lens to the City's policies and programs, as part of a multifocal lens" (EDAC 2008). Their support for the Multi-Focal Lens was more clearly and strongly articulated in the April 1, 2008 letter from the then-Chair of EDAC, as it came to view the Multi-Focal Lens as a promising opportunity for EDAC to shine and to uphold its own primary goal, the Corporate-wide application of the Equity and Diversity Policy.
} 
and Inclusion Lens' in partnership with the City of Ottawa (Status of Women Canada 2009), and the City of Ottawa matched this at 50 per cent. ${ }^{75}$

As I discovered in these records as well as the interviews, financial cost was definitely one of the most important factors for the City's Executive Management and Council to decide against the creation and implementation of a new equality-related initiative in the City. As I have shown, the Equality Framework reference group was very conscious of this from the beginning, and both the Accessibility Advisory Committee and the Equity and Diversity Advisory Committee made a case to the City that their respective proposed lens would not add cost to the City but have a cost-saving effect, and would even provide a boost to Ottawa's economy at large. CAWI made essentially the same argument as these groups - thus tracing the gradual formation of the common frames featuring a strong element of resonance with the City's dominant frames emphasizing the financial cost-benefit, which was being adopted by these key actors during this stage of this local history.

Yet, the fact that CAWI's Gender Equality Lens was the tool that was eventually selected by the City to use as the model for all these various inclusion-related tools for the City of Ottawa as a whole. In this sense, this local history also points to the strategic importance of the close working relationships that CAWI had with key City officials positioned in the right place, with the right level of authority as well as mandate of the department. This was to a significant degree due to the official 'partnership' status that

\footnotetext{
${ }^{75}$ The slippery language between the gender-focused and the multi-focal nature of this new Lens was found in CAWI's grant application, partly because the Status of Women Canada's grant program was specifically for women. The application that CAWI submitted reflected this, as it framed the aim of the Lens in terms of "empower[ing] the City to promote equity and inclusion while recognizing the full diversity of women in all policies, programs and services", and counted "ten groups" rather than eleven to be "identified as "most affected' by social exclusion in Ottawa" (Status of Women Canada 2009, italics mine). This also indicates the fact that CAWI itself was not yet fully able to articulate the notion of intersectionality beyond its gender focus.
} 
CAWI did secure at its inception, and the close and continuing working relationships with their ally individuals as well as with their ally departments who could open doors into the decision-making chains within the City's bureaucratic hierarchy. Another factor may related to the Gender Equality Lens itself, as this was the only tool that had already realized a tangible form and was already implemented in the City, producing positive results among the City's own employees. In addition, this tool offered relatively easy analytical convertibility to become a multi-issue, multi-focal, and intersectional lens to simultaneously consider differences and inequality among eleven marginalized groups and individuals in Ottawa, and not just between women and men. Given these, CAWI was able to make the case that of all the existing lenses under discussion, the Gender Equality Guide/Lens was the most readily adaptable for the purpose at hand.

\subsubsection{Equity and Inclusion Lens Development Approved}

From here on, the most urgent task at hand for developing the newly approved Equity and Inclusion Lens became broadening both the scope of analysis and of the stakeholders to be engaged, which would be coordinated by CAWI. Much investment had to be made into the latter, as all the eleven target groups had to be reflected in the new analytical framework, and for that to happen, these groups' participation in the actual process of co-developing this new tool would be essential. Given that these eleven groups had been working in isolation from one another to pursue their respective goals up to that point - or at least their efforts had not been integrated systematically and consistently with each other's - CAWI, as the coordinating body for this new project, had to work especially hard at forging a new coalition among these diverse community groups to ensure the project's success. 
Analytically speaking, the Equity and Inclusion Lens was not as full-fledged as some of the contributors wished it could have been, especially in retrospect, for several related reasons. While the Gender Equality Lens featured a more precise analytical focus on the differences and inequality between and among various groups of women and of men, the E\&I Lens shied away from employing a direct comparison of the differences and inequality between and among the eleven groups. Instead, the E\&I Lens opted for the simultaneous focus on eleven marginalized population groups in the city, presented in eleven separate Snapshots. This was partly because the E\&I Lens was an initial attempt at an emergent intersectional coalition, and was not yet equipped to develop a truly integrated analytical framework that would have allowed the users to freely alternate between any of the eleven categories (e.g., gender, age, class, ability, race, etc.) as one of the multiple "entry points" to intersectional analysis. ${ }^{76}$ Several Reference Group members recalled that initially, many of the Reference Group members were still "unsure", "confused" or "skeptical" about what a "Multi-Lens" would look like, and some were "worried" about "losing specificity" of their community and its issues, and apprehensive about "being lumped together" with everybody into one lens (Interviews: a, $\mathrm{b}, \mathrm{e}, \mathrm{d}, \mathrm{g}, \mathrm{i}, \mathrm{j}, \mathrm{m}, \mathrm{p}, \mathrm{q}, \mathrm{t})$. In light of the still nascent coalition building effort, such an approach to comparing the existing inequalities within and between "groups" could easily lead the emerging coalition too close to degenerating into comparing wounds between and among the eleven target groups - and fracturing a budding solidarity among them. ${ }^{77}$

\footnotetext{
${ }^{76}$ In fact, many academic researchers were also documenting their own challenges of developing and applying such an intersectional analytical framework beyond a simple 'box' approach to multiple identity categories (e.g., McCall 2005).

${ }^{77}$ This risk was partly real under the surface, as evidenced in the interview comments by various contributors of the Lens (in particular Reference Group members), although this was not enough to cause them to leave the project. One member pointed out that existing inequity and hierarchy among eleven communities/movements poses a problem for less organized ones. For example, one Reference Group
} 
This was also partly due to the conceptual and analytical foundation upon which this new multi-focal E\&I Lens was based. That is, the Gender Equality Lens was based primarily on a binary comparison between two gender (or identity) categories taken as discrete and mutually exclusive ("women and men"), often directing the focus only on what it considered the more disadvantaged one of the two ("women"). In addition, the transition from the GEL to the E\&I Lens was conceptualized by the key coordinators as an "expansion" of this gender-based binary analysis - similar to the way in which Status of Women, the main funder of both GEL and the E\&I Lens, evolved its analytical framework from "Gender-Based Analysis (GBA)" to "Gender-Based Analysis Plus $(\mathrm{GBA}+) "{ }^{78}$ In developing the E\&I Lens, this framework was inadvertently transposed onto the ten "other" categories of analysis, and more specifically, onto ten other "groups", who were viewed as falling into the "most disadvantaged" or "most excluded" end of the spectrum - or the 'disadvantaged' side of the binary. The by-product of this analytical

member explained that many people with disabilities could not be as mobilized as the women's movement, which has developed "sophisticated theory and policy tools", and be institutionally mobilized to talk to and influence decision-making at the policy level. Another member pointed out a similar problem from a different angle, pointing out that the issue of "race" and "racism" is easily sidelined in a multi-issue initiative like this Lens due to the particularly high level of discomfort and reluctance to delve into this issue among many people. This view was shared by yet another member, who pointed out that many people in the City and elsewhere "get uptight" as soon as the discussion turns to people with disabilities, Aboriginal peoples, visible minorities, or GLBT people or those who are perceived as 'different' from the 'normal' population, compared to other 'low-tension' ones such as seniors or youth (which most individuals in society get to experience at some point during their regular life course). Another different member emphasized that "we're not competing for oppression. We're all in this together and we all fall if we don't address these forms of oppression". One member attributes this inter-group tension or suspicion in part to the "add-on" or "additive" approach to intersectionality that has historically been developed in the federal government, which has created "a sense of loss" among feminists who felt displaced when the issue of 'race' crowded out the focus on gender. One of the key coordinators expressed her concern as a feminist that in pursuing a multi-issue or intersectional took like the E\&I Lens, "gender loses out" because "women always come last" and because the specificity of gender-based analysis is lost (Interviews: a, b, d, e, i, j, n, p).

${ }^{78}$ Status of Women Canada went through this transition from its original "GBA" (since 1995) to "GBA+" (since 2009), which it defines as "an analytical tool the federal government uses to advance gender equality in Canada. The "plus" in the name highlights that Gender-based Analysis goes beyond gender: while "[g]ender is a major factor in GBA+", which is "used to assess the potential impacts of policies, programs or initiatives on diverse groups of women and men, girls and boys", GBA+ "take[s] into account gender and other identity factors... factors such as age, education, language, geography, culture and income" (SWC 2013a, b). 
approach was to leave out the 'advantaged' side of this binary, and with it a more nuanced understanding of equity and inclusion as a continuum or spectrum, involving not only one axis, but multiple ones simultaneously.

Yet, as simplicity was strategically required by the partnership frame emphasizing the "user-friendliness" of this tool to appeal to the City staff's needs, thereby increasing resonance, this strategic contradiction became a recurring theme that the Snapshot Workgroups came to face. For example, several Reference Group members noted that a more sophisticated "multi-focal" analysis of intersectionality would be "too complex" and "too big" to capture in a simple, user-friendly tool for the busy City audience (Interviews: $\mathrm{d}, \mathrm{i}, \mathrm{n}) .{ }^{79}$ Moreover, in light of another strategic need to create buy-in from the target audience, turning attention directly and explicitly to the advantaged groups along the eleven axes (of power or oppression) in this tool, would most certainly not achieve resonance or buy-in from the majority of the target audience in the City. Such a risk would have been exacerbated through this focus on population 'groups', which projects the systemic relations of power or inequity in society onto people and personalizes advantages and disadvantages in a relatively rigid, and divisive, way.

All these factors converged to form yet another key strategic priority for the new Reference Group during this early stage of the coalition building. That is, this new intersectional coalition needed to recognize the differences and commonality among the eleven communities (rather than inequality among them) so as to allow these groups to come together. This was also strategically important for allaying their fear about their

\footnotetext{
${ }^{79}$ This view was expressed especially by those who already had had the experience to "go in depth" into the specific issue of gender through the GEL (Interview: d).
} 
unique experiences and voices getting lost in the mix - hence the box- or silo-like structure of eleven separate Snapshots to accompany the Lens.

This in turn was met with disparate responses from members of the Reference Group. For example, some Reference Group members viewed the Snapshots as a way to create a dedicated space for each of their communities and wholeheartedly welcomed them. Some members, and one member in particular, problematized this reductionist approach, but viewed it as an instrumentally effective way to convey an otherwise "too complicated" idea of intersectionality to the target audience in the City in an easy, unintimidating, and consumable way (Interviews: b, c, d, n). In contrast, one member expressed strong discomfort that this structure reinforced a false and divisive view of identity and exclusion as it "simplifies" and "divides us" into separate groups, when "our identities are multiple and whole" and in reality never divided into different chunks, and that "there is only one philosophy of exclusion we need to address" (Interview: e, n). ${ }^{80}$ Some remembered a "warning" by one of the members that this would add a significant amount of extra work, time, and resources to complete, and another member commented that in retrospect, this indeed turned out to be the case (Interviews: a, e, g).

As the Reference Group members' intersectional consciousness evolved and developed over the course of the process, however, their initial trepidation about "loss", "lumping together" or "watering down" the specificity of each community gradually diminished, at least in a general sense. Several members emphasized the "great learning" they experienced by working with, and being exposed to, different communities and their

\footnotetext{
${ }^{80}$ Some in fact identified this as one of the biggest limitations or weaknesses of this Lens as it currently stands. As they got working on their respective Snapshots, almost all Workgroups seemed to struggle, at least to some extent, with the simple, silo-like structure of the Snapshot, as they realized the extent of the huge internal or intra-categorical diversity of each community that could not easily be captured in a few short pages.
} 
issues, which they would not have even considered had they continued working in their

"own little world", as one member put it (Interview: t). Some of the Reference Group

members commented also that these shifts in the Group's perspective on what it means to

work with an intersectional lens is a testament to the progress they made as a community

and as a city (Interviews: $\mathrm{d}, \mathrm{e}, \mathrm{j}, \mathrm{p}, \mathrm{q}, \mathrm{t}$ ).

\subsubsection{Recruitment of the Equity and Inclusion Lens Reference Group}

On May 20, 2008, just before the SWC grant was confirmed, the three key

coordinators had their initial brainstorm for potential members, drawing first on the pool

of individuals who had contributed to the Equality Framework discussions and/or the

Gender Equality Guide/Lens, and then consulting other individuals they knew in related

areas for further suggestions as to who would make a suitable candidate ${ }^{81}$ Between June

4 and June 24, 2008, the key coordinators and a few other individuals from their close

network conducted their initial presentations/consultations on the proposed Equity and

Inclusion Lens with the Advisory Committees whose mandate related to the eleven

groups ${ }^{82}$ This was done to brief them on the project and to seek their input regarding

\footnotetext{
${ }^{81}$ From those who were involved in the Equality Framework discussions, the key coordinators had identified: the executive director for Social Planning Council of Ottawa to assist with the overall planning of the E\&I Lens, another former SPC and the then- director from United Way for "Recent immigrants" (which was the title at that time), an academic from Carleton University for "Visible minority". From the CAWI network and the Gender Equality Guide/Lens, they had identified an academic from the University of Ottawa for "Francophone", and suggested to consult a few Aboriginal contributors of the GEL and the City representative to help identify suitable candidates for "Aboriginal persons". They also identified the Anti-Poverty Community Coordinator for the Coalition of Community Health and Resource Centres of Ottawa for "Poverty", and the Corporate Accessibility Specialist with the City's Accessibility Office for "Persons with disabilities, and an individual from the Council on Aging of Ottawa for "Seniors". The key coordinators had no concrete leads for "GLBT", "Seniors", "Youth", and "Rural" at that point (CAWI 2008-05-20).

${ }^{82}$ These Advisory Committees were: Accessibility (Disabilities), Equity and Diversity (GLBT, Immigrants, Visible Minority, Women), French Language Services (Francophone), Poverty Issues (Poverty), Rural Issues (Rural), and Seniors (Seniors). The City's Aboriginal Working Group was contacted (Aboriginal), though the presentation was not made until a later date due to scheduling conflict. The key coordinators did not contact the Ottawa Youth Commission at this time, as they were not an Advisory Committee, and they may not have been aware of the work of the OYC at that time (CAWI 2008-06-04). The individuals who co-presented along with the key coordinators were the Reference Group member who led "Women" (who
} 
their hopes and concerns for the Lens. At these presentations, the key coordinators also asked the Advisory Committees for suggestions as to who would make a suitable candidate to serve on the Reference Group, and who from the Advisory Committees would be able to act as a "liaison" for the Equity and Inclusion Lens (CAWI 2008-06-04, 08-02, 08-18).

\subsubsection{Concerns Raised by the Advisory Committees}

Between the time of funding approval and the first meeting of the E\&I Lens Reference Group, the key coordinators of the Lens conducted outreach to all of the Advisory Committees. The responses and concerns they received from the Advisory Committees at this time signaled plainly to the key coordinators yet another set of strategic priorities at the scale of the emergent intersectional coalition. In addition, these Advisory Committees' strategic concerns regarding the efficacy of this Lens-to-be as a whole also provided the basis for the strategic priorities that they were to address at the partnership scale. Some of these priorities were the continuation of what the key coordinators had already anticipated or were aware of, and others were new priorities they now had to tend to. The Advisory Committees' responses also highlighted the differences or even disparities among the community movements in terms of their respective movements' perception of their progress or struggles, as well as differing discursive strategies they tended to employ. ${ }^{83}$ Out of all these diverse responses and

had been part of CAWI's predecessor WGWAMSO as well as the GEL Reference Group, who also had subject expertise and a lived experience of disability) who presented to AAC, and the CAWI co-founder who was also part of the French Language Services AC presented to this AC.

${ }^{83}$ For example, the Rural Issues AC used a blunt and confrontational critique of the City's urban centrism in its governance and organizational culture as the heart of the problem leading to a "complete lack of trust" between them and the City, and openly criticized the City for this blunder since Amalgamation. In contrast, as French Canadians, FSLAC framed their priority in terms of "rights" rather than "equity and inclusion" in society. For AAC their priority was making the city "accessible" and to shift the focus away from peoples" "disabilities" that often labelled them negatively as "different", while SAC emphasized the 
strategic concerns thus emerged the core of the framing at the scale of this emerging intersectional coalition, as well as the new City-community partnership to develop the E\&I Lens (and to do so in a way that would entice the City to actually implement it when it was developed, although there was no concrete plan for it at that time.)

Different Advisory Committees showed different levels of interest or support for this new 'multi' Lens, and wondered about the positive and negative implications of being part of an intersectional coalition. For example, EDAC showed strong support, as their E\&D Lens had now merged with this E\&I Lens, and others like the Seniors Advisory Committee showed interest in the potential of this Lens to shed light on the differential needs of the diverse segments of a given community - or the intra-categorical intersectionality of seniors - such as "isolated seniors" and "seniors with disabilities" (EDAC Minutes 14 2008; CAWI 2008-08-02). ${ }^{84}$

At the same time, multiple AC's raised the same concern that a "multi-" lens that "lumps together" all these communities may "lose a clear focus" on the specific needs of each. Some also raised a slightly different concern that given this breadth of scope featuring eleven communities, this Lens might in fact make the internal diversity within each of these communities invisible, who may be experiencing intersecting or multiple barriers. At the same time, they also worried that singling out these eleven communities and highlighting differences between them could be used to "further exclude or discriminate" against them by reinforcing the existing negative assumptions or

need for differential and dignified support for seniors in varied life circumstances, which necessarily changed over time as part of aging and life course (CAWI 2008-08-02; Interview: f).

${ }^{84}$ For example, SAC members was interested in the potential of this intersectional Lens to disaggregate and "break down" the specific needs experienced by sub-categories of seniors into "different segments of the document", such as those who are isolated, living in long-term care facilities, or living with temporary disabilities, or who had recently been hospitalized, etc. (CAWI 2008-08-02; City of Ottawa SAC 2008; interview: $\mathrm{m}$ ). 
stereotypes about them. In addition, some ACs worried about being "viewed as different" by other communities included in Lens due to prevalent stereotypes or dominant attitudes about their community (AAC 2008 Minutes 16; CAWI 2008-08-02; Interviews: a, e, p). All these responses and concerns informed the new strategic priority on coalition building among these disparate community movements in creating this intersectional tool.

While some of these ACs preferred to have a population-specific Lens, others felt that their community did "not need to be part of" an equity and inclusion-related lens at all. ${ }^{85}$ For example, French Language Services AC felt that they were already relatively "advanced" compared to other marginalized communities highlighted in this Lens, as they already had constitutionally guaranteed rights and the City also had its own Bilingualism Policy in place (CAWI 2008-08-02; Interviews: a, f). For them it was more a matter of implementing these rights and policies on the ground - hence their main concern and skepticism was focused on how much this Lens would actually be used by the City employees (City of Ottawa FLSAC 2008). ${ }^{86}$ In this sense, their input informed the strategic priorities more at the partnership scale than at the coalition scale.

Many of these ACs also offered strategic input about making this Lens an effective one that would "actually be used" by the City staff after it was completed, which in turn formed the basis for the strategic priorities at the partnership scale in particular. For example, whether this Lens would "actually be implemented" and "not sit on shelves" was a recurring theme that the Advisory Committees - and later the

\footnotetext{
${ }^{85}$ One interviewee recalls that the Rural Issues AC did not feel the need to be part of this Lens for marginalized communities, partly due to their generally socially conservative outlook (CAWI 2008-08-02). ${ }^{86}$ The minutes from the FLSAC meeting on June 5, 2008 captures this concern as following: "After the presentation, the FLSAC members as well as the FLS staff expressed concerns about the project with regard to the tool's distribution within the City of Ottawa and the method for determining its impact on the practices of the City of Ottawa. It was noted that the document must first respect the City's Bilingualism Policy as well as being useful, practical and easy-to-use" (FLSAC Minutes 8 2008).
} 
Reference Group members, and subsequently the Snapshot Workgroup members - all raised repeatedly. The fact that there was no concrete implementation plan with allocated resources in place at that time added to the salience of this question (CAWI 2008-08-02; Interviews: a, e, f). The common discourse about "building on existing work" and "not duplicating" the cost, time or effort also emerged strongly out of these AC consultations (CAWI 2008-08-02). This was an important strategic response to the (real and perceived) lack of resources in the City (as well as in many community organizations). It was also a way of validating the work already done by the target audience (and coalition partners) to date in order to solicit their buy-in for this new Lens, without criticizing, dismissing or sidelining their contributions. In addition, another strategic need to make this Lens a 'simple', 'easy', and 'user-friendly' for the City audience was also reinforced by this round of $\mathrm{AC}$ consultations.

All of these strategic concerns and suggestions from the ACs thus fed into the common coalition and the partnership frame that aimed to generate audience buy-in by increasing the resonance of this Lens with the City staff, while paying attention to the cross-movement dynamics among the eleven groups. In addition, one interviewee recalled that a more radical or oppositional concepts such as inequity and oppression "annoyed" some AC members. This is an example of a radical frame not resonating with the dominant frame that supports exclusion and inequity, and how the language and/or the idea of oppression or structural inequality can rub some people the wrong way, especially if they espouse dominant attitudes or assumptions. Similarly, some Reference Group members also made distinctions between "easier" issues or groups to discuss, and "harder" issues or groups that get "many people uptight", and gave issues related to 
Aboriginal peoples, ${ }^{87}$ GLBT communities, people with disabilities, and visible minorities as examples (Interviews: $b, j, p$ ). These comments and interactions with some of the $\mathrm{AC}$ members may have signaled to the key coordinators the importance of prioritizing resonance over radicalism in the Lens in order to maximize the positive reception by its target audience (Interview: m).

This initial round of consultations thus provided strategic priorities for the key coordinators as they embarked on the concrete development process in September 2008 namely in bringing everyone in this new coalition on board and on the same page, more specifically in terms of a shared goal and a shared strategy to get there. It was clear that each Advisory Committee - connected to the broader community groups in their respective sectors - had a different take on this proposed intersectional Lens. This was partly because the nature of the issues they were dealing with was different, and so were the history of their struggles or relationships with the City and mainstream society, as well as the framing strategies they employed to advocate for their communities.

\subsection{E\&I Lens Reference Group - Role and Structure}

The "reference group model" consisting of both community and City representatives was selected to guide the development of the E\&I Lens, as this had proven effective based on the previous experience with the Equality Framework and the Gender Equality Lens, and the terms of reference for this was modeled after those of the Gender Equality Reference Group (CAWI 2008-05-20). The initial plan for the E\&I Lens

\footnotetext{
${ }^{87}$ As for the Aboriginal Working Group (an equivalent of an Advisory Committee), the CAWI key coordinator noted that they never met as a group in one room because of the existing political tensions among the stakeholders in various Aboriginal communities. In this sense, the history of the "divide and conquer" strategy utilized by the Canadian government still played a role in creating a sense of competition over funding and resources to diverse Aboriginal communities. However, the contributors to the Lens and the key coordinators also made a conscious effort not to make this an opportunity for others to exploit these divisions to the further detriment of the Aboriginal communities in addition to not exacerbating the negative stereotypes about these communities (Interview: a).
} 
Reference Group, as proposed in the grant application prepared by CAWI, was to

include:

One representative from each of the 10 inclusion groups ${ }^{88}$ community volunteers, City staff, 2 University representatives, the CAWI Project Manager and contracted experts...to ensure that the interests of all equity groups and city departments are considered during the process (Status of Women Canada 2008). ${ }^{89}$

Here, the two strategic priorities to develop this Lens based on the input of the community-based intersectional coalition of eleven equity groups, and of the Citycommunity partnership are clearly reflected in this project plan, which were informed by the earlier experiences of the Equality Framework and the Gender Equality Lens.

City employees from departments and teams that oversaw the areas of work related to the objectives of the Lens, and/or worked closely with these communities, were recruited into the Reference Group over time. Two departments in particular were involved from the very outset, namely Human Rights and Employment Equity (HREE), which was the official "lead department" to oversee the development of this Lens as assigned by $\mathrm{EMC},{ }^{90}$ and the Accessibility Office (and its Corporate Accessibility

\footnotetext{
${ }^{88}$ The eleven "target groups" in the Equality Framework came to be called "inclusion groups", "equity groups", "equity-seeking groups", "equity and inclusion groups" and also "equity and inclusion areas" around this time (CAWI 2008-04-03, 05-20, 05-27).

${ }^{89}$ This teetering between the "ten" and "eleven" target groups in CAWI's grant application is a slippage from CAWI and the Gender Equality Lens, and may reflect the transitional stage that CAWI was in at the time moving from "a feminist organization to a full-fledged intersectional organization", as one of the Reference Group members observes (Interview: j). For example, the reference to " 10 other groups" means the marginalized groups in addition to "women", which was the focus of the Gender Equality Lens. "2 university representatives" were included to partly to ensure "analytical rigour" in this new intersectional tool, but this also reflects the wording CAWI uses to describe its own Steering Committee membership structure, which features community women, City representatives and two academics from the two local universities. This CAWI- and the GEL-specific language in this grant may also be attributed to the fact that it was written for Status of Women Canada, which funded the GEL in the past. In this sense CAWI was framing this E\&I Lens project as an "expansion and adaptation of the GEL" to a "multi-focal" lens featuring multiple marginalized population groups in the city as a way to sell it to this particular funder whose focus is specifically on women's issues (Status of Women Canada 2008; Interviews: a, e, m).

${ }^{90}$ This office (Human Rights and Employment Equity, later renamed to Diversity and Employment Equity, and is currently called Diversity and Inclusion) and the manager's portfolio included multiple equity groups, in particular the "designated groups" in the City's Equity and Diversity Policy (EDP), (i.e., Aboriginal peoples, people with disabilities, visible minorities, women as designated in the federal Employment Equity Act, plus GLBT which the City added voluntarily). HREE and its manager worked
} 
Specialist) as it worked closely with the Accessibility Advisory Committee and the proposed Accessibility Lens. During the last stages of the development process, Organizational Development and Performance (ODP) also joined the Reference Group, as this team was assigned to lead the implementation of this Lens once it would be completed. ${ }^{91}$ Other City departments and teams that worked on relevant issues such as poverty and groups such as seniors, youth, immigrants, Aboriginal peoples, etc., were also recruited into the Reference Group over time, especially into the different Snapshot Workgroups starting from December 2009 and onwards.

Note that the initial wording used in the grant proposal listed "representatives" from each community and "contracted experts" as separate individuals; however, the revised Terms of Reference reworded this slightly to combine the two roles into "community experts", who could be either "members of a specific community or staff for an agency serving a specific community". Their main role was therefore not to directly "represent" a group, but to contribute their subject expertise on one or more of the eleven communities, which could be based on their personal and/or professional experience. ${ }^{92}$

closely with the Equity and Diversity Advisory Committee, which covered GLBT, women, visible minorities, and immigrants (as a closely related group to 'visible minorities'). Although this was not officially part of this office's portfolio, this manager also worked, though less closely, with the French Language Services Advisory Committee (Francophones) (Interview: g).

${ }^{91}$ Here, let me note that both of these designated lead department managers for the E\&I Lens were also the designated City members to sit on CAWI's Steering Committee, which was part of CAWI's official partnership with the City. Moreover, the HREE manager had participated in the development of the GEL earlier as part of the Gender Equality Reference Group (when she was with Business Transformation Services), and the other ODP manager had implemented the GEL in its pilot in Community and Protective Services earlier. In this sense, the close and continuing working relationships with the City departments and officials that CAWI had cultivated over the years clearly and significantly contributed to the development and implementation of the E\&I Lens.

${ }^{92}$ The language used in this Terms of Reference also reflects the budding intersectional outlook of the key coordinators in that it recognizes that an individual's knowledge, experiences and expertise may cover more than one of the eleven areas or groups in the Lens, and it explicitly requires that the members be "committed to working in an intersectional way so as to address the specificity of a specific equity/inclusion group while promoting an understanding of how they intersect" (CAWI 2008-05-27, 0529). 
Another key role for them was to serve as an ongoing liaison or channel linking the Reference Group and the wider community(ies), as well as with the Citizens Advisory Committees of the City, ${ }^{93}$ during the course of the development process. ${ }^{94}$ To this end, the selection criteria also specified that these individual have organizational affiliation with local community agencies serving or working with these groups, so that they would have wider cachet within each of the eleven communities in Ottawa (CAWI 2008-05-27).

However, these different roles asked of the Reference Group continued to carry multiple meanings and a slight tension in how the members of the Reference Group understood their role. For example, some members took no issue with this characterization of their role to "represent" their respective equity group, ${ }^{95}$ while one member explained that she initially felt uncertain whether she would be perceived as a legitimate representative for the community when she herself was not an actual member of that community, but had a history of working with it (Interview: f). These views

\footnotetext{
${ }^{93}$ These Advisory Committees at the time of the Lens development were: Accessibility Advisory Committee (people with disabilities), Equity and Diversity Advisory Committee (GLBT, immigrants, visible minorities, women), French Language Services Advisory Committee (Francophones), Poverty Issues Advisory Committee (people living in poverty), Seniors Advisory Committee (seniors), Rural Issues Advisory Committee (rural residents), Aboriginal Working Group (Aboriginal peoples), Ottawa Youth Commission (youth). As a result of the restructuring of the Advisory Committees in 2012 to reduce operational cost, however, they have been reduced and consolidated to a total of five (i.e., Accessibility Advisory Committee (as mandated by AODA), Arts, Culture, Heritage and Recreation Advisory Committee, Community Services Advisory Committee, Environmental Stewardship Advisory Committee, and French Language Services Advisory Committee), plus a few other related bodies such as the Aboriginal Working Committee, new Seniors Round Table, and the "Open Mic sessions" as part of the Council's standing committee for Rural and Agricultural Affairs, where "individual citizens [can] raise issues directly to their elected representative" (City of Ottawa FEDCO and Governance Renewal Subcommittee 2012; City of Ottawa 2013a).

${ }^{94}$ An internal memo prepared by the CAWI Coordinator in April 2008 delineated the division of responsibilities between the key coordinators of the Equity and Inclusion Lens from CAWI and from the City. This memo indicates that it was a conscious effort on the part of the CAWI key coordinator, and possibly the City's coordinator as well, to build in the mechanism for community engagement into the project plan based on the "Equality Framework discussions" and London's Framework, where the City "sponsors annual fora with leaders in the specific equity groups in order to inform the establishment of benchmarks and indicators" (CAWI 2008-04-03).

${ }^{95}$ For example, one member simply explained that his role was to "represent" the given community on the Reference Group. For another member, his lived experience as a member of that given community was the most important reason why he served on it, stating "I grew up in poverty all my life" (Interview: m, q).
} 
underscore the continuing relevance of identity in this context. On the other hand, some other members expressed strong discomfort about being considered a "representative" of a given equity group, for they considered it to be a rather essentializing and reductionist treatment of any community, thus practically impossible for any one person to do (Interviews: b, c, n). These individuals instead sought to distinguish their role to be contributing their "subject expertise" in a given area, rather than their ascribed identity as a member of an equity group. Yet others saw their role to be somewhere between these two functions, viewing "experience" as a bridge between identity-based representation and expertise on an equity issue and the community affected by it, rather than as an essentializing characteristic used to "represent" a whole population or community. ${ }^{96}$

These discussions underscore the tension between the individual and the collective identities that the key coordinators and the Reference Group were working out as they embarked on developing their emerging intersectional analytical framework for the new Multi-focal Lens, and as they were fleshing out the strategic choices to ensure the successful completion of the Lens as a broadly representative and legitimate tool. ${ }^{97}$ For example, some of the Reference Group members grew uneasy about how their "expertise" was sometimes conflated with their identity tied to their membership in an equity group. This was an important political point, because a person's individual merit -

\footnotetext{
${ }^{96}$ In the case of the Reference Group member who represented the Francophone portfolio, she explained that initially she was unsure and slightly uncomfortable given that she is not a Francophone herself, but she felt comfortable after the FLSAC appointed her to this role, given their previous working relationship with her on this AC. (Interview: f). The staff representative from Child and Youth Friendly Ottawa was clear about her not being a youth herself, but because she works with youth who often cannot be at a table like this, her mission was to ensure that youth perspectives were represented at the table and to take the discussions back to the youth that she worked with (Interview: $h$ ).

${ }^{97}$ This also underscores the fact that the nuanced understanding of intersectionality was not yet fully articulated or established as a common framework at the time, but also the fact that there were multiple strategic priorities or purposes that the Reference Group was trying to address, some of which contradicted one another.
} 
cultivated through a wide range of professional experiences and effort - cannot and should not be reduced, or attributed merely to their minority status, for this can slip into a form of tokenism. Such confusion would also reduce these individual members' intersecting and complex identities and life experiences into a flat, singular, fixed identity category, such as a senior, a visible minority, a poor person, a person with disability, etc. as though these were separate and mutually exclusive identities. This could also risk slippage into an expectation that the individual member can or should somehow "represent" or "speak for" a given group as a homogeneous whole. ${ }^{98}$ For them, such a view would go against the very notion of intersectionality - that people's identities often overlap or cut across these categories, and so do the barriers that limit their full participation in the social life of the city.

At the same time, however, for many other members, direct representation by an actual member of a marginalized community, who had the lived experience of marginalization, was a politically significant and indeed necessary priority for this Reference Group. That is, creating this Lens without the direct input or representation of members of the excluded community under discussion would render the process itself exclusive, non-representative, and illegitimate. ${ }^{99}$ This had another layer of political significance, for the 'knowledge of the oppressed' was often devalued, ignored and excluded from the City's decision making processes, whereas that of the City officials and contracted professionals, who were removed from the realities of marginalization in

\footnotetext{
98 "Speaking for the Other" had come to be a heavily criticized idea since the 1980s in postcolonial feminist literature, to which some members of the Reference Group working in the areas of race and gender were likely exposed (e.g., Mohanty 1984; Spivak 1988).

99 These were related to the notions of "empowerment" and the "bottom-up approach" to community development, as well as to the slogan "Nothing about us without us", as commonly associated with the disability rights and ethnic minority movements (Interview: r).
} 
their own lives, was favoured and exalted above them. ${ }^{100}$ For them, this was part of the reason for forming this City-community partnership, so that the community could make claims on how the City conducts itself in relations to these marginalized communities. Likewise, this was an important part of the reason for forming this intersectional coalition with the direct representation of all eleven marginalized groups.

Although the Reference Group did not fully resolve these conceptual, political, and analytical differences in the meanings of their roles, most members settled with the emerging coalition discourse that their role was to bring the "perspectives" of a given community to the table based on what they knew about the realities of a given community. Their lived experience - in terms of their identity/membership in a group or of their expertise - was still an actively valued contribution at the Reference Group meetings, especially as the CAWI coordinator encouraged it to come into the discussion. However, these multiple and contested meanings of identity, representation, group membership, and intersecting and multiple identities and barriers carried into the development process of the Diversity Snapshots later on. This is where many of the Reference Group members felt the contradictory tension between the simplified, reductionist and single-issue structure of Snapshots on the one hand, and the reality of "diversity within" each of these eleven communities due to the multiple and intersecting identities and barriers that each 'community' or each individual experiences in real life. This manifested in terms of the tension between the strategic priorities to make this multilens featuring eleven marginalized communities as simple, user-friendly and comprehensible as possible for the target audience, and to present accurate and respectful

\footnotetext{
${ }^{100}$ This may also reflect the broader pattern of governmental authority shifting to a smaller cadre of technocrats, an aspect of neoliberal governance.
} 
depiction of these communities and the people in them on the other (Interviews: c, d, e, g, $h, i, j, k, p, t, u)$.

The Reference Group met once a month at City Hall ${ }^{101}$ between September 2008 and June 2009 to provide input and guidance on all aspects of the Lens development, from conceptualization of its objectives, scope, target users, structure and content, and strategy for its eventual implementation. In between the monthly meetings, the key coordinators of the Lens development, who were paid by their respective employers to work on this project on a part-time basis, developed further the pieces of the Lens based on the discussions at the preceding Reference Group meeting. The key coordinators would also conduct additional research, as well as outreach and consultation with key stakeholders in the City and the broader community, which would feed into the substantive work done in between the Reference Group meetings. Occasionally ad-hoc committees for specific areas of discussion were created in between the regular monthly meetings, supported by the members of the key coordinator team to take on some of the most important strategic and substantive work outside the Reference Group discussions. ${ }^{102}$ The key coordinators would set the agenda for the next Reference Group meeting based on the discussions from the previous meeting as well as the progress made by the key coordinators and these ad-hoc sub-committees.

\footnotetext{
101 This was true except for the very first meeting which took place at OC Transpo Headquarters in September 2008 (Reference Group meeting \#1 minutes).

${ }^{102}$ For example, two community members of the Reference Group on the "Aboriginal peoples" and "Immigrants" portfolios volunteered to meet outside of these regular meetings in November 2008 to flesh out the strategic considerations regarding the potential risks to the success of the project and how to mitigate them, which was consolidated into a single page document, and shared at the following Reference Group Meeting. This document most clearly, directly, and succinctly articulates the strategic priorities, concerns, and the plan of the Reference Group. On another occasion, a community member on the "People with disabilities" portfolio met with the CAWI key coordinators in December 2008 to start developing the list of "questions to consider" in ten areas of work, which came to form the bulk of the substantive content of the User's Guide.
} 


\subsection{Snapshot Workgroups - Role and Structure}

A Workgroup was established to develop each of the eleven Diversity Snapshots, each with a similar membership structure, to meet several strategic priorities identified earlier. Each Workgroup was to have at least one Reference Group member who would act as the 'lead', who would play a key role in providing substantive input on the content of the document, and to act as a "liaison" with the associated Advisory Committee for the given community ${ }^{103}$. The Workgroup lead could be a community or a City member of the Reference Group, and in some cases a Workgroup featured co-leads, one from the City and one from the community (e.g., People with disabilities, and to a lesser extent GLBT), or both from the community (e.g., Aboriginal peoples, one Inuk and one Metis). Each Workgroup was also to have a designated liaison from the Advisory Committees themselves, so that the ACs could have substantive input into the content and the direction of the document.

In addition, each Workgroup was to have representatives from both the wider local community, as well as from the City of Ottawa employees, to ensure the content appropriately reflected the perspectives of those who were the topic of this document (the community) and those who were the intended users of it (the City employees) and involved them in the actual process of developing it. This strategic outreach and the intentionally participatory process helped incorporate both perspectives (and their respective priorities) in the content of the document, but also served to add legitimacy to this tool in the eyes of the stakeholders on both sides, and to create momentum and buyin from both the wider community and the target users.

\footnotetext{
${ }^{103}$ Although as an exception, in the case of Women Snapshot, an AC member from Accessibility Advisor Committee (who also served as the liaison for the People with disabilities Snapshot) fulfilled this role.
} 


\subsection{Snapshot Format - Strategic Rationale and Effects}

The standard format for the Snapshot was in a sense 'imposed' by the key coordinators, mainly through the "questionnaire" that was given out to each Reference Group lead before the Workgroups were established to start developing the Snapshot drafts. The opening lines of each Snapshot were used as a condensed version of its main content - or its frame - to convey the 'flavour' of the document to readers as they might not (or were expected not to) read the entire document. The format of the Snapshot weaves in 'positive' and 'negative' content in anticipation of target audience responses. This approach came partly from the community members' concerns about the Snapshots reinforcing negative stereotypes or the dominant frame about each equity group/community, or portraying the issues to be difficult and costly to fix/change. Each Snapshot thus starts out with positive content (e.g., the community's first person voice on "who we are"/self-identity, contributions, and future vision). The 'negative' content is sandwiched in the middle, and occupies the most space within the entire document (e.g., barriers that get in the way of people and the overall vision for a nice City for everyone that the City staff needed to learn about if they are to promote equity/inclusion).

Each Snapshot ends on a positive note that points toward solutions or actionoriented resources for the readers. It includes existing international conventions, federal and provincial legislation, municipal policies and Council mandates that reinforce the City employees' responsibility, and also ability, to promote equity and inclusion for a given community (this was done through both 'prohibiting' legislation such as antidiscrimination and harassment and 'enabling' ones that give explicit permission or encourages municipal employees to take proactive steps in promoting equity and 
inclusion). This section also provides additional legitimacy to the community's claims on City employees through the power of law, especially from above (from the Council that sets the direction for City bureaucracy, and higher levels of government to which the municipal government is accountable). It also includes a section on "What's happening in Ottawa" that highlights what the City is already doing to promote equity and inclusion, which provides affirmation and validation to the audience for their institution's current work. This also points the readers to existing resources and practices across the Corporation, but also in Ottawa at large in other public institutions such as the police and school boards, and non-profit or community groups. Good practices from other municipalities are also included as a way to provide the readers with practical ideas that they could emulate, but also to 'normalize' equity and inclusion practices as the business of municipal employees in general (and a gentle, tacit pressure on the City of Ottawa not to fall behind other cities). Each Snapshot then concludes with cited sources, and, in some of them, an appendix of "Definitions" at the end for interested readers.

This appendix on "Definitions" was added to some of the Snapshots as an optional section. This was not in the original Snapshot plan/format, because the initial strategic priority for this was to keep it short and simple as per the partnership frame of user-friendliness. Initially the Reference Group proposed to create " 2 pagers" about each community. This then grew to " 8 pagers" accompanied with a " 1 pager" that summarizes it, and finally to 13 to 15 pages per Snapshot, including this new appendix "Definitions" for some of them. ${ }^{104}$ This was because the Workgroups insisted on expanding the length of this document, in particular the GLBT Workgroup that "pushed the envelope", whose

\footnotetext{
${ }^{104}$ The name of the Snapshots also changed from simply " 2 pagers", to " 8 pagers", to "Focus Documents" in following the lens analogy to zoom in on a particular community, then to "Community Snapshots", and eventually "Diversity Snapshots".
} 
effort then fed into the coalition's repertoire, which other Snapshots benefited from. The Definition section also became a place for the Workgroups to fold in radical elements that could not go into the main text of the Snapshot. Note that despite the coalition frame that prioritized a short, simple, quick and user-friendly tool for the target audience driven by the pursuit of resonance with the dominant frame in the City, the community members of the Reference Group and the Workgroups kept pushing back against the demands placed by the City and its dominant culture and frame.

This is evident in the ways in which the size of the Lens grew from a short guidebook with a handful of pages, to the creation of additional eleven documents that was neither in the original plan, nor in the budget. These Snapshots themselves also grew from the initial proposed length of two pages each, to eight, to sixteen pages for the longest ones in the end, adding up to the total of twelve documents containing 189 pages - which is neither particularly 'quick' nor 'short'. Over time, the Snapshot Workgroups also grew in size to include more individuals from both the community and the City, thus increasing the financial and human resources and time required to develop them. This reflects the dynamic negotiation between the City as the Corporation, and the user needs of the target audience, and the community's desires and demands.

\subsection{Snapshot Development Process - Strategic Rationale and Effects}

There were multiple strategic intentions and effects of the Snapshot development process and the final product, and the reception of the Snapshots, some of which were intended, and others unintended. On the coalition building front, the Reference Group's decision to create this via a participatory process was partly to get buy-in and to placate the skeptical members of other communities (besides women) by providing a dedicated 
space for each of the eleven communities to highlight their own issues and experiences of the people. On the front of target audience needs, the Snapshot was also intended to serve as an "education piece" or "information piece" for the readers as an optional or supplementary resource, to help bridge the gap between their mandates on paper towards action through additional concrete knowledge about the local communities. However, the structure of the Snapshots and the development process by separate Workgroups also inadvertently imposed silo-like divisions among the eleven groups despite the intersectional reality in real/lived experience, which some Reference Group and Workgroup members saw as problematic, and even as misleading and 'mis-educating' for the target audience.

At the same time, this process added additional cost and time required to complete the E\&I Lens than initially budgeted when the funding was first approved by the City and SWC in 2008, even though the original strategy by the key coordinators was to keep the cost minimal. And yet, this additional process actually became an important venue: 1) to generate more 'buy-in' from the target audience groups in the City, whose portfolios were aligned or oriented to each community or issue (e.g., poverty, seniors, youth); 2) to recruit and cultivate an internal network of 'champions' by engaging these City employees in this process who would then help legitimatize this tool in the wider audience in the City; 3) to 'validate the City's existing work' to foster more audience buy-in; and 4) to more thoroughly and effectively 'tie in' the community messages to both the institutional structure and culture of the City. The development of these Snapshots helped create 'buy in' not only from the communities but from the target audience. 
And yet, once this development phase of the Lens, which was primarily community-driven and featured engagement of allies within the City, concluded and the focus shifted to the City-driven implementation phase, the dynamics of the Citycommunity partnership changed again. Those who are privy to the continuing developments of this implementation effort are more hopeful about how this Lens is being rolled out in the City under the lead by the Community and Social Services Department and is being taken up by City staff (Interviews: a, e, j, k, r). These are mostly City members of the Reference Group or Workgroups or City employees who are directly involved in the implementation phase, and to a lesser extent the CAWI Coordinator who is still involved in this process, albeit in a much more reduced capacity from a removed position. The primary approach being used by the City is 'train the trainers' so that the knowledge and capacity to implement and use this Lens becomes rooted with the City employees themselves and their workplace, rather than gets 'outsourced' to external experts (such as community members and leaders). This is done to facilitate organizational cultural change within the City, but also for cost saving so that the City does not need to pay external or community consultants to deliver training.

This has left many of the community members cut off from this phase altogether, especially as there has not been sustained funding to ensure the community feedback and engagement mechanism vis-à-vis the City on this. ${ }^{105}$ That is, now that the development stage was completed, many of the community members that I interviewed were starting

\footnotetext{
${ }^{105}$ It is important to note here that the Equality Framework had envisioned an annual reporting back mechanism between the City and the community as part of its ongoing implementation and evaluation process. However, as discussed earlier in this chapter, the City has only committed resources to "develop" the E\&I Lens, only as a "one time cost", and on the condition of the SWC cover the $50 \%$ of it so that the City would not have to pay for $100 \%$. Moreover, EDAC and CAWI in fact actively made this part of their 'pitch' to the City's EMC emphasizing this cost-saving incentive for the City to approve the development of this "multi-" lens. This is an example of a strategic choice opening doors in one way (in the short-run), but also closed others in the other (and in the long-run).
} 
to express concerns about the status of the implementation of this Lens that they created in partnership with the City. Some wondered what has happened to this Lens after all, and some were disappointed by the lack of apparent progress on it, and/or the lack of transparency from the City to keep the communities informed. Some still conceded that "change takes time" or expected that "this will be a slow process" or that "it won't happen overnight". However, others showed frustration, and some have even grown skeptical or jaded, stating that this Lens turned out to be yet another initiative that "sit on shelves" after community members invest so much time and energy into creating it (Interviews: b, d, i, l, n, q, t, u).

This offers a lesson about the importance of having a clear implementation plan and the resources to sustain it - even though it can be difficult to secure. This also serves as a lesson for the community leaders, and especially their allies within the City, about the insular and exclusive nature of the boundaries of "polity", which tends to close off if we are not conscientious about keeping it open to those who are situated outside it. Partnership requires cultivating and sustaining relationships. The City needs to continue treating community partners as partners on an ongoing basis and not only when it is convenient or easy to do so, especially when the specific project funding to start up a new partnership expires. Likewise, community leaders also need to consciously work at continuing relationships with the City, and find ways to support their allies in doing so. 


\section{Chapter: People with disabilities and GLBT Snapshots Subcases}

\subsection{Chapter Introduction}

This case chapter examines the first two subcases in two sections, first on the People with disabilities Snapshot, and then the GLBT. Each section starts out with the key message(s) of the Snapshot. In each section, I first present the opening lines or the synopsis of each Snapshot, as this was meant to capture this key message for the target audience in the most concise manner. I briefly analyze e the framing strategy of this synopsis, then move onto the key message(s) that the Workgroup participants - both the community movement members and the City members - wished to convey in their Snapshot. Next I present the key debates or discussions that occurred within the Workgroup as they developed and negotiated over the draft, which I gathered from the interviews I conducted, as well as the written records of the development process from the time when these debates occurred. Here I highlight the strategic priorities or concerns these parties saw as necessary to address, such as the existing dominant frame(s) in the City about the community in question, and how the Workgroup sought to counter it through various framing strategies.

Each section then identifies the key factors that shaped the particular process for this Workgroup to arrive at their final text of the Snapshot, which served to enhance and/or compromise their desired key message. If there is a relatively high level of alignment among the Workgroup's desired key message, their key discussions and strategic considerations, and the final text, I take that to mean that generally they were able to convey their message while meeting the strategic objective to counter the 
dominant frame and finding a way to make it resonate with their audience. Each subcase concludes with a brief summary before moving on to the next one.

\subsection{People with Disabilities Snapshot Workgroup Subcase}

\subsubsection{Key Message}

Each Snapshot includes a brief opening passage on the first page - taken from the first section "Who We Are" - which serves as a quick synopsis for busy readers. Aside from the title of the document itself (i.e., the name of the group), this is where the overall frame of the Snapshot is conveyed to the reader, especially as this may be the only thing that a time-crunched prospective reader may ever read. In the case of the People with disabilities it reads:

We are parents, professionals, workers, students and volunteers. We wish to participate fully in the life of our city. Our accessibility gets limited not because of our disability, but as a result of the physical and social barriers. As we raise awareness about these barriers, we help make the city more accessible for everyone (CAWI and City of Ottawa 2010g: 2)

The passage opens with the message that "we" are real, living, normal people with complex identities and roles - not merely a label or a legal category "persons with disabilities", or simply, “disabilities”. After separating this prevalent and stigmatizing label from the people themselves, it announces that it is not we as people or individuals who are inherently disabled; rather, it is society that is disabling to people (disables people) as it imposes artificial barriers that limit accessibility. Thus it quickly shifts the focus away from disability itself (and the people tied to that label) as the cause of the problem, and presents an alternative view or frame that the real issue here is barriers in society and their impact on accessibility. The final sentence offers a solution to the problem and the key contributors to it: people who experience barriers to accessibility who can help raise awareness about, and facilitate the removal of, more and more of 
these barriers. It wraps up with a positive reinforcement about the outcome of such change, that improved accessibility can only be better for everybody in our society, and not just those with disabilities.

In this opening passage, both 'people with disabilities' and the pursuit of an accessible society are presented solely in positive terms. That is, there is no direct reference to the negative assumptions and stereotypes about this group in the text, which many of the readers might have - for example as dependent, incapable, and resourcedraining population whose 'special needs' require others to go out of their way to 'accommodate' them (Interview: p; Prince 2009: viii). This pre-empts right away the idea that these people are a burden on society - and the readers - and that a solution requires large-scale changes and resource allocation. Instead, people who experience barriers (rather than the essentializing label 'people with disabilities') are portrayed as active contributors to society at large as volunteers, workers, parents, etc., and also as resourceful problem-solvers for others, especially for the readers of the Lens who are asked to take action to promote equity and inclusion for this group.

This message thus seeks to appeal to the self-interest of the readers by offering a clear and simple solution to them, and such a solution does not place the burden of responsibility solely on the target audience. It brings together both the grieving party ('people with disabilities') and the target (many of whom without disabilities) in a shared solution to create an accessible society for all. ${ }^{106}$ This text presents this as a win-win

\footnotetext{
${ }^{106}$ The last sentence also suggests a simple process or roadmap to move from the problematic status quo to the desired destination and the solution. That is, raise awareness first, for lack of awareness about how barriers are limiting accessibility for different people is presented as a major barrier in and of itself; then introduce the practice to remove these barriers will follow. It frames this process as simple as a matter of shifting a perspective - or seeing through a new lens - which very closely mirrors the overarching frame used in the Equity and Inclusion Lens.
} 
situation, by playing up the idea that changing the status quo is not a painful process for the dominant group characterized by a sense of loss or increased burden, but one that brings about mutual benefit for those with - and without - disabilities. ${ }^{107}$

In short, these four lines do everything that a transformative frame does: reframes the core of a problem, why it is wrong, who is responsible for solving it, offers a clear solution that is not too daunting for the audience, and spells out its benefits to them. It challenges the dominant frame as it subverts the negative stereotypes and assumptions associated with 'disabilities' and 'people with disabilities' into something wholly positive. Yet it does not sacrifice resonance with the target audience, either, as their alternative frame does not adopt an "oppositional frame" (Morris and Braine 2001), which may alienate or threaten the dominant population amongst the audience. Instead, it draws them into a common interest marked by a concrete mutual benefit to both sides, through a shared solution they are offering to make the readers' work easier.

\subsubsection{Key Debates and Discussions at the Workgroup}

The interviews that I conducted with the members of this Snapshot Workgroup indicate that the key messages they ${ }^{108}$ wished to convey were commonly shared among

\footnotetext{
${ }^{107}$ Again this passage bypasses the negative statement that the status quo is detrimental to people with disabilities, though it is still implied.

${ }^{108}$ This Workgroup featured co-leads from the E\& I Lens Reference Group, one from the community and the other from the City's Accessibility Office (Corporate Accessibility Specialist). It featured two additional community members who also served on the Reference Group, each of whom led or co-led their own Snapshot Workgroups ("People living in poverty" and "Women"). The City lead member was replaced by an incoming Corporate Accessibility Specialist half way through the Snapshot's development process, at which point two additional City representatives from the Accessibility Office also joined the Workgroup. The Accessibility Advisory Committee liaison took an active part in developing this Snapshot (and later participated in another Snapshot Workgroup on "Women"), and the Workgroup received "blessing" from Chair of AAC who did not participate directly in the process (Interview: d). The project lead of the E\&I Lens development (manager of Diversity and Employment Equity) also participated in this Workgroup, mostly in an observing role, as this community was one of the designated groups in the Employment Equity Act and the City's Equity and Diversity Policy. The other City key coordinator of the Lens also participated in an observing and "learning" role (interview: e). Everyone on the Workgroup was thus connected to the E\&I Lens Reference Group, Advisory Committee, or the City's Accessibility Office,
} 
them, and are well reflected in the final draft of this document. That is, all agreed on the need to convey the diversity within the label 'people with disabilities'. They also agreed their discussions with each other should be based on lived experiences of people with different disabilities. In addition, they had respectful dialogue with one another on three main areas of debate. I will take these issues in turn.

\subsubsection{Breaking Down the Label "Disability"}

To begin, all of the interviewees identified the need to convey the sheer diversity within this label 'people with disabilities' as one of their first responses during the interview. This was important to the Workgroup members for several reasons. First, there are many different types of disabilities, and the barriers associated with each of these vary immensely. Next, the lived experiences of these barriers for each individual also varies tremendously, based on the types and the levels of impairment they may have, for instance when living with a visual impairment, dyslexia, or depression (Interviews: $t, p$, q, r). In addition, each person has their own individual preference for the kinds of accommodations they need and want, which is not simply shaped by the types of disabilities they have. ${ }^{109}$ This was essential for ensuring the dignity and respect for each

making this a particularly densely interconnected and tight-knit Workgroup in terms of the participants' organizational affiliations and positions.

${ }^{109}$ As the community lead member puts it: "It need to be inclusive. It need to include everyone with disabilities... and also the understanding of the differences between individuals themselves...because everyone's needs are different, everyone's requirements are different". Similarly, a City member notes: "I wanted to make sure that the Snapshot accurately reflected the diversity of the - for lack of a better term the community of people with disabilities. We all have different experiences and just because groups may appear to have the same disability, it doesn't mean their needs are always the same" (Interview: r). Similarly, the Accessibility Advisory Committee member likened defining disabilities to "trying to nail Jell-O to a wall" and advised that "it is easier to define the access needs of individuals rather than the types of disabilities". She explained that "Many disabilities and levels of disabilities are evolving in the way they are defined" and "There will always be the need to accommodate the individual, so a one size approach will never fit all" because "Every disability affects an individual differently", providing an example that "Rarely are people who are blind completely blind, so accommodations as well differ to this group, from large text to computer voice technology to Braille, it depends on the communication preference of the individual" (CAWI 2009-03-06). 
person as a complex human being with their own unique personality, aspirations, life circumstances and activities that all shape who they are, which is much broader and deeper than simply their 'disability'.

In addition, the Workgroup members were aware that the label 'disability' almost always conjures up the image of "someone using a wheelchair" in the mind of "the average person" in their audience, which is only but one kind of physical and externally visible disability (Interviews: $\mathrm{d}, \mathrm{p}, \mathrm{r}$ ). This reinforces another common assumption that the all people with disabilities are the same, that their disabilities are the same, that their personal differences do not exist, and that the solutions for them are also the same - such as "the ramps" and "the door openers"(ibid). The Workgroup members thus sought to counter this negative effect of this homogenizing label 'people with disability' that erases the individuality - and indeed the humanity - of the person, as it focuses too heavily on the 'disability' portion at the expense of the 'people' portion of it. One community member puts this succinctly:

First, we're individuals, we're people. And treat the person, not the disability. Or service the person, not the disability. It's the individual that we [at Independent Living Resource Centre] work with, it's not disability (Interview: $t$ ).

The desire to show people with disabilities as people first is echoed by another City member, who identified it to be the most important message the Workgroup tried to convey:

I remember us talking about - us wanting to show people as people, not labels. So there was that concentration on 'I'm your teacher, I'm your neighbour, I'm your grandfather'. Let's move away from putting people in a homogeneous lump. I think that was probably our biggest one (Interview: p).

Of course, failing to consider a particular type of disability leaves a particular type of barrier unnoticed by policy makers, service providers, and coworkers - thus undermining 
accessibility for these people. ${ }^{110}$ Likewise, failing to recognize the individual differences in needs, preferences and choices for accommodations falls short of proper removal of such barriers. All of the above converge to form a main thread in their message, i.e., ultimately to urge their audience to focus on accessibility and removing barriers affecting real people in everyday life of the city, which is captured in their vision of "an accessible city" (CAWI and City of Ottawa 2010g).

Thus the Workgroup members did not want 'disability' to remain the defining factor of these people's identity, either as individuals or as a community. As one City member points out, some people may not at all "identify as being people with disabilities, but they may still experience barriers" to access in their lives (Interview: $r$, italics mine). This redirects the focus back on barriers and accessibility, away from the notion of "disability" as an (all-encompassing) identity category. The Workgroup members also recognized that while others may indeed relate to this label, it still would not be the only aspect of who they are (Interviews: $d, p, r, t$ ). In addition, these members emphasized that the people with disabilities "are everywhere" in the broader community as the readers' neighbours, colleagues, professors, students, parents, etc., and that they are also part of the "other communities" highlighted in the Lens, for they may be women, men or trans, Francophones, immigrants and/or Aboriginal, etc. (ibid). This, too, counters the dominant society's tendency to view 'people with disabilities' as different and separate from other

\footnotetext{
${ }^{110}$ One community member explained this in her interview: "We're talking about people with wheelchairs, we're talking about people with visual impairment, we're talking about people with intellectual disabilities - the whole gambit. [But] 'the average person' would automatically think of someone who is using a wheel chair... So when they're talking about accessibility, ramps and door openers are the first thing that are thought of. They don't extend that to access of information, or access to support services" (Interview: d). This is echoed by another City member: "Our Snapshot at least opens people's minds to realize that accessibility and disability isn't just physical disabilities. That it is invisible disabilities and other disabilities that they may not have considered" (Interview: r).
} 
people in society, and from people without disabilities. This point is significant in light of the history of imposed segregation of people with disabilities away from mainstream society into medical institutions and other charitable 'care' facilities, often without their consent or against their will - all based on the assumption that these people are incapable of making their own decisions and depend on others' help (Interviews: p, r; Lepofsky 2004; Prince 2009).

In addition to highlighting the diversity of experience within this community, this Workgroup spent a significant amount of time checking different opinions and viewpoints among themselves, based on the lived experiences of people with different kinds of disabilities. The interview comments make it clear that this in fact served as a guiding principle for this Workgroup's deliberation process. Here, a person's real, lived experience and the insights arising from it was viewed as a particularly valuable resource to be shared. ${ }^{111}$ Interviewees expressed that they felt free to voice their opinions especially when they differed from those of the others. In turn, they consciously sought to understand others' perspectives and rationales for their opinions, as they deliberated on what words or phrases to adopt in order to refer to a particular type of disability, or to a group of people who live with it, as well as what content to leave out and why. ${ }^{112}$ In

\footnotetext{
${ }^{111}$ One City member commented on her belief about the importance of having lived experience related to the topic or the population in question: "While you can have a certain amount of professional experience and that's all very valuable, having a lot of lived experience is also useful, because then you can say 'Have you considered this?', 'Here's another perspective that could be incorporated there', or 'Here is another issue that could be added" (Interview: r).

${ }^{112}$ For example, as one member recalled: "We spent a lot of time on making sure we are using the language that we felt was appropriately representative for the group we were trying to discuss in the Snapshot. 'Is this language appropriate? Is everybody comfortable with it?' And somebody would say, 'No I am more comfortable with using this word instead to describe this experience'. ... Having that discussion was very useful, because hearing it from somebody who has a concern, you got a chance to have a little bit of learning yourself and say 'Oh that's why it's more appropriate to use that word versus another word', or 'Oh I didn't think about it that way' and 'That's a good consideration', and to be able to move forward as a group" (Interview: r). Another community member recalled a concrete example of such exchange, when the Workgroup decided to change the phrase "mental illness" to "mental health issues". This was done at
} 
describing this process, other community members of the Workgroup explicitly stated that they did not feel any sense of "disappointment" or their views being "shafted" by others in this difference- and experience-based, consensus-driven discussion. ${ }^{113}$

Interviewees in this Workgroup recalled that there was "not a heated debate" or strong "disagreements" among the members, although there were a few topics of debate that their Workgroup tackled (Interviews: $\mathrm{d}, \mathrm{t}$ ). One of these debates was on how to - or $n o t$ to - use labels and definitions to represent the experiences of this population. The City co-lead member in particular recalls the Workgroup's early discussion about their desire not to use definitions at all, partly because labels inevitably reduce and limit the vastly diverse human experiences into a homogeneous and monolithic stereotype. ${ }^{114} \mathrm{In}$ fact, the two co-lead contributors of this Snapshot, who were responsible for the People with disabilities portfolio on the Reference Group, had asserted clearly at the outset of the project that they "will not explain 'who we are' by listing sub-categories of disabilities, as this type of thinking could leave certain groups out (CAWI 2008-09-25). ${ }^{115}$ They were

the request of one community member, who informed the group based on his active involvement with the mental health communities that the former is associated with a stronger stigma (Interview: $q$ ).

${ }^{113}$ For example, one member stated: "If you read over a draft and you felt there was an element missing, we'd rephrase it and reword it and rebalance. And I thought that was done pretty well. Nobody was feeling they were getting shafted because their issue didn't have a priority or anything like that. I didn't get any feeling of that". Similarly, a different member also commented: "I do remember some changes along the way... But I don't remember feeling overly disappointed or feeling like everything was lost because we did this. I didn't feel that" (Interviews: $d, t$ ).

${ }^{114}$ This member recalled having this discussion early on in the process: "We had a discussion about not defining disability and putting that up front. I remember when building a Snapshot, people [in the coalition/partnership] wanted us to use definitions, and we did talk about disability not being definable. It's undefinable and it always should be undefinable" (Interview: p).

${ }^{115}$ This is found in the report from the very first Reference Group meeting on September 13, 2008, where the Reference Group members "shared key points about their respective group on: Who we are; Inequities We Face; Barriers for Accessing Services; and What the City is doing" as a way to learn from one another about their respective community and as part of their initial intersectional awareness building within the coalition. When the Reference Group made the decision to create Snapshots, this initial report was used as the basis for each Snapshot. At this meeting, the two co-leads sought to capture the fluid and porous nature of the boundary demarcating the category 'people with disability', stressing the following points: "People with disabilities are everybody. People do not necessarily categorize themselves as a person with a disability. People move in and out of this group - every lifestyle, social strata, work environments, and 
aware of the fundamental limitation of labels and categories: a list of subcategories can exclude some parts of the whole experience of a person, or that of some groups of people, no matter how many of them you list in an effort to include everybody. This initial view was reiterated again by the rest of the Workgroup members at the second Workgroup meeting in May 2009, ${ }^{116}$ as the minutes records:

We are people (individuals) - not a category. Don't label. Different words - Ability, DisAbility, AccessAbility - [have] different meanings to different people, but what matters is the intent behind it. "Special needs" [is] condescending. If not sure, ask. [Focus on] the fact that physical act is limited in your life situations, rather than a medical issue you have (CAWI 2009-05-13a).

This view of the Workgroup members was closely reflected in the final draft of their Snapshot, as it is presented upfront in the very first section "Who We Are":

Some of us don't consider ourselves as "a person with a disability"... The label "disability," or the kind or level of impairment, does not define who we are as a person or a community. It is about whether each person has access to full participation and can contribute equally to our city. Accessibility gets limited not because of our disability, but as a result of the existing barriers in society (See Definitions) (CAWI and City of Ottawa 2010g: 3 [bold in original]).

Here, there is a slight compromise added at the end of this paragraph ("See Definitions")

for the sake of clarity for the audience - or user-friendliness of the document. This reflects a small compromise on the part of the Workgroup co-leads and the other members to respond to the strategic priorities arising from the higher scales - the coalition and the partnership - to make this Snapshot a "simple", "quick", "educational" and "user-friendly" for the target audience (Interviews: d, p, r). Even with this minor

generations - which is unique to this category. Disability is often thought of as physical, but is very broad some are visible, (non- visible) invisible, acquired later in life, or from birth. Everyone has an equal chance to become 'disabled'. Some see it as part of their identity, but not all (watch for stereotype)" (2008-09-25 Multi-Focal Lens - Sept 13 Report). Note also a hint of liberal master frame here in terms of the "equal opportunity' for all to develop a disability.

${ }^{116}$ The consistency of the views shared by different members of the Workgroup, both from the community and the City is very evident here. That is, by this time the lead City member had left the City and the position of the Accessibility Specialist was replaced by a new staff person, and the other City member of the Workgroup had just joined the City's Accessibility Office a few weeks prior to this (Interviews: p, r). 
compromise, this shows that what this Workgroup wished to convey was generally reflected in the final text of the document.

\subsubsection{Balancing the 'Positive' and 'Negative' Content}

The second topic of debate was how to balance the 'positive' content about people with disabilities with the 'negative' one. Here, there is a tension between the shared strategy adopted at the higher scales of the intersectional coalition and the Citycommunity partnership on the one hand, and the movement-specific strategic priorities and preferences of the Workgroup on the other. However, in this case who pursued resonance and who imposed radicalism was reversed. That is, ideally the City members of the Workgroup preferred to focus mostly - even solely - on the positive contributions made by this community as 'regular' citizens (e.g., as working people, raising children, volunteering, etc.).

This is because they wanted to opt for a discursive strategy that would play up the 'positive' content and resonance so much to the point that it would displace the 'negative' stereotypes portrayed by the dominant discourse out of the frame of the picture. They wanted to use the positive contributions and solutions that this community offers to society, precisely so that it would steer the reader's attention away from the dominant discourse that portrays them as "helpless" and "miserable" (Interviews: p, r). One member explained that she wanted the document's focus not to be "all about what is missing but highlight what is working really well and what is really useful for society" (Interview: p). In other words, they wanted to make sure the document's framing was focused not just about the "problems" and deficiencies associated with people with disabilities, but to shift the association to solutions and benefits to society (ibid). 
However, given the shared discursive strategy adopted at the coalition and the partnership scale - which imposed the shared format for all the Snapshots to include both 'positive' (vision, contributions, solutions) and 'negative' content (barriers and inequities or status quo) - this Workgroup had to oblige to follow the same format. In addition, they themselves, too, realized the strategic necessity of including this 'negative' content as part of their frame if they hoped to change the audience's attitude:

People have to be familiar with the barriers so they will see them. If you don't experience them yourself, you don't notice that there is no curb cut. Unless you know about that, you're not going to notice, and you're not going to do anything about it (Interview: p).

Therefore, this Workgroup knew they still had to "educate" the readers about the barriers - the negative content - so that they would be able to start noticing them, and removing them (Interviews: $\mathrm{d}, \mathrm{p}, \mathrm{r}$ ).

In this sense, this Workgroup made another compromise to oblige with the shared strategies adopted at (or imposed by) the higher scales of the coalition and the partnership. And yet, such compromise left some of the Workgroup members wondering about the strategic consequence of reinforcing the dominant frame by allowing this negative content to enter their frame:

And yet when we talk about barriers, we get into a litany of how bad life is. And for that, a reader goes right back to segregating people [with disabilities] because they feel sorry for them. The person is put right back into a label, a box, and is likely to be shipped off to be taken care of somewhere in an institution (Interview: $p$ )

This also speaks to the persistent power of the dominant frame to pull the readers back to its grip, even when the movement frame tries so hard to reframe it, and indicates the member's strategic awareness of the real power of such discourse. In the end the Workgroup decided to conform to the shared discursive strategy imposed by the coalition and the partnership on them in the end. However, as the above discussion shows, this compromise still left this member wondering about the long-term implication of doing so 
for the movement-specific strategy to pursue its main objective: i.e., to shift the dominant discourse about this community and about the issue of accessibility. ${ }^{117}$

\subsubsection{Wishes of the Community vs. Needs of the City Audience}

The third topic of discussion that the Workgroup identified was capturing the sheer diversity of this community as accurately as possible that was irreducible to simple categories and subcategories on the one hand, but at the same time having to reduce and simplify the content to make the Snapshot "short, reasonable and understandable" for the audience (Interviews: $d, t$ ). In this sense, they felt the opposing priorities for them to address - one that emanated from the needs of the community to portray themselves as accurately as possible to reflect the people's lived reality, and one from the needs of the audience. They knew that somehow they needed to bridge the two in order to get the audience to move away from the existing dominant frame, and to start removing barriers to promote accessibility for all people with any kind or level of disability.

In sum, interviewees reported that through an acknowledgement of diversity within the community of people with disabilities, basing their deliberations on lived experiences, and due to their commitment to inclusive dialogue, this Workgroup was able to debate whether or not to use labels and definitions, how to deal with positive attributes and negative stereotypes, as well face the dilemmas of reducing complex realities to simplified public messages. These discussions also show the contradictory tension between resonance and radicalism that the Workgroup had to manage as they sought to find the right balance between the two in order to achieve their objective - of presenting a transformative frame that countered and replaced the dominant frame - while still

\footnotetext{
${ }^{117}$ In fact, this member stated in the interview that this still continues to be an ongoing struggle for her and for the whole movement, and that they do not yet have a good solution to this discursive conundrum (Interview: $\mathrm{p}$ ).
} 
conforming to the shared strategic package of the coalition and the partnership. In other words, this Workgroup felt the tension between their movement-specific goals, priorities and strategic preferences on the one hand, and those adopted at the higher scales of the coalition and the partnership on the other.

\subsubsection{Key Factors}

\subsubsection{Shared Movement Affiliation}

The interviewees identified a high level of correspondence among the members in terms of their understanding of the goals and priorities for this Snapshot, which shaped the terms of debate at this Workgroup, as well as the decisions they collectively made as they settled on the final version of their draft. Here I consider what contributed to this. First, a high number of the Workgroup members were affiliated with similar disabilityrelated social movements. They were thus able to draw on this shared knowledge and experience to take on the challenges - and to guide their practice - at this Workgroup. Three members of the Workgroup were connected to Independent Living movement and Disability Rights movement, which put multiple members on the same page in terms of their goals, values and beliefs regarding this community of people with disabilities. ${ }^{118} \mathrm{It}$ was also significant that this involved two lead members of the Workgroup (one from the community and the other from the City), as well as an additional member from the City. This provided a strong common ground between the community and the City perspectives in the process. Here, the City representatives both self-identified with, and

\footnotetext{
${ }^{118}$ The City co-lead member of the Workgroup explained that she "came from a strong background of working with folks with disabilities in an advocacy role in the Independent Living Movement... and had worked within the IL Movement for over 20 years". Another City member had also worked in the IL movement for over 10 years, which she describes as "very much a community based movement". The community co-lead member was also affiliated with the IL movement as she was the Executive Director of the local IL Resource Centre in Ottawa, and all these members expressed that they brought with them the values and beliefs of this movement to the Snapshot (Interviews: $\mathrm{p}, \mathrm{r}, \mathrm{t}$ ).
} 
wholeheartedly supported the grassroots, community-centred approach to creating this Snapshot.

The underlying philosophy of these social movements that these members brought with them in part explains why this Workgroup was able to operate in a "very collaborative environment" (Interview: d), which sought direct representation of the community stakeholders as much as possible, and even if that was not entirely possible, to seek people's lived experiences as one of the most valuable input into a discussion. As one member explained, the notion of "Nothing about us without us" was important in grassroots movements like the Independent Living movement, and was taken seriously at this Workgroup. ${ }^{119}$ This has additional historical and political significance as people with disabilities had too often been denied the ability to represent themselves in policy - and even family - discussions that led to decisions that affected them. Decisions about where and how people with disabilities could live had often been made without their own input, consent, will or choice, as these were typically done for them, by others, such as their caregivers and medical professionals (Prince 2009; Interviews: p, r). In addition, the members were acutely aware that the enormous multiplicity crammed into this single and homogenizing label 'people with disabilities' had to be conveyed in this document, because not including certain disability groups or barriers could ultimately obstruct the removal of these barriers. This made it all the more critical that various disability groups or sub-movements be represented and reflected in the Snapshot as much as feasible.

\footnotetext{
${ }^{119}$ One City member expresses her belief in the importance of drawing on people's lived experience in any effort to represent them in documents like the Snapshots: "I am a believer in the phrase "nothing about us without us". If you're going to speak about a particular group - whether persons with disabilities or visible minorities or whatever - you want to make sure you're including people who have the lived experience of that" (Interview: r).
} 
To do so, this Workgroup chose the overarching concept of 'accessibility' and a 'cross-disability perspective' in developing this Snapshot. This helped in bridging the internal boundaries between sub-groups while avoiding the inevitable exclusion of some groups that comes with listing out a series of subcategories. And yet, ensuring a crossdisability perspective in a document like this still requires conscious and sustained effort. It is still a relatively recent practice, especially given that historically, advocacy for people with disabilities had been done by separate groups of people with a specific kind of disability in an ad hoc, patchwork manner (for example CNIB on behalf of those with visual impairment, or CMHA for mental illness) (Lepofsky 2004). Luckily, Independent Living Movement and Disability Rights movement, which the Workgroup members drew on, developed as a decidedly "cross-disability movement" (Interview: r). Thus the Workgroup members already had this cross-disability coalition building under their belts, and this constructively informed their approach to the deliberation process at the Workgroup table. ${ }^{120}$

Their connection to these social movements also allowed the Workgroup members to draw on the discursive resources from these movements in shaping their key message. The fact that a transformative frame was readily available through these broader movement enhanced this group's ability to convey their message effectively in short space, even though they still had to work hard to flesh it out to suit the particular format of the Snapshot. This is reflected in the terms of the debate at the Workgroup as well. For

\footnotetext{
${ }^{120}$ Two members of the Workgroup, each from the community and the City, comment on the necessity to "practice what you preach" in terms of the way that they conduct their own Workgroup or Reference Group meetings and discussions, so that the process itself is accessible and inclusive to all participants and not based on ablist assumptions. In making these comments these members link it directly to the larger objective and the spirit of the E\&I Lens as a whole, demonstrating that their understanding of the purpose of the Snapshot was aligned closely with the coalition frame on equity and inclusion.
} 
example, one member explained that the debate on whether or not to use labels in the

Snapshot came from "a mixture of the IL Movement and the Disability Rights

Movement", noting that the latter was particularly strong in their stance that "labels tend

to segregate and discriminate" (Interview: $\mathrm{p}) .^{121}$

In fact, Church et al (2007) capture these "ongoing and unresolved debates about

ways to talk about disability" within the Canadian disability movement. Here, these

authors actually identify the discursive strategy used by the co-lead of this Snapshot

Workgroup as one of the established strain of it, called "people first language" (ibid: 2).

Church et al explains that this discourse claims "we are people first, and disabled only

incidentally", and its strategy is "to use language to dislodge bodily difference,

'impairment' and/or limitation as a 'master status' in defining how people are perceived

and treated" (ibid). ${ }^{122}$ Moreover, the frame this Workgroup adopted aligned with master

frames in broader social and political context - namely the "rights frame" and the "choice

frame", ${ }^{123}$ both of which are identified by Benford and Snow (2000: 618), as this

${ }^{121}$ The Workgroup member explained that "Disability Rights Movement worked a lot with the international classification of disability which is this huge international body that spends decades talking about a word or a label. People with disabilities were saying 'Stop that process. Stop trying to describe us"' (Interview: $p$ ).

${ }^{122}$ Note here, however, that Church et al. themselves disagree with this 'people first' language as a discursive strategy as they view it as pushing disability "into a periphery". Instead, these authors, writing from the standpoint of "participants and allies to the Canadian Disability Rights Movement", seek to reclaim and embrace the term "disabled" as a "valued aspect of identity", positing that it "does not signify "damaged" identity. Instead, it is a differently legitimate form of personhood that can be fully incorporated into a valued self" (Church et al. 2007: 2). This shows the ongoing, contested, and continuously evolving state of the broader debate on language, labels, identity, and the meaning of 'disability' within the Canadian disability-related social movements, even though this particular Workgroup was not fractured as a result of it.

${ }^{123}$ Another Workgroup member explained the philosophy of the Independent Living movement in terms of individuals" "choice" and "control" over how they want to live their lives. She states: "Independent Living movement is a consumer-run, consumer-controlled movement which believes that persons with disabilities have the rights to have choices and control in the decisions of their lives... [It] focuses on the key principles of empowerment and independence and choice and control for individuals regardless of disability" (Interview: r). Similarly, another member speaks of the Disability Rights movement in terms of their connection to the broader concept of rights - as in civil rights, consumer rights, and more broadly, human rights: "Disability Rights movement is part of the IL [Independent Living] movement, and it's not unlike other movements of people fighting for their rights, whether it be civil rights movement or consumer 
buttressed the legitimacy to their claims. In fact, Prince explains that within the Canadian disability movement "Equality and inclusion are principled evoked by individual, families, community groups, social movement organizations, and coalitions to legitimate claims for human rights, social acceptance, public participation, and an array of material benefits" (2009: vii). ${ }^{124}$

\subsubsection{Strategic and Frame Alignment with the Reference Group}

This Workgroup also had the highest rate of the Reference Group members participating in it, ${ }^{125}$ which provided yet another common ground linking the Workgroup members. This meant that they came into the Snapshot development process with an already shared understanding of the purpose of the Lens as a whole, and how their Snapshot fit within that big picture as a companion piece. This included the intersectional coalition building effort among the eleven movements, as well as the strategic discussions at the Reference Group table on how to design this Lens so as to ensure its successful implementation by the City. Their conscious understanding of, and agreement on, the strategic need to appeal to the needs and interests of the target audience, in turn afforded them the ability to incorporate resonance with the dominant frame into their narrative. The Workgroup members thus understood the ultimate strategic necessity to

rights movement. It's people with disabilities saying that we have basic human rights that are not recognized, and the things that are done to us in the name of taking care of us or the best interest [for us] are discriminatory in nature. ...It's about a community hanging true to its philosophies and not selling short or compromising on that. The right to a human right. It's basic and can't be forfeited, it can't be half way there" (Interview: p). Here is an example of a radical frame that is simultaneously resonant because it appeals to a powerful master frame about human rights within Canadian society.

${ }^{124}$ Prince himself evokes yet another master frame of "citizenship" as a way to "overcome the marginalization of persons with disabilities". Here, he argues that "a politics of cultural recognition, a politics of economic redistribution, and a politics of political representation" must all come together in order to advance "full citizenship for all members of society" (2009: vii).

${ }^{125}$ Seven (7) out of the nine (9) participants on the Workgroup sat on the Reference Group and the other two (2) served on the Accessibility Advisory Committee, thus were well informed about the purpose of the Lens as a whole (one as the Advisory Committee liaison and the other the Advisory Committee Chair. The Chair provided approval and "blessing" to the Workgroup rather than active participation, thus practically bringing the number up to seven (7) out of eight (8) (Interview: d). 
tailor the document to the readers' needs. This helped them make a consensus-based strategic decision with relative ease, especially as they sought ways to cut down the text to make it short, informative, and user-friendly for the audience despite their desire and obligation to the community to capture its huge diversity.

For example, one member explained these two contradictory priorities - one for the sake of the community and the other for the sake of the audience in the City.

We could go on for volumes to talk about accessibility... But we realized there are limitations to the amount of material we can put in there, the limited boundary we had. You have to be concise and yet informative. So anything to be put in the Snapshot had to be pointed, it had to be informational, it had to be readable... We realized the value of fleshing this out as simply as we could, so we wanted to keep our Snapshot short and reasonable (Interview: d).

Significantly, she attributes this collective strategic realization to the fact that these members had been meeting many times through the Reference Group (and the Workgroup) by then. ${ }^{126}$ This was echoed by another community member, who explained that the Workgroup was able to agree on how to reduce the text "because it was clear what the City was looking for from the beginning" (Interview: t). ${ }^{127}$ This member also noted:

As much as we wanted everything in our Snapshot, we also realized that people at the City don't sit down and read these things, so it has to be quick and easy and informative, and we'd have to do it in a way that was going to capture their eye and not get distracted and on to something else. And this relates to the overall picture of the Lens as well (Interview: $t$, italics mine).

This indicates that she derived this from her work on the Reference Group, whose main task was to ensure an effective design of the Lens as a whole.

\footnotetext{
${ }^{126}$ This member explained that "Everybody was coming at it from the same page. And of course these Snapshots were done long after the Reference Group had been meeting for many times... So people fully understood the process by this point" (Interview: d).

${ }^{127}$ The community lead member underscored the absolute necessity to edit the document from the perspective of the readers: "I really believe that if it's not accessible it's not going to be used. So not only you need to go out to people with disabilities and tell the story from their perspective, you have to come from the other side, from the City employees' perspective... and understand what their needs are. If we want to produce something that is going to be user-friendly and usable for the people that you're producing it for, you have to consider: 'what do they need? And what do they want to see?" (Interview: t).
} 
Moreover, these comments show that there was a close alignment of the transformative frame used in the Snapshot (movement frame) with that of the "coalition frame' emphasizing the intersectional approach to equity and inclusion, and the 'partnership frame' emphasizing the user-friendliness of the tool. In addition, this their movement frame aligned well with the coalition and the partnership's effort to 'tie in' the Lens with the Service Excellence mandate of the City by emphasizing that using this tool helps the City staff do their work more efficiently and effectively. ${ }^{128}$ Furthermore, this movement-specific frame about "barriers" or "barrier-free", "access" or "accessible", and “inclusion" or "inclusive design" all informed and fed into the E\&I Lens's overarching concepts about equity and inclusion as prevented by systemic barriers to a very significant extent. ${ }^{129}$ This Workgroup thus benefited from their ability to draw on the strategic discussions and insights at the Reference Group level in multiple ways.

\subsubsection{City-Community Alignment}

This shared understanding came also from the fact that the City representatives on this Workgroup were in close agreement with the community members in terms of

\footnotetext{
${ }^{128}$ One community member's comment reflects this well: "We had to convey a complex message to the City that all equity groups are important and nobody should be left out. That the city is made up of all of us and not just of able-bodied white middle class government workers, and Ottawa's bigger and broader and more diverse and richer than that. We've expanded their job now. But we had to say it without overwhelming them with more work. We did it by emphasizing the positive difference it would make in the city. The way the city would be - it would be richer from the involvement of everybody. The programs would be better. The participation would be better. The value of the program is enhanced now because you've reached out to people who you've missed before with your traditional type of outreach and your traditional type of delivery. By missing out on the participation from each equity group, the City is missing out". (Interview: d). This member had been involved in the Gender Lens over the years, and has brought this cumulative knowledge about strategic considerations vis-à-vis the City. This partly explains why the Women Snapshot was done so quickly - the frame was already developed, for this specific target audience, and by then participants had already developed that intersectional solidarity perspective.

${ }^{129}$ This is evident for example in the ten-point vision of what a city for everyone looks like, presented as the first content page of the User's Guide immediately following "A message from the City Manager". Out of the ten, "Barrier-Free" is the second point and "Accessible" is the fourth (CAWI and City of Ottawa 2010a: 3).
} 
mission, key message, and strategic concerns. The 'City' and the 'community' perspectives were not presented as opposing sides within the context of the Workgroup, even as the target audience was viewed as those whom they needed to educate, convince and change their mind about what the problem is, and what needs to be done about it, but without overwhelming them. The City members were able to offer their insider knowledge of the City's culture and the target audience to the community members, thus effectively leveraging the potential of this partnership for the benefit of the community movement. ${ }^{130}$ Indeed, the City co-lead member explained that she spent a lot of time and effort thinking about how to motivate and convince City employees to adopt accessibility as a priority in their work both in action and in attitude, long before she joined the Equity and Inclusion Lens development process (Interview: p). As a result, this Workgroup was able to readily incorporate the City staff users' view into the decisions at the Workgroup level.

The City's Accessibility Office (AO) clearly viewed its constituents to be "the community" first and foremost, and "the staff" to be their "audience" in this document "who will interact with the community" after all - thus bringing the focus back on the community (Interviews: p, r; CAWI 2009-05-13a). For instance, the two City members of the Workgroup both explain that the "main clientele" and "stakeholders" of their work in the AO is both "internal and external", meaning that they provide support to the City

\footnotetext{
${ }^{130}$ One of the City members shared the same thought for the same purpose as the community members, and this shows in the discussions she recalls having with them: "I do remember talking about 'If we're building all this material, then who reads it and why?' And if it's a Lens to be used by the staff at City Hall, how are staff at City Hall going to pick this up and read it? Or when? What's it like when they are in the office? So how do we get readers to read it? How do we get our audience to read it?' And that was a difficulty" (Interview: p).
} 
employees in complying with AODA requirements, with the ultimate goal of meeting the accessibility needs of the residents (Interviews: $p, r$ ).

In addition, when deciding what terminology to use, AO chose to align its orientation and terminology with what the community uses, even if it deviated from the City's official term in its municipal policy. This is clearly recorded in the Workgroup meeting minutes in May 2009 (CAWI 2009-05-13a). Here, the Workgroup also referenced the higher-scale discourse from the provincial legislation AODA as an additional legitimatizing force for their decision to side with the community movement frame, and to bypass the official terminology in the City's Equity and Diversity Policy. ${ }^{131}$ Indeed, the Workgroup urges that "If the City wants to serve the constituents, the City must get on board with the community, AAC, Accessibility Office, otherwise E\&I [Lens] will be irrelevant". Indeed, it even urges the City to "take a leadership in educating the other levels of government" if the current government practices differ from "what the community feels" (ibid). ${ }^{132}$

Finally, as it is evident here, the structure within the City, namely the Accessibility Office and the provincial and municipal legal framework that governed its work, aligned with the movement frame that the Workgroup was using. The Accessibility Office now derived institutional power from the provincial legislation AODA. Interestingly, this provincial legislation itself was the result of the years of advocacy by the organized grassroots movements by people with disabilities gradually to "take over"

\footnotetext{
${ }^{131}$ The minutes explain that "Accessibility Office uses "people" because that is the term used in the community that is our clientele. The audience is the staff, who will interact with the community. Shine the light on who we are serving"... [And] AODA (Provincial) uses "people" all the way through" (CAWI 200905-13a).

${ }^{132}$ In this sense, the discourse chosen by the Accessibility Office was 'radical' against the institutional discourse of the City, but such choice was supported both by the grassroots movement frame and the legal institutional discourse at the provincial scale. This, again, is an example of a radical frame that is simultaneously resonant.
} 
civil society organizations, and to restructure the state itself through legislative changes (Interview: p). Once legislated, AODA in turn provided another legitimatizing force to back up the Workgroup's transformative frame about the focus being on accessibility, and not the label "disabilities" or the discriminating stigma attached to it. The City colead member explained that having it legislated was "a strong motivator" for her internal clients in the City who would otherwise not have taken action to remove certain barriers (ibid) ${ }^{133}$

This does not mean that this Workgroup had no difficulty in arriving at their final draft or compromise something along the way, however. For example, one member recognized that it was "difficult to shift" the frame of the document from label to people, and from disability to accessibility (Interview: p). This was particularly the case because the category that was used in the rest of the Lens, which put emphasis on "disability", went against the spirit of their own chosen transformative frame. This member recalled that an effective transformative frame that defies the use of labels - "to describe something without describing it" - was actually not available to the Workgroup at the time, although the "the Convention on the Rights of Persons with Disabilities has done that for us since that time". In the same vein, striking the right balance between the positive (people's resourcefulness and contributions) and the negative contents (barriers and inequities) continues to be a challenging task even in her current work, as "it is very difficult not to fall back onto the negative stereotype" (ibid). In fact, one of the

\footnotetext{
${ }^{133}$ This member even admits jokingly that she was appealing to the legal authority of ADOA even before it actually became law, telling other City employees "'you won't believe what's coming down the pipe here if you don't comply!" because "when it's law people do feel an urgency that they must do something". However, she explained that she was "very very careful not to rely on the legal argument in the long run" because real systemic change is bigger and deeper than a simple legislative change, and she did not want the City employees to view accessibility only as a list of legal compliance they need to check off, and not change anything about the attitudinal barriers in the corporate culture (Interview: $p$ ).
} 
definitions that are included in the final draft contradicts the transformative frame that the Workgroup wanted to stick to, thus serving as a compromise on their key message. ${ }^{134}$ In fact, the Workgroup's decision to include sections on barriers and inequities (negative content) and to use definitions at the end were not strictly their own choice, but more of a result of the uniform format required of each Snapshot to use. As one member noted, "We created a Snapshot, because everyone else was creating a Snapshot so we needed to do one, too" in the coalition context (Interview: p). Another member also admitted that this Snapshot does not convey the wholeness of a person fully, and added that even though the text clearly asserts the importance of individual differences and preferences, she is "not sure if the readers really understand it" (Interview: $t$ ). Both members commented on the limitation of the 'box approach' to the eleven Snapshots that divides people into eleven groups as though these communities are separate entities. This way of presenting 'people with disabilities' in the context of ten 'other' groups reinforces the reductionist, homogeneous and one-dimensional perception of what or who people with disabilities are, and more generally, what human experiences and subjectivities entail.

However, discursively speaking, People with disabilities Workgroup was relatively well-positioned within the context of this coalition and partnership despite the other challenges that still remained for them. There is a high degree of agreement among the members on their desired key message, based on their shared understanding about what the dominant frame entailed as manifested in the common stereotypes or

\footnotetext{
${ }^{134}$ Statistics Canada's definition of "activity limitation" reads as: "any limitation on activity, restriction on participation or reduction in the quality or type of activities because of a physical, mental or health problem" (CAWI and City of Ottawa 2010g, italics mine). This views the individual's impairment as the source of barriers, rather than the attitudes, practices and environments in society.
} 
assumptions, which they expected the 'average' audience at the City to have. They also shared an understanding of what about the dominant frame needs to be challenged and changed, and how they might be able to transform it through an alternative frame. ${ }^{135}$ In short, they understood their common goal to develop a document that conveys their transformative frame that challenges the dominant frame while remaining true to the community movement's spirit (i.e., to capture the expansive, diversity of views and information, to educate the readers about a nuanced, complex, and diverse message) - but heeding closely to the audience needs by making the document simple, short, and easy so that this would be used by City employees.

\subsubsection{People with Disabilities Case Summary}

The People with disabilities Snapshot presents one example of a transformative frame, which sought to push the dominant discourse out of the picture and replace it with an entirely alternative frame. The Workgroup opted for this strategy because the dominant frame in the City and in the audience's mind was so strong that it could easily contaminate and take over the discursive landscape that the Workgroup was seeking to change. They shifted the discussion away from the negative portrayal of disability as individual (bodily) deficiency and the cause of the problem of exclusion and burden on society, but instead to the barriers in society as the real cause that needs fixing. This allowed them to make the main focus of the Snapshot not on the 'problem' but on the positive attribute of accessibility and its value to the whole society. This way, the 'blame' did not fall on neither this community nor the audience, but only on the external, and systemic, 'barriers in society'. This then enabled both parties to be part of the positive

\footnotetext{
${ }^{135}$ The name of the "Independent Living movement" conveys a direct opposite of the dominant frame about people with disabilities as 'dependent'.
} 
solution, allowing all of 'us' to claim only the positive attributes of accessibility as shared societal good for everyone (Interview: a). In addition, this Workgroup avoided the risks associated with a radical frame: that is, by not naming the dominant frame, it bypassed the need to directly oppose it or the potential f reinforcing it, while still managing to tacitly challenge it.

This was not without struggles or compromise on the part of the Workgroup members, however. The coalition- and the partnership scale priorities to make this tool a simple, practical, educational and user-friendly tool, and to follow the shared format of the Snapshots in doing so, meant that this Workgroup had to work with 'labels' and 'definitions' about disabilities, and also introduce 'negative' content on the barriers and inequities affecting this community. The Workgroup members saw that both of these had the potential to reinforce the dominant frame, and that this ran counter to their main movement-specific objective for this Snapshot. Although this Workgroup had to make these compromises to conform to the shared strategic priorities at the coalition and the partnership scales, overall they were still able to come up with the Snapshot that generally reflected their chosen or preferred content and framing strategy.

This was because many other key factors contributed to this Workgroup's ability to formulate a transformative frame to achieve the movement goals, while keeping in line with the higher-scale priorities of the coalition and the partnership. For example, this Workgroup featured a high number of Reference Group members of the E\&I Lens, who had keen strategic awareness of the need to balance the competing priorities of the needs of the community on the one hand, and the needs of the audience as the intended users of this tool. Many of the community and the City members, especially the two co-leads from 
both sides, shared strong personal affiliation with - and commitment to - the Independent Living and the Disability Rights movements. This in turn allowed the Workgroup to draw extensively on established and shared movement frames. These movement frames also incorporated master frames such as equality frame and rights frame (in particular human rights frame and consumer rights frame) that Benford and Snow identified (2000). This further helped validate their case for treating members of this community equally with the same respect and dignity as everyone else in the city, thus increasing resonance.

In addition, the official frames and the institutional framework of the City, in particular the Accessibility Office and the provincial legislation AODA, aligned well with the movement frame. These official frames themselves offered a transformative frame for the Workgroup to draw on, which had reframed the focus of the issue and the solution in terms of accessibility and barriers, and not about disabilities per se. This in turn meant that the shared discursive strategy to 'tie in' and 'align' the coalition and the partnership frames with the existing institutional framework of the City and beyond worked well to support the movement-specific frame of this Workgroup. Indeed, this also meant that the Workgroup benefited from the strategic advantage of the City-community partnership particularly well, thanks to the strong relationships between the community movement and the City ally members. They also benefited from the fact that these ally members' institutional position within the City (i.e., Accessibility Office), whose official mandate was to promote accessibility across the City of Ottawa. That is, challenging and changing the status quo was in fact an important part of their job responsibility. 


\subsection{GLBT Snapshot Workgroup Subcase}

\subsubsection{Key Message}

We are fabulous! We are gay, lesbian, bi-sexual, trans and two-spirited. We are parents, grandparents, professionals, workers and students. We are part of every aspect of our city, contributing every day - even if you may not know it (CAWI and City of Ottawa 2010d: 2).

What stands out in the opening lines of the GLBT Snapshot is the humour and the lighthearted tone that plays on (and, in a sense, reclaims) a common stereotype of gay men in popular culture. This is unlike any other Snapshot in that it dares to be funny and even silly at the outset (or for that matter, anywhere in the document). It is followed by an upfront expression of the diversity and multiplicity within this 'we' that quickly clarifies some of the subgroups captured in the umbrella term "GLBT". However, it immediately connects them to a much wider range of social roles that 'we' takes on in families, workplaces, schools and communities. This is not an innocent or weightless statement, however, as it is a subtle but poignant jab at the dominant assumption of who belongs in these heteronormative spaces, making visible their invisible exclusion in everyday spaces.

The first part of the text in the section "Who We Are" elaborates on the opening lines. Here, the idea of multiplicity within the community, and the centrality of each individual's preference, set the ground for this Snapshot's transformative frame. The first paragraph is all about the fact that 'GLBT' community is made up of very many and very different sub-communities, which are not at all homogeneous. Rather than presenting a series of categories to describe each subgroup that makes up the GLBT community, the Snapshot presents this information solely in terms of how individuals within each of these 
sub-communities self-identify. ${ }^{136}$ The second paragraph then refers to the common statistic "one in ten" to show that people attracted to people of the same sex is much more common than many expect. This is quickly followed up by an educational message that accurate statistics are difficult to gather because "people's sexuality evolves over time" (thus rejecting being fixed into a rigid category or label), and because individuals "selfidentify differently", and importantly, because "we are careful when... coming out" for fear of alienation and real threat of violence. And this, in turn, is only necessitated by the existence of homophobia and transphobia in society (CAWI and City of Ottawa 2010d: 3).

The third paragraph then provides a waiver on the evolving nature of language. This explains upfront that terms used to describe a group will inevitably change over time, and there will never be a singular agreement on them, for individuals will always self-identify differently, and what makes up a community will also change. This Snapshot thus acknowledges the existence of the lively - and at times contentious - debates within this community over names, terms and acronyms, all while deflating the tension surrounding it as well as the potential nervousness over 'politically correct' language on the part of the audience. ${ }^{137}$ However, this section brings home the key message that what is most important amidst all this confusing language change, and all kinds of sexual and gender identities and expressions, is the respect for each person's dignity and choice (CAWI and City of Ottawa 2010d: 3).

\footnotetext{
${ }^{136}$ The text reads: "Some of us are working people, parents, grandparents or youth. Some of us identify as women, as men, as both, and some of us identify as neither. Some of us are Aboriginal and may identify as "two-spirit". As two-spirit people, we like to define ourselves and we don't want to give up any aspect of who we are to do that (2-Spirited People of the 1st Nations 2008)" (City of Ottawa and CAWI 2010d: 3).

${ }^{137}$ This waiver reads as follows: "In this document, we use the acronym "GLBT" as in the City of Ottawa's Equity and Diversity Policy. However, we recognize the ongoing lively debates about definitions within the GLBT communities - terms and their meanings change over time, or vary across cultures or generations" (City of Ottawa and CAWI 2010d: 3, bold in original).
} 
Unlike all the other Snapshots, the GLBT Snapshot features two additional subsections entitled "Respectful language" and "Trans people" within "Who We Are". Also unlike other Snapshots, these subsections also appear in the table of contents, which further serves to draw the readers' attention to them (CAWI and City of Ottawa 2010d: 24). "Respectful language" is presented as a side bar on the first page of the text, which explains to the audience that this 'fuss' over language, as manifested in the seemingly ever-increasing number of letters added to their acronym "reflects our diversity and efforts to celebrate many forms of sexual orientation and gender identities as part of human diversity" (ibid 3). This segment captures the key themes in their message in several simple sentences: multiplicity within this community, the importance of acknowledging it through changing language, and the simple principle of respect for each person as the most important value underlying all this fuss ${ }^{138}-$ a value everyone in the audience should be able to relate to, queer or straight.

The second page of "Who We Are" is entirely dedicated to the other subsection "Trans people". ${ }^{139}$ It opens with an explicit acknowledgement about the specific experiences pertaining to the ' $\mathrm{T}$ ' portion that is very different from the 'GLB' part of this internally diverse community. However, it still builds on the same key messages about

\footnotetext{
${ }^{138}$ The full text of the "Respectful Language" subsection reads as follows: "You may have come across the variations of "GLBTTTIQQ" (gay, lesbian, bisexual, transgender, transsexual, two-spirited, intersex, queer, questioning), such as LGBT or GLBTTQ. // Language is important to us because it is about our sense of respect for each other, and we do not necessarily all want to be lumped together. // This reflects our diversity and efforts to celebrate many forms of sexual orientation and gender identities as part of human diversity. // We welcome you to use the terms in this document - but also to be aware of the changing, dynamic debates around language, and that some people may prefer one expression to another. If you are not sure, ask: "How would you like to be addressed?" (City of Ottawa and CAWI 2010d: 3, bold in original).

${ }^{139}$ Out of the eleven Snapshots, "GLBT" and "People living in Poverty" are the only two (2) whose section on "Who We Are" substantively takes up the second page, and the former is the only one that uses up the whole two pages on this. People living in Poverty's includes a chart on income levels as well as a paragraph dedicated to acknowledging the ongoing debates on how to define poverty, and this waiver on definitions was in fact taken from the initial innovation by the GLBT Workgroup (City of Ottawa and CAWI 2010d; 2010f:4).
} 
the importance of respecting individual self-identity amid the vast diversity of gender identities. Again, an upfront waiver is provided on the use of the term "Trans" as a "broad umbrella term" that contains lively debates and disagreements over its meaning by members of this community. A short explanation on the difference between "sexual orientation" and "gender identity" is also provided in a separate text box at the bottom of the page (ibid 4). In addition, there is another side bar containing practical tips for the readers called "Working with trans people - What can I do?", taken from Ottawa Police Service GLBT Liaison Committee's report. These tips reinforce the principle of respect for the person's expressed preference and/or decision as to how they self-identify, and/or whether they are "out" or not, in a particular social situation. These text boxes and side bar are included here so as not to leave the audience confused or nervous about not knowing what to do with the complex and nuanced information about this community of people, which the Workgroup anticipated to be new to them.

Like the People with disabilities Snapshot, the GLBT document refuses to use a fixed and homogeneous label to define this community's identity, even though it was the title of their document. The text asserts unambiguously that the cause of their exclusion is found in society at large in the form of homophobia and transphobia, and most certainly not the inherent nature of their identity. For example, the very first barrier named in the "Barriers and inequities" section is "Homophobia", declaring in its first sentence that "Almost all barriers GLBT people face come from the assumption that everyone is straight (heterosexism) and dislike of homosexual people (homophobia) in society" (ibid 6). ${ }^{140}$ This is followed immediately by the second barrier "Transphobia", which explains

\footnotetext{
${ }^{140}$ It should be noted that biphobia does not receive much attention in the main text, but briefly appears in the "Definitions" section at the end of the document, where it is presented as: "The irrational hatred and/or
} 
that this is commonly confused with homophobia. It adds that such confusion nonetheless causes harm to those who identify as or are perceived to be trans, due to the compounding effects of "sexism and gender stereotypes" on top of transphobia and homophobia (ibid). These first two barriers thus frame the rest of the discussion in this section to stem from these two different, but related, dominant attitudes/ideologies in society.

The cause of the social problem and a solution is thus subverted in this frame: it is not because these people are gay, lesbian, bisexual or trans that they experience barriers, but it is because society is homophobic and transphobic and is founded upon the heterosexist, patriarchal and cisgender (non-trans) norms that remain unquestioned. This is a strong, radical frame that directly confronts the dominant frame. And yet, this Snapshot weaves the grave and the playful back and forth, lightening up the tone while reinforcing the same core message. For instance, the following section "We envision...a GLBT-friendly city" concludes with one solution to this reframed social problem: "the cure for homophobia is discovered" (ibid 11). ${ }^{141}$ This combines social critique with humour by inverting the dominant frame that presents homo/bisexuality or trans identity

fear of those people who love and have intimate relationships with people of both sexes. The discrimination that bisexual people face is different from those of lesbians and gays. Bisexuality is often seen as a phase or process of experimentation only, thus a person can be only gay or heterosexual but never both. Bisexual people are often pressured to "choose a sexuality" (City of Ottawa and CAWI 2010d: 14). While this makes a strong statement about biphobia, the fact it is left out of the main text may be a causality of not having direct representation at the Workgroup table, especially when it has to be cut down, reduced, simplified. Incidentally, the fact that bisexual people are "pressured to choose a sexuality" does not align with the 'choice' frame used in the main text of this Snapshot.

${ }^{141}$ This line was taken from Canadian Auto Workers' Union's educational material on LGBTQ rights entitled "To our allies: Everything you ever wanted to know about Lesbian, Gay, Bisexual, and Trans issues...Well, maybe not everything...." The casual, slightly humorous tone is also found in this source, from which the Workgroup drew on. 
as a disorder or deviance that need to be cured - and asserts back instead that it is the straight people's fear and hatred of these that is in need of a cure. ${ }^{142}$

\subsubsection{Key Debates and Discussions at the Workgroup}

\subsubsection{Definitions and the Language Debate within the Community}

While the interviewees from the GLBT Workgroup $^{143}$ did not recall a heated

debate in their group, they all recalled the same topics of discussion. One of these debates

was on how to use definitions in this document and whose definitions to use in presenting

the name of this community. This is a big sticking point for this community - "the

elephant in the room" in as one member put it - as it is under constant, heated debate

within the broader gay, lesbian, bisexual, trans, two-spirit, intersex, queer, and

questioning communities (Interviews: j, 1). In a movement of people whose identity -

whether on the basis of sexual orientation, gender, gender identity, and/or sex - does not

conform to the dominant norms of society, being able to define oneself with dignity, and

not being excluded or oppressed because of it carries immense political and personal

\footnotetext{
${ }^{142}$ The community member highlights this as an important point in the Snapshot "because most people reading that would say 'Oh homophobia doesn't need curing, homosexuals do'” (Interview: 1).

${ }^{143}$ This Workgroup featured a lead member from the Reference Group, who dually represented the community and the City-affiliated institution, the Ottawa Police Service (OPS). Another staff member from OPS (Coordinator of OPS GLBT Liaison Committee) participated in the Workgroup as well as in the Reference Group. One community member (who also belonged to a national labour union) and one Advisory Committee liaison from Equity and Diversity Advisory Committee (EDAC) participated in the face-to-face Workgroup meetings. In addition to this small core group who met in person, this Workgroup featured other community members who provided feedback and input remotely. One of these contributors was initially a Reference Group member until he had to move out of Ottawa and be replaced by the OPS lead. This member provided the content of the initial "Questionnaire" that formed the basis of the Snapshot, and contributed feedback on the Snapshot via the OPS lead towards the end of the process, especially on the experience of "racialized" members of the community. Another community member provided input on the indigenous and two-spirit component of this Snapshot by email and phone directly to the writer, and another community member (who also belonged to CAWI) contributed feedback, especially from the perspective of GLBT people with disabilities. The core members also sought feedback from other leaders in the local community(ies) on the later drafts. In this sense, while this Workgroup was rather small in size, it indirectly featured a high level of 'intersectional representation' of the GLBT community in its membership. The project lead of the E\&I Lens development (manager of Diversity and Employment Equity) and the other City key coordinator of the Lens also participated in this Workgroup, mostly in an observing role, as this community was one of the designated groups in EEA and EDP, and part of EDAC's mandate.
} 
significance. And of course, omitting one letter from the long list can be particularly hurtful to those who also seek recognition and inclusion of their identity within this movement.

The interviewees explained that this is significant given the historical evolution of their movement's own boundary and mandate. It had initially started with a single subcommunity specific to gay men fighting for gay rights, but has since expanded gradually, over time, to include more and more of the sub-communities such as lesbian women, bisexual people, and more recently trans people, to form the basis of what can be broadly termed Queer rights movement. The name of the community has taken on an acronym that has increased its component letters over time, from G, to GL, to GLB, to GLBT, to GLBTQ, to GBLTQI, to GLBTQQI, and many other variations of it (and many starting with "L" to signal a feminist stance). And today this broad umbrella community includes very diverse sub-communities, whose boundaries and meanings are constantly being debated and evolving as a result of it. The same trend is evident in Ottawa's local history of this community as the two members of the Workgroup recall, starting with Gays of Ottawa, then changing to Association of Lesbians and Gays of Ottawa after lesbian women challenged its male-dominated and patriarchal focus, then to "Association of Lesbians and Gays and Bisexuals of Ottawa" (Interviews: j, 1).

However, as all three members explained, this evolution has in no way been an automatic process for their movement, for these debates have been accompanied by tensions based on the different grounds of identity and exclusion covered in this "alphabet soup" coalition of a movement (Interview: 1). For example, one member remembers the lengthy internal discussions, resistance and struggles every time the 
community voted on whether or not to 'add a letter' to their community organization's mandate. He speaks of a particularly strong resistance when the community voted to include "bisexual" to the mandate of Pink Triangle Services (PTS), and more recently "trans" before it was finally approved (Interview: j). ${ }^{144}$ Another member also explains that in her home town Vancouver, the contentious human rights case involving a trans woman Kimberly Nixon has had a particularly divisive effect on the Violence Against Women community, as "trans rights" and "women's rights" were pitted against one another if falsely, with women's groups necessarily siding with opposing camps of the debate (Interview: v). Another community member also adds that the broad term "Queer" is increasingly used as a reclaimed term that embraces the diverse segments of this community without getting caught up in the language debate. He points out also, however, that this term evokes very painful memories of persecution for the older generation, making it difficult for them to relate to it (Interview: 1).

\subsubsection{Trans Representation}

In addition to definitions and language, the GLBT Workgroup also discussed how to present the 'Trans' piece in the Snapshot in particular, given the context of this intramovement diversity, and also of internal tension and hierarchy flowing from it. The lead member admits that while much progress has been made for gays, lesbians and bisexual people over the years, the benefits of this have not translated into advancement of trans rights per se (e.g., the inclusion of sexual orientation as a human rights ground and

\footnotetext{
${ }^{144}$ This member's full quote reads as follows: “...Again I go back to Ottawa gay politics where they changed the name from "Gays of Ottawa" to "Association of Lesbians and Gays of Ottawa" to "Association of Lesbians and Gays and Bisexuals of Ottawa", so it went from GO to ALGO to ALGBO. And every step of the way I remember voting and moving motions, and Pink Triangle Services AGMs about including 'Bisexuals' because there's been a lot of resistance to that. I was part of the support for the whole effort of adding "Trans" to the Pink Triangle Services mandate through a very good friend of mine... But it isn't through a process that's easy. It's through some real struggle within the community" (Interview: j).
} 
legalization of same sex marriage). ${ }^{145}$ Trans activists have been pushing for rights on the basis of gender identity and expression, though not necessarily sexual orientation, as many trans-identified activists are heterosexual themselves. As this member points out, many of the trans activists have indeed supported the struggles of lesbians, gays, bisexual people as their "allies". However, the same has not been reciprocated by gay, lesbian and bisexual people in support of trans rights as many of them are cisgender themselves and do not necessarily share the same understanding of or concerns over trans issues (Interview: j). ${ }^{146}$ Put bluntly, as one of the newer additions to this broad, internally intersectional movement, the struggles of trans people have historically lagged behind within this community (ibid).

It was thus important for this Workgroup to dedicate significant attention to trans issues in the Snapshot. As one Workgroup member states, "there was not even a question about it" as the Workgroup showed strong support and understanding for trans issues every time she raised it (Interview: v). This was especially important for this member who participated in the Workgroup as an "ally" for trans rights. However, not being trans herself, she was very concerned by the lack of direct representation of trans people or the "real trans voice" at the table (ibid). This concern was in part warranted, as another member commented in his interview, "because who comes to the table and speaks helps set the agenda" at community discussions. ${ }^{147}$ Based on his experience at the GLBT Liaison Committee of the Ottawa Police Service, lack of trans presence does create this

\footnotetext{
${ }^{145}$ At the time of the development of this Snapshot, "gender identity" or "gender expression" was not yet part of the protected grounds under Ontario Human Rights Code, though it has been so recognized since 2012 (OHRC 2013, n.d.a, n.d.b).

${ }^{146}$ As one member points out, "If you're a hardcore gay or lesbian you'd say 'Trans is trans. They should have their own booklet. They shouldn't be taking up space in ours"” (Interview: $\mathrm{j}$ ).

${ }^{147}$ Ironically, such unintended exclusion arising from lack of direct representation took the form of "biphobia" appearing only in the "Definitions" section.
} 
issue. When discussions on trans issues do occur, they often take a lot of meeting time partly because this is least understood of the four groups included in their mandate, and partly because its unique issues and its intersections with sexual orientation, gender and gender identity make "people's heads explode" (Interview: $\mathrm{j}$ ). This in turn gave the lead member an understanding of the need for - and the value of - having cross-issue discussions at the GLBT Liaison Committee. As a result, the trans ally member was pleasantly surprised by how "progressive" the police were on this matter (Interview: v).

\subsubsection{Key Factors}

\subsubsection{A Safe, Open, and Welcoming Space}

While these were serious topics of discussion, the interviewees recall being part of a particularly "safe" and "welcoming" atmosphere, in which these discussions took place (Interviews: $\mathrm{j}, 1, \mathrm{v}$ ). One community member described it felt like "getting together and chatting over a cup of coffee" (Interview: 1). Another member emphasized that it was "not simply safe but actively welcoming" for the members to share their perspectives "at any level" (Interview: v). That is, one could share intimate personal life experiences as easily as a pointed critique at policy or structural level, or share expertise from their professional and/or activist lives, which made participation particularly easy for everyone. Similarly, the City lead member also recalls that it was "a rare safe space" where he could be "out" and participate fully and personally "as a gay man" without fear of repercussions, and not having to limit his role strictly to his public and professional aspects of himself (Interview: j). ${ }^{148}$ This seems to have had a positive feedback effect on the other members and this relaxed atmosphere. One community member remembers

\footnotetext{
${ }^{148}$ As this member admitted, it was not always safe to be openly "out" within the institutional cultural context of the police force even as his portfolio was to increase the police's responsiveness to the safety needs of Ottawa's GLBT community.
} 
being quite surprised in a positive way how "out" the City member was at this table, especially given his official role within the police. She found this to be significantly more progressive as an institution than she had expected, which further encouraged her to feel safe to participate in frank discussions.

The interviewees also commented that they felt that their Workgroup was united around a "common goal" to complete this Snapshot that would educate the readers about this community in ways that would break down stereotypes (Interviews: $1, j, \mathrm{v}$ ). The group shared a common purpose not only in terms of the end product but also of the process, in which the group was able to "make sure everyone feels heard", and see "everyone's voices reflected in each draft" (though "not in an egotistical or narcissistic sense" as one member explained) (Interview: 1). One community member in particular speaks about the importance of interpersonal dynamics based on a shared goal, in which "people can set aside personal politics" and "personal agendas" that lead to "competing interests" in the room, which he truly felt this group had.

That whole Snapshot could've been all shot to pieces with one wrong head in that room. Somebody who was in there to prove a point or [they have] power could have sidetracked that whole process or delayed it, or made it much more difficult and a chore. This didn't feel like a chore. This felt like a community contribution" (Interview: 1). ${ }^{149}$

Similarly, the other interviewees also commented on a pleasant surprise they felt in this particularly open, collaborative and comfortable atmosphere at this Workgroup, where

\footnotetext{
${ }^{149}$ This community member elaborated on the dynamics of this Workgroup as follows: "That was the nice thing about the group that we more or less had a common interest in the success of the document that we were able to put away personal politics. Because any time I'm in a community organization, I tell the people I'm working with to 'leave their tiaras at the door'... And everyone coming through the door should be equal, and have an opinion, and be heard. And the objective of holding a successful meeting is making sure that everybody feels that they've been heard, and to give everyone an opportunity. So you can't have competing interests. And I didn't find that at all with anyone working on the Snapshot. I didn't feel like there were personal agendas. The people around the table I thought were all there for the common goal of getting this Snapshot written... to dispel the stereotypes and inform [the readers] who our community is... I really felt that around the table was a similar goal, which is why I think that the meeting went so well and was so comfortable and they all contribute" (Interview: 1).
} 
they "looked forward to going" and definitely "did not dread it" as a potentially tense or uncomfortable encounter (Interviews: j, v).

\subsubsection{Internal Discussion and Strategic Framing for the External Audience}

This safe space internal to the members of this community movement in turn allowed this Workgroup to have a frank discussion to name the core issues driving the exclusion of this community. As the members explained, confronting these uncomfortable issues was absolutely important for this Snapshot to do, because otherwise they would defeat the very objective of their Snapshot: to educate and break down the dominant attitudes and stereotypes about this community. In fact, one member stated that he was not at all willing to "sugar coat the issues" because "that would have been as deceitful as their stereotypes about us, and would have been feeding into that". ${ }^{150}$

Similarly, the lead member was also proud of the fact that "We didn't shy away from some of the tough issues" (Interview: $\mathrm{j}$ ). The result is a direct discussion on "the tough issues" such as homophobia and transphobia as the underlying cause of all barriers and inequities affecting this community, as well as other internal exclusions such as racism and sexism within this community. This Workgroup thus chose to directly confront the dominant attitude in the Snapshot, rather than avoid it to cater to the perspective of the non-GLBT and non-ally members of the dominant group. ${ }^{151}$ As one member proudly explains, this enabled them to "not shy away from the tough issues"

\footnotetext{
${ }^{150}$ This member adds: “Again the intention was to reduce stereotypes and be informative. So I didn't sugar coat the issues at all. That would have been as deceitful as their stereotypes about us, and would have been feeding into that. And the whole objective of this document was to be truthful and educating about our community, to break down stereotypes. I just wished for the audience to learn something about us, not the stereotypes...Besides I'm getting old. I don't have time to waste. Life is too short for that!" (Interview: 1)

${ }^{151}$ The lead member explained: "We did it in a way that confronted the common responses we get, like 'Well just keep it to yourself'. 'It's not an issue - it's just statistics.' 'Why is that relevant?' 'I don't tell anyone I'm straight - why do you have to tell me you're gay?' 'Why do you need a parade?', 'Why Pride?'... Or even in terms of 'That's political, why are we involved in it?' All of that'.
} 
such as homophobia and transphobia on the part of the dominant society, as well as the internal tensions in the community as ostensibly manifested in the language debate, or internal exclusions such as racism, transphobia, and to a lesser extent, biphobia (Interview: j).

At the same time, the Workgroup members also shared a strategic understanding of the anticipated audience response to such direct confrontation on tough issues, such as dismissal, criticism, defensiveness, fear, and ignorance. In other words, they viewed the target audience in the City as external to their movement, and not (yet) "proven" to be their committed allies (Interview: j). The Workgroup members thus made a very conscious and strategic distinction between the internal debates that needed to occur (only) among themselves, and what information should be conveyed to the external audience and how. This strategic distinction in turn enabled the Workgroup to further develop their collective decision on the discursive strategies to ensure that they do not sacrifice their core message, while not alienating the target audience. In short, the Workgroup made a strategic distinction between radicalism they could not compromise on and resonance with the audience as they deliberated on how to frame their Snapshot for their audience.

This is how this Workgroup came up with various tension-deflating discursive tactics to pre-empt, counter, bypass, deflate or deflect the "tension, fear, and trepidation" that their radical message was likely to trigger on the part of the audience (Interview: $\mathrm{j}$ ). These tactics include the intentional use of humour, as well as an upfront waiver on the use of language before moving on to the more serious and potentially uncomfortable issues. For example, they decided to open the Snapshot with "We are fabulous!", to let 
the audience's guard down and to lighten up the tone of the discussion. As the lead member explained, "We need to invite people who otherwise would be scared or reluctant or hesitant to engage in this stuff. It might at least give them a bit of 'Oh what? Oh okay, what else does it say?" (Interview: j).

This humour tactic had an additional subversive element to it as well, for it appropriated the dominant stereotype about "flippant" gay men (Interview: j). By using this in a positive way, it helped counter the negative feelings of fear, hatred or disgust the audience may feel towards the GLBT people because of their homo-/bi-/transphobias, and/or reduce the fear and confusion they may have about the language about this community. Instead, the Workgroup sought to signal to the audience that "we" are not scary, but also that the audience need not be uptight about the language.

Obviously we always worried about whether it would in some way denigrate or make us seem flippant... But I certainly remember wanting to convey to people who may be terrified about gay and lesbian issues, that actually we don't mind 'having the piss taken out of us', that we are actually pretty good at joking and pretty good at taking a situation and de-escalating it by going from outrage to outrageous (Interview: $\mathrm{j}$ ).

This member thus explains that he wanted to convey to the audience that "we are screwed up about [the debate] ourselves and it's ok" and that this community is quite capable of laughing it away (ibid).

These discursive tactics were also informed by other strategic considerations. For example, the Workgroup decided to present the subsection 'Respectful Language' "right up front on the very first page" (Interview: 1). This was because the Workgroup knew that the never-ending debate on acronyms

is one of the first things that people would look at and pick apart. If we don't address it, it gives them the excuse not to read the rest of the document, saying 'Well if they can't even agree on the name, why should I read their document? (Interview: 1) 
Moreover, the Workgroup was also aware of the audience's discomfort with not knowing what they should say or do given this confusing debate. As one member noted, "people have a problem with things they don't understand, and a lot of the times people are shy to ask because they don't want to feel stupid. But this document made it okay not to know something" (Interview: 1). These discursive tactics thus gave the audience a 'permission' not to know the right answer all the time, whether it was how to refer to this community, how to call someone from this community, or how to interact with trans people.

At the same time, however, the Workgroup was also concerned that if they were not careful in how they present the internal struggles of their movement, the external audience may want to "exploit" these internal divisions "to our detriment". ${ }^{152}$ This was another strategic reason why they decided to present the ever-changing language solely in positive light in this Snapshot, by framing it in terms of their community's commitment and ability to celebrate its own internal diversity, rather than draw attention to its internal tensions. This positive framing in turn allowed the Workgroup to move on to the more uncomfortable and ugly truths about homo-/bi-/trans phobias in the "Barriers and inequities" section, which the audience might not want to hear otherwise.

Moreover, the GLBT community's self-admission of their own internalized homo-/bi-transphobias and racism and sexism against each other within this community had an additional positive - and subversive - framing effect for the Workgroup. It served

${ }^{152}$ The lead member finds it funny and ironic that "when the City wants to put together a little Lens [about us], in fact they have no clue how much struggle it has even for all of us to be in the same room. So I laugh when I think about it. And it's funny because when I am sitting at my professional tables, people talk about the LGBT community with a combination of awe, reverence, and disdain all in one. They ascribe an amount of unity and cohesion to 'those people' as they call us that is so well beyond what's true in the experience" (Interview: j). That said, he also adds that "we've had these private discussions where we in fact say that it's a good thing that they don't see our internal challenges, because they might want to exploit them to our detriment" (ibid). Here, again, 'we' is used to refer to those internal to this community and/or the movement, and "they" to refer to those external to it, i.e., City representatives. 
to offer a 'safe space' to the target audience to 'come out' with their phobias without the fear of being judged or shamed as the (only) oppressor in the room. This subverts the normal roles and power relations between the marginalized and the dominant groups, in which the marginalized GLBT community would normally demand a 'safe space' from the dominant straight society. Here instead, it is the GLBT community offering it to straight people to reflect on their own phobias about this community. At the same time, this also bridges the confrontational divide between the 'GLBT community' and 'the (homo-/bi-/trans phobic) audience' implied in their radical and otherwise 'oppositional' frame, hence still manages to maintain resonance.

\subsubsection{Shared Movement Affiliation}

One of the important factors that shaped the development of this Snapshot was the members' strong affiliation with broader Queer rights movement, made up of many submovements, which informed their approach to this Workgroup, as well as their strategic decisions in shaping this document. The lead member has been part of the gay rights movement, human rights movement and anti-hate crime activism, and the community member and Advisory Committee liaison has been active in the gay rights movement and HIV/AIDS activism. ${ }^{153}$ While the community of (white) gay men has been the entry point into what has become a cross-identity movement, they are both proud of the expansion of their community/movement over the years. Another community member identified with the LGBTQ, feminist, and labour movements as equally important to who she is and the work she does, and her work as an ally with trans people has been very important to her. In addition, yet another community member contributed the knowledge of the Two-Spirit

\footnotetext{
${ }^{153}$ This member noted in the interview: "I've been doing gay rights stuff since the $80 \mathrm{~s} .$. As a gay man... I totally come out of that $80 \mathrm{~s}-90$ s activist mentality" (Interview: $\mathrm{j}$ ).
} 
movement, and the initial community lead member had highlighted the experience of racialized members of this community at the Reference Group Orientation at the beginning of the project. ${ }^{154}$ Furthermore, as one of the community members added, his colleague had been vocal about Francophone and disability rights within the Ottawa's LGBTQ community, and this person also provided feedback on this Snapshot to check for these specific perspectives. ${ }^{155}$

The Workgroup members' previous experiences in various aspects of this very dynamic cross-identity, cross-issue, and cross-movement coalition, and in confronting the realities of exclusion on multiple fronts many times over, provided them with several critical insights. First, the basis for this broad movement is quite intersectional, as the basis of exclusion was different for each of these sub-communities, and so was their embodied experience of it and their political priorities. However, they have had to find ways to work with - and for - each other. ${ }^{156}$ In fact, this put them face to face with the danger of 'identity politics gone wrong' that can erupt in anger, resentment, exclusion, and competition among sub-communities, and ultimately lead to the dissolution of a

\footnotetext{
${ }^{154}$ As noted earlier, the report from this Reference Group Orientation subsequently formed the basis of the GLBT Snapshot as it did for all other ones.

${ }^{155}$ In fact, this person had also been an active member of CAWI especially during its early years.

${ }^{156}$ Gays, lesbians, bisexual activists have pushed for equality of rights based on sexual orientation, but within that movement feminists (primarily women) pushed back against patriarchy for gender equality, while they stood in solidarity with gay men to advance their common cause. As discussed above, there are differences and tension between trans and non-trans groups within the broader movement, and another Workgroup member noted that the struggles of intersex activists are also quite different from the rest of the movement (Interview: 1). In addition, while contemporary Two-spirited activists may identity to be part of the broader Queer community, many also reject the Western gender and sexuality norms imposed on them through colonization and reclaim their own traditional cultural values and practices that embrace a much broader range of gender roles/identities and sexual orientation. In fact, one Workgroup member emphasized that "two-spirit" is a contemporary urban terminology, for it was created "during the Third Annual Intertribal Native American, First Nations, Gay and Lesbian American Conference" held in Winnipeg in 1990 (Centre for Addiction and Mental Health 2011).
} 
movement, as it happened in the case of the Queer Nation Ottawa. ${ }^{157}$ This also meant the danger of such internal divisions being used against them by dominant groups in society to pit one subgroup against one another, undermining the solidarity of these allies to advance their movements' goals.

However, this broad movement has developed a strong tradition of working as allies in each other's struggles, opening up the possibilities for people to work across identity categories and positions of privilege and marginalization on different bases of exclusion. That is, one's support for a population-based cause does not need to be restricted by one's own identity category - offering a basis for an intersectional solidarity by linking marginalized sub-communities with each other, as well as marginalized with dominant groups. One member has learned from this experience, and embraces the importance of tackling racism and sexism within their own community. ${ }^{158}$ Similarly, another member remains a very strong and vocal ally for trans rights, even as she believes in the fundamental inability for her to "speak for others" (Interviews: j, v). Furthermore, the fact that the open-ended debates to redefine who makes up and belongs in this community, and what cause its movement stands for, has created a movement culture and discourse that allow its members to critique their experiences of exclusion or invisibility within it. This equipped the Workgroup members with more comfort and available

\footnotetext{
${ }^{157}$ Warner (2002) writes about the brief emergence and collapse of the Queer Nation movement that started in New York, then also spread to Canadian cities in the 1990s, in which the lead member took part in its Ottawa body. While this 'nation' "had started as an inclusive, high-energy movement of feminists, AIDS activists, anti-racists, peace advocates, and other social activists" (260). As Hayashi (1992) documents, its racialized members felt increasingly alienated as it "progressively became mired in factionalizing, splintering and drawing of lines" between subgroups and identity labels (14). Indeed, Warner notes that Queer Nation Ottawa in particular was "roundly criticized for not dealing with racism", and concludes that "like queer nation groups elsewhere, Queer Nation Ottawa quickly... dwindled and died" (2002: 260-1). 158 "We tackle sexism and racism [in the Snapshot] which for me are important - because they are important within the community. You can talk to many racialized queer people who do not have a great time in the mainstream gay community because of racism" (Interview: $\mathrm{j}$ ).
} 
discourse to talk about these tough issues involving intra-movement differences, tensions, conflicting interests, and inequalities among themselves. This in turn prepared them for the task to create this Snapshot as part of the intersectional Lens, for these are all indeed an important part of striving to create equity out of the existing reality of inequity.

\subsubsection{Discursive Strategic Repertoire of Affiliated Movements}

This Workgroup was also able to draw on a greater range and number of social movement frames, ranging from radical to resonant to transformative. For example, the lead member explained that the strategic combination of humour with a strong - or even radical - political message has been an important aspect of the history of queer activism, in particular of gay and lesbian protests. ${ }^{159}$ Some of these discursive tactics used in the Snapshots are found in these movement discourses. For example, the original Queer Nation Manifesto from New York City ${ }^{160}$ conveys a very radical, oppositional, and militant message, calling for a revolution by "Queers" against straights to reclaim their rights by force. Yet, this anger is interwoven with black humour throughout as it gets at the blunt truth about the oppression of this community by straights. ${ }^{161}$

\footnotetext{
${ }^{159}$ The lead member gives the examples of "a protest in Ottawa where a gay man would dress up in drag and protest in high heels. That's certainly not threatening. Some would think it was demeaning. But there is a whole other aspect of gay and lesbian protests that does this", and names the Queer Nation, and the use of "die-ins" (instead of sit-ins) by AIDS Action Now and Act UP to protest the government inaction on the epidemic.

${ }^{160}$ This Manifesto was distributed as a leaflet at the New York Gay Pride Day parade in June 1990 in conjunction with ACT UP (Aids Coalition to Unleash Power). Act UP describes itself as "a diverse, nonpartisan group of individuals united in anger and committed to direct action to end the AIDS crisis...WE ARE NOT SILENT... Disseminate information! Agitate! Resist!". Their slogan "Silence = Death" carries an extreme urgency (ACT UP n.d.). The lead member references this idea as a reason why his community cannot afford to sell themselves short in its activist work, because the result of that is death, as seen in the HIV/AIDS disproportionally affecting the gay community in the 1980s and 90s (Interview: j).

${ }^{161}$ The Manifesto mocks the oppressive discourses and practices of straight people by turning it upside down, for example by calling for "hate" toward straight people as their enemy oppressors, and demanding a "moratorium on straight marriage" or "public display of affection". It also mocks to offend the dominant sexual morality through its uncensored use of lewd, sexual swear words and other taboos, and by claiming their presence as a consistent part of humanity and human history, regardless of whether this offends their morality or not. And at the same time, it humorously mocks this militant stance itself by declaring that "An
} 
Likewise, the upfront waiver on the use of a controversial term to refer to their own community in part derived from a similar discursive repertoire used in the Queer Manifesto. This Manifesto is where they started to reclaim the thus far derogatory term "Queer", even as they acknowledged that it may still be received negatively by some members of its own community. The intended result was to grab the audience's attention, make a political point without escalating the tension or violence. And yet it never diminishes or shies away from naming the severity of the issue they are trying to address, such as the social, psychological, physical violence brought against members of this community, and even death, resulting from assaults or from the HIV/AIDS epidemic to which governments had long turned a blind eye. This was indeed just like what this Snapshot did.

Another example of discursive resources that combines humour with a political message that the Workgroup drew from an established movement is the booklet by Canadian Auto Workers Union, as recommended to the Workgroup by one of the community members. This humorously plays on the dominant society's phobia about the queer people and their sexual practices to lure the readers in, as the title reads "Everything You Ever Wanted to Know about Lesbian, Gay, Bisexual, and Trans Issues...Well, Maybe Not Everything...". Yet, it sends a serious message as well as it extends the invitation to the readers to join this political movement as "Our Allies", rather than antagonize them. ${ }^{162}$ In fact, this entire booklet is explicitly written to convert

Army of Lovers Cannot Lose" and calling other queers to "just to love each other! Every time we fuck, we win" (The Queer Nation Manifesto n.d.).

${ }^{162}$ The humorous but subversive line "A cure for homophobia is discovered" is taken from this source, and so is the short blurb on "Why Pride?", which the Workgroup members found to be an important message to include in the Snapshot, as this is also one of the tough issues that receives negative responses from nonallies (CAWU n.d.). 
readers into "allies". Thus the discourse designed to 'educate' and 'appeal to' the straight and non-trans audience was quite well put together in this booklet, written as a question by a straight person and an answer by members of the queer community in the workplace setting (as it is a labour union resource). This Workgroup was thus able to readily use these established discursive resources in their Snapshot for their audience situated in the City of Ottawa as their place of work. ${ }^{163}$

In addition, the key message in this Snapshot about respect for individual preference, choice, and equal respect for it, was also part of the broader master frames as recognized by Snow and Benford, such as the choice frame, equality frame, rights frame, and human rights frame. ${ }^{164}$ The text of the Snapshot itself references the advancement of human rights and protection against hate crimes through Constitutional and other legal changes as one of the important contributions made by the GLBT community. The local examples include the edification of the Human Rights monument in front of City Hall as well as the first gay rights protest in Canada, ${ }^{165}$ which have benefitted the whole country

\footnotetext{
${ }^{163}$ These questions, written in a casual and conversational tone start with the common questions that the members of this community get asked by those outside of it: "Why are some people gay? It is genetic? Is it choice?"; "What about the gay gene?"; "I want to know more, but I don't want to offend anyone with my questions"; "I don't know what language to use - is it okay for me to say 'fag', 'queer', 'dyke'? I hear my friends in the LGBT community use those words..."? It weaves in a series of politically-charged and definitional questions such as "What exact is homophobia?" (4); "What does heterosexism mean?" (5); "What is the symbolism behind Pink and the Black Triangles?, "Why pride?", "Why doesn't everybody just come out?", and other definitional ones on "gender identity", "gender expression", "sexual orientation", "trans", and there is an additional "Definitions" section at the end like the GLBT Snapshot. Finally, the booklet concludes with a direct message to the readers who are now recognized and referred to as fullfledged allies, which frames the purpose of ally-work to promote human rights as a mutual interest to the LGBT and non-LGBT members of the labour movement: "To our allies... Thank you for working with us in building a safer, fairer, world. We know that you know that it's in all of our interest to protect and promote human rights. We also know that you take risks on our behalf and that it's not easy. Please, keep at it; we need each other" (29) (CAWU n.d.).

${ }^{164}$ It is also worth noting that these master frames used in the GLBT as well as the People with disabilities Snapshots embody liberalism as a brand of political philosophy. To borrow Ferree's expression (2003), such frame is therefore "institutionally anchored" within Canadian society, whose political (and economic) structure follows a variant of "liberal democracy" (c.f., MacPherson 1977).

${ }^{165}$ This monument itself - created in 1989 as a result of the work of grassroots activists, many of whom were based in Ottawa - draws on the rights frame and the equality frame drawn from the international law
} 
and not just this community (CAWI and City of Ottawa 2010d: 5). The lead member of this Workgroup talked about their "struggles for trying to get basic human rights" as the common ground connecting gays, lesbians, bisexual and trans people despite the differences and tensions among them as discussed above. ${ }^{166}$ In fact, he views "broad human rights activism" as one of the streams of the activist work by and for the LGBTQ or the Queer communities that he has been part of since the 1980s:

I put my activism in the 1980s and 90s in three different streams. One was some broad human rights activism based on the work I was doing on Parliament Hill when I was working for a fairly activist member of parliament at the time, a guy named Svend Robinson, and that came at the same time that I was doing local community work in Ottawa around AIDS and Queer Nation. And that flowed into the activism around hate crimes based on some events here in Ottawa in 1989 [which is referenced in the Snapshot itself.]... So human rights legislation stuff, GLBT Queer stuff and AIDS activism, and then leading into hate crimes stuff. And then it was hate crimes stuff that was really my main focus from 1989 to 95 , and then I started at the Police so it shifted from outside to inside the institution. So I shifted away from being either outside critiquing versus inside trying to bring about institutional change (Interview: $\mathrm{j}$, italics mine). ${ }^{167}$

This lead member's own account of his activist biography corresponds well with the broader historical trajectory of the queer activism in Canada and specifically Ottawa since the late 1980s (Warner 2002: 191, 290-1). Warner characterizes Canadian queer

(but with a strong spirit of civil society). Inscribed on the granite stone is "a quotation from the Universal Declaration of Human Rights" in Canada's two official languages, celebrating that "human rights are willed into being as the constitution of a society". "EUQALITY, DIGNITY and RIGHTS" are the key words engraved on two of the most visible parts of this monument, one of which is an arch representing "a tribunal where covenants are defined, legislated, declared and defended" (The Canadian Tribute to Human Rights 2008).

${ }^{166}$ The lead member also uses the equality frame as a way to bridge resonance and radicalism - the need to invite the audience in an non-threatening and non-hostile manner, while addressing the tension or resistance from them in order to push for the social change he is seeking to bring about. In his interview he states "There is the classic thing about 'Who's against equality? Because nobody's against equality. But when their actions do undermine equality, that's when we encounter the tension points, where people say 'I'm not against equality. What do you mean?' Then we can talk to them and take through the steps, saying. 'Of course you don't mean it. But let's look at how your actions do end up having impact on inequality. Let's look at that', and change from there" (Interview: $\mathrm{j}$ ). The result is a transformative frame that provides a solution for the audience that does not make them feel bad, embarrassed about it, nor resentful towards the minority group. The solution being offered resonates with the official mandate or mission of the audience as well as their self-interest, which coincides with that of the marginalized community. Importantly, equality frame is broadly resonant master frame because it is used in liberal society.

${ }^{167}$ This murder triggered community activism calling for action against hate crime, which led to the creation of the "Hate Crimes Unit" at the Ottawa Police Service as the first in the country (Interview: j). And, as this had been institutionalized at OPS, the Hate Crimes Unit regularly reported into its GLBT Liaison Committee, and this was part of the discourse used there (OPS GLBT Liaison Committee 2009a; b). 
activism in the late 80s as following two distinct tracks, both of which this member identifies being part of: one "exclusively rights-oriented", focusing on "human rights" and "equality rights" for members of LGBTQ communities through legal channels, and the other "radical" track employing "liberationist" and direct action tactics to "push the envelope in areas of sexual expression, community standards, fighting against police and state harassment of queer sexuality, rejection of victimization and vilification, and assertion of visibility and pride". The latter was exemplified in the Queer Nation, in which this member was also a part (191). ${ }^{168}$ In this sense, this Workgroup was able to incorporate elements of both radical (anti- or at least extra-institutional) and 'institutional' strategies to social change for the benefit of the queer community(ies), which in turn mirrored - and aligned with - the 'partnership' model used in developing the E\&I Lens. ${ }^{169}$ This Workgroup was thus able to build on the lesson of the risk and necessity of being radical, but also of the benefits of working within the state structure to advance their objective.

Moreover, the Workgroup imported the discourse of "disproportionate harm" from the trans policy paper on Justice Canada (1995) to introduce hate crime, bullying,

\footnotetext{
${ }^{168}$ In fact Warner cites and quotes this lead member as part of his discussion about the movement's shift from the radical queer politics to more institutionalized strategies, which includes the permanent edification of OPS Hate Crimes Unit and the GLBT Liaison Committee, as well as his employment by the Police as the Director of Community Development to head this committee.

${ }^{169}$ Some of movements that the lead member has been connected to are intersectional orientation, and employs various direct action tactics against the state or the dominant society, which have influenced his own politics. And others are exclusively institutional (Parliament, Human Rights legislation). For example, AIDS Action Now describes itself as: "a community-based group engaged in the struggle against HIV/AIDS... committed to an activism which includes, among others, such activities as lobbying, direct action, demonstrations, civil disobedience, and education aimed at solving the AIDS crisis" and believes that "it is necessary for us to deal with issues of social inequality around race, sex, class, sexuality, ability, both inside and outside our organization. Therefore our work incorporates an anti-racist, anti-sexist and anti-heterosexist perspective" (AAN n.d.). Similarly, Queer Nation Ottawa's manifesto asserted "We are a Queer Nation of unapologetic lesbians, gays, and bisexuals of diverse races, abilities, ages, creeds, classes and cultures working together to collectively eliminate homophobia and promote and celebrate the visibility of queers by employing non-violent direct action" (Warner 2002: 261).
} 
violent assaults and death, and suicide affecting GLBT people, and trans people in particular (CAWI and City of Ottawa 2010d: 7-8) ${ }^{170}$ Significantly, this concept and discourse of "disproportionate" taken from the justice system gets at the overarching message about equity, that the playing field is uneven for individuals belonging to different minority groups, and even among the eleven equity groups or within each one of them is an internal inequality. Similarly, "harm" focuses attention on the outcome of inequity, regardless of the intent on the part of the system or the perpetrator. Not only did this draw legitimacy from the official government discourse, this also aligned very well and resonated with the overarching notion of equity in the Lens as a whole. This boosted the legitimacy of this Snapshot's frame even more as it urged the readers to take these concepts seriously in their work.

\subsubsection{Alignment with the Institutional Framework}

Thus, GLBT Workgroup also had the lead contributor who acted both as the community representative and the institutional (City) representative, who helped bridge the perspectives of the community and the intended users of the Lens. The lead member explained that he was wearing "two hats" at the GLBT Workgroup, both as an outsider and insider to the institution of the City of Ottawa (Interview: $\mathrm{j}$ ). He talked about how he constantly worried on the one hand about how the City could remain genuinely accountable to the community's effort and expectations invested into a tool like this

\footnotetext{
${ }^{170}$ At the provincial level, the Ontario Attorney General and Minister of Community Safety and Correctional Services appointed the Hate Crimes Community Working Group in December 2005. This community-based Working Group held regional community-based consultations across the province in 2006, and produced a report that year, which laid out the strategic priorities and recommendations to the province on hate crimes affecting "Aboriginal, racialized, religious, Lesbian/Gay/Bisexual/Transgendered/ (Two-Spirited)/Intersexed (LGBTI) and other marginalized communities in Ontario" (Mock et al. 2006: 9). Notably, three members of the GLBT Snapshot Workgroup (two co-leads and one additional OPS representative), one community member of the Visible minority Snapshot Workgroup, and the chair of the Equity and Diversity Advisory Committee, as well as one representative from OPS Hate Crimes Unit had all participated in the regional consultation for Ottawa (ibid: 112-5).
} 
Snapshot and the Lens as a whole. On the other hand, he also thought hard about how to make it appeal to the City staff so that the tool would actually be implemented and "become part of the fabric" of the institution, and not as a simple "checklist" that the City can use to claim that it has fulfilled its obligation to the community (ibid). ${ }^{171}$

These strategic considerations partly explain the Workgroup's ability and effort to seek resonance with audience needs, by giving permission for the reader to not to know something, providing practical tips to accompany complex realities of community members, as well as offering 'Definitions' as an addendum as an optional resource that readers can reference to clarify potential confusion. This Workgroup also sought discursive alignment with the partnership frame of the Lens, which emphasized userfriendliness of the tool. They also decided to opt to keep the title of the document in line with the City's existing structure and official terminology "GLBT", rather than to seek to change it to better reflect the realities of the community, even though they immediately identified it as a highly controversial term within their community. This reduced discursive friction between the community voice and the City's existing structure at least on the surface level in terms of the title of the document. As we have seen, however, the body of the text was able to directly tackle the core issues such as homophobia and transphobia, as well as the intense debates on language within the community.

\footnotetext{
${ }^{171}$ This member elaborates on this challenge of 'bridging' the two worlds as follows: "I always felt I had two hats on. Being on the LGBT Workgroup was one hat, but I also felt that I had some experience and insight based on working in the City bureaucracy - even though it was one step removed by being with the Police. And I had a sense that how [tools like E\&I Lens] get used, or more properly, not used... So going back to the question of how genuine is an organization, I spent a lot of time thinking and worrying about the credibility both of the process for developing this tool, and of the institution [in the eyes of the community]. Because if its done in a way that's not genuine, you'll end up with a product that [community] people in good faith invest time, energy, and heart into, but then it ends up with the City simply saying 'Well, we did it.' And it's just a checklist. It's just checked off the list, and no one ever uses it or it's not implemented. It doesn't become part of the fabric. So part of me was always looking for ways for this tool to be seen as a complement, not an impediment [by City staff]. As something that would help in the work, not hinder the work. And part of that was also about believing that the issues being touched on in the tool were easy" (Interview: j).
} 
Finally, the institutional structure of the City supported this strategic direction chosen by the Workgroup. In fact, "GLBT" was added to the mandate of the City's Equity and Diversity Policy, therefore the Equity and Diversity Advisory Committee, as a result of the voluntary decision and commitment of the City. This was done in particular by the manager of Human Rights and Employment Equity branch, who later became the project lead of the E\&I Lens development, to go "above and beyond" the minimum legal requirement as set out in the federal legislation Employment Equity Act (Interviews: a, e, $\mathrm{g}, 1) .{ }^{172}$

Such 'voluntary' commitment from the City had come as a result of the sustained effort by the local community activists and the City's internal allies who championed GLBTQ rights in the City. One community member recalled this local history in the preamalgamation City of Ottawa since the mid-1990s, when the GLBT community members had worked closely with ally Councillors who helped them have the City declare the Pride Day (Interview: 1). ${ }^{173}$ Similarly, the manager and the project lead of the E\&I Lens also recalls that it was Alex Munter who had flagged the need for the City - and her office - to pay attention to the GLBT community as an 'at risk' group for exclusion,

\footnotetext{
${ }^{172}$ As discussed in Chapter 2, the federal Employment Equity Act designates four groups as its target populations: Aboriginal peoples, members of visible minorities, persons with disabilities, and women (Employment Equity Act).

${ }^{173}$ Such 'voluntary' commitment from the City came with a caveat, as it required at one point that the local GLBT community to take the then-Mayor of the City to the Human Rights Commission - thus applying a community pressure and legal pressure on the City, before the Mayor finally declared the Pride Day. One Workgroup member recalled this process: "Well the GLBT community has always had a fairly good relationship with the city since Mayor Holtzman up until Mayor Holtzman no." ...Mayor Holtsman was the mayor before Jim Watson. She refused to proclaim Pride Day, and they took her to court and she lost. She paid the fine before she'd declare Pride Day. She was just not a pleasant woman to put it mildly... This would've been 1996 and the first Pride Day was proclaimed in 97, or 95- 96... Because it was Mayor Jim Watson who was a Councillor at the time, and Diane Holmes, and Stefan Machevo who was a councillor from Newmarket who was 'out'. And Alex Munter was another 'out' Councillor. And they walked us through the process of going before committee and getting the approval. And I was part of that process. Because I remember having to go to City Hall and make a presentation" (Interview: 1). This same story is recapped in the local LGBTQ news article (Fagan 2010).
} 
which led to the inclusion of this group as part of the Equity and Diversity Policy, which she is proud to have developed in collaboration with EDAC upon amalgamation (Interviews: g). ${ }^{174}$

The local community's advocacy effort was thus being supported by some of the key institutional allies including the City's elected officials. The City manager responsible for this portfolio received it as a directive from the Councillor(s), but also matched it with her own (personal) commitment to champion this as part of her own legacy. In addition, the fact that OPS already had a well-established and operating GLBT Liaison Committee linking law enforcement and the marginalized community boosted the legitimacy of the claims of the community within the City. The City lead of the GLBT Workgroup noted that representing the police - which is considered a prestigious institution - helped him command added respect and leverage when interacting with the City officials to push for this cause. This institutional context and its historical background, as well as the supportive role that the manager/project lead played in it, partly explains the unexpectedly high level of support the Workgroup received from her for all of the decisions by the Workgroup members.

This came half as a surprise for the Workgroup, for they viewed this City official to be the representative of the City management, which, they had hoped - though did not entirely expect - to be on their side. As one member noted,

I felt the City people who were in the room were with us. I didn't necessarily have information about those outside the room... But our work was supported, it was adopted. And then of course there is the fact that the head of the administrative side of the organization [City Manager] endorsed it and gave clear direction" (Interview: j).

\footnotetext{
${ }^{174}$ One of the City's key coordinators of the Lens also noted that the City somehow knew the need to add GLBT to its Equity and Diversity policy mandate, and that knowledge had come from working with the community, though she did not know the precise circumstances that led to this decision by the City (Interview: e).
} 
The Workgroup members remembered that they "pushed the envelope" as they demanded to create the Snapshot that worked for their community and not necessarily neatly conform to the specified scope, format or length as initially imposed on them by the key coordinators of the Lens. For example, they remember arguing to add "Definitions" as a new subsection at the end of the Snapshot, which made the document even longer than it was supposed to be. This demand was granted by the key coordinators of the Lens, despite the strategic priority at the partnership scale to keep this document as simple and short as possible (Interviews: $\mathrm{j}, 1, \mathrm{v}$ ).

Similarly, one member recalled suggesting the opening line "We are fabulous!" specifically as a "bureaucratic test" to see how far the manager/project lead from the City was willing to "play with us", while he half expected that line to "never see the light of day" if this manager rejected it as inappropriate for the audience (Interview: j). Another community member also found the manager be so unexpectedly supportive and receptive of their voices. In fact she admits that as a lifelong trade unionist, she "had to consciously set aside her prejudice against management" when working with this manager on this Snapshot, though she was surprised that it turned out to be unnecessary after all. All of the interviewees gave this manager credit for being so open-minded to and supportive of what they considered sometimes 'outrageous' demands and suggestions (Interviews: $\mathrm{j}, 1$, v).

\subsubsection{GLBT Case Summary}

The GLBT Snapshot presents a different kind of a transformative frame from the People with disabilities case, for it intentionally chose to directly confront and problematize the dominant attitude on the part of the straight and non-trans population 
(i.e., homo-/bi-/trans-phobia) as the root cause of inequities and barriers experienced by this community. In this sense, this Snapshot 'dared' to work with an explicitly radical, and even an "oppositional frame" (Morris and Braine 2001), which tends to divide the readers and the community into the binary of the oppressor and the oppressed, and to place the 'blame' squarely on the former. However, it combined this radical element with other discursive tactics drawn from their movement repertoire, such as subversive humor, appropriation of the dominant frame, and self-admission of internalized phobias and 'isms'. These incorporated into the Snapshot to deflate the tension, defensiveness, fear or anger on the part of the audience that such confrontational frame tends to trigger.

These discursive tactics also helped break down the rigid binary between the dominant/straight versus marginalized/GLBT, the oppressor versus the oppressed, and the City audience versus the community. This further deflated the tension associated with their radical, 'oppositional' frame, even while the Workgroup made a conscious (and private) distinction between their movement and allies, and the external audience. This Snapshot also offered simple, practical and 'user-friendly' tips and solutions for the audience, which helped reduce audience resistance and increase their 'buy-in'. In sum, the combination of these discursive tactics enabled the Workgroup to pursue an explicitly radical frame while still maintaining high level of resonance.

This was in part possible, thanks to the strong movement affiliation the Workgroup members shared, which spanned across the City-community boundary. They were able to draw on well-established movement frames, spanning across radical direct action wing outside the polity, and the 'institutionalized' wing within the polity, to form the basis of their transformative frame. They also drew on broadly resonant master 
frames such as 'equality frame' and 'rights frame' in Canadian society (as liberal society) to increase their legitimacy and resonance. The Workgroup featured a strong ally member who acted as its (co)-lead, whose official position within the police further added to the legitimacy and resonance of the community movements' claims. This Workgroup's movement frame also aligned well with and was supported by the institutional framework of the City (Equity and Diversity Policy) as well as the police (GLBT Liaison Committee). In this sense, the framing strategy chosen at this Workgroup aligned well with the broader framing strategies of the coalition and the partnership.

Here, note that the GLBT Workgroup succeed in 'pushing the envelope' against the limitations imposed by the partnership and the coalition by extending the length of the Snapshot beyond the common format, for example by being the first to add the "Definitions" subsection at the end. This movement-specific discursive innovation and strategy thus travelled up to the coalition and the partnership scales, which in turn travelled down to the other individual Workgroups. These Workgroups were now 'allowed' to add the Definitions, or in the case of the People with disabilities, they 'had to' include it even though this was contrary to their ideal or preferred strategy to move away from labels and definitions altogether.

Similarly, the GLBT Workgroup's discursive innovation on the upfront waiver on language as part of "Who we are" was exported to other Snapshots, including the Visible minority Snapshot as I will discuss in the next chapter. In this sense, this Workgroup was discursively well positioned within the multi-scaled nature of the framing strategies involving the community movement, intersectional coalition, and the City-community partnership. This also sheds light on the very different ways these multi-scaled strategic 
priorities and decisions played out for each individual Workgroup, sometimes supporting their movement-specific goals and sometimes hindering them. 


\section{Chapter: Immigrants and Visible Minorities Snapshots Subcases}

\subsection{Immigrants Snapshot Workgroup Subcase}

\subsubsection{Key Message}

We are from all over the world and have chosen to make Canada our home. Our diverse cultures enrich the city. We wish to contribute our skills and experiences to strengthening our neighbourhoods, workplaces and the city. In Ottawa, we are growing at twice the rate of the general population and will be key in replacing the aging workforce (CAWI and City of Ottawa 2010e: 2).

\subsubsection{Overarching Frame: Immigrants as Resources and Opportunity}

One of the overarching key messages conveyed in this opening paragraph, and throughout this Snapshot, is that immigrants are indeed resourceful and skillful people, who would love nothing more than to contribute their gifts, which they have cultivated throughout their lives in different parts of the world, to enrich their new chosen home: Canada/Ottawa. However, this Snapshot quickly advances the narrative that they are prevented from doing so because of the barriers that exist in Canadian society or the host society (CAWI and City of Ottawa 2010e: 2). This point is quickly turned into the selfinterest of the target audience, however, by emphasizing that this country/city is in fact brimming with opportunity 'we' present to 'you' - but only if 'you' are ready to take it. It thus urges the audience to think of what 'you' are missing out by not tapping into 'our 'potential, and that the solution is easy: embrace it!

The idea that immigrants represent opportunities to Canada/Ottawa is front and centre of "Who We Are", as well as the next section "Contributions We Make". For example, the very first paragraph of the text states: "We come here to use our rich and diverse skills and experience to contribute to building and improving our neighbourhoods, communities, the city, and the country" (ibid: 3). Similarly, the "Contributions" subsection builds on this by stating: 
We are qualified, educated, experienced and a younger workforce that is driving the growth of Ottawa's aging labour market. We are prominent in Ottawa's business community. We bring indepth knowledge of cultural, political and business nuances of global markets, linguistic diversity, and ability to cater to the diverse needs of the community. These are a strategic resource in acculturating Canadian businesses (City of Ottawa 2007)....We bring new opportunities to Ottawa through increased social, economic and cultural linkages to communities and markets around the world (CAWI and City of Ottawa 2010e: 4).

This emphasizes how immigrants help revitalize the dwindling labour supply and boost the Canadian economy, when Canadians cannot and will not be able to do it on their own. While the text here does not directly mention them, this counters the negative stereotypes implied in the dominant discourse about immigrants, such as the audiences' prejudice or xenophobic trepidation that they may take away jobs from Canadians, be a drain on the Canadian welfare system, or undermine the Canadian national identity.

This Snapshot also presents an alternative interpretation that the problem is not that immigrants innately lack skills or competency themselves, but that Canadians do not view the immigrants' experiences as skills "yet". For example, there is a special sidebar that runs along the right side of the page in the "Contributions" section, entitled "Barriers to Language Development". One of the bullet points in it states:

Non-official languages are not yet seen as assets despite the changing demographics of Ottawa with more than 70 languages spoken in the city (CAWI and City of Ottawa 2010e: 4, italics mine).

This conveys that contrary to another dominant frame, immigrants do not innately lack competency compared to Canadians. Rather, the 'real' cause of the problem is the barriers in the host society that are preventing these passionate people from sharing their gifts with the world. These barriers include for example the prejudice among Canadians that assumes immigrants to be incompetent or "less than" Canadians or views "difference" in culture, language, religion or 'race' as problematic/undesirable, or the institutional barriers to credential recognition and transfer (CAWI and City of Ottawa 2010e: 10). 
In reframing the nature of the problem, however, this Snapshot shifts the 'blame' away from immigrants themselves, but does not place it directly onto the target audience, either, for it does not specify by whom the immigrants' cultural and linguistic diversity is not seen as asset. Instead, it blames barriers in society, therefore not directly a group of people or individuals belonging to it, thus deflecting potential backlash from the target audience. The use of word "yet" also implies that such shift in attitude/perspective among Canadians is coming soon - if people choose to see it through this 'lens'.

Similarly, the opening paragraph ends on an orientation toward the future characterized with opportunity rather than loss, when immigrants will be the City's primary source of labour force. The text also replaces the existing fear on the part of the dominant society to lose something that immigrants are viewed to be taking from them whether it is their jobs, tax-funded welfare money, or definition of what it means to be Canadian and who counts as one - with the benefits of living in a more vibrant and welcoming society for all to enjoy, especially for the host. It does so, again, by playing up what Canada/Ottawa is missing out by not embracing such rich resources, socially, culturally, and linguistically, but especially economically.

This Snapshot thus counters and replaces the dominant frame in multiple ways: it displaces negative stereotypes about immigrants, subverts the cause of the problem from the inherent lack of skills or competency of immigrants to the external or societal barriers that prevent them from contributing their talents. It reframes the onus for solving the problem from immigrants themselves only to a mutual, dynamic, and shared one between the host society (or dominant society) and the newcomers. In other words, it externalizes the cause of the problem beyond individuals or beyond groups (immigrants versus 
Canadians), and collectivizes the responsibility for challenging and changing the status quo among all of 'us' as a society. ${ }^{175}$ Similar to the People with disabilities Snapshot, these negative stereotypes are not directly mentioned in this opening paragraph or in "Who We Are", but only its positive and transformative alternatives and solutions are discussed. Finally, the text spells out the direct benefits of doing so to the host - and therefore their audience - clearly and strongly throughout. The Snapshot thus reinforces the message that this is not a zero-sum game where the newcomer gains and the host loses, but it is a 'win-win' game that only brings mutual benefits to all.

\subsubsection{Diverse Settlement Processes: Racism as Part of the Barriers}

Another key message is captured under one of the topic sentences under "Who We Are" which states "We all have different experiences of settlement", that the settlement processes are much more dynamic and variable than the dominant discourse assumes it to be (ibid 3). Many related messages are woven into this, for example that "immigrants" contain hugely diverse immigration categories and statuses, circumstances of their migration and arrival, and the settlement and integration processes, and that different immigrants experience hugely diverse set of barriers that are external to them. It also seeks to dispel the common assumption about the 'standard' settlement process that all immigrants are expected to go through. In addition, this Snapshot emphasizes that settlement is not only a matter of immigrants adapting themselves to fit into the host society, but the cultural and linguistic 'distance' between the source society (where immigrants come from) and

\footnotetext{
${ }^{175}$ This also counters the dominant frame that assumes that the identity or the life of "immigrants" only starts after they arrive in Canada and that nothing from before exists. These dominant frames portray these immigrants to be the cause of the problem in terms of their own inability to integrate into Canadian society, or their own inability to get a job due to their lack of skills, competency, or (Canadian) experience.
} 
the host society (Canada), as well as the "[r] eadiness of the host society to welcome and integrate immigrants (ibid: 5).

The other key message that is woven into the overall narrative of this Snapshot is that racism is a part of the story of the more recent cohorts of immigrants from nonEuropean, non-white (and non-Christian) backgrounds. "Who We Are" as well as "Barriers and Inequities" sections clearly explain that racism is one of the key barriers to the economic integration of skilled workers discussed above, as well as the broader settlement and integration processes of all immigrants into (the dominant) Canadian culture and society (ibid: 3,7 ). The patterned difference between the integration of 'white' immigrants and the 'racialized' immigrants - and especially the continued exclusion of second- or third-generation children of racialized immigrants - is used to delineate that 'race' is indeed a key factor for their (continued) exclusion in Canada, and not simply their immigration status (ibid: 7). This example is also reinforces the message that settlement processes do vary among immigrants based on many factors like the place of origin, cultural and linguistic similarity, and existence of racism in Canada. ${ }^{176}$

The Snapshot does so by explaining that today, more and more immigrants come from outside Europe such as Africa, Asia, the Middle East, etc., whose cultural and linguistic diversity and difference from 'Canadian' norm is much greater than the previous generation(s) of immigrants (ibid: 3-4). When they arrive in Canada these

\footnotetext{
${ }^{176}$ The subtext here that is not directly and explicitly mentioned, but certainly hinted, is that the 'standard' settlement process in the dominant imagination is largely based on the particular experience of European immigrants during the long economic boom in the post-war. The cultural and racial similarities between the source societies and the host society were much greater for this cohort of immigrants, and so was the willingness on the part of the host to receive them as part of Canada. This Snapshot explains 'around' this story, by pointing out that immigrants today are much more diverse racially, culturally, regionally and linguistically than before, the two-way nature of the settlement processes, diverse settlement processes based on diverse barriers - which includes racism for racialized immigrants today, as well as changing economic conditions.
} 
immigrants are viewed as less integrated into Canadian society as they are more 'visibly' different in culture and in 'race', and are much more strongly racialized than European or 'white' immigrants. While not directly discussed in the text, this implicitly conveys that this makes these newer and racialized immigrants appear as though they are the problem, in comparison to the 'white' immigrants from the previous generations who seemed to have problems integrating or cause fewer problems to host society.

That said, the Snapshot packages the issue of racism, racial discrimination, racial prejudice, and racial inequality mostly in terms of economic or labour market exclusion, which, again, it ties directly to the missed opportunities or the economic loss on the part of the dominant/host society, and the positive benefits of removing racial barriers to them. In this sense, the three key messages of this Snapshot support each other in a relatively tight package, thus forming a coherent transformative frame that resonates with the dominant frame but also challenges and modifies it.

\subsubsection{Key Debates and Discussions at the Workgroup}

\subsubsection{Limited Scope of Official Definitions: "Recent" and "Skilled" Immigrants}

One of the first discussions that this Workgroup ${ }^{177}$ had was on the scope of this

document as reflected in the name of this group. Initially at the beginning of the Snapshot development process, the title of this Snapshot was set to be "Recent immigrants". This

\footnotetext{
177 This Workgroup featured a lead member from the community (who served on the Reference Group), who had been part of promoting the Equality Framework while working with CAWI and SPC during the years covered in Chapter 2. Another community member of this Workgroup also sat on the E\&I Lens Reference Group, who had been part of CAWI's evaluation of the Gender Equality Lens and a former member of the City's Equity and Diversity Advisory Committee. The official EDAC Liaison for the Immigrant Workgroup was the same as the one on the Visible minority Workgroup, and the City member on this Workgroup also participated in the Visible minority one. Additional community member participated via phone by providing input and resources directly to the writer. The project lead of the E\&I Lens development (manager of Diversity and Employment Equity) participated in this Workgroup mostly in an observing role, as this community was included as part of EDAC's mandate though not in EEA or EDP. The other City key coordinator of the Lens participated in this Workgroup as a substantive contributor given her personal and professional background in working with immigrants, and this member also participated in the Visible minority Workgroup (Interviews: a, e, g, i, k).
} 
was the term the City had chosen as it considered this group to be the most vulnerable or at risk among the immigrant population, and also as developed historically as discussed in Chapter 2. However, the Workgroup members raised concerns that this was too narrow in scope, and had the risk of leaving out of the picture many other kinds of immigrants who are at different stages of their settlement and integration process. Given the purpose of the Equity and Inclusion Lens, it was important for the Workgroup to include those who may still experience significant barriers, exclusion and inequities in the city even if they are not officially considered 'recent' immigrants as part of this Snapshot (CAWI 2009-04-15).

For example, the City's official definition of recent immigrants referred specifically those who as those who arrived in Canada and in particular Ottawa in "less than 10 years". Part of the logic for this is that after ten years immigrants should be able to stand on their own, or qualify for other incremental entitlements and rights associated with progressing onto citizenship status (or to permanent residency before that if they did not arrive already with that status). However, this logic itself is predicated on another common assumption that all immigrants go through the same settlement process at the same rate. The Workgroup members thus pointed out that this does not account for the divergent realities of what migration, settlement and integration looks and feels like for different immigrant groups from different places, under different immigration categories, under different life circumstances. Such ten-year cut-off line is therefore an arbitrary one that has serious implications for those who do experience barriers and inequities in reality, even after 10 years of arrival (CAWI 2009-04-15). 
The Workgroup members saw that this was particularly important in the immigrant settlement sector, because what the official definition says about one's immigration and citizenship status, especially as defined and granted by the Canadian federal government in the legal sense, is closely tied to what kind and amount of supports, services, entitlements, and rights that one is officially eligible to receive (CAWI 2009-04-15). This applies to various settlement services often restricted to immigrants (which may be specific for different categories or classes of them) as well as citizenship rights granted exclusively to Canadian citizens, whether they are provided through the federal, provincial or the municipal government or through non-profit service agencies that receive government funding. The members thus pointed out that the legal definitions themselves can often become a legal barrier to people in accessing and utilizing the supports they require in their transition into a new life in Canada or in Ottawa. ${ }^{178}$ In other words, the Workgroup knew that official or legal definitions themselves often served to place eligibility restrictions or as eligibility cut-off line delineating who is no longer qualified to receive the City's support services - and who the City is not responsible for supporting.

The Workgroup thus decided to opt instead for "Immigrants". This seemingly minor change to the title of this Snapshot was significant for this Workgroup also because of the other commonly used official terminology within the City at the time, i.e., "skilled" immigrants (CAWI 2009-05-13b). This tended to exclusively focus on economic

\footnotetext{
${ }^{178}$ The minutes from the first Workgroup meeting states that "Federal legal categories [are] not necessarily reflective of how people self-identity themselves, but legal status does affect eligibility to services and opportunities" and "Arbitrary eligibility criteria for access to services" that are "often tied to immigration and citizenship status" but "not set with immigrants engaged in the process" of migration in mind, making "policies and services... no good for anyone". "The five-year cut-off" for settlement services is an example of this (CAWI 2009-04-15). Here, we can see this argument is well positioned to lead into another business case to change such 'wasteful' public resource by aligning the legal and policy structure to better reflect and serve the reality of the lived experience of people in the community.
} 
immigrants, based specifically on labour-market needs of Ottawa as the host society. This was a salient point of critique for the Workgroup, given that this was the focus of the City's own Immigration Ottawa Initiative (IOI) that had been recently established at the time (City of Ottawa Labour Market Integration 2007; City of Ottawa CPSC 2008). IOI aimed at attracting more economic immigrants to Ottawa, in particular the "skilled immigrants" or "skilled workers", and facilitating their integration into the city, and more specifically into its labour market.

However, the exclusive focus on 'skilled' or 'economic' immigrants portrayed or assumed other types of immigrants to be not skilled, or not economically productive, and not useful or valuable to the city. This included family-class immigrants (especially those of non-working age such as seniors), refugees and refugee claimants, as well as workers under other immigration categories such as migrant agricultural workers or live-in caregivers who made up the city's population. This view not only discredits the economic contributions that all these immigrants do make, but also disregards the much wider range of contributions that all immigrants, including 'skilled immigrants', make to the city as a whole through its civic, political, social and cultural life as well. Similarly, the targeted support to this one particular type of immigrants, and especially in only one aspect of their settlement needs related to labour market integration, deprioritizes the needs of other immigrants as well as the broader range of barriers and inequities outside of the workplace or the labour market. The Workgroup instead decided it was important to use an "inclusive definition" of who immigrants are, so as to challenge this narrow definition the City's current terminology implied (CAWI 2009-05-13b). 
The Workgroup also resisted taking the official or legal definition as a reference point to represent this population in this Snapshot because of its implication to identity and sense of belonging (CAWI 2009-04-15; 05-13b; Interviews: i, $k, n$ ). Identity is often a salient theme in the lives of many immigrants, especially as it goes through a significant transformation over the course of their migration history. The Workgroup also sought to convey that people's "lived experience and meaning of 'being an immigrant' do not match the legal definitions", and that "[s]elf-identity or labels by society are connected to the sense of belonging" (CAWI 2009-04-15). That is, people's understanding of who they are as a person or even as a community is much more complex than what their legal papers say about their status. In addition, the Workgroup was quick to point out that such personal sense of belonging or self-identity was often hurt by "social exclusion due to racism" (ibid). Thus, it was important for this Workgroup to bring out the "inclusive", "diverse" and "nuanced" definitions of "who immigrants are" that went beyond the legal status and a narrow focus on economic integration, but a broader social inclusion and integration that encompassed the people's sense of belonging in society (CAWI 2009-04$15 ; 05-13 b)$.

The Workgroup sought to make sure that their Snapshot would be encompassing and reflective of the diversity of circumstances and experiences of those who migrate to Canada/Ottawa, and not just 'recent' immigrants, and not just 'skilled' immigrants. They challenged the City's rationale and assumption that narrows the scope of who is marginalized in the city, and towards whom the City should target its support efforts, and decided to expand the scope of who should be included in this Snapshot, and how far the City's responsibility extends, precisely because the two official definitions that were in 
use by the City at the time were particularly narrow. They instead chose a much broader and encompassing category "Immigrants" as the alternative title for this Snapshot (CAWI 2009-04-15). ${ }^{179}$ Their critique of the City's official terminology was then accepted by the key Coordinators of the Lens including the City project lead, and ultimately this translated into the title and scope of the final version of this Snapshot. In this sense, this was an example of the movement frame critical of - and challenging - the City's dominant as well as of the official frames, and 'winning' in their negotiation over it with the City.

\subsubsection{Labour Market Exclusion as 'Missed Opportunities'}

Still, the Workgroup identified economic exclusion - especially in the form of labour market exclusion - as one of the most pressing issues facing immigrants in Ottawa (Interviews: i, k). Moreover, it was important for this Workgroup to present the challenges that immigrants experience "not as a matter of the individual but the societal conditions", or "systemic barriers that hinder some people" (CAWI 2009-05-13b). This is why the Workgroup chose to first highlight immigrants' readiness to make contributions through "skills, experience, labour market, innovations, new ideas to Ottawa, and for our children", but explain that "the challenges they face don't allow them to contribute" (ibid). As an example, the members raised the high rate of unemployment and poverty among immigrants despite the "rich skills" they bring to Ottawa, which was caused due to lack of foreign credential recognition, which, in turn, was caused "because of racism" (ibid). The Workgroup thus saw the need not only to raise this as a key barrier in the

\footnotetext{
${ }^{179}$ For example, there are economic and family classes of immigrants, refugees and refugee claimants, temporary or migrant workers, live-in caregivers, some of whom have obtained permanent residence or citizenship, and others not, and there are also long-term immigrants and subsequent generations of Canadian-born children of these immigrants.
} 
Snapshot, but also to break down the myths surrounding it, by linking the cause of immigrants' (economic) exclusion constantly to the societal barriers, especially racism.

Such reframing about the economic exclusion of immigrants was important to their main objective. There was additional urgency to this, given the prevalence of this problem that pushes so many immigrants to under- and unemployment, which feeds into a series of settlement challenges such as meeting basic needs (Interviews: i, k). Moreover, without such explicit reframing, the apparent inability of these immigrants to get a proper job to support themselves and integrate smoothly into Canadian society further feeds into the negative stereotypes about immigrants themselves as incompetent, inferior (to Canadians), and dependent on support services (provided by Canadians). ${ }^{180}$ Or, it would reinforce another dominant assumption that 'skilled immigrants' are the only kind of competent, valuable, and 'useful', immigrants to host society.

This is why this Workgroup sought to play up the immigrants' positive benefits to Canadian/local economy rather than a drain on it. The Workgroup sought to make a strong 'business case' for proactively welcoming immigrants into Ottawa's local economy, for example by highlighting their unique human capital that can fuel innovation here, and built a more responsive workforce to the consumer needs and preferences. Such business case would add also that consumer tastes are also diversifying quickly through increased immigration, and the 'Canadian' workforce and businesses

\footnotetext{
${ }^{180}$ This dominant frame postulates that such supports are paid for by Canadian tax dollars - even though in reality immigrants and foreign workers also pay taxes into the Canadian welfare system (and 'subsidize') Canadian beneficiaries, as many of these immigrants and temporary workers are not legally eligible to receive such benefits. Similarly, another dominant discourse is that when they do get jobs they are taking those from Canadians ('Immigrants are stealing our jobs!'). Such views are embraced by organizations such as Immigration Watch Canada, an organization made up of "Canadians who believe that immigration has to serve the interests of its own citizens. It cannot be turned into a social assistance / job-finding program for people from other countries. It should never be a social engineering experiment that is conducted on Canada's mainstream population in order to make it a minority" (Immigration Watch Canada 2010).
} 
must adapt quickly (CAWI 2009-04-15; 05-13b). The Workgroup thus sought to play up the comparative advantage these immigrants could provide to Ottawa in an increasingly competitive global economy, which the Ottawans did not yet fully realize. They decided to highlight their ability to "bring opportunities to Ottawa" and to open up access to new or expanded markets around the world through their personal and cultural "connections" to their home countries (CAWI 2009-05-13b), and this was reflected in the final text.

\subsubsection{We Are More than Just the Economy}

However, as the interviews as well as the preceding discussions show, the Workgroup members were acutely aware of the limitations of this economically focused discourse. That is, while this gave a powerful boost to their business case for welcoming immigrants, relying solely on this exclusively economic discourse about the cost and the benefit of immigrants' labour market integration would also risk all other non-economic issues falling off the agenda for the City and its employees (CAWI 2009-04-15, 05-13b). In addition, relying too much on this direct appeal to the self-interest of the target audience in trying to win their hearts and change their mind about immigrants, would also risk turning immigrants into simple economic resource or commodity that Canada/the City can take advantage of. It would also run the risk of reinforcing the idea of doing so only if and only when it is convenient to them, or the benefits are directly apparent to them. Such a view would not nurture the deeper, broader, and long-term cultural change in the City that truly embraces immigrants as full members of Ottawa or Canada beyond simply as workers or revenue boosters.

The Workgroup participants thus sought to broaden the scope of discussion to include social, cultural, political and legal realms, both in terms of the kinds of barriers 
and exclusion the immigrants face, as well as the contributions, strengths, and resources they bring to Ottawa (Interviews: e, i, k, n). The Snapshot could then talk about the settlement and integration processes as a whole, and not limited to employment. This way the other important questions about sense of identity and belonging, access to essential information and services to assist in settlement and integration processes, political participation in decision-making, as well as the immigrants' contributions to "community building" could be woven into this Snapshot (ibid; CAWI 2009-04-15; 05-13b).

Importantly, this also allowed the Workgroup to raise the other key messages, that settlement processes indeed differ significantly for different immigrants, which in turn opened up the point that the often unspoken issue of racism underlies so many of the other challenges that many (though not all) immigrants face, including labour market exclusion as well as the assumption about the homogeneous settlement/integration process (ibid). By bringing these issues as part of the discussion, the Workgroup was also able to expand the scope of what the settlement and integration process entails, along with who is responsible for facilitating or inhibiting it.

These points are well reflected in the final text of the Snapshot. For example, the fifth point in the "Barriers and Inequities" section of the Snapshot explains that "Immigrants in Ottawa are diverse, and so are their settlement needs and experiences. The process takes shorter or longer depending on many factors" (CAWI and City of Ottawa 2010e: 7). It then gives an example of a 'racial' difference among immigrants, starting to segue into a more direct discussion about the role of racism, by stating that "European immigrants tend to fit in suburban and rural neighbourhoods more than visible-minority immigrants" (ibid). It proceeds to explain immediately, in bold: 
There is a misconception that all immigrants go through the same settlement process and become integrated after a certain amount of time. Delayed integration - often due to racism - may be misinterpreted and stereotyped as failure or deficiency of the individual or the specific community, when in fact it is the societal barriers that the City and the community can address together (CAWI and City of Ottawa 2010e: 7, bold in original).

Here, it identifies a problem (i.e., there is a misconception), names the real cause of that problem (i.e., racism), provides an alternative explanation for another related misconception about the cause (from inherent inability of the equity group to an externalized societal barrier), and points the readers towards a shared solution that involves both the City and the community.

\subsubsection{Naming Racism as the Societal Barrier}

In fact, at the first Workgroup meeting where they brainstormed the "barriers" affecting this population, the first four they raised were explicitly about racism. They named "racism and cultural hierarchy" in Canada first, then "attitude/mentality both by Canadian-born people but also immigrants" as the second. As the third they identified "the racist assumption that "white" = "Canadian"; "non-white" are "immigrants" (outsider)" (CAWI 2009-04-15). The minutes further elaborates that such assumption "excludes non-white people (immigrants or not)" from integrating into Canadian society, but this also "excludes white-looking immigrants from immigrant services" (ibid). It also points out the racist logic at the heart of this, that "All but Aboriginal people are immigrants to Canada at one point, but some people are seen and labeled as "immigrants" ("outsider") after years or even generations" since arriving in Canada (ibid). Their racial analysis continues into the fourth barrier they named, that " 2 nd and 3rd generation immigrants of colour [are] having challenges" while it is "not common for 'white' looking immigrants and their 2nd, 3rd generations to have integration challenges", thus making this "not a matter of 'citizenship/immigration status' but persistent racism" in 
Canada (ibid). Moreover, the Workgroup criticized the (liberal) "assumption that

'everyone is equal', and there is no systemic barriers, [which] puts the expectation and fault on the individual immigrants" for not 'making it'. Finally, they pushed against this (liberal) assumption by adding that "some barriers you can overcome (as an individual) but some are systemic and societal" (ibid). ${ }^{181}$

In the final text of the Snapshot, the Workgroup chose a rather direct and explicit approach to naming racism as a barrier and explaining its impact on the people who experience it once it was introduced into the document. The introduction of this point was slightly delayed, for example until the middle of the section "Who We Are" as well as the middle of the Snapshot under the "Barriers and Inequities" section, rather than at the outset. That is, they chose to sandwich the radical element (racism in Canada) in between resonant pieces that played up the economic benefits of immigrants, and/or reduced the sense of fear that a radical message might bring up in the readers. ${ }^{182}$ That said, it still makes a strong point about the persistent effects of racism on non-recent immigrants who have been living in Canada/Ottawa for a long time, but (only) if they are visible minorities:

In addition to settlement issues, visible-minority immigrants - and even their Canadian-born children and grandchildren - face the added barrier of racial exclusion. Many Canadian-born

\footnotetext{
${ }^{181}$ Here, note that the other two Workgroups (GLBT and People with disabilities) appealed to the liberal notion of universal equality of individuals by embracing the equality frame and the rights frame as broadly resonant master frames in Canadian society. However, for the Immigrants Workgroup, this acted as one of the exclusionary dominant frames that they sought to counter through their movement frame.

${ }^{182}$ For example, the Snapshot states straight up that "Recent immigrants are faced with different types of racism" (City of Ottawa and CAWI 2010e: 7). The first type of racism is "Canadians' negative view of diversity and immigration, fearing job competition and other economic burdens": the dominant frame which the Snapshot has debunked in early parts of the document already. The second type is what the immigrants themselves bring with them from their home countries, in the form of "ethnic hatreds that carry over" (ibid). What this does - although not explained to the reader explicitly - is to acknowledge the reality of both 'white' and 'non-white' racism among immigrants themselves, so that 'white' readers do not feel singled out for their racism against non-white people. Finally, the third type of racism is the "non-existence or lack of coordination of services that take racism into account", which hints at - yet breaks - the silence on racism among all of the service providers in Ottawa, and not only the City (ibid).
} 
children and grandchildren of immigrants are assumed to be immigrants or outsiders. This not only affects their sense of belonging but has implications for material inequities. For example, they experience negative stereotyping, streaming in education, under and unemployment, racial profiling in the justice system, or in recent years, Islamophobia (See Diversity Snapshot - Visible Minorities) (CAWI and City of Ottawa 2010e: 7, bold in original).

Here, the fact that the "subsequent generations" of children and grandchildren of these visible minority immigrants, who are born in Canada and are not immigrants, still have not achieved full integration (while children of White immigrants have), reinforces the point above that racism in Canada as host society is a serious barrier to integration. This example pre-empts the non-believing audience to 'explain away' these Canadian-born visible minorities' lack of integration in terms of their immigrant status, real or presumed.

This point also reinforces the earlier correction to the dominant frame that portrays the delayed integration of these visible minority immigrants in terms of their inherent inability, compared to the superior nature of the previous generation of white immigrants who 'blended in just fine'. Rather, it presents racism on the part of Canadians towards non-European or visible minority immigrants to be the real barrier. In addition, this reinforces the other key message that settlement and integration of immigrants is a dynamic, two-way process involving immigrants and the host society, and not just the former. That is, it is not because the White European immigrants were inherently 'better' than the racialized ones today, but because the cultural similarity and racial acceptance by host society was greater, and the economic climate was more favourable.

\subsubsection{Key Factors}

\subsubsection{A Partially Transformative Frame as the Official Frame}

One of the key factors that enabled this Workgroup to convey their key message was the availability of extant frames within the City that they could readily use to formulate a transformative alternative to the exclusionary dominant discourse. Here, what 
I call the 'economic benefits frame' was emerging as an increasingly popularized alternative the 'exclusionary dominant frame'. This was accelerated especially through the City's newly launched Immigration Ottawa Initiative (IOI), which was quickly gaining an official frame status within the City (City of Ottawa CPSC 2008-06-11). Launched by the City in 2007, IOI specifically aimed at attracting skilled or "internationally trained workers" and facilitating their integration into Ottawa' labour market (City of Ottawa CPSC 2008). As evident in the Deputy City Manager's report to the Council's CPS Committee in June 2008, a member of the City's senior management viewed this as directly tied to its economic bottom line. That is, the City was starting to view the economic integration of immigrants to be both beneficial to, and necessary for, the City's "economic prosperity, meeting looming labour shortages, [and] maintaining and growing the tax base" (ibid). ${ }^{183}$ This information from the City was being communicated to the Snapshot Workgroup through the two City members of the Workgroup, ${ }^{184}$ who in turn helped to leverage the City-community partnership more effectively at the Workgroup level.

\footnotetext{
${ }^{183}$ The appeal to the economic bottom line is very clearly conveyed in this report, which emphasizes "the emerging global, national and local issue of the labour market integration of immigrants", which "encompasses critical challenges to economic prosperity, meeting looming labour shortages, maintaining and growing the tax base and, helping immigrants receive the support they require (e.g. supports to employment) to successfully integrate into the workforce" (City of Ottawa CPSC 2008-06-11). It further advances the economic case to support this by referencing the research by the Conference Board of Canada which "indicates that by 2011 , newcomers will account for $100 \%$ of the net labour force growth in Ontario. This underutilization of newcomers accounts for a loss of between $\$ 2$ and $\$ 3$ billion dollars per year for the Canadian economy" (City of Ottawa CPSC 2008-06-11).

${ }^{184}$ For example, one of the City members provided the following to the Workgroup in June 2009: "In 2007, Phase 1 of the Immigration Ottawa Initiative (IOI) was launched. The goal of Phase 1 was to raise awareness regarding the various barriers facing immigrants within the City of Ottawa and to identify potential solutions to address the issues. Raising awareness included such activities as assessing the labour market situation of immigrants in Ottawa, developing an Immigration Ottawa web portal, participating in community activities to increase the hiring of skilled immigrants and learning about stakeholders at the local, provincial and federal levels as well as exploring potential funding opportunities" (CAWI 2009, June $19)$.
} 
In the City's own internal discourse, the successful (labour market) integration of (skilled) immigrants was now being reframed as, and tied to, the City's own economic growth strategy and potentially increased revenue, rather than as an added burden for the City to take care of the excluded and increased spending. This emerging official discourse itself contained an element of resonance with one of the existing dominant frames within the City, i.e., economic bottom line. In addition, this was a particularly high priority for the City in the context of entrenched neoliberal urban governance. ${ }^{185}$ The point that immigrants can help Ottawa gain an increased access to global markets also catered directly to the City's interest in its bottom line. This might have appealed perhaps to the sense of fear of Ottawa as a city being left out or falling to the bottom of the global competition, both for capital and for talented workforce, to drive growth. This economic benefits frame about immigration integration thus offered a tangible, positive solution to close off such fear: embrace immigrant contributions. This alternative discourse thus reframed the issue in terms of the self-interest of the City and of Ottawa as host society, and not only of the immigrants themselves.

Moreover, this business case was being institutionalized as a new Council directive in July 2008, when Council approved CPS Committee's recommendation that the City commit to working with the Immigration Ottawa Initiative to raise the profile of immigration issues across the City and to commit to action as a corporate citizen and an enabler for social change throughout our community (City of Ottawa Council 2008c, italics mine).

\footnotetext{
${ }^{185}$ This is evident in the Council's budgetary deliberations, the City's annual reports, strategic plans, as well as its organizational structure. For example, "economic development" has a dedicated department and is positioned high in the Corporate hierarchical structure, reporting directly to the City Manager's Office (City of Ottawa 2013a). In addition, as discussed in chapter 2, "cost-saving" was also a strong incentive for the EMC when it approved CAWI's proposal to "consolidate" the Gender Equality Lens into "one Lens". Here, the only one condition it imposed prior to approving the development of E\&I Lens was that CAWI obtain the partnership funding from Status of Women so that the City would not have to bear the full financial cost (Interview: g).
} 
What we see here is the clear, voluntary, and institutional commitment on the part of the City, including its senior management as well as its legislative arm, Council. In this sense, the Immigrants Snapshot Workgroup was already gaining a high level of buy-in, commitment, and even championing of their cause from the institutional leaders of the City through IOI - albeit with a strong emphasis on the economic integration. Moreover, the Council decided to take a strong leadership role within the broader society by committing to act as "an enabler for social change", and therefore, to change the status $q u o$. Thus, not only did this internal discourse of the City contain an element of resonance, it also embraced an element of radicalism to challenge and change the status quo the (labour market) exclusion of immigrants. In addition, this emerging official discourse was in itself starting to expand its scope to include other non-economic aspect of integration, such as encouraging "civic participation" of immigrants and the importance role of the host society in "building a welcoming community". ${ }^{186}$

This emerging official discourse of the City therefore served as a strong basis for a transformative frame, which incorporated resonance but also challenged the exclusionary status quo, at least in the economic realm. This official discourse came with an open acknowledgement about the existing barriers the economic integration of internationally trained workers, and the need for the City and the local employers to proactively remove such barriers. This alternative frame within the City thus already reframed the cause of the problem and the burden of responsibility for solving it, away from immigrants alone to a shared one that also required Canadian employers to take

\footnotetext{
${ }^{186}$ That is, while Phase I of IOI was all about the economic and labour market integration of immigrants, but Phase II turned the focus on to "the settlement and integration of immigrants" with a focus on "four priorities: civic participation, social inclusion, economic integration and building a welcoming community" (City of Ottawa CPSC 2008-06-11).
} 
responsibility and action. The City was publicly taking on the exclusion of these immigrants as a problem that directly concerned itself, and starting to view itself as a 'champion' and a leader in reaching out to, and encouraging, the local private businesses to change their existing attitudes and practices by hiring (skilled) immigrants. This offered the Workgroup a particularly robust extant frame that had already linked the interests of the immigrant community as the excluded group on the one hand, and the City and the host society on the other - and therefore, as a matter of mutual interest and benefit for all.

\subsubsection{Alignment with the Coalition, Partnership and the City's Official Frames}

This meant that it was relatively easy for this Workgroup to align their movement frame with the official frame of the City, and this offered added legitimacy to their message as they sought to reach their audience within the City. This frame alignment was also done by citing extensively the then-recent report by IOI, which was again provided by the City members of the Workgroup. This report, entitled "Faces of Ottawa: A snapshot of immigrant labour market integration - Highlights" offered the Snapshot Workgroup an official source of relevant facts, statistics, and a basis for the business case in support of immigrants' economic integration. In addition, there were already available in a written "snapshot" format that was readily convertible to be used for the Diversity Snapshot (City of Ottawa Labour Market Integration 2007).

Moreover, this 'economic benefits frame' of hiring immigrants - which portrayed them as diverse and valuable human capital - also aligned well with the two institutional pillars of the E\&I Lens to which it was 'tied in'. That is, this aligned closely with the 
aims of the Equity and Diversity Policy. ${ }^{187}$ This also aligned well with the Service Excellence mandate of the City, which aimed to increase both job satisfaction and enhanced work performance and efficiency of City employees, in order to achieve its ultimate goal of "client satisfaction" of Ottawa residents. ${ }^{188}$ All of these fed into the Workgroup's business case for diversifying the City's workforce in order to better respond to the changing and diversifying needs of its clients, i.e., the Ottawa residents. In short, this Workgroup was able to make a convincing case that immigrants can help the City achieve its own mission and business goals.

Moreover, this Workgroup's robust frame in turn fed into the coalition and the partnership frames of the E\&I Lens. This is reflected in the final text of the User's Guide, as one of the reasons for "Why This Lens?". Here, the second reason to this question reads:

It's Good Business. Our residents are becoming increasingly diverse, and so are their needs and aspirations. Diversity in our workforce, at all levels, is essential to translate these needs into effective delivery of policies, programs, and services. It is more cost effective to address inequities before they become wider social problems (CAWI and City of Ottawa 2010a).

This meant that the overarching frame of this Snapshot aligned well with the strategic priorities at the coalition and the partnership scales, as they sought to tie in the E\&I Lens with these two institutional pillars of the City in order to increase its resonance and

\footnotetext{
${ }^{187}$ Equity and Diversity policy states that "The City of Ottawa is committed to providing quality services by establishing a qualified workforce that reflects the diverse population it serves. It is City policy to foster an environment that respects people's dignity, ideas and beliefs, thereby ensuring equity and diversity in employment and ensuring customers and others have access to City facilities, products, services, and grants as defined by human rights legislation". This policy places an emphasis on removing "barriers in the workplace" or "systemic discrimination" in the City as a workplace on the one hand, and "outwardly focussed activities" such as "client service delivery" and "ensuring customers... have access to City facilities, products, services, and grants" on the other hand (City of Ottawa 2001).

${ }^{188}$ The City's management toolkit defines Service Excellence in terms of "creating positive client experiences" and "first and foremost an attitude that reflects how people delivering a service feel about their work and how clients feel about the service they receive. It is about creating moments that make people say 'WOW'. The focus here is explicitly on client satisfaction, but achieving this goal is directly linked to "engaged workforce" (City of Ottawa 2009b).
} 
legitimacy. In this way, the 'economic benefits frame' used in the Immigrant Snapshot achieved not only resonance but frame alignment in multiple ways.

\subsubsection{Frame and Resource Convergence in Broader Society}

This emerging alternative frame playing up the economic benefits of immigrants was also a part of a burgeoning discourse in the broader local society in Ottawa. At the time, local community organizations and initiatives targeted at facilitating the labour market integration of "skilled immigrants" and "internationally trained professionals" were receiving significant funding from the federal and the provincial government, and were expanding rapidly in the city. Leading local organizations such as Hire Immigrants Ottawa (HIO), which emerged out of the Internationally Trained Workers Partnership, as well as LASI World Skills among many others, were actively creating cross-sector partnerships to facilitate this process, especially by working closely with businesses and employers as key stakeholders. ${ }^{189}$ These new initiatives and their expanding networks were powerfully contributing to the growing 'economic benefits frame' of hiring this particular kind of immigrants - those that were skilled, educated, and trained overseas. This frame emphasized those who were suitable to fill the specific skill gaps and shortage in the local labour market, without employers having to spend too much money or time on their training.

\footnotetext{
${ }^{189}$ In the case of HIO, the primary focus is on employers' needs and removing barriers employers face in accessing immigrant workers, rather than immigrants in accessing employment. It describes itself as "a community-based initiative that brings together employers, immigrant agencies and stakeholders to enhance employers' ability to access the talents of skilled immigrants in the Ottawa area", and was launched in 2006 as a response to a growing need to identify and address barriers faced by employers in the hiring and integration of skilled immigrants into the labour force" (HIO 2006, italics mine). HIO's "lead partners" are: City of Ottawa, LASI World Skills Inc. (a coalition of Local Agencies Serving Immigrants), Le Regroupement des gens d'affaires de la Capitale nationale (RGA), Invest Ottawa, Ottawa Chamber of Commerce, and United Way/Centraide Ottawa - host of the HIO Secretariat (ibit).
} 
This discourse thus drew heavily on the business-sector ideas and language, and was framed from the perspective of businesses and employers. ${ }^{190}$ The expression "champions" was also used actively by this emerging subsector of immigrant settlement, as in the case of HIO's Employer Council of Champions ${ }^{191}$, which recognized and celebrated the leaders in the area, which in turn provided further publicity, and thus economic incentive, for these recognized employers. In addition, this Workgroup was able to draw on the concrete, hands-on, practical and actionable tips and resources, written in plan and easy to follow language that these local initiatives already had produced. For example, HIO’s “Employer's Guide to Integrating Immigrants into the Workplace", ${ }^{192}$ which this Snapshot cites as part of the "Tips" under the "Barriers and Inequities" section of the Snapshot (CAWI and City of Ottawa 2010e: 5).

The City of Ottawa was an active and official partner in many of these initiatives, alongside the business organizations such as the Ottawa Chamber of Commerce and Invest Ottawa. ${ }^{193}$ Here we see that this emerging 'economic benefits frame' in the City was also aligning and resonating with, and being supported by, a growing frame within

\footnotetext{
${ }^{190}$ Very similar ideas and language used in the Immigrant Snapshot, and the User's Guide of the E\&I Lens, are also found on the Ottawa Chamber of Commerce's own website. It includes a section on "Why Hire Foreign Trained Professionals", where it declares that "Hiring Immigrants is Simply Good Business... Employers who diversify their workforce are better able to: Attract and retain top talent to alleviate skill and labour shortages; Better understand and respond to the increasingly diverse local customer base; Expand local markets, and develop new global markets, by leveraging immigrants' international experience and cultural awareness; Enhance productivity, creativity, employee relations, and decision-making through diverse approaches; and Save on employee training costs by utilizing transferable foreign work experience" (Ottawa Chamber of Commerce 2008). While this has a much stronger and explicit economic self-interest of the employers than the language used in the final text of the E\&I Lens, some of the ideas and expressions used here are very close to "It's Good Business" segment in the User's Guide (CAWI and City of Ottawa 2010a: 5).

${ }^{191}$ The Employer Council of Champions" features "senior executives from top Ottawa employers that champions the integration of skilled immigrants into the labour force", and its sector-specific working groups cover the: IT, Health, Public, Finance, and BioTec sectors (ibid).

${ }_{192}$ The source of funding for the production of this practical guidebook targeted at employers is also telling of this trend, as it was "provided by the Ontario Chamber of Commerce with support from the Government of Ontario" (HIO 2008: 29).

${ }^{193}$ Invest Ottawa has been described by the Ottawa Citizen as "a City-funded lobby group" for the business community (Pilieci 2013).
} 
the broader society, which was being promoted through the local non-profit and the private sector 'partners'. Moreover, such growth was further propelled by the policy and funding priorities not only at the municipal government but at the provincial and the federal levels. Both of these higher levels of government were investing in the targeted support to facilitate the economic integration of skilled immigrants, driven by a growing realization of the economic necessity of doing so for Canada and for Ontario. ${ }^{194}$ In this sense, the possibility existed for this Workgroup to achieve horizontal alignment of their movement frame with those in the other sectors at the local scale, and vertical frame alignment within the coalition and the partnership scales, as well as with higher levels of government.

\subsubsection{Strategic Resonance and the Risk of Reinforcing the Dominant Frame(s)}

While this discursive landscape within the City and the broader society presented a tremendous strategic possibility for the Workgroup to capitalize on, this also ran the risk of veering too close to the dominant frame which was narrowly focused on the economic bottom line and the self-interest of the host society (and the employers in particular), which often manifested in an exclusive attention on skilled immigrants. While emphasizing resonance with these two frames were instrumental to eliciting a 'shallow' buy-in from their audience based on their immediate self-interest, this did not help nurture the mutual commitment that is beyond the immediate self-interest. In other words, while this was effective in convincing the audience that "Because it's good business" - which is the second reason presented in the User's Guide portion of the E\&I Lens, it was not as effective in convincing them based on the first reason - "Because it's

\footnotetext{
${ }^{194}$ Federal immigration policy and funding priorities were shifting away from the previous Liberal government's emphasis on the Family Class and the Humanitarian Class, to the Conservative government's focus on Economic class.
} 
the right thing to do" (CAWI and City of Ottawa 2010a). Without such buy-in, it can become challenging to institutionalize a sustainable and lasting cultural change within the Corporation of the City and in the Ottawa community at large, where immigrants are welcomed, valued, and embraced not only when they bring a particular kind of economic benefit to the host society, and not only in times of short-term labour market shortage.

Another potential risk that accompanies a discursive strategy to extensively embrace the economic dominant frame, and a 'partially transformative' frame that heeds close to it, is that this could also contribute to legitimatize and reinforce the dominant frame itself. This is especially the case given the fact that beyond the specific scope of this project of Diversity Snapshots, these dominant frames are prevalent and entrenched in broader society, in particular in the business sector. ${ }^{195}$ For example, the Ottawa Chamber of Commerce is a strong "champion" for hiring internationally trained professionals. However, its own version of "business case" frames the same topic using a very similar set of ideas and expressions, but from a slightly different angle that reflects a slightly different interest than those in this Workgroup. That is, the Chamber of Commerce adds that hiring internationally trained professionals means that employers do not need to invest in human resource training and development on an ongoing basis (Ottawa Chamber of Commerce 2008), for the welfare of the workers was not their primary interest. If the employers prefer to hire these cheaper and ready-to-deploy internationally trained workers without having to invest in their training, then such a

\footnotetext{
${ }^{195}$ This is a sector that often commands the attention of the municipality's key decision makers, including the mayor, the Council, and the executive management, as the City views them as an important "partner" in financing its operation. This is evident for example in the City's "financial statement discussion and analysis" (FSDA) which is included in the annual report each year. Since 2009, "The Outlook" section of FSDA has highlighted year after year that "The City has developed constructive relationships with other levels of government and the private sector in order to obtain sustainable funding to provide the municipal infrastructure" (City of Ottawa 2010: 29; 2011b: 6; 2012: 3; 2013:7).
} 
frame could easily fuel another age-old dominant frame that immigrants are stealing jobs away from Canadians. Or, in times of major economic downturns, such a frame grounded primarily in the economic self-interest of the employers could quickly evaporate, if the deeper buy-in or understanding of the importance of embracing immigrants, beyond the short-term economic interest, has not been achieved. ${ }^{196}$

\subsubsection{Combining, Extending, and Modifying Frames}

However, instead of viewing resonance and radicalism as an either-or choice, this Workgroup modified and extended the dominant- and the partially transformative economic benefits frame, by incorporating some radical elements into them, and created a more fully transformative frame that retains resonance but still pushes against the status quo. For example, this frame included the economic appeal such as the increased prospects of capitalizing on talented human capital at low cost, accelerated innovations, expanded access to investment capital and global markets, and being better tuned into diversifying consumer tastes and preferences. This helped appeal to the self-interest of the City of Ottawa and its bottom line, and its key economic stakeholders, i.e., the business sector as employers. This argument for hiring immigrants also contained a radical element in itself in the sense that it countered the other set of exclusionary dominant frame grounded in attitudes of xenophobia or racism that supported continued economic exclusion of immigrants. Instead, it reframed the immigrants' exclusion in

\footnotetext{
${ }^{196}$ Federal government's expansion of the temporary skilled foreign worker program specifically and exclusively based on the short-term labour market needs of Canadian employers, at the expense of reduced spots for more permanent immigrants and under other classes, is also dangerous, for it reinforces the economic and self-interest based immigration policy based on the dominant frame, but also feeds the dominant backlash against immigrant workers, and does not foster any vision or interest in an inclusion and equity-oriented discourse about immigration.
} 
terms of missed and wasted economic opportunities for the host, and hiring them as a relatively easy and certainly desirable business solution.

This way, removing the barrier of racism could be presented as being in the direct interest to the host society if it wants to get the 'benefits' of immigrants' contributions. The Workgroup was able to weave in a radical element into the Snapshot, in this case, racism in the host society as a major barrier to the inclusion of immigrants. Keeping in line with the economic benefits frame - and in particular the 'benefits' part of it - racism could now be presented as a major barrier for the host society to tapping into this great, and currently underutilized, economic resource. Even though this is presented more 'softly' in terms of the lack of cultural competence on the part of employers (rather than as racism per se), this nonetheless reframed the issue of racism not in terms of the inherent inferiority of 'immigrant workers' or their incompatibility with Canadian workplaces, but in terms of barriers posed by the host society.

The Workgroup also extended or expanded the 'economic' part of the economic benefits frame into a 'broader benefits frame', which could then encompass the broader social, cultural, political, and other economic contributions and benefits that immigrants of all kinds can offer to Ottawa. While building on the economic focus of the dominant frame and the partially transformative frame, this extended version was able to counter these two frames' exclusive focus on the economic bottom line or the self-interest of the host society in determining what kinds of immigrants to attract, and for what reason. Moreover, building on this expanded transformative frame, the Workgroup was now able to incorporate another radical point into the Snapshot. That is, by expanding the discussion beyond the narrow confines of the economy, the Workgroup could now insert 
the issue of racism back into the broader diverse settlement and integration processes of immigrants beyond the labour market.

This is a radical point as it challenges directly and explicitly the status quo of inequity in the form of racism, but also because it names the host society as the source of it. It shifts the 'blame' for delayed integration from the immigrants to the host or the dominant society, which was the majority of their target audience. In this sense, this is an 'oppositional frame"' that explicitly names and critiques the unequal power relations between the oppressor and the oppressed in society. In addition, this expanded discussion about the diverse settlement processes, and the role that racism plays in delaying integration for many racialized immigrants, in turn counters the other dominant and official frame in the City, which assumes a universal and homogeneous settlement process following a linear progression towards full citizenship.

\subsubsection{Strategic and Forced Resonance: Letting Go of the Radical by Necessity}

However, the Workgroup members discuss in their interviews the other factors that made it strategically desirable, but indeed necessary, for them to omit some of their most fundamental - and the most radical - elements of their message out of this Snapshot. Some of the Workgroup members identified the unequal structure of "power", "power relation" or "power imbalance" in society as the most fundamental factor behind the inequity and exclusion in the city, and it is this that needs to be challenged in order to create inclusion and equity (Interviews: anonymized). These members critiqued their own Snapshot and the Lens as a whole as it "doesn't consider power", "does not include a power analysis", or "not directly say it here" (ibid). Yet, they explained that they had to concede with a "simplified" narrative in the Lens, for example one that presents 
demographic categories like "race", "ethnicity", "immigration status" or "gender" as "a factor of exclusion", which in turn set the context within which their Snapshot was presented to the reader. In short, they needed to work within the interpretive context that was set by the frames adopted at the coalition and/or the partnership scale.

However, one member pointed out that such narrative "misnames the problem" that one's immigration status or one's 'race' is the problem. Instead, the real factors of exclusion or inequity are "racism" or "patriarchy" as internalized and practiced by all of us in society, or "bias", "greed", "historical racism", or "lack of accountability" of the City to those who are often excluded in our city. ${ }^{197}$ This member explained, however, that such misnaming "makes people feel good" especially those in the target audience, as it "normalizes exclusion" without pointing out or challenging the "structural" or "systemic" nature of it. Hence, it leaves the status quo untouched at the base. That is, it achieves a form of resonance - or more specifically, avoids potential backlash - but only at the expense of mis-framing the real issue by omitting the most important, radical message. This Workgroup member was fully aware of the very "damaging” and indeed "oppressive" effects of leaving out the radical element from the frame of the Snapshot and the Lens:

This way of speaking... stigmatizes the issue and makes people who are excluded feel bad about it. It's oppressive. The language is oppressive in big ways, damaging ways. Not only does it not

\footnotetext{
${ }^{197}$ This Workgroup member elaborates on this "mis-naming of the process of exclusion". When you say "race, ethnicity is a factor of exclusion - no my race is not a factor of exclusion. My beautiful colour has not offended anybody. It's how people perceive it because of their history. Because of them. Not me... So when this [Lens] tells me my race and ethnicity is a challenge, you have no idea how happy I am with my race and ethnicity... I come from a lineage that is beautiful. Seriously my lineage is wonderful, I am very very proud of it. And I think my colour is one of the most beautiful colours. It's very appealing to look at. I like myself when I look at it. When people tell me my race is a factor my instinct is 'Exactly what do you mean?' Greed is a factor bias is a factor bias based on historic racism is a factor which was based on greed. This is the factor. All of us in various combinations [of bias and greed] is a factor. And lack of accountability is a factor. Race is not a factor. It's not my race - it has nothing to do with it. Why are we afraid to say no? What are we telling our young people... that race is a factor? So it's oppressive, it's exclusion really, to speak this way (Interview: anonymized).
} 
allow us to think properly but it also diminishes, devalues, denigrates, excludes (Interview: anonymized). ${ }^{198}$

Moreover, this member wonders how this could "continue to be damaging" also for the long-term goal of the community movement pushing for equity and inclusion. This is "because the moment they associate race as being a factor of exclusion, it just adds to the perception that it's about the race, not the power" (ibid). This further normalizes the very exclusionary language, thought, and practice that this Workgroup was trying to eradicate.

Instead, the Workgroup had to "let it go for strategic considerations" and "because this is what's possible at this time"; and frankly, "nobody will listen to you" if you say openly that equity and inclusion is all about changing the power structure of society (Interviews: anonymized). One member explained in more detail that this is "because the conversation [on power] is difficult and people are not on the same level of awareness", and "because we will not have enough time and resources and awareness to actually propose a different approach" (Interview: anonymized). This is again linked to the uneven power structure between the excluded communities and the City, where the two sides cannot negotiate as equals or as equal partners, even though the Lens was being developed as an official partnership project between them. For example, one Workgroup member explained that the people who are systemically excluded in society "don't have power" or "a real voice" to force change on the part of the City:

But the reality is... the power relation is such that the people excluded don't have power despite the [formal] democratic processes. So there are no consequences for institutions not to do anything... And there is real zero voice. The numbers of these people when you add up the eleven excluded groups is so high, but their participation in voting voice, their representation, their

\footnotetext{
${ }^{198}$ This member elaborates on these damaging effects at personal level: "People categorize me left and right... It's very oppressive, extremely oppressive and damaging. I tell my young nieces and nephews 'you are not Black, you are not an immigrant, you are just [names of children], you are you. You are the daughter of [name], who was the son of [name]. This is your history. Do not subscribe to these divisions. And do not allow them to categorize you, it is very damaging. I don't even have enough words to stress how damaging it is. And we expose our children in the schools to this, and it's horrible (Interview: anonymized).
} 
relationship with the Council is almost all zero. If the City Council or the City Manager does not do anything [about it], then there will be little consequences [for them]. ... So they may say 'It's complicated therefore we will do very tiny incremental things', and nothing would happen. Their jobs are not jeopardized. They don't feel guilty about or may not be even aware of what the damages of these exclusions are [to people who are excluded]. So there's little consequence. So we content ourselves because of the structures (Interview: anonymized).

As underdogs structurally excluded from the polity, these marginalized communities including immigrants, have no option but to seek small "concessions" from those in positions of power. Otherwise, the Workgroup members explained, they can so easily get shut down, ignored, and be left without a recourse, as there is no real mechanism for the excluded community(ies) to enforce 'accountability' from the City. ${ }^{199}$ In addition, as one member puts it:

...power is a real thing... If you alienate those from whom you want to get concessions, they have the power to not ever listen to you again... So we make choices that are the least harmful, because not to do anything is not conceivable" (Interview: anonymized). ${ }^{200}$

Similarly, another Workgroup member commented on the sheer difficulty of securing

"the political will" from the City's senior decision-makers to initiate any real challenge to

tackle the existing systemic barriers and structure of power.

\footnotetext{
${ }^{199}$ Similarly, another community member commented on the lack of transparency and accountability on the part of the City to the community, speaking from the perspective of the community being cut off from the implementation process of the E\&I Lens and the Snapshots in the City: "What is actually happening during the implementation phase? How sincerely are people implementing this? During the implementation phrase we [from the community] are not there to look at it ourselves, so this is really difficult for us see what is happening over there... I don't know in terms of the commitment, in terms of understanding, what's happening there. I actually don't know... It is not possible for me to look at what is actually going on. We don't have that much access... We are not enlisted to do that evaluation, although I believe in general they incorporated other initiatives But the City is really slow" (Interview: anonymized).

${ }^{200}$ This member states: "It's very hard to get there. We have learned some things about people who have to be strategic and be trying to advance this we have learned a couple of things. We have learned that power is a real thing. And you are pursuing concessions however small they are. And if you alienate those from whom you want to get concessions from they have the power to not ever listen to you again, and there's no consequence [to them]. So we choose to do we make choices the least harmful. Not to do anything is not conceivable" (Interview: anonymized). This is an example where it becomes evident to us that the movement actors are not naïve to believe that their (transformative) movement discourse directly equates (transformed) reality, but rather that it is a medium through which power is exercised and negotiated. Even then, these actors are aware that they are not equal agents free from the other non-discursive structures of power in society, which still shape the terms of their negotiation, such as the City's decision making and resource allocation structure. In a sense, this view is close to Edward Said's description of the relationship between "discourse" and "power" as in the discourse of Orientalism as a mechanism of European domination of what it portrayed as "the Orient" (1994[1978]).
} 
You would like to see the ideal situation. You would like to see the mainstreaming of power analysis, and challenging power relations. But it's not possible if you don't have the really really strong political will and commitment. That is why there are systemic barriers in society and they remain in place. So within this environment, there is still hidden racism - well, not hidden, it is open. There is open racism happening in our city. So this is really difficult if you want to see change and make a difference in people's lives. It requires a strong commitment from the other side... This is not easy, to get the political will [from the City] (Interview: i).

These interview comments reveal a deliberate and strategic framing that the Workgroup engaged in, not entirely as a matter of choice but also by necessity, given how far they saw that their "ideal situation" is from "the reality" (Interviews: anonymized) ${ }^{201}$ In this context, letting go of some of the radical elements - even though they were at the very core of their understanding of inequity and exclusion - was strategically requisite to ensure resonance, to obtain buy-in, and to continue working at creating "the political will" of those in positions of power in the City. In addition, much like the other Snapshot Workgroups, this Workgroup also emphasized that "it was really really important to make this simple, user-friendly, and easy for people to understand the issues, and easy for people to use it" (Interview: i). Another member concurs with this view, that as much as the "misnaming" could be potentially damaging to the cause, "it was necessary for didactic reasons", and "it may indeed be useful for people to think through it slowly" and to take small steps. A different member stated that they can still be satisfied with the way the Snapshot was written, and with the way that the Lens contains eleven Snapshots, because “although power isn't here directly, it's imbued in it" by virtue

\footnotetext{
${ }^{201}$ The community movement does not view this with an entirely a pessimistic outlook or complete stoicism: "One thing we would like is a critique [of status quo] - but the reality is the reality. The constraints are real, the constraints in terms of language, in terms of resources, in terms of time. In terms of expectations of these leaders - productive leaders in the City... So you have to be strategic, but also be compassionate, in terms of where we are at. Individuals are products of our society, and our limitations of understanding as a society - so you are compassionate with individuals. ... These are the conditions, so you work with this reality, and you make it happen, and you recognize small progress but nevertheless progress" (Interview: anonymized, italics mine).
} 
of having the focus on those who get affected the most by systemic inequity, thus at the lower end of the spectrum, "so it's there, in a way" (Interviews: i, n).

In these comments by the interviewees, I can see the dynamic interactions across scales which are central to my argument. The power dynamics at the partnership scale between the City and the excluded community - certainly shapes the conditions under which this individual Workgroup could choose their discursive strategies, even as the their participation in this official City-community partnership through the E\&I Lens opened up access for the community to seek concessions from the City. The discursive strategy adopted at the coalition and the partnership scales at the Reference Group - to prioritize user-friendliness for their audience, and thus resonance, made it riskier for the Workgroup to present their core understanding of what the real barriers were: the unequal structure of power in the city/City.

And yet, we can also see that the Workgroup did not simply resign themselves to these frames 'imposed' upon them, but actively and strategically sought to align their movement frame and seek resonance with the extant frames in the City and the broader society, and also to transform them to suit their goals. These included the dominant frames, partially transformative economic benefits frame as an emerging official frame in the City, as well as an emerging master frame in the local society (though leaning close to the economic dominant frame). The Workgroup engaged both in cutting out some of the more radical elements out of their frame, but also pushing these extant frames to broaden their scope, so that some of the radical elements of their message could still be incorporated into the Snapshot, to form a transformative frame that still retained strategic resonance. 
After conducting these interviews, I realized that this is evident in the other ways in which the Snapshot frames the scope of the narrative on globalization, changing immigration patterns and their impact on Ottawa for their audience. That is, the final text of the Snapshot informs the readers that increasingly recent immigrants to Ottawa are coming from region outside of its traditional source of immigration, i.e., Europe, such as Africa, Middle East, Asia, Caribbean and South America, and as such, more of them are "visible minorities" (CAWI and City of Ottawa 2010e: 3). As a radical element the Snapshot points out that racism in Canada is a key factor in delaying the integration of these immigrants, while the resonant (and transformative) element emphasizes the benefits that these immigrants bring to make Ottawa a prosperous city, in particular through their economic contributions to give Ottawa an advantage in the increasingly competitive global economy.

However, in analyzing this text I see that it does not wade into the racist foundation of Canada's immigration laws, policies and practices (Henry et al. 2005) that explain why "visible minority" immigrants were not recruited to settle the recently 'vacated' indigenous land like European immigrants were, even though the Workgroup members did share this critical perspective. ${ }^{202}$ Nor does the reference to the changing migration patterns extend to the fact that these racialized recent immigrants are arriving in an increasingly bifurcated global economy between the global north and the south, which in turn is closely linked to the history of European colonialism in the latter part of the world. While this Snapshot almost touches upon these much broader, deeper, macrohistorical factors behind these changes affecting Ottawa, it does not dare wade into them.

\footnotetext{
${ }^{202}$ Although the final text under "Who We Are" does refer to "changing immigration policies" as part of the different experiences of, and barriers in, the settlement processes of immigrants (CAWI and City of Ottawa 2010e: 2).
} 
Naming these would make it 'too radical' and would not serve the immediate and strategic purpose to obtain the buy-in from their target audience while educating them on what they can do in their everyday work situations to ameliorate the status quo in the City. Such macro-scale analysis critical of the very foundation of Canada and the global economic order would most certainly fall far beyond the scope of responsibility that the target audience as municipal employees for the City of Ottawa was expected to handle in their own work.

\subsubsection{Workgroup Composition and Strategic Awareness}

Finally, this Workgroup featured a high number of individuals who were part of the Equity and Inclusion Lens Reference Group (like the People with disabilities Workgroup did), but these individuals had historically been part of the continuing community effort to push the City to advance the Equality Framework and the Gender Equality Lens as well, and they had variously taken a leadership role in each of these three interrelated initiatives. ${ }^{203}$ This meant that these individuals brought an acute awareness of the strategic necessity to sell the idea of broad-based equity and/or gender equality to the target audience in the City, including what has been effective and what has not (Interviews: a, e, i, n). In this sense, they had internalized the strategic necessity of audience buy-in and resonance even while they pursued a much bigger vision of equity and inclusion in the long run.

As part of this vision, the Workgroup members also shared the same commitment to addressing racism in the City/city, as well as the strategic awareness that this was an issue that was often avoided by the 'mainstream' society. Such strategic insight about this movement-specific priority was also shared between the Immigrants and the Visible

${ }^{203}$ Put differently, these individuals had been part of CAWI's early history. 
minorities Workgroups. This was done mainly through some of the members who participated in both Workgroups, namely the two City ally members and the EDAC liaison member. This overlap in membership between the two Workgroups partly informed how they thought the issue of racism should be conveyed in this Snapshot, especially given the difficulties the other Workgroup had in raising it as part of the Visible minority Snapshot. ${ }^{204}$ Moreover, before the Snapshot development process officially started, the lead members from these two Workgroups who also served on the Reference Group had discussed how to coordinate between these two Snapshots, given the overlap in terms of population and barriers, namely racism, affecting these two communities (CAWI 2008-11-27).

It was thus planned in advance that the Immigrants Snapshot would focus more on the specifically settlement-related issues for immigrants, while including a reference to the role of racism affecting the racialized segment of this community which extends into the second- and third-generation immigrants. In turn, the Visible minority Snapshot would shed light on the role of racism more prominently, especially in the lives of nonimmigrant racialized Canadians who are often "assumed to have just arrived", and whose continued experience of exclusion due to racism as often sidelined by 'mainstream' society in favour of attending to the settlement needs of newcomers (CAWI 2008-11-27). Although it was unforeseen by these members at the time, this division of content between the two Snapshots partially contributed to the additional challenge that the Visible minority Workgroup experienced later on. That is, the more radical content on racism was reserved as the exclusive focus for the Visible minority Snapshot, while the 
more resonant and partially transformative frame about (economic) integration of immigrants was reserved for the Immigrants Snapshot.

\subsubsection{Immigrants Case Summary}

The Immigrant Snapshot thus used the dominant frame as the basis for their transformative frame. It closely engaged with the economic benefits frame that emphasized the exclusively economic benefits of labour market integration of (skilled) immigrants, especially to the host society and in particular the employers, but extended it to broader benefits of not only economic but also political, social and cultural integration of (all) immigrants to both immigrants and host society. It then brought a radical element back into this expanded frame by naming racism in host society as a significant barrier to immigrant integration, and a barrier to the immigrants but also to the host, as this prevented them from accessing the full benefits that immigrants offered. This way, resonance acquired through the dominant frame opened the possibility to reintroduce a radical element into it, and thus to make it a transformative frame.

This framing strategy was made possible in part by the readily available (partially) transformative frame, which was also becoming the official frame of the City. This also meant that their community movement-specific goals aligned well with the City's institutional framework. This was also backed by the commitment from its highest leadership to champion this cause as part of its own business case, and to act as 'enabler of social change' in the broader local community. In short, the City itself showed readiness to challenge the status quo, thus reducing the 'risk' associated with a radical element in their frame. These factors converged to form a particularly effective transformative frame that also aligned well with the coalition and the partnership frames, 
which emphasized resonance in order to generate audience buy-in, while still containing some elements of radicalism as part of it.

At the same time, however, this still came at the expense of the Workgroup's most fundamental and radical message about the problems of the unequal power structure between this community (and all other marginalized communities) and the City. In this particular sense, radicalism and resonance constituted mutually opposing elements in their frame, for they had to let go of this fundamental critique of the status quo for the sake of keeping their Snapshot resonant and aligned with the user-friendly scope of this tool. Moreover, racism in the dominant society was one element of radicalism in this Snapshot, and not its primary focus. In contrast, racism in the dominant society constituted the central focus of critique in the Visible minority Snapshot, and as the next section shows, this triggered stronger resistance from the City.

\subsection{Visible Minority Workgroup Subcase}

\subsubsection{Key Message}

We are diverse, and the fastest-growing population sector in Ottawa. One third of us are Canadians by birth and our families have been part of building Ottawa for more than a century. We are grouped together for being nonwhite, but in reality, we are a rich mix of ethnic origins and cultures from as many as 100 different nationalities (CAWI and City of Ottawa 2010j: 2).

Like many other Snapshots, the opening lines of the Visible minorities Snapshot convey the internal diversity of this community that is often obscured by a single label 'visible minorities'. However, unlike the other three Snapshots, the opening line in this one does not contain the key elements of a transformative frame that names the core of the problem, its reframed cause, who is responsible for solving it, and an alternative solution, as well as why such solution should interest the target audience. Instead of presenting them in a tight, complete package upfront in this opening paragraph, these 
elements are instead spread over the rest of the Snapshot, presented in more subtle, indirect and ambivalent ways. Or, when it is directly presented, its introduction is delayed within the document, a subsection, a paragraph, or a sentence. In a sense, this Snapshot skirts around the core issues that the Workgroup members wished to convey.

This slightly different framing in this Snapshot reflects the intense process of negotiation that occurred between the City and the community over the content of this Snapshot and how it could be said, as well as the strategic compromise the Workgroup made in light of the existing dominant- and the official discourses within the city. Therefore, the meaning(s) of this final text can be better understood in light of the two key messages that the Workgroup sought to convey through this Snapshot: to name racism as the core issue, and to critique the term 'visible minority' for being a powerful source of racialization and stigmatization for this community. These were particularly salient in light of the existing dominant discourse(s) in the City/city, which tended to deny the existence of racism and insist on using 'visible minority' as the official and appropriate terminology for the City to use (Interviews: a, b, e, k, o, u; CAWI 2009-04-07, 04-15). With this in mind, I will first present my analysis of the Snapshot text below, then discuss the key messages that the Workgroup identified during the development process of this document in more detail.

To begin, the text in the opening lines and the next subsection "Who We Are" subtly signals that those in this community may not embrace or identify with this category 'visible minority', therefore hinting at some kind of problem with the term but not making it explicit. ${ }^{205}$ However, the rest of the text contains some elements of a

\footnotetext{
205 "We are grouped together for being nonwhite, but in reality, we are a rich mix of ethnic origins and cultures..." indicates a subtle sense of objection to being lumped together simply for "being nonwhite",
} 
transformative frame borrowed from other Snapshots. For example, much like in the People with disabilities Snapshot, this one also presents a positive portrayal of this population that counters the negative stereotypes/assumptions associated with 'visible minorities' as people. This is done by referring to the long-standing, historical presence and contribution of this population to building the city "for more than a century" (CAWI and City of Ottawa 2010j: 2). The text plays up the demographic diversity and sheer heterogeneity of this population as well, which is often masked by this this umbrella category.

The "Who We Are" section features other elements of a transformative frame, which included the discursive innovations imported from the GLBT Snapshot as discussed in the previous chapter. For example, it presents a waiver on the use of the City's official language in this document, mentioning that "there is a debate about the use of the term 'visible minorities' (See Definitions)” (CAWI and City of Ottawa 2010j: 3), which directs the readers to the addendum at the end of the document for more detail. This waiver is followed up with a practical suggestion for the audience to "respect each person's self-identity and dignity" and to "ask" the individuals "how would you like to be addressed?" (ibid). However, unlike the GLBT Snapshot, this segment does not provide an explanation of what the debate is about and why it is important to this community.

These various discursive tactics therefore do not result in a clear, concise, and complete package of transformative frame like the other Snapshots do, as the key

which does not match the reality of who "we" actually/really are (CAWI and City of Ottawa 2010j: 2). The use of a passive voice here also hints very subtly that such lumping together is arbitrarily done by somebody else, and is not the self-chosen definition of who "we" are, though it does not quite say so directly or specify who is doing such lumping together. While this indirectly rejects the arbitrary nature of racial categorization or racialization, it shies away from using the word 'race' or 'racialization' to refer to this mismatch between this imposed or ascribed identity vs. self-identity. 
elements of (re)framing a social issue are not all present in the opening paragraph, such as the core problem facing this community, its real cause, and who is responsible for solving it, as well as the alternative solution to it. Moreover, these discursive tactics borrowed from the transformative frames of other Snapshots are full of ambivalence in this Snapshot. For instance, the heavy use of statistical data and categories to talk about this "population sector" (CAWI and City of Ottawa 2010j: 2) establishes objective and undeniable facts about who these people are, but it also has the effect of playing down the 'first person voice' of this community, which was an important part of the reason for creating these Snapshots in the first place. This sense of connection with the community and an understanding of who they are, what their visions and aspirations are, what their challenges are, and what solutions they'd like the City to pursue as told from their perspective, was an important part of what the City audience found attractive about these Snapshots. Or, in short, this 'first person' voice was an important part of generating the audience buy-in to support their vision. However, in this particular Snapshot the readers do not get to hear this yet.

Another example of ambivalence is the reference to the visible minorities' historical contribution to the city. One the one hand this counters one aspect of the dominant stereotype that takes 'visible minorities' to be synonymous to 'recent immigrants' - and not 'Canadians' as they are assumed to be outsiders who do not belong here. On the other hand, the text does not educate the readers about such connotation implied in the term 'visible minority' as an important factor in these people's experience/sense/feeling of exclusion, and why some people may not embrace this term. Even while there is an undertone that hints at this indirect critique of the stereotype, 
unlike in the GLBT Snapshot, the text here shies away from breaking the news to the readers about what exactly the underlying problems are: the issue of racism and the logic of racialization embodied in the term 'visible minority'. ${ }^{206}$

Being ambivalent, this is not entirely negative, however, and we see evidence of strategic framing on the part of the Workgroup at work. For example, the statistical and objective tone used in the first two thirds of this subsection allows the Workgroup to conclude this subsection by (finally) presenting the core issue behind the experiences of being a visible minority in Ottawa: "Racial prejudice and racism" (CAWI and City of Ottawa 2010j: 2). It declares that to be a "historical reality" that "persists today" - as an established, unbiased, thus undeniable, fact (ibid). On the one hand, this leads to a noticeable delay in talking about the core issue of racism until further into the document - for example until the very end of "Who We Are", or until the middle part of the Snapshot under "Barriers and Inequities" section, and this reduces the transformative effect of the opening lines. On the other hand, once the taboo of naming racism is lifted further into the text, this Snapshot raises the substantive issues related to racism clearly, directly and unequivocally, even while it avoids using the 'strong words' such as 'racism', 'race', 'racialization' (all the 'r-words') or 'white privilege' and opts for 'softer' expressions such as "racial prejudice" and "racial discrimination" (ibid).

\footnotetext{
${ }^{206}$ The word 'race' or 'colour' is not mentioned in 'Who We Are' except as part of the direct quote from the Statistics Canada's official definition of "visible minority". In a sense, this helps convey the Workgroup's message that many people in the community do not embrace the arbitrarily imposed racial category by the government as a meaningful self-identity to them, and seek to distance themselves from it. (And the 'community narrative' part of the text immediately follows up this definition with a waiver on this official language, noting that there $i s$ a debate about it (in the community)). On another level, this could be interpreted as 'couching' this controversial word 'race' as part of the government's official discourse, to add legitimacy in naming it in the text and to mitigate the negative reaction from the audience before the Workgroup could move into directly naming 'racism' at the end of this section. On yet another level, the prominent positioning of this official definition in the body of the text here, and at the beginning of this paragraph (rather than in the "Definitions" section at the end of the Snapshot), also reflects the insistence by the City representative to stick to the official language 'visible minority' in this Snapshot rather than the alternative expression that the Workgroup suggested instead, i.e., 'racialized' people or community(ies).
} 
In short, despite the delay and the avoidance of these words, the "Barriers and Inequities" section of the Snapshot conveys the substantive content about the core issues of racism in a manner that is direct and to the point, and counters the dominant discourse(s) about racism and about visible minorities. For example, the first three barriers presented in this subsection deal directly and specifically about racism in content, under subheadings of "Attitudes", "Stereotypes", and "Denial of racism" (CAWI and City of Ottawa 2010j: 5-6). These set the context for the rest of the section, which moves onto the other concrete areas of inequities that visible minorities face as a result of racism, such as employment, housing, access to services, etc. ${ }^{207}$ This part of the Snapshot also presents various related concepts in plain language, even though the phrases such as 'racialization' and 'white privilege' are directly not used to describe similar content. ${ }^{208}$ The text here also creates some breathing room for the audience who might feel defensive and uncomfortable while reading these lines about racism, by frequently referencing the often "unconscious" or "unintended" effects of racism as a systemic issue rather than a conscious and intentional act on the part of the individuals, in order to mitigate the

\footnotetext{
${ }^{207}$ Though again, the word "racism" is used only in the indirect and negative manner in these subheadings, for the terms "attitudes" and "stereotypes" sound innocuous enough, and the word "racism" is used only as part of the third subheading that names and problematizes the "denial of" it rather than racism per se (CAWI and City of Ottawa 2010j: 6). So when the readers skim these subheadings - which appears on the very first page under "Table of Contents" of this Snapshot as a summary of barriers affecting this population - the word "racism" does not stand out too much as a main focus of the document, which could put off many readers and push them away from reading further on.

${ }^{208}$ For example, the text reads: "Racial discrimination is a major barrier for visible minorities. It is present in individual attitudes and behaviours such as in inter-personal relations. It is also present in how society is organized, including the norms and assumptions that underpin institutional practices or the way we do business. This results in advantages for those who are considered "white" and inequities for those who are considered to be the "other" or "non-white"" (CAWI and City of Ottawa 2010j: 5). Under the first barrier "Attitudes", it explains: "Consciously or unconsciously, people are socialized to perceive certain physical and social characteristics (e.g., skin tone, hair texture, cultural habits, dress, language, accents, as well as religions, political beliefs and surnames) as a sign of racial differences, and what is desirable and undesirable (Lopes 2006). As a result, people may think, say or do things that have a negative effect on visible minorities, even when they did not mean to do so" (ibid, italics mine).
} 
readers' fear of being accused of being racist as the Workgroup had discussed (CAWI 2009-05-06; 06-07).

In this sense, despite this compromise of not having a complete transformative frame in the opening lines, the body of the text successfully conveys one of the most important messages that the Workgroup wished to convey in this Snapshot. In addition, it also contains some elements of an alternative frame to counter the dominant stereotypes or assumptions about 'visible minorities', and ways to increase resonance with the audience - or, at least, to reduce resistance or backlash that this counter frame might trigger. Yet, the final text of this Snapshot still remains ambivalent, for some of the key elements necessary for a transformative frame as a tight package are missing, indirectly presented, delayed, interrupted by cited facts and sources, or dispersed across different parts of the document. ${ }^{209}$

\subsubsection{Key Message(s) of the Workgroup: Getting Racism on the City's Agenda}

Now I present the two key messages that the Workgroup members identified when developing this Snapshot, based on both the interviews and the documents recording the development process of it, such as the meeting minutes of this Workgroup. While the final text of the Snapshot is ambivalent, what the Workgroup members including both community and the City representatives - wished and sought to convey were very clear in these two data sources. First and foremost, the members of this Workgroup agreed unanimously from the very outset that racism is the core issue underlying almost all barriers and inequities associated with being a 'visible minority' in Ottawa (CAWI 2009-04-07). Based on their professional and personal experiences, these

\footnotetext{
209 This is also indicative of a systemic inequity in which racialized individuals or groups' subjective accounts of racism do not count as sufficient evidence in and of itself to prove its existence to the dominant group in society, but it must be vetted and approved through the latter (white people).
} 
members were tuned into the everyday experiences of racism as a lived reality for many members of the community, manifesting not only in "covert" but in surprisingly "overt" forms (Interview: o). They used various expressions to name this issue - such as "racism", "racial discrimination", "racial prejudice", "colour prejudice", "colourism”, "skin colour discrimination", "systemic racism", "covert racism", “overt racism”, etc. but concurred at the base that addressing this issue in the Snapshot had to be their highest priority (Interviews : b, k, o, u).

The Workgroup members viewed this Snapshot as a potentially great opportunity to "break the silence" on racism in the City and to start a long-term process of moving this issue forward, both in discourse but in substantive terms (CAWI 2009-04-07). This was because they were quite aware that despite this reality of racism, the City had been reluctant to acknowledge it and take proactive measures to address it, and ultimately, to eliminate it. ${ }^{210}$ In fact, the Workgroup shared an understanding that raising the issue of racism was "seen as taboo" in the City and more broadly in Ottawa and Canadian society, and that it would not be easy for them to do it in this Snapshot (CAWI 2009-04-07). ${ }^{211}$

The Workgroup members saw that such reluctance or silence on racism on the part of the City to be an additional urgent reason why they should tackle this head-on. Otherwise, they discussed, this document would not only be pointless but could even reinforce the existing forms of racism, which occur silently and are made invisible, but continue to

\footnotetext{
${ }^{210}$ One Workgroup member pointed out that City programs tend not to "talk about who is living in poverty" or "who is dropping out of school" and "misses the target group" - in this case many visible minority residents. This member reiterated that in order "to really meet the needs of the community, the issue of racism needs to be looked at". Otherwise, the lack of attention to racism as a factor in these patterns of inequities further "feeds into [racial] stereotypes about neighbourhoods or communities" (CAWI 2009-0407).

${ }^{211}$ Another Workgroup member asserted that racism is a "question of social justice. We can't talk about social inclusion, exclusion, equity without talking about social justice. It's seen as taboo but we do need to talk about this [racism], regardless of how we call people" (CAWI 2009-04-07).
} 
have devastating impacts on the people in the community and the City as a workplace nonetheless (Interviews: $\mathrm{b}, \mathrm{k}, \mathrm{o}, \mathrm{u}$ ). This sense of urgency was informed also by the lived experience of many people in the community, for as one member put it, "people are hurting from racism" (Interview: o). Another member also expressed a similar sense of urgency stating that "silence" on the issue of racism on the part of the Workgroup "is not an option" (CAWI 2009-04-07).

\subsubsection{The Term 'Visible Minority' as Laden with Problems}

The other key message that the Workgroup members identified from the outset was the inadequacy of the term 'visible minority' to refer to this community of people, or to talk about the issue of racism that is affecting them for numerous reasons. What I found through my frame analysis is that this term 'visible minority' attaches a strong stigma to non-white skin colour, and to those who have it. In addition, this term embodies a series of often unstated and unarticulated assumptions not about those who are labeled 'visible minorities', but also about what 'race' means at a more fundamental level. While the Workgroup members did not have a coherent frame to re-articulate the problems of these unarticulated assumptions to replace them with a transformative alternative, they did raise a series of interrelated bits of critique about this term.

At their very first Workgroup meeting, the members challenged the City's use of the term 'visible minority' for this Snapshot and the E\&I Lens, for it is "loaded with a sense of inferiority, exclusion, and Othering", and the use of this term to refer to this population reinforces the existing negative stereotypes about 'visible minorities' (CAWI 2009-04-07). For example, this terms is often conflated with "immigrants" in its popular usage in Canadian society, which reflects the assumption that if someone is deemed 
"visible minority" - i.e., not white - then it is taken as a (visible) sign that they are "not from here", therefore "not Canadians", and "don't belong here" (ibid). This seemingly innocent conflation of the two terms reflects a deeply racial assumption about the white skin colour tied to one's 'true' Canadian-ness and insider-status in Canada, and the nonwhite skin colour as outsider status. This silent marking is done regardless of one's own sense of self-identity as Canadians, and regardless of one's actual citizenship and/or immigration status (e.g., obtained citizenship, or born in Canada and therefore Canadian citizen throughout one's life). ${ }^{212}$ The use of this term 'visible minority' imposes such connotations against the will or the self-definition of these individuals or groups. As the Workgroup members explained, its impact is hurtful, constant, and permanent - for gaining citizenship status does not allow these individuals to be considered fully or truly Canadian, all simply because of how others judge their skin colour.

In addition, some of the Workgroup members critiqued the rationale embedded into the definition of this term, which is based on the (perceived) 'non-white' skin colour. The lead member in particular raised that this had the effect of naturalizing the archaic notion of 'race' as something grounded in one's biology, and thus inherent to oneself rather than societally created (CAWI 2009-04-07; Interview b). That is, the term 'visible minority' takes for granted - instead of highlighting and problematizing - the societally constructed nature of 'race' and the social process of racialization. It normalizes this process of attaching meaning to people's skin colour as though it is a legitimate basis of

\footnotetext{
${ }^{212}$ As one member explained: "Some people in our communities, who are racialized individuals, are constantly fighting not to be defined or labelled as 'immigrants'. This has devastating emotional impacts to be always defined as 'outsider', 'immigrant', 'you don't belong here". Another member added to this, stating that "It's way more about race and racism than citizenship and immigration status. People who are immigrants have another reference point. People who are Canadian citizens over many generations and who don't define themselves as immigrants, but are always labelled as such, are vociferously excluded in their own country [and this] makes them doubly angry" (CAWI 2009-04-07).
} 
categorizing human beings, and of attaching negative valuations such as inferiority and exclusion, in this case, to the non-white or dark skin colour. Another member of the Workgroup also pointed out that even the United Nations has critiqued this term "for being racist" and that it was "only used in Canada", adding to the Workgroup's overall critique of this term (CAWI 2009-04-07). ${ }^{213}$ While this was not articulated as succinctly during the Workgroup meetings, their critique can be summarized as follows: this term itself 'racializes' people based on the arbitrary criterion of their perceived skin colour being either 'white' or 'not white', but without bringing this racializing logic out in the open, thus reinforcing it as an unchallenged norm.

The Workgroup also variously pointed out that the term 'visible minority' displaces the focus of the issue away from racialization and racism in society, to the (supposedly) inherent inferior nature of those who are deemed as 'visible minorities' themselves. For example, one member noted that the term "limits and narrows the scope of the discussion" and "misses the mark" as it diverts attention away from the societal problem of racism itself, and instead to the non-white skin colour of visible minorities, and thus something inherent to them (CAWI 2009-04-07). Another community member explained this using a more concrete example in Ottawa's local context, that when the City looks at social issues in Ottawa, such as high rates of poverty, school dropout, or

\footnotetext{
${ }^{213}$ While the exact content of this critique was not elaborated in great detail during the Workgroup meeting, this member was referring to the report released by the United Nations' Committee on the Elimination of Racial Discrimination in 2007, in which it critiqued Canada's use of this term on the ground that it "seemed to somehow indicate that 'whiteness' was the standard, all others differing from that being visible", and "may not be in accordance with the aims and objectives of the Convention", i.e., International Convention on the Elimination of All Forms of Racial Discrimination (U.N. 2007: 17; CanWest News Service 2007; National Post 2007). This Convention defines racial discrimination as "any distinction, exclusion, restriction or preference based on race, colour, descent, or national or ethnic origin which has the purpose or effect of nullifying or impairing the recognition, enjoyment or exercise, on an equal footing, of human rights and fundamental freedoms in the political, economic, social, cultural or any other field of public life". Note that while UNCERD acknowledged that 'visible minority' is a term grounded specifically in Canada's Employment Equity Act (1995), it took issues with the broader usage of this term within the Government of Canada beyond this initial, narrow context of administering this legislation (UN 2007: 17).
} 
incarceration in certain neighbourhoods or communities, it "does not ask who is affected" and misses the racial dimension of these problems (ibid). Thus, using this language of "visible minority" in the context of identifying issues or problems in the community without calling attention to racism itself has the ill effect of mis-attributing the problem to the 'visible minority-ness' of the population, or their non-white skin colour.

Several members of the Workgroup also pointed out that as a government terminology (and as one member added more specifically, as a "statistical category"), this is an "externally" and "arbitrarily" developed category that is "imposed" upon this population. Therefore, it is not a meaningful "self-identity" or self-defined identity for these people themselves (Interviews: b, k, o, u; CAWI 2009-04-07). Given especially the negative stereotypes and strong stigma attached to it, and this arbitrary imposition of it upon them against their preference, the Workgroup pointed out that many people in the community do not embrace or identify with this term (ibid; Interviews: b, k, o, u). Thus, the Workgroup identified a huge gap between the City's official terminology to refer to this community, and what this term means in the community especially to the lived experience of the people who are labelled as such. They saw this gap needed to be addressed as part of this Snapshot.

\subsubsection{Key Debates and Discussions at the Workgroup}

Much of the internal debates that occurred within this Workgroup revolved around these two key messages identified above. The Workgroup thus quickly formed the dual priorities they wanted to pursue in developing this Snapshot, namely: 1) to raise the issue of racism in this Snapshot first and foremost, but 2) also to start urging the City to discontinue its use of what they viewed as essentially a racist term 'visible minority' in 
the process (CAWI 2009-04-07). Both goals were interrelated, and both directly challenged the status quo in the City. During the first half of the development process of this Snapshot, the Workgroup engaged in an internal and frank discussion on the substantive content they wished to convey and concomitant discussion to strategize how they could/should do so, given how taboo their main message was in the City. During the second part of the process, they engaged in an intense process of negotiation with the representative(s) of the City who was also the project lead (primary coordinator) of the E\&I Lens development. From that point on, the Workgroup had an additional round of internal discussion to recalibrate their strategic approach. This led to the mutual compromise between the community and the City, which was manifested in the form of the final text of the Snapshot that I discussed earlier.

\subsubsection{Internal Discussion on Substantive Content}

During these discussions, the members exchanged examples and anecdotes about people's experiences of racism in the city/City, based on what they knew through their professional as well as personal connections in the local community, their own direct experiences, as well as what was being covered in the local news at the time. ${ }^{214}$ Although the members already "understood the issues and the concepts [of racism] well", these discussions helped develop an even stronger sense of urgency among the Workgroup members to raise the issue of racism in the City through this Snapshot, as well as solidarity among them in doing so (Interviews: $b, \mathrm{k}, \mathrm{o}, \mathrm{u}$ ). For example, one member in

\footnotetext{
${ }^{214}$ For example, in May and June 2009 when the Snapshot was under development, the case of the assault on a local taxi driver by an off-duty Ottawa Police Officer who "allegedly" used racial slurs during the assault, was being covered widely by local news such as the CBC News Ottawa (2009a; 2009b), Ottawa Citizen (2009a; 2009b), and Ottawa Sun (2009a; 2009b; 2009c). Both City and community Workgroup members commented that these news stories added to both the urgency and the legitimacy of the case that the Workgroup members were making about the realities of racism in Ottawa and the need for the City to be proactive in addressing it, especially as they were facing resistance from the City to do so at the time (Interviews: k, o).
} 
particular commented that she realized that the state of racism in the city was even worse than she had expected, making this issue even more urgent to address. ${ }^{215}$

One of the prominent examples of racism that these members raised was labour market exclusion of visible minorities, manifested in the disproportionately low rate of hiring, retention, and promotion of visible minority candidates as they were often assumed to be inferior to white candidates by hiring managers and by colleagues in the workplace (Interviews: b, k, o, u). The members variously explained how this issue was connected to a common negative assumption that visible minority candidates only got into their position through employment equity and not on their own merit. Three different members commented explicitly on the lack of inclusive and supportive workplace culture that often pushes visible minority workers to leave their job, especially when they cannot find support they need in addressing racism that they encounter in the workplace (Interviews: b, o, u; CAWI 2009-04-07). And yet, this is often not acknowledged as the reason for their departure, which in turn individualizes the problem in terms of their personal incompetency or suitability for the job. In turn, this feeds into the actual pattern of underrepresentation of visible minorities in senior positions, but into the existing stereotypes about their overall inferiority to white workers as well (Interviews: b, o, u) ${ }^{216}$

\footnotetext{
${ }^{215}$ This member commented that she was "surprised to hear how much overt racism was happening in Ottawa and not just the covert racism, which is much harder to pinpoint" (Interview: o).

${ }^{216}$ While this was not the focus of discussion during the Workgroup meetings, three different Workgroup members commented on the "inadequate" or "tokenistic" implementation of employment equity measures as a serious problem. One member discussed how this reinforced these racist stereotypes about visible minority workers but also served as "window dressing" for the government to claim that they are doing enough when they were not. Another member pointed out that governments tend to "go for lofty things" such as "big and broad policy statements and legislations", but without substance to change the everyday practices on the ground, in this case racism or racial discrimination in the workplace. And yet another commented on the absence of support services for victims of racism in the city, stating that "When people suffer from abuse, there is a service for that. When people suffer from sexual assault for example, there is a service for that. But when people are suffering for racism, where do they go? Yes there is employment equity, but there isn't anything that can actually help them" (Interviews b, o, u).
} 
All of the interviewees recalled that they debated on the preferred or more desirable alternative to 'visible minority' that they could use as a name for this community, and as the title of this Snapshot. They brainstormed alternative names that were used in the broader community, such as "ethnocultural" or "multicultural" communities, "people of colour", "communities of colour", and "racialized communities" (CAWI 2009-04-07). However, they also quickly realized that many of these terms still had the same problem that they are "still not a self-definition" by these people themselves (ibid; Interviews: $b, o, u$ ). That is, while these words focused instead on ethnicity, culture or 'colour', the same racial logic remained as these words only marked and Othered nonwhite groups, while leaving unmarked whiteness and taking it as the unspoken norm just as the UN critique pointed out.

The expression "racialized" communities or people thus became more or less the consensus that the Workgroup identified as a preferred alternative to 'visible minority'. This language would bring the social processes of racialization to the forefront of the discussion, and avoid biologizing the notion of 'race', or attributing the problems faced by this population to their inherent (racial) characteristics or skin colour. It would also help expand the scope of discussion to include non-biological dimensions of racialization and racism. The lead member of the Workgroup in particular pushed for this alternative, and the other community members generally supported this choice at the time (CAWI 2009-04-07; CAWI 2009-06-30; Interviews). ${ }^{217}$ However, as I discovered through my interviews and additional research, this alternative 'racialized' still did not offer an

\footnotetext{
${ }^{217}$ Although through the interviews I conducted, some Workgroup members explained that this was a new or emerging term originating in academia, and thus not necessarily or not yet an universally accepted or even understood expression in different pockets of 'visible minority communities'. In fact, as I will discuss under "key factors", the names of this community continues to be a highly debated and thus unresolved topic in the visible minority community(ies) to date (Interviews: b, k, o, u).
} 
adequate alternative to the existing language of "visible minority" (See "Key Factors" on p. 234).

\subsubsection{Internal Strategic Deliberation}

During this initial meeting, the Workgroup also engaged in an explicitly strategic discussion on how best to approach their dual priorities to raise the issue of racism and to challenge the City's official term 'visible minority'. For example, one community member stressed the urgency to challenge the current language, given the strong association of the word 'visible minority' with the imposed sense of inferiority and exclusion in people's lived experience with it. $^{218}$ However, while agreeing with this view, other members also saw the risk of raising the issue of racism per se, as well as of challenging the official terminology in the City. One community member cautioned others that talking about racism as the central focus could "change the conversation". One City member added that this would likely be met with resistance or backlash from the City and/or their audience, given how "taboo" racism is considered to be in the City (CAWI 2009-04-07). Thus, while they all agreed in principle the ultimate need to challenge the status quo on both fronts, various members exchanged slightly different views on which strategies were desirable or necessary in the short-term and the longterm.

For example, a couple of the members, one from the community and the other from the City, pointed out that challenging the official terminology used by the City as enshrined in the Equity and Diversity Policy (which in turn was backed by the federal

\footnotetext{
${ }^{218}$ This community member's comment indicates how closely this term is associated with the hurtful experience of exclusion in the lived experience of those in the community: "I don't understand why we have to use the language 'visible minority' if the Equity and Inclusion Lens is about challenging exclusion" (CAWI 2009-04-07).
} 
Employment Equity Act), would lead to an onerous debate about language. Such debate would, they added, be followed by a long and slow bureaucratic process, which in turn would practically slow down and even stall the entire process (CAWI 2009-04-07). Given this, one member advised the Workgroup not to let the City use the debate on the "language as an excuse" to distract attention from and not to move on the more substantive issue of racism itself (ibid). ${ }^{219}$ One of the City members concurred based on their knowledge about the City's internal bureaucratic culture, adding that "If I go back to my managers to change this [language], it'll take ages and stop the process" (ibid).

To this, yet another member contributed a slightly different point, that it was this Workgroup's role to initiate a long-term process of getting the City to change its official terminology, as part of their broader objective to get the City to embrace its public leadership to fight against racism in Ottawa. ${ }^{220}$ For this member, this Snapshot presented a valuable opportunity to open such a dialogue with the City over the long term, even if the language could not be changed within the short timeframe of this particular project. Thus, given these considerations on the problems with the current official term used in the City, and therefore in the E\&I Lens and this Snapshot, the Workgroup decided to "negotiate the use of terms of the City policy and the meaning in the community/people's lived experience" in this Snapshot, although how exactly to do so and in what time line still remained undecided (CAWI 2009-04-07).

\footnotetext{
${ }^{219}$ This community member's comment was as follows: "Racism tends to change the conversation. We want to change the term, but without stopping the process of working on this Snapshot and E\&I Lens. We'll raise this issue and concern in different places across the City. Let's not stall the organizational change process by using the discussion on language as an excuse" (CAWI 2009-04-07).

${ }^{220}$ The comment by this member read: "It will take time, but we can start criticizing this term and change the discourse over time. We can be the wedge. We do need to use the federal legal term [for now], but be proactive about what it means or what we don't want it to mean, what negative consequences it has, and what term we want to use for what reason" (CAWI 2009-04-07). In a sense, this comment by this member offers a strong basis for a potential transformative frame - although the direct answers to these questions were not contained in the opening lines of the Snapshot.
} 


\subsubsection{Negotiation with the City: Prioritizing Resonance and Vertical Frame}

\section{Alignment}

Such negotiation began with the second Workgroup meeting, at which the manager of the City's Diversity and Employment Equity branch and the project lead of developing the E\&I Lens joined. Here, the manager and the Workgroup exchanged their views, and the manager generally supported the Workgroup's position and offered input from the City's internal perspective, emphasizing the need to keep this Snapshot more or less "in line with other Snapshots", and to "make it educational" for the target audience (CAWI 2009-05-06). Based on this collegial exchange between the Workgroup and the City representative, they proceed to explore possible ways to present the two key messages. Following this, exploratory drafts were developed at the suggestion of the key coordinator, drawing on the sources suggested by the Workgroup members, which included an extensive academic and popular education materials on race, racism, racialization, anti-racism, and White privilege - i.e., with more radical content in relation to the dominant frame in the City. At their third meeting, the Workgroup discussed these drafts, where the City and the community members concluded that while "the content is fine", the "format needs to be adjudged" to make it more "user-friendly" for the audience of this particular project (CAWI 2009-06-07).

Here we start to see the strategic priority at the higher scale of the partnership coming into conflict with the movement-specific priority at the individual Workgroup. That is, it is at this meeting that the Workgroup also experienced a surprising level of resistance from the manager and project lead of the Lens, who, based on intimate knowledge of the City's organizational culture, commented that such material would not 
at all be received well by the audience. Part of the reason for this was that this manager saw the strategic necessity of making this Snapshot as simple, user-friendly, easy to follow, by not deviating from the official terminology used by the City that the readers are required to use in their work situations (Interview: g). Another part was the strategic need to make this document as non-threatening as possible for the audience, for she anticipated that talking about racism often raises "fear" on the part of many managers and employees of the City, especially the "fear of being perceived as racist" or "being called racist" (ibid; CAWI 2009-05-06, 06-07). Finally, another part of the reason for this resistance was that the issue of racism was not serious in Ottawa to warrant such prominent attention in this Snapshot (CAWI 2009-06-07; Interviews: b, g, o).

This radical exploratory draft triggered a negative reaction from this manager, leading to her new stance that the Snapshot must not discuss racism or racialization or use the expression 'racialized' communities, but instead continue to work with the current official language of the City "Visible minority" and stick to the barriers named in other Snapshots such as employment, housing, access to services, etc. (CAWI 2009-0607). This suddenly "polarized" the debate in an "explosive" way between naming racism

and not naming it, naming "White privilege" and not naming it, and changing the term to an alternative "racialized" and continuing with "visible minority (Interviews: b, e, k, o). Here, the community-City divide was overlaid on top of this polarization, despite the fact that prior to this moment such divide was not prominent.

\subsubsection{Recalibrating the Strategy}

This led to a separate internal regrouping meeting among the community members of the Workgroup only, to discuss how to proceed in light of this recent turn of 
events (CAWI 2009-06-30). ${ }^{221}$ Here, they continued their internal strategic deliberation, with each member suggesting a slightly different approach. Through this discussion they reconfirmed their main priority to raise the issue of racism in the Snapshot again, but relax on the second priority on the terminology. In July 2009, the Workgroup held a "common ground meeting" between the community and the City representatives to redefine and reconfirm the City's commitment to support the community's effort to pursue elimination of racism (2009-07-16a, b, c). This was in a sense a renewed effort by the community members of the Workgroup to secure the City representative's 'buy in' to address racism in this document as a legitimate and good step for the City to take, and to "negotiate a deal" on how to proceed from then on (CAWI 2009-06-30; 2009-07-16a, b, c; Interview: b). ${ }^{222}$

The Snapshot development process resumed soon after, involving a series of mutual compromise from both sides. For example, the community got to name and feature racism significantly in the document, especially in the "Barriers" section, though it was also heavily edited by the City representative and their staff, who emphasized 'objective' statistics that were more reliable as well as the legal definitions. (That is, instead of taking at face value the claims made by the community - which was the done in other Snapshot Workgroups). The City representative got to appoint and bring in another ('white') City manager, who would help adjust the document for their target audience, i.e., other (mostly 'white') managers across the City (Interviews: anonymized).

\footnotetext{
${ }^{221}$ I recall that this was done partly as a way to 'shield' or protect the City members of the Workgroup who were acting as allies within this Workgroup from this intense contestation between the City and the community, especially as this conflict was between the community members and their superior (manager). ${ }^{222}$ At this point, one of the community members leaves the Workgroup in part to protest this turn of events, and the other key member who pushed for a more "radical" frame falls ill and de facto leaves the Workgroup.
} 
These mutual compromises led to the ambivalence in the final text of the Snapshot, which contained some positive result, as several members of the Workgroup came to see in retrospect. For example, one City member in particular commended on this Snapshot for its strong focus on racism as an unequivocally systemic and structural issue, as well as some critique on the term visible minority (or at least an acknowledgement that there is a debate about it). A different community member also echoed this, stating that the document "covers what it needs to cover" in terms of educating the readers about racism (Interviews: b, e). It is true that several members did comment that this process of contestation "took so much time and energy", sometimes "away from the main issues" and thus was "frustrating" at times (Interviews: b, k, o).

Yet, one City member added a positive spin to this "explosion of emotions and perspectives", explaining that in retrospect this serendipitously strengthened the document more than any others, for it became the "only Snapshot that was written both by visible minorities and Caucasians" (Interview: $\mathrm{k}$ ). That is, this process ended up incorporating the perspectives of not only "the community" but also of "the audience" into the document, thus bridging the gap in perspectives between the two 'sides' (Interview: k). Yet other community member also added that in the long run "what counts is the process of engagement" of the community and the City, and that this was nonetheless "a step in the right direction" as the community continues to work to find ways to engage the City in the long journey to address racism, in collaboration with the community (Interview: u). 


\subsubsection{Key Factors}

\subsubsection{Strategic Priorities in a Bind}

Here I present the factors that contributed to this particular experience and process that this Workgroup experienced in developing this Snapshot, as they sought to bridge the distance between the original message they wished to convey on the one hand, and the strategic concerns in light of the dominant frame(s) and the status quo in the City on the other. As the preceding discussion illustrates, it was not the lack strategic awareness on the part of the Workgroup themselves that was the issue, but the two main priorities they had to address put them in a bind. That is, on the one hand they saw the cost of not challenging the City's continued use of its official terminology, because not only was this term offensive and hurtful to many who are called as such, leaving it unchallenged would reinforce and naturalize a racist logic embedded in it and leave racism as a societally created problem out of sight and out of mind. Continuing to work with this language in this Snapshot without problematizing these aspects of it would implicitly endorse such logic of exclusion and racial inferiority/superiority of non-whites and whites. It would ultimately undermine their most important objective of using this Snapshot: to start bringing racism out on the City's agenda.

Yet, when faced with the difficult decision to choose only either one of the two priorities - of addressing racism or changing the language - the Workgroup had to prioritize the former over the latter (CAWI 2009-04-07). While the Workgroup managed to include a prominent discussion of racism in the Snapshot in the end, this had to be done at the expense of continuing to work with the existing official term 'visible 
minority' and all the unstated racial logic and assumptions implied in it. ${ }^{223}$ That is, by continuing to work with this term, the Workgroup was also working with the taken-forgranted assumption built into the term and concept of 'visible minority' itself. It takes whiteness as the invisible, colour-less and unmarked norm that is left out of the picture or 'frame' while its binary counterpart was visibly marked and associated with (inherent) inferiority. The Workgroup was thus also working with the biological notion of race defined in terms of one's (perceived) skin colour, but without explaining this societal process implicit in it.

This added to the discursive challenge for the Workgroup to reframe the conversation about 'visible minorities' only to race/racialization and racism in society at large, like the People with disabilities Snapshot did when it reframed the dominant discourse about 'disabilities' by shifting the conversation to 'access' and 'barriers' in society. This was an essential part of a transformative frame that would externalize the cause of inequity, away from inherent inferiority of the population to a societallyproduced, systemic barrier. While such re-framing was pursued by other Workgroups in their respective Snapshots, as well as in the overarching frame used by the coalition and the partnership in the User's Guide portion of the E\&I Lens, this discursive option was more difficult for the Visible minority Workgroup to pursue.

\footnotetext{
${ }^{223}$ The power of the dominant frame in naturalizing the notion of 'race' was so powerful that the members of this Workgroup found themselves slipping back into it during their meeting discussions. It took a while before the lead member brought the conversation back to the point that "My skin colour is not a barrier for me. Other people make it a barrier [and] impose it on me" to reframe the issue away from 'race' per se to racism in society. (CAWI 2009-04-07, italics mine).
} 


\subsubsection{Polarized Discourse: 'Radical' and 'Oppositional' Message against the Dominant Frame(s)}

At the same time, however, the first priority that the Workgroup decided to pursue also put them in a strategic bind, for naming racism and tying it to this unnamed and unmarked whiteness and white privilege was considered particularly radical, given the existing dominant discourse(s) in the City at the time. The dominant frame considered naming this a taboo, and this topic was often evaded, and when it was raised, it was met with strong denial. As one Workgroup member noted, in discussions about racism "personal becomes political becomes personal" (Interview: o). Similarly, different Workgroup members also commented during the interview that "white people personalize this issue" and "get defensive", making it particularly challenging to broach this topic without getting into an emotionally charged, and even "explosive" discussion (Interviews: $\mathrm{b}, \mathrm{k}, \mathrm{u}$ ). Indeed, the manager/project lead had also pointed out to the Workgroup during the development process, that there is a "fear surrounding the topic" among many of the City managers and employees, particularly of 'being perceived as being racist' or 'being called racist'; similarly, another community Workgroup member also noted that "it is a shame to be a racist" in Canadian society (CAWI 2009-05-06; 0607).

Although this did not come up directly in the Workgroup discussions, part of this heightened sense of 'fear', 'shame', and 'guilt' and therefore 'denial' of racism on the part of many City managers and staff, many of whom consider themselves 'white', is caused in part by another layer of the dominant frames in Canadian society. That is, in common parlance the word 'racist' is very narrowly associated with an individual, overt, 
and intentional form of racism or bigotry, and especially White supremacy, but not with the more covert, systemic, institutional, cultural or otherwise internalized forms of racism that are often unconscious and unintentional on the part of the individuals. The word 'racist' thus conjures up the image of an avid KKK supporter, for example, but not those who unconsciously or unintentionally partake in systemic forces of racism in society. Moreover, those who are socialized and racialized as 'white' do not think consciously of their racial identity or privilege, and systemic racism does not occur consciously on the part of these individuals. In a discursive context in which the construct of whiteness is constantly made invisible, unnamed, unmasked and normalized through the language of ‘visible minority', it is no wonder why many individuals feel particularly uncomfortable, and even angry, to be associated with being racist in this narrow sense of the word.

At the same time, however, such misconception is not entirely innocent, for as Dijk notes "[d]enials of racism are the stock in trade of racist discourse" (1993), and this narrow definition does work effectively to dismiss claims that racism exists in society, be it individual, cultural, institutional or systemic. This is part of the reason why naming racism was considered taboo - or radical - precisely because this would expose the unequal power relations between 'white' and 'non-white', which was supposed to be masked, at least according to the dominant frame. Gabriel calls this "exonomination" or "the power not to be named", which the term visible minority gives to whiteness (1998, 13). In fact, one Workgroup member articulated this in the interview that the language of 'visible minority' "turns the gaze outward" on to the racialized individuals and communities, but never "inward" onto "Whiteness", "White culture" or "White privilege" that is at the heart of systemic racial inequity in Canadian society (Interview: b). 
At least for two of the Workgroup members, this was at the core of the issue of systemic racism, which the Snapshot needed to address. For example, one member explained in the interview that it is precisely these masked relations of power and the role of the dominant population in it that needs to be challenged, if they are to change the status quo (Interview: b). Moreover, it was important to challenge the role of the individuals within the racist system, especially in "accruing benefits" from such system because this is what maintains the system (ibid). ${ }^{224}$ In this context, both the first and the second strategic priorities that the Workgroup identified constituted a decidedly radical element, for they sought to expose and challenge what is supposed to remain unnamed and invisible according to the dominant frame(s): the reality of racism and the role of whiteness and white privilege in reproducing it.

Moreover, the combination of this movement frame with the particularly rigid binary framework dividing 'whites' from 'non-whites' built into the dominant frame exacerbated this sense of 'blame' placed on 'whites', who were the majority of their audience. This further polarized this discussion, for this binary framework did not easily allow such blame to be externalized and collectivized in terms of systemic barriers 'out there' in society, in which everybody became racialized and learned racist ideas and behaviours and became embedded in unequal relations of power. In fact, one Workgroup member sought to avoid this 'oppositional' interpretation of their key message by their

\footnotetext{
${ }^{224}$ Here, one member also noted that going after the "win-win language" to garner support from the "mainstream" society for this cause does not to work, for racial equity requires shedding and letting go of some of these unearned systemic privileges by these individuals who currently benefit from the dominant system, and this language of 'win-win' makes it difficult to raise this point. This member states: "One thing I can't stand is the win-win sort of language, because I think people sometimes have to give up. And that's okay - by giving up you also gain... Giving up power, giving up privileges, giving up some of the status and the benefits, because you gain so much in other ways if you give up a little bit of that (Interview: b). Here, we see both a tension between this frame with a resonant frame, but also a potential for a transformative frame to convey the value of equity to all people society, including those currently holding dominant status.
} 
audience, by seeking instead to "blame the system" because "the system is racist, not the City, not the people" (CAWI 2009-06-30). In addition, even the member who strongly pushed for challenging the role of whiteness also lamented this binary framework imposed by the language of 'visible minority', for it had the unfortunate effect of erasing the role of internalized racism on the part of everyone - including the racialized individuals and communities themselves (Interview: b).

Spreading out this 'blame' across multiple groups and individuals in society, rather than assigning it to either the marginalized group or the dominant group might have reduced this heightened sense of fear and defensiveness of the part of their target audience. However, as two of the Workgroup members noted in the interview, they did not have as much time explore these "deeper issues" about various forms of intra-group racism or the reality of systemic inequalities between (and within) subgroups, or to strategize on the effective framing of these ideas to the target audience. They, along with others in this Workgroup, explained that they had the additional task of negotiating on the "basic" content for their Snapshot over whether they could raise racism in it or not (Interviews: $\mathrm{b}, \mathrm{o}$ ).

\subsubsection{Lack of a Clear, Coherent, Alternative Movement Frame}

Another key factor was that this Workgroup did not have access to a clear, coherent and established alternative frame that could serve as a basis for a transformative frame to replace the dominant frame(s), which allowed them to talk about racism and challenge the racist logic embedded into the term 'visible minority'. In fact, this often manifests in an never-ending series of debate at the local community level, as well as broader national public debate on the meaning of 'visible minority', which in turn diverts 
energy and attention away from the substantive issue of addressing racism (Interview: o).

For example, the highly stigmatizing connotation of the term 'visible minority' as well as the fact that this is an externally developed and arbitrarily imposed category on them has spurred an extensive, and recurring debates within many visible minority communities and sub-communities over the meaning of this term, often in search of a meaningful and dignified alternative (Interview: $b, \mathrm{k}, \mathrm{o}, \mathrm{u}$ ).

This is because the term 'visible minority' deeply "undercuts... the very essence of self-identity", as well as "sense of belonging and inclusion in the Canadian context" (Canadian Race Relations Foundation 2007). This is painfully felt at the local community level as well. One community member made a similar observation that this word creates a "sense of slight", which is "somehow wrapped up in notions of identity... although it's hard to put a finger on it" (Interview: u). This member also added that "people want to be accurately described, and they don't want to be embedded in the inaccurate descriptions or pre-judgments about themselves", and this often leads to "a big debate about what others think [about us]" (ibid). Another member echoes this, again linking this back to the fact that 'visible minority' was an arbitrarily and externally imposed category that was never their own self-defined identity in the first place. ${ }^{225}$

Similarly, a different community member also described in length the almost requisite discussion on "identity" at local gatherings of "visible minority' groups in Ottawa:

\footnotetext{
${ }^{225}$ This member notes: "It's a very fixed kind of category that is very difficult to shed. It captures a snapshot, a frozen understanding of who we are. It's still a matter of how others categorize us, not necessarily how we see ourselves. So this is not a category that we developed" (Interview b). Here is a small instance of frame disalignment between the movement and the coalition and the partnership frames, in the sense that "snapshot" carries a negative and exclusionary connotation for this particular community, rather than help them convey a new, transformative narrative about their experience of exclusion.
} 
Identity always seems to be an issue for visible minority groups, and certainly in the Black community. Identity seems to be really really important for people. I guess it's personal - it informs where you're going as an individual, maybe where you're going as a people. Because if their identity isn't clear, they don't know what their journey is. ... So the identity discussion seems always need to happen (Interview: o).

Several Workgroup members also indicated that these ongoing debates about the meaning of "who is visible minority" and alternative self-chosen names or definitions of self often lead to a massively diverse list of names, none of which serves as an overarching common identity that various visible minority groups can rally around. ${ }^{226}$ Community and City members of the Workgroup explained that this is partly because of the enormous "diversity within the community", whose single commonality is the arbitrary criterion of "not being white", and partly because even within each of these subcommunities, "everyone identifies differently as individuals" (Interviews: k, o). Such variation is only to be expected, however, given the very design of this category "visible minority" as a "statistext", an invented statistical category for a specific political project in this case the introduction of it as a newly legislated employment equity category - but one that does not match the subjective experience or identity of the people captured under it (Kobayashi 1993). ${ }^{227}$

\footnotetext{
${ }^{226}$ Various Workgroup members gave examples of the kinds of specific identities that these people often choose, such as "Chinese", "Filipino", "Black", "African", "Muslim", "Somali”, "Asian", or hyphenated combinations of "Chinese-Canadian", "Black Canadian", or in some cases simply "Canadian" (Interviews: $\mathrm{b}, \mathrm{k}, \mathrm{o}, \mathrm{u})$.

${ }^{227}$ Moodley (1985) also had predicted such fragmenting effect that the newly introduced federal term "visible minority" would have on the hugely heterogeneous population groups across Canada, who had divergent experiences of racism and other systemic inequities. He had critiqued that this would make for a poor basis for a policy that would only generate "one-size-fits-all" interventions. Moreover, given these divergent experiences, he anticipated these diverse groups would have a hard time building a sense of solidarity or mobilizing themselves under a shared cause, and indeed the Workgroup members' comments support these predictions from the 1980s. Ironically, this aligned very well with the key thrust of the frame used in the E\&I Lens that 'one-size-fits all' indeed does not fit all. This was precisely because of the 'diversity' of experiences among Ottawa residents, and precisely because of the systemic barriers that put different groups or individuals at a different degree of disadvantage, and 'equity' was all about attending to such differences and existing inequalities.
} 
In fact, this has been the longstanding critique by many scholars and activists in Canada since this category was first being introduced in the 1980s by the federal government as a Statistics Canada's new category as part of the then-newly created Employment Equity Act. ${ }^{228}$ Moreover, even strictly as a statistical category, the term still "lends itself to confusion" because it is made up of incongruent list of subcategories, some of which are "defined nationality/ethnicity some by continent and some by subcontinent" (Siemiatycki 2011:3), and some by colour, and some by country or national origin. ${ }^{229}$ Moreover, within some of these regionally-based subcategories such as "Latin American", the visible minority designation applies only to those who are 'non-white', which further adds to the confusion. In a sense, this reflects the very nature of 'race' as an artificial, fluid and context-specific category, made up of a mishmash categories arbitrarily pulled together into one word. ${ }^{230}$

And yet, this being the official government term feeds into a fixed notion of 'race', and in its popular usage it is also (mis)taken as though it represents an identity category, when in fact is does not. Moreover, while the members of the Workgroup recognized the importance of having these ongoing debates on names and identity in local community fora, the debates over this confusing and hurtful term often ends up distracting these local community groups from "focusing on the important stuff", i.e., their various experiences of racism and how to combat it (Interview: o).

\footnotetext{
${ }^{228}$ The lead member of the Workgroup in fact recalls "vehemently opposing this category" as communitybased advocacy group when it was first being introduced by Statistics Canada in the 1980s (Interview: b).

${ }^{229}$ The subcategories as set by Statistics Canada are: "South Asian, Chinese, Black, Filipino, Latin American, Arab, Southeast Asian, West Asian, Korean, Japanese, Visible minority, n.i.e. ('n.i.e.' means 'not included elsewhere'), Multiple visible minorities", and "Not a visible minority" (Statistics Canada 2013).

${ }^{230}$ Here I am referring to the idea of race as a social construction, but one that is closely intertwined with a system and ideology of power and domination in society that configures and reconfigures hierarchies among various 'races'. And in this sense, it is a real social phenomenon even though the very categorization of 'race' or races has no biological ground.
} 
In light of these ongoing debates, one of the community members of the Workgroup came to the conclusion that "the language is inadequate, period... and [we] still don't... have good language" to describe the issues or the people in question. ${ }^{231}$ In fact, two of the community members raised a similar point that the currently existing language is inadequate, but this "may never be resolved" because the language used by communities of people to organize around racism "has always been changing and always will be" (Interviews: o, u). As an example, they both referred to the historical evolution of the proper or preferred language used to refer to racialized minorities over time, with humour, from "Negro to Black to African American to people of colour to now, racialized" (Ibid).

In contrast, the lead member who had pushed to the expression "racialized" noted that this term might actually have a potential to reduce the sense of guilt or fear on the part of white people in talking about racism, precisely because this term emphasizes the social processes in which everyone is a part (Interview: b). (That is, not just the visible minorities as the dominant discourse presumes, or not just the white people as an oppositional frame emphasizes). This thus does not draw a stark dividing line between 'whites' and 'non-whites' the way 'visible minority' does. And by doing so, this member added, it draws attention to the systemic or societal aspects of racism rather than the individuals' role in it (ibid). While such speculation is counterfactual, in light of the frame analysis in this study, I can see that this alternative approach might have allowed

\footnotetext{
${ }^{231}$ The full comment by this member reads: "the language is inadequate, period. I still don't think we have good language. Can't tell you exactly what's missing... And yes it's important if you want people to know what you're talking about. Language is a tool that you have... But I don't think we ever quite resolved it. I think that the fact of the debate is in some ways a good thing that people are trying to invent the language. You're trying to invent the language to more properly and more accurately describe something, describe an issue. For me the important part is the engagement" (Interview: $u$ ).
} 
this Workgroup to combine radicalism with resonance, by naming racism as a problem openly, but not letting it alienate their target audience by proactively reducing the sense of blame, defensiveness and fear that often exists on their part.

However, the academic or theoretical discourse did not directly translate into the final text of this Snapshot. As this lead member also admits - and in fact as another community member also points out - the term 'racialized' is "academic in origin" and such view is not necessarily shared by others whose reference point is not based in the academic literature (Interviews: b, o). While one community member noted that this term "racialized" is increasingly being used "here in the community", it is still not a commonly understood term across the board, and it can sometimes impede communication across community groups. ${ }^{232}$ This lack of a clear and commonly understood alternative term to refer to the community, and to describe the nature of the issue at hand - in this case the causes and mechanisms of racism - often forces many community groups to resign themselves to the official government term that is at least most widely circulated and thus understood by most people (Interviews: o, u). Part of the issue here is also that an 'academic' or 'theoretical' term could be yet another externally

\footnotetext{
${ }^{232}$ This reflects another dimension of gaps in discourses across the "academic" and the "community" or "grassroots" sectors; in fact, the two are often juxtaposed as contrasting sectors especially by those who identify with the latter. This is yet another form of identity politics as well as claims over sources of knowledge, authority and legitimacy. In fact, one of the key coordinators of this E\&I Lens who selfidentified with the community also emphasized the importance of not making this Snapshot 'too academic' but (instead) 'user-friendly' for the City audience. This was yet another way the higher scale priority to pursue audience buy-in and resonance interacted in a complex and twisted way to put pressure on the radical aspect of the message conveyed by the community (and academic) member of the Workgroup. Yet, some of the sources referenced in the final draft of this Snapshot were written by academics, such as Saloojee's article on "Social inclusion, anti-racism and democratic citizenship" (2003) and even Peggy McIntosh's well-known piece on White privilege (1988), which partly informed and contributed to what came to be re-evaluated by other Workgroup members later on as being the "strongest" Snapshot in its "structural analysis" of racism and power in society, thus making a positive contribution to the purpose of the project. That said, the nature and purpose of academic theoretical literature to analyze and state what the scholars view as 'truth' indeed did not align well with the ostensibly strategic nature and purpose of framing, which was one of the core elements of the strategic package of the E\&I Lens.
} 
developed and imposed term for some people in 'the community'. In this sense, even there was a potentially viable alternative to replace the existing language of "visible minority', it still did not serve as not a commonly accepted frame across the different segments or sectors that make up this community.

\subsubsection{Frame Dis-Alignment: Contesting the Official Discourse and the}

\section{Institutional Framework}

A key element of the common discursive strategy that all Workgroups shared was to use the official discourse and the institutional framework of the City as a source of added legitimacy and resonance of their movement frame. However, this strategic option was not available to the Visible minority Workgroup, for their key message went quite directly against the City's official terminology 'visible minority' as institutionalized in the municipal Equity and Diversity Policy, and in turn the federal Employment Equity Act (EEA) that legally mandated the City to do so. The legal authority imbued into this term 'visible minority' made it additionally challenging for this Workgroup to articulate their transformative message about the societally produced nature of the problem: racism in society.

Moreover, the inadequate implementation of employment equity as a legislative measure has ironically produced many negative effects to reinforce existing forms of racism in practice, despite the original intent on paper to address systemic inequity in employment. ${ }^{233}$ For example, one Workgroup member critiqued the "superficial" and "tokenistic" ways in which employment equity has been implemented in many

${ }^{233}$ The strong emphasis placed on the "intent" of employment equity and related human rights legislations has long been identified by policy researchers as a major obstacle to combating racism, racial discrimination and harassment on the ground (MacKenzie 1994; Al-Waqfi and Jain 2007). And similarly, the distinction between "intent" and "effect" has been well established as part of the anti-racist analysis of systemic racism. 
workplaces, in which "the employer can let in a select few" racialized candidates "without changing the system" and "without changing the White culture" in the workplace that play a key role in sustaining racial inequity (Interview: b). Once let in, these individuals are often expected "not to rock the boat". And if and when they do call attention to or challenge the systemic forms of racism in the workplace - or if they file an official complaint or grievance about racism ${ }^{234}$ - they are often perceived as not being a team player and find themselves further isolated from coworkers and supervisors (Interview: b).

In addition, as a legal measure with a specific, and thus narrow, mandate pertaining only to employment, the Employment Equity Act does not address the other important dimensions of racism in practice out of its scope, such as the systemic, institutional, cultural, and attitudinal forms of everyday racism in the workplace and beyond. Some Workgroup members also pointed out that when these workers experience covert (or sometimes overt) forms of racism in the workplace, they lack the institutional as well as cultural and interpersonal support necessary to address and solve them (Interviews: $b, o, u) \cdot{ }^{235}$ They explained that this often leads them to leave their job as the workplace can no longer become a welcoming and supportive environment for them. And yet, these challenges are often interpreted by others in the workplace in terms of these

\footnotetext{
${ }^{234}$ This description fits with Jiwani's critical discussion of "the model minority", who buys into the (liberal) myth of "equality and individual success", "believes in the system" and "does not complain about its unfairness" nor demand more from Canada, but is supposed to be "grateful" for the opportunity granted to them by "charitable " (2006). Here, like in the case of the Immigrants Workgroup, the (liberal) master frames of equality and rights of individuals worked against the movement-specific content of their frame. ${ }^{235} \mathrm{Al}$-Waqfi and Jain found that human rights legislations and employment equity policies have proven more effective in reducing "access discrimination" to employment, but not so much in "treatment discrimination" that occurs "after hiring", which is "more subtle and hard to combat" (2007:99). Similarly, Dua found that the individually-based complaint or the tribunal system is not set up to handle systemic or institutional forms of racism, as these are much harder to prove and take longer to investigate for equity officers, and such prolonged process often aggravates the interpersonal tension within the workplace (Dua 2009).
} 
individuals' personal incompetency for the job or incompatibility with the workplace, thus leaving the systemic nature of the problem unacknowledged. In this sense, employment equity measures have turned out to be ineffective not only in terms of recruitment but also in retention and promotion of racialized workers (Ibid).

Moreover, the Workgroup members variously pointed out that this has fed into the persistent racist assumption that racialized candidates get their position because of employment equity or "quotas", while white candidates are selected solely based on their merit rather than as a result of systemic white privilege in the workplace structure and culture (Interviews: b, u). Without a concurrent 'cultural change' in the workplace to move away from existing racist thinking and practice, such superficial implementation of employment equity as a 'legislated' measure has actually reinforced the existing racist logic that associates 'visible minority' with natural inferiority in contrast to whiteness with natural superiority without even bringing up to the surface. In addition, as implied in the comments by some Workgroup members, while employment is an important area of equity it is still way too narrow in scope to stand in as a measure against racism in a broad sense. And, this was precisely the kind of public leadership and initiative that this Workgroup was pushing the City to venture into.

Furthermore, the aggressive introduction of employment equity as a legislative measure - but without an accompanying systemic and cultural change away from racism - has served as a fodder for one of the most powerful backlash discourse as in the case of the provincial government of Ontario in the 1990s. Three of the Workgroup members who were present in Ontario at that time recall this experience rather vividly, when the provincial NDP government led by Bob Rae, pushed by what Harney calls "Ontario's 
anti-racist movement", introduced one of the most comprehensive employment equity measures in North America (Harney 2002). ${ }^{236}$ However, this was met with an even stronger backlash discourse which portrayed it as "affirmative action", "quota system", and "reverse racism" against whites and males, and was repealed just as quickly and aggressively when Mike Harris's Progressive Conservative government came to power in 1995 (Interviews: b, o; Harney 2002; Bakan and Kobayashi 2007a, 2007b; Kempthorne 2013). One community member of the Workgroup uses this experience as "a case in point" that illustrates the critical importance of targeting "cultural change" and “cultivating the [internalized] understanding" of the value of practicing equity among "the oppressors", because without it, "laws and be created but they can be removed over night" (Interview: u).

\subsubsection{Partial Alignment with the Coalition and Partnership Frames}

This powerful lesson about the gap between the formal and legislative change and the informal and cultural change informed the strategic focus of this Workgroup in their effort to bring about a long-term, systemic change towards equity. In addition to the Workgroup member who emphasized the importance of "cultivating the understanding" among the City staff about the value of "embedding equity" into the institution's culture and practice, other members also commented on the importance of changing the "workplace culture" and people's "attitudes on the ground" so that the existing legislative framework could actually be "fully embraced and implemented" (Interviews: b, o, u). In fact, one member pointed out that otherwise, such formal and legal structure can serve

\footnotetext{
${ }^{236}$ In fact, two of the Workgroup members worked as part of the government implementing these active anti-racism and employment equity measures at the time, one as part of the provincial government's Directorate on Race Relations, and another as part of one of the municipal governments' employment equity office. However, these offices and positions were all removed after Mike Harris's Progressive Conservative government came to power (Interviews: b, o).
} 
simply as "window dressing" or an excuse for the government to claim that they are taking proactive measures against inequity, even when it is not translating into substantive change in the real life experiences of people in the community (Interview: b).

In fact, this lesson informed the coalition as well as the partnership frames of the E\&I Lens, about the importance of 'cultural change' and the facilitative role that this Lens would play. As discussed in earlier sections of this thesis, the coalition and the partnership emphasized the 'voluntary', 'easy', and 'user-friendly' nature of this Lens that the City staff would 'want to' use because it 'helps them do their work more effectively and efficiently'. This is why the community and the City sought to design and portray this Lens as certainly not a stuffy, onerous, long, complicated, and complianceoriented policy or mandate that the staff 'have to' do, which ultimately 'creates more work' for them.

Most of the interviewees in this Workgroup saw the Lens's emphasis on its practical and everyday applicability to the City staff's work as a potentially great opportunity to facilitate this kind of cultural change in the City, which they knew from their movement-specific experience, was sorely lacking as they have sought to combat racism over the years. This in part was what motivated them to participate in developing this Snapshot (Interviews: $\mathrm{b}, \mathrm{k}, \mathrm{o}, \mathrm{u}) .{ }^{237}$ In this sense, the Visible minority Workgroup was also in a good position to align its movement frame with the coalition and the

\footnotetext{
${ }^{237}$ There were some differences in the strategic approaches to creating such cultural change among these members, however. For example, one member emphasized the need for "individuals in positions of privilege to do their homework" about their privileges before working with the community, which is informed by the anti-oppression framework. Similarly, another member emphasized the need to change the "white culture" and the "white system" in the workplace. Yet another member emphasized the need to "find a common interest between me and my oppressor" in order to initiate a cultural and attitudinal change within institutions like the City, because "if you bark at them they can put you in jail... and yank the chain around your neck each time you do that... so don't go there" (Interviews: anonymized). While the analysis of racial power dynamics is more or less shared among them, the possible strategic pathways vary slightly.
} 
partnership frames about this cultural change, through this emphasis on everyday practice and everyday implementation of this hands-on tool by City staff, being supported by the City's emerging Corporate-wide priority of "Service Excellence".

\subsubsection{Clash of Priorities across Scales: Lack of An Ally in Key Position}

However, these higher scale frames - and the higher scale strategic priorities promoted by the coalition and the partnership in creating and 'selling' this E\&I Lens to the target audience in the City still backfired on this particular Workgroup. It backfired in the sense that the Workgroup was told by the project lead that their Snapshot needed to conform and align with the City's existing official language of 'visible minority' as specified in its Equity and Diversity Policy, and with the federal Employment Equity Act. That is, instead of using the Snapshot to open up a discussion on various forms of everyday racism in the City embedded in its existing workplace culture, the Workgroup was asked to stick to the narrow, and legal, language about 'visible minorities', and confined specifically to the context of employment equity as a legislated mandate, with which managers across the City had to comply.

Ironically, this flowed from the nature of this Lens being a non-mandatory, nonlegislated, and thus voluntary tool for the City employees to use - or not to use. This made the "audience buy-in" the linchpin upon which the success of the Lens as a whole depended in terms of its reception, uptake, and actual implementation by its intended users across the City, as the project lead (who was also the manager of Diversity and Employment Equity for the City) explained in the interview (Interview: g). Given the hierarchical structure and the culture of the City as bureaucracy, it was particularly essential to obtain buy-in from managers across the City, for they occupy the position and 
thus hold the authority to decide whether or not to direct their employees below them to use this Lens and the accompanying Snapshots. And as the designated project lead responsible for developing this E\&I Lens and one of the key coordinators of this process, this manager knew more than anybody the strategic necessity of ensuring this.

This manager explained that her role as the project lead was to "sell the Lens" to her audience, and a key strategy she pursued was indeed to "tie in" the Lens and the Snapshots with as many existing legislated mandates, strategic priorities, frameworks and Council directives within the City as possible, to give this Lens a (pseudo) legal and mandated status when it was in fact voluntary (Interview: g). This was important for increasing the legitimacy, urgency and relevance of the Lens to managers across the City. The manager explained that this way they would see that this Lens is connected to what they "have to" do as part of their job as managers, and that there would be some kind of consequences otherwise from their superiors - thus serving as "a stick". ${ }^{238}$ This manager also tried to use this "tie-in" and "buy-in" to create an added incentive for managers to want to use - or as "a carrot" as she puts it - by "selling" the idea that because this Lens brings together all these disparate pieces of legislation, City policies, priorities, and directives into "one stop shop", using this tool would save them time, effort, and resources to fulfill all of these requirements in their job (ibid).

And, to maintain the efficacy of this strategy, it was important for this manager to make sure that all parts of the E\&I Lens, as well as the Snapshots, indeed made these

\footnotetext{
${ }^{238}$ This manager explained that this is why they first obtained endorsement from the senior management team of the City and especially the City Manager for this Lens, as they hold the highest position of authority within the bureaucratic hierarchy of the City. Even if this Lens is not a legislated mandate, these individuals can send directives to their staff down the hierarchy - starting from the top at the City Manager, then the senior management team, then through mid-level management all the way down to all other employees reporting to them (Interview: g).
} 
managers' work easier and simpler, and this included keeping the terminologies in line with the actual legal mandates, such as the Employment Equity Act. Introducing different languages that do not clearly connect to the existing legislation and policies, in this case "racialized communities", would not serve this purpose (Interview: g). In addition, given the existing culture of the City in relation to the issue of racism, this manager also knew that bringing this up does create a sense of fear or anxiety on the part of their audience, and the Snapshot simply had to be presented in a way that would not put off the readers. Otherwise, the 'buy-in' that the partnership and the coalition desperately need would be close to impossible to achieve. Yet, as we have seen, the existing discourse or culture on this topic is avoidance and denial. Thus, although the movement frame at the Workgroup level and the coalition and the partnership frames aligned well in terms of pursuing 'cultural change' in the City, there was still a gap between the Workgroup's movement frame that contained a radical element, and the partnership frame that prioritized resonance over it. In this sense, the strategic priority and the frame at the higher scale acted as an additional constraint on the community movement's ability to develop and pursue their movement frame. ${ }^{239}$

\subsubsection{Visible Minorities Case Summary}

In summary, the final text of the Visible minority Snapshot 'skirts around' some of the core message that the Workgroup wished to convey, and instead delays, or

\footnotetext{
${ }^{239}$ Incidentally but importantly nonetheless, the overlapping role that this manager played as the project lead for the Lens as a whole and in the Workgroup points to the importance of having an ally for the community movement who holds a management or otherwise high-authority position within the City's hierarchical structure. There were no doubt strong allies in this Workgroup who also worked within the City; however, they happened not to occupy a management position. And while there were two managers who participated in the negotiation with the Workgroup, and the second manager was brought into the process precisely to bridge the tension between the community and the manager in the middle part of the Snapshot development process, these managers did not act as a direct advocate for the community movement per se.
} 
indirectly or subtly presents it, or omits. However, the delayed segments $d o$ convey the core message about the systemic nature of racism in society - the radical part of their frame - quite directly, and in fact in the most "systematic" and "strongest" way (Interview: e). In this sense, the Workgroup chose radicalism over resonance - somewhat like the GLBT Workgroup chose to confront the tough issues, precisely because otherwise they would feed into the dominant frame. In this sense, the framing strategy in the Visible minority Snapshot was the opposite of the People with disabilities case. That is, it was more effective for the People with disabilities Snapshot to push the dominant frame out of their frame altogether, but in the case of the Visible minorities, it was essential that the movement frame named it openly as part of their frame, precisely because the dominant frame tended to mask, erase, and hide the reality of racism even while it silently perpetuated it.

Yet, many factors specific to the Visible minority Workgroup converged to work against their effort to expose and counter the dominant frame. Importantly, many of these inhibiting factors were closely tied to the higher-scale strategic priorities and the shared framing strategies of the coalition and the partnership, thus making it doubly and triply difficult for this Workgroup to pursue their movement-specific goals and movementspecific framing strategy. For example, the strong emphasis placed on resonance and 'buy in' in the coalition and the partnership frames made this Workgroup's radical critique of the status quo of racism, as well as of the current official terminology 'visible minority', less desirable. Within this context, these two points of critique were considered particularly radical due to the powerful and persistent dominant frame(s) within the City and in broader society: one that denied the existence of racism, but perpetuated the 
dominant assumption about the inherent inferiority of the visible minorities, while diverting attention away from the real cause, i.e., systemic racism, as well as the role of white privilege in it.

The higher-scale framing strategy to 'tie in' the movement-specific claims to the existing institutional framework of the City and higher scales of government such as legislation and policies did not work for this particular Workgroup, for they were actually seeking to challenge the official and the 'legislated' language enshrined in the Equity and Diversity Policy (EDP) of the City, and in turn the federal Employment Equity Act. Moreover, the fact that the EDP was one of the two institutional pillars to which the E\&I Lens was 'tied in' added to the frame dis-alignment of this Snapshot with the coalitionand the partnership frames.

In addition, the fact that the Workgroup had to compromise on one of the two priorities to address in their Snapshot further undermined their ability to come up with a complete transformative frame to challenge, counter, and replace the dominant frame. That is, challenging racism was the most fundamental - and most radical - objective for this Workgroup, and they could not compromise on it. The current terminology seemed like a less urgent issue, and the Workgroup made a compromise to let this one go so that they could earn the ability to pursue the first priority. And yet, without proper language that allowed the Workgroup to name the real problem and the real cause, they had a difficult time formulating an alternative frame that would challenge, transform, and replace the dominant frame effectively. In other words, by continuing to work with 'visible minority', the Workgroup was pulled back into reinforcing the dominant frame even as they sought to push against it. 
This Workgroup also did not benefit from having an established and coherent movement frame, which the Workgroup members shared, and agreed on, as a clear alternative to replace the dominant and the official frames. The discursive landscape at the local community level was still fragmented and in search of a workable alternative, and this was caused in part by the introduction of the federal term 'visible minority' in the first place. When the academic theoretical discourse offered one potential alternative, this was not shared or accepted across all the sectors and communities. Such academic discourse was also viewed as not suitable for the higher-scale priorities requiring 'simple' and 'user-friendly' document. Or, in some cases it was seen by some in the broader community as yet another externally imposed category by others, and not a self-definition they could relate to as their own. As well, when some members drew on the anti-racist frame to challenge white privilege in the City, this clashed with the resonance requirement of the coalition and the partnership frame.

Moreover, this strategic compromise also had implications for the Workgroup's ability to achieve resonance in their frame. That is, by continuing to work with the official (and dominant) frame that was grounded in a binary division between whites and non-whites, the Workgroup had an even harder time closing off this division that unnecessarily pitted the audience and the community against one another. That is, because the overall frame of the Snapshot was still based on this stark binary between whites and non-whites, the Workgroup's critique of racism, and in particular the role of white privilege in it, was interpreted in a polarized way. In other words, a particularly stark 'oppositional' frame was overlaid onto the Workgroup's radical critique of the status quo, thus fuelling even greater (potential) audience backlash. This particular 
combination of factors further undermined the Workgroup's ability to reframe the issue of racism in a non-binary framework, which was essential for generating resonance and audience buy-in, and for creating a transformative frame.

All these factors conspired against this Workgroup's effort to convey their radical core message, but to do so without facing defensiveness, denial, and resistance from the target audience. Even then, the Workgroup still chose to stick to their radical message, and the serendipitous result was that this Snapshot came to be viewed as "one of the strongest of all eleven documents" (Interview: e) ${ }^{240}$. In this sense, the framing strategy in this Snapshot was the opposite of the Immigrants Snapshot, in the sense that it opted for radicalism at the cost of reduced resonance, whereas the Immigrant one opted for stronger resonance at the expense of not including one of its most fundamental and radical element into the Snapshot. Either way, both Snapshots still conveyed some of their core messages and still contained elements of radicalism, much like the GLBT and the People with disabilities Snapshots did. These four cases show, however, that the shared discursive strategies at the coalition and the partnership scales indeed played out quite differently at the scale of the individual Workgroups, sometimes facilitating their movement-specific goals and sometimes not.

\footnotetext{
${ }^{240}$ This was in fact the overarching partnership (and coalition) frame used in the E\&I Lens, which highlighted the systemic - and often unintended - nature of inequity and exclusion in the city/City, caused by the existence of systemic barriers in society.
} 


\section{Chapter: Conclusion}

\subsection{Dis/Alignment of Strategies and Priorities between Scales}

As I have shown in the preceding chapters, every single Snapshot Workgroup worked within the strategic parameters set before them at the higher scales of the intersectional coalition and the City-community partnership, by virtue of being part of the Equity and Inclusion Lens. All of the Workgroups shared a generally common structure, featuring a mixed composition of community and City representatives. All shared the same format for their main document, the Snapshot, necessitating a common discursive strategy that required the Workgroups to balance the 'negative' content with the 'positive' in order to "tie in" the Snapshot to the existing institutional frameworks and initiatives within the City and higher scales of government to increase its legitimacy and resonance. Outside of these shared (and imposed) discursive strategies, these individual Workgroups variously drew on established movement frames from their respective associated social movements and, when available, master frames in order to strengthen the former.

Within this context of layers of shared strategies, all of the Snapshot Workgroups shared the common objective of countering negative stereotypes and assumptions about the given communities that the dominant frame portrayed. At the same time, they also shared another strategic objective of increasing the resonance of their Snapshot frame in order to generate audience buy-in to support their cause. As such, they all sought to develop a transformative frame that featured a strong element of resonance to entice the audience to buy into their message, but that still contained some form of radicalism that allowed them to challenge the exclusionary dominant frame and the status quo. As part of 
this effort, all Snapshots sought to reframe the cause of the exclusion and inequity of their community away from the inherent characteristics of the group and towards the societal and systemic barriers, or oppression.

However, I have shown in the preceding chapters that the specific ways in which these higher-scale priorities played out at the scale of the individual Workgroups varied significantly from Workgroup to Workgroup. Put differently, the strategic priorities that the coalition and the partnership set at these higher scales did not always work to support the movement-specific goals, priorities, and strategies at the Workgroup level. In addition, I have also found that each Workgroup actually pursued a slightly different combination of resonance, radicalism, and dominant-, official-, and master frames in their respective Snapshot in order to arrive at a particular kind of transformative frame within these parameters. The GLBT, People with disabilities, and the Immigrant Snapshot Workgroups were more or less able to align their movement-specific framing strategy with those at the higher scales of the coalition and the partnership, although there were still variations among them, and even compromises on the part of some Workgroups as they chose (and had to) conform to the shared strategic package. However, the common framing strategy that emerged out of this process did not align well for the movementspecific goals, strategies, as well as the particular constraints placed on the Visible minority Workgroup, and consequently they did not arrive at what was considered a complete transformative frame in this context.

\subsection{Resonance, Radicalism, Dominant Frame, and Transformative Frame}

Here, a common formula or structure for a transformative frame emerged out of this process of calibration among the eleven community movements and the City in this 
multi-layered coalition and partnership. Such a transformative formula required first and foremost that the cause of the problem be reframed away from the community in question, and instead towards a societal or systemic cause - thereby 'shifting the blame' away from the community and also from the audience. This also meant that a transformative frame needed to find a way to move the discussion out of the binary framework implied in the dominant frame (which 'blames' the marginalized community for their own exclusion by attributing it to their inherent characteristic), as well as in the oppositional frame (which 'blames' the dominant group for oppressing the marginalized community).

A transformative frame also commonly featured an appeal to the self-interest of the target audience, and also to the dominant group and/or the society at large. This was often done by emphasizing the benefits of solving this reframed problem that would accrue to them, and not just to the marginalized group. Offering a concrete and practical alternative solution to this reframed problem was another key element of a successful transformative frame, which in turn empowered the audience to be part of the solution (rather than the problem). These discursive tactics enabled the Workgroups to bridge the two sides of the binary implied in the dominant frame (and the oppositional frame), and thereby collectivize the problem, the blame or responsibility for solving it, the solution, and the benefits of solving it as a shared societal good for everyone.

Within this common formula, however, each Workgroup pursued different ways to combine these elements, especially the dominant frame and radicalism. For instance, the GLBT Snapshot opted to directly oppose the dominant frame by naming homo-/bi/transphobia as the root cause of all barriers and inequities experienced by the GLBT 
community. It adopted a radical- and even oppositional frame, but combined it with other discursive tactics that deflated the tension, fear, guilt or anger that such a confrontational frame tends to trigger on the part of the target audience (and dominant group). In contrast, the People with disabilities Workgroup preferred a strategy of not naming the dominant frame at all, instead opting to bypass it and replace it with a completely different alternative, so as to prevent the dominant frame from reclaiming the discursive landscape they were trying to transform.

On the other hand, the Visible minorities Workgroup wanted to directly name the problem with the dominant frame as part of their transformative frame so that they could counter it (somewhat like the GLBT), precisely because the dominant frame(s), along with the official frame of the City, tended to mask, or erase the reality of racism from public discourse. The Immigrant Snapshot took yet another approach, by using the dominant frame as the basis for the transformative frame, extending and expanding it, so that a radical element could be re-introduced into, or couched within, it. And yet, the case study also showed that their most fundamental and radical critique had to be left out of this frame for the sake of keeping it simple, short, user-friendly - i.e., so as not to undermine resonance.

This comparative analysis thus highlights a certain level of tension between resonance and radicalism that all four Workgroups had to grapple with, even while there were differences in the ways in which they sought to incorporate them into, or leave them out of, their respective frames. As the preceding analysis shows, this was partly a choice that each community movement made in terms of what kinds of discursive strategy they wanted to pursue in their Snapshots. The other part was that such strategic choice was 
always in part constrained or made out of strategic necessity. For example, it was a strategic necessity to pursue resonance and "let go" of the fundamental and radical message because otherwise "nobody will listen to you", as one of the interviewees in the Immigrants Workgroup noted. By the same token, the Visible minority Workgroup saw that letting go of the most fundamental objective of addressing racism just because it was "taboo" would render their Snapshot pointless. Similarly, for the GLBT Workgroup, "sugar-coating" the "tough issues" so as not to make the audience uncomfortable would defeat the purpose of the Snapshot and "feed into" the dominant stereotypes. Regardless of whether they prioritized resonance or radicalism or both, however, each Workgroup's strategic decision was as much a choice as a necessity. In this particular case, then, strategic resonance and forced resonance were opposite sides of the same coin.

\subsection{Radicalism as a Higher-Risk Strategy within the Multi-scale Context of the}

\section{Coalition and Partnership}

I found that the strategic package developed at the higher scales of the coalition and the partnership emphasized resonance as a higher priority, but this made radicalism a doubly and triply undesirable discursive option for community movement actors to pursue. For example, both the coalition- and the partnership frames of the Lens prioritized the user-friendliness of the tool as a way to solicit audience buy-in. Critiquing or challenging the fundamental power relations in society as the real cause of inequity, and calling for such fundamental change in society, did not constitute a simple, easy, quick, user-friendly and cost-effective solution for the individual City managers and employees to adopt. This made it harder for the individual Workgroups to insist on 
incorporating radicalism in this fundamental sense as a prominent part of their Snapshot frames, as we saw in the cases of the Immigrants and the Visible minority Snapshots.

In addition, the official discourse of the City-community partnership frame also tended to mask the fundamentally unequal power relations between the City (polity) and the community. Critiquing this fundamental power relation also fell beyond the scope of the partnership frame emphasizing user-friendliness to solicit audience buy-in. Such a fundamental critique, with explicit power relations analysis between the dominant and the marginalized in society, thus became even more "radical", and also not resonant, within this multi-scaled nature of the strategic priorities of this project. This was clear in the case of the Immigrants Snapshot, in which the Workgroup members felt that they "had to let go" of this fundamental point even though it was the very core of the issue they were seeking to address and change through this Snapshot, but also though the E\&I Lens as a whole.

Moreover, it was part of the strategy for the community movements to form this official partnership precisely so that they could gain entry into the polity and negotiate with the City on more equal footing. In this sense, the community actors wanted to portray themselves as equal partners to the Community rather than the perpetual underdog, which was a common image portrayed in each of the exclusionary dominant frames. In this way, these community movements could increase the legitimacy and resonance of their claims in the eyes of the City audience. The official discourse of partnership was thus part of the framing strategy to counter this dominant frame and the status quo of the communities being excluded from the polity. Bringing up this status quo and the dominant frame would also undermine their strategic objective. Again, we see 
the tension between the movement actors' core objectives (radicalism) on the one hand, and the strategic objective (resonance) on the other. In short, their strategic priority to create an equal partnership again came into conflict with the other fundamental priority of challenging and changing unequal relations of power.

\subsection{Radicalism at the Workgroup Scale: Varied Movement-Specific Conditions}

All of these strategic considerations at the coalition and the partnership scales therefore meant that the pursuit of radicalism was left to the individual Workgroups to sort out on their own; however, as I have shown, each Workgroup was equipped with a different set of conditions or factors that guided how they arrived at their movementspecific transformative frame. For example, the availability of a coherent movement frame(s) for the Workgroup to draw on, as well as of master frames that could help increase the resonance of such movement frames, turned out to be a significant factor. In addition, the extent to which the official discourse and the institutional framework within the City supported and aligned with their movement frames - especially the radical elements - also played a role (e.g., the City's own commitment to be an "enabler of social change" in the community through IOI, or the dedicated Accessibility Office backed by AODA, or the GLBT Liaison Committee of the Ottawa Police). Another related factor was the role and position of the City ally members of the Workgroup within the Workgroup, as well as their institutional position within the organizational hierarchy of the City, and that of their affiliated ally department.

Aligning the movement frame with the City's existing institutional framework, such as policies, mandates, and legislation from higher levels of government was an important discursive strategy for the Workgroups to pursue, particularly as a way of 
increasing the legitimacy and resonance of the E\&I Lens in the eyes of the target audiences in the City. Moreover, this was a necessary strategy because the key coordinators of the Lens had not secured the buy-in and commitment from the Executive Management (and ultimately Council) to make this Lens "mandatory" for all City employees to use and report on. Given this crucial limitation at the highest scale of the partnership, all contributors of the Lens needed to pursue this shared discursive strategy of linking to established policies. This discursive option generally supported the goals of the individual Workgroups in pursuing a common formula for a transformative frame, helping to institutionally anchor them, especially in the case of the People with disabilities, the GLBT, and the Immigrants cases.

The Visible minority Workgroup also sought out this same strategy; however, it did not work as well for them. This was because one of their key movement-specific priorities was to actually challenge the official term used by the City that was enshrined in its Equity and Diversity Policy, which in turn was legally mandated by the federal Employment Equity Act. This was not a peripheral issue for this Workgroup, for this official term 'visible minority' played a prominent role in reinforcing the dominant racist logic and frame in the views of many community members. The fact that this term was institutionally and legally anchored at the municipal and the federal levels thus made it difficult for them to challenge it. In addition, it so happened that the Equity and Diversity Policy was one of the two institutional pillars to which the key coordinators of the E\&I Lens sought to "tie in" this tool (along with the City's Service Excellence mandate). Thus, the visible minority Workgroup was caught between the alignment of the Lens with the City's institutional framework at multiple levels of government, as well as with the 
coalition- and the partnership-scale frames, and their own desire to challenge the official discourse and institutional framework.

Another key factor for the variation between individual Workgroups was the availability of established and readily usable frames for each of them to draw on in formulating the basis for their transformative frame. As this comparative analysis found, some Workgroups were better positioned for this task of developing a frame that ensured enough resonance without foregoing the radical core of challenging the status quo, as they were able to access well-developed and established movement frames, to which most or all of the Workgroup members generally subscribed. These frames sometimes came from broader social movements, or "master frames" in society like the rights frame and the equality frame, and sometimes from institutional or official frames or even legislation (e.g., ADOA, Immigration Ottawa Initiative). The People with disabilities Workgroup drew on established frames from the Independent Living and Disability Rights movements, and the GLBT Workgroup from the broader LGBTQ Rights movement with both its "radical" and "institutional" wings. The immigrants Workgroup drew on the partially transformative frame that was emerging as a new official frame for the City and for broader society.

In contrast, however, such strongly established alternative frames to counter the dominant frame were not readily available to the Visible minority Workgroup, nor was it shared or accepted across the sectors this Workgroup encompassed. The discursive landscape within the local community was fragmented and confused, and this fragmentation was in part caused by the official discourse/frame of "visible minority". The alternative frames that some of the Workgroup members drew on were not well 
suited for "strategic framing" and the "user-friendliness" required for this project, and was not accepted by some quarters of the community. For example, the discourse on "racialization" and 'race' as a social construct that came out of academia was not accepted by all of those in the community, partly due to the historical tension and power relations between the two sectors, and partly because the "intellectual" and "complex" discourse that aimed at conveying the 'truth' did not readily fit the strategic framing requirement of this tool, namely "user-friendliness". In addition, while some members of the Workgroup also appealed to the discourse and terminology used in international conventions and declarations, this only offered a critique of the official discourse and was not a complete frame with an alternative solution. Plus, as discussed, the Canadian federal government defied the UN criticism, citing that international conventions are only normative and not "enforceable".

Finally, the roles and positions of the City ally members also turned out to be a significant factor. That is, the People with disabilities and the GLBT Workgroups both featured a City member who was a strong ally who personally self-identified with the community movement and its goals, and was "fluent" in both the movement and the City's Corporate language. Moreover, such strong ally members were also given positional and institutional authority to bridge the two frames - the community movement and the official frame of the City - in order to change the exclusionary dominant frame of the City to ultimately support the movement goals. These City ally members officially acted as co-leads for their respective Workgroups and therefore had the structural authority to set the direction for the development of their respective Snapshots. In addition, this structural authority was shared with a community co-lead, 
thereby allowing the Workgroup to leverage the strategic benefits of this City-community partnership at the Workgroup scale as well. These City allies also occupied management or Corporate-wide advisory positions within the bureaucratic hierarchy of the City. Furthermore, their respective department or office had to, as part of its official and primary mandate, promote inclusion and equity for the given community - in short, they belonged to an ally department. These factors contributed to greater additional institutional legitimacy for these allies to support the community movement as part of their job even if it went against the exclusionary dominant frame or status quo in the City.

The strategic significance of this only becomes evident when compared to the Visible minority case, which also featured committed City ally members who identified with and supported movement goals. However, these allies did not occupy management positions. Indeed, the negotiation between the movement frame on the one hand, and the dominant and official frames of the City on the other, could only resume after the two managers from these allies' respective departments were brought in to the negotiation at the Workgroup. Put differently, these ally members were not given the positional or institutional authority to 'call the shots' in clear support of the community movement, when the conflict between the priorities of the movement and that of the City - and the partnership - arose.

One important insight that emerges from this study is that over-emphasizing one at the expense of the other can often lead to an ineffective frame. Pursing resonance at the expense of not challenging the status quo can hurt the movement cause in the long-run. Conversely, focusing too much on critiquing the status quo without supplementing it with resonance and other elements of a transformative frame (such as appeal to interests, 
benefits to the audience, and alternative solutions) can also hurt the movement cause, at least in the short term. In this sense, this comparative analysis brings home Ferree's point (2003) that radicalism - and not just strategic resonance - should remain a choice for movement actors to pursue, especially if their end game is a fundamental social change to existing relations of power. To this, I also add that this is especially an important strategic choice for movement actors and their institutional allies to keep open, especially if the strategic pressure to pursue resonance becomes so high, as in the case of the Equity and Inclusion Lens.

However, I also add a caveat to Ferree's notion of resonance and radicalism (2003). That is, while she presents these as either supporting or challenging the dominant frame, this empirical study clearly shows that the two are not necessarily oppositional to one another, nor mutually exclusive. I therefore add that Ferree's concept proved useful in drawing out the tension that - often, but not always - exists between resonance and radicalism, as many contributors of the Lens certainly grappled with this tension, especially at the Workgroup scale. However, my study makes it evident that this was not an inescapably either-or choice that actors had to make. Instead of having to choose one of the two, this study shows that most contributors of the Lens - movement actors as well as their City allies - actively sought to integrate both resonance and radicalism into a single frame. Moreover, this comparative analysis of the four Workgroups shows that there are multiple and creative ways to engage with both resonance and radicalism as part of the strategic framing effort of a given movement. In this sense, the concept of transformative frame which I advanced in this thesis expands and enriches this theoretical discussion beyond this binary of resonance on one side and radicalism on the other. 


\subsection{Contributions to the Literature}

Thus, the main theoretical contribution of this research is to combine, modify and integrate various theoretical concepts from the 'cultural turn' in American social movement theory, from theories of neoliberal governance and from theories of intersectionality, in order to explain how and why actors made political decisions and used certain discourse in order to pursue their equity-related goals. For example, I draw on the concepts of resonance and radicalism and overlay them onto the strategic necessity of pursuing frame alignment. In this case, frame alignment occurred both as part of the coalition building effort among the movements, and between the movement frame and the dominant and/or official frame of the City as part of their partnership building process. This is critical in underlining the different pathways to social change that political actors take - in this case, through discourse to cultural change and ultimately to material changes in the lives of Ottawa residents.

This thesis also documents the lived process of trying to forge a new intersectional and cross-movement coalition among various identity-based movements, driven by their broadened vision of equity and inclusion, and in part by the strategic necessity to come together in an increasingly precarious and competitive era of neoliberalism. However, this was not a smooth and seamless process. On the one hand, this study shows the ways in which this new intersectional coalition innovatively sought to collaborate with, and build connections to one another, across the differences of their identities and in their experiences of marginalization. This act of building an intersectional coalition established solidarity where, in many cases, it had not existed before. Yet, this remains a clumsy and cumbersome process as these movements and 
actors wade through the persistence of identity politics and questions of representation within a framework that reinforces a non-intersectional and non-plural views of who we are as human beings.

This study also contributes to the ongoing analysis of the shifts in what social movements are by pushing us to look at them in non-traditional ways as situated outside of the polity, and rather at the ways in which they engage in a variation of public-private partnership with the state in an era of neoliberal governance. This research sheds light on these changing relationships between social movements and the state, taking into account the continuing patterns of power imbalance across this blurred - but still persistent - line between the inside and the outside of the polity. This also provides an updated empirical study on municipal bureaucratic politics and culture in Ottawa in the 2000s, the first decade following its amalgamation when the new City of Ottawa was going through an institutional transformation of its own and serving an expanded and rapidly changing demographic. In short, this study documents this transitional moment for these identitybased movements and the City-community relations in Ottawa around this time period, and in the process poses questions about the limitations of existing theoretical concepts.

\subsection{Looking Forward}

One of the key lessons emerging from this study is the importance of pursuing radicalism, even if it seems strategically not expedient, and even dangerous, sometimes. Without pursuing a radical vision that is different from the dominant status quo, how can social change be possible - especially when that vision is about equity? This was an important point that was at times discouraged for the sake of prioritizing strategic resonance. By not shying away from critiquing the status quo and the reality of exclusion 
and inequity in our city, some of these movements helped keep open the discursive space for all other movements within this project to continue pushing the equity agenda forward.

In this sense, the strategic decision to form the coalition and the partnership served to allow each of the individual movements to share with, contribute to, and benefit from, the strengths and sometimes weaknesses of each other's frames. That is, the element of radicalism found in one part of the Lens (for example, the GLBT or the Visible minority Snapshots) made a significant contribution to the rest of the movements, the coalition, and the partnership by ensuring that the Lens as a whole still remained grounded in the ultimate vision of a city for everyone, and did not get carried away with the short-term strategic pursuit of resonance alone. Likewise, individual Workgroups (such as the Visible minority Snapshot) also benefited from the elements of resonance found in other parts of the Lens, even if it might have lacked it within its own Snapshot. Even though these individual Snapshots were developed in separate silos so to speak, collectively they were still able to benefit from and strengthen each other's framing efforts through their common participation in this coalition and partnership.

The new priorities for the future are continuing to cultivate this sense of a crossmovement coalition and City-community partnership. This study underscores the importance of striving to ask the tough and sensitive questions among and about ourselves, which this coalition and partnership was not in a position to delve into at the time - such as the inequities within and between communities, and the disparities in the progress or setbacks experienced by different movements. Such tough questions were avoided during this early attempt to build a new intersectional coalition in favour of 
simply finding differences and commonalties among the eleven groups. However, a more direct interpretation of equity that takes horizontal inequalities into consideration - the differences within groups - will be important as we continue to find ways to advance equity and inclusion for all. In fact, this will continue to be necessary if we are to be able to operationalize intersectionality in concrete political terms and move beyond the tropes of identity politics. In fact, many project participants started to raise these questions themselves, especially in retrospect, which reflects the growing sense of intersectional identity and solidarity on their part.

Similarly, on the City-community front, the power disparities between the City (polity) and the often excluded communities are real, and a conscious and continuing effort needs to be made not only by the community actors, but also by City representatives to acknowledge them as they are occurring. We can then find ways to even them out on an ongoing basis, rather than masking them through a discourse of partnership and working closely only when it is convenient, or only when there is specific external funding. Continuing to keep open the boundary of the polity is one concrete act that many community members indicated that the City needs to do.

Future lines of inquiry could build on this work to examine what this study did not do, for example a closer comparative study of the discursive landscapes of each of these community movements in the broader public discourse, including media and popular discourse. Another potential area of study would be the clusters of relationships or networks among these eleven community movements after this one-time project funding expired, to examine which of the movements are continuing to deepen their relationships with one another and which ones are drifting apart, and why. In a similar 
vein, future research could also examine the role of policy priorities and funding structures in supporting (or not supporting) which kinds of issues pursued by which movements, and what kinds of coalitions and partnerships are encouraged (or not).

Such tough questions could inform these actors from all movement backgrounds about which areas currently present strategic opportunities, but also which areas are in greater need of attention precisely because they are currently not resonant within dominant society. As this study makes clear, the 'progress' or the journey towards equity and inclusion is a long and non-linear process, in which the different sectors or movements may experience rapid progress at one time, and greater setbacks at another. (And of course, what is considered 'success' in what time frame is always ambivalent and contextual.) With this in mind, it is my hope that the insights from this study will continue to remind us of the importance of not losing sight of our ultimate vision, and of continuing to find inspiration in our own contributions to this vision over the years, both collectively as a city, through our respective movement-specific journeys, and as individuals. 


\section{Appendices}

\section{Appendix A Interviews Conducted}

Abella, K. (2012 October 26). Personal interview, Ottawa.

Andrew, C. (2012, August 24). Personal interview, Ottawa.

Bowa, A. (2012, August 9). Personal interview, Ottawa.

Collicott, V. (2012, August 16). Personal interview, Ottawa.

Doerge S. (2012, July 4). Personal interview, Ottawa.

Doerge, S. and Serje, M. C. (2012, July 16). Personal interview, Ottawa.

Emburg, L. (2012 October 15). Personal interview, Ottawa.

Emburg, L. (2012 October 30). Personal interview, Ottawa.

Freire, C. (2013 February 4). Phone interview, Ottawa.

Hassan, M. (2012 October 10). Personal interview, Ottawa.

Hatt, K. (2012 November 21). Personal interview, Ottawa.

Husne Ara, S. (2012, October 4). Personal interview, Ottawa.

Lecomte, R. (2013 January 22). Email interview, Ottawa.

Luther, R. (2012, July 31). Personal interview, Ottawa.

Malone, C. (2013 February 1). Personal interview, Ottawa.

Mohamoud, H. (2013 January 22). Personal interview, Ottawa.

Nicholson, C. (2013 February 7). Personal interview, Ottawa.

Onyalo, S. (2012 November 6). Personal interview, Ottawa.

Pailalunga, K. (2013 February 7). Phone interview, Ottawa.

Pepper, D. (2012 November 2). Personal interview, Ottawa.

Pepper, D. (2012 October 25). Personal interview, Ottawa. 
Pollack, M. (2013 June 14). Phone interview, Vancouver.

Reid, M. (2012 December 5). Phone interview, St. Johns.

Serje, M. C. (2012, August 21). Personal interview, Ottawa.

Shultz, D. (2012, September 19). Personal interview, Ottawa. 


\section{Appendix B Documentary Data: Non-Publicly Available Sources}

City for All Women Initiative (CAWI). (2005-04-22). Incorporating equity into City of Ottawa planning - Proposal presented by CAWI, April 2005.

........(2005-08-02). Community letters of support to equity in the Corporate Plan. (2005-08-30). Gender Equality Planning Pilot workplan: Gender Equality Reference Group.

.......(2005-09-06). Preparing to speak to Corporate Services.

..(2005-09-13). Gender Equality Guide - Sept 13.

.......(2005-09-20a). Disposition - Equality in the City Corporate Plan:

Recommendations accepted by Corporate Services and Economic Development Committee.

.......(2005-09-20b). First draft - Gender Equality Guide summary of feedback.

........(2005-10-12). Feedback on Gender Equality Guide - Oct 12 version.

........(2005-10-13). Dear reader - Feedback from CPS staff.

.......(2005-11-14). Developing an Equality Framework in the City of Ottawa.

(2005-11-21). Community letter to Bob Hertzog. Letter from CAWI Steering Committee to the City of Ottawa Chief Corporate Planning and Performance Reporting Officer.

.......(2005-11-29). Gender Equality Guide - Draft.

.......(2005-12-19). Learning from the London, UK - Equality Framework.

.......(2006-01-06). Learning from London meeting.

..(2006-06-15). Equality Planning Framework 1 pager bilingual.

.......(2007a). Final report on the evaluation of the Gender Equality Guide pilot:

Findings and recommendations, January 2007.

.......(2007-03-22). Briefing note to Donna Gray, GEL \& one lens.

........(2007-07-09). EDAC business case. 
.......(2007-09-18). Integrating equality into city planning - update for Steering Committee. Internal Report to CAWI Steering Committee.

........(2007-10-16). Integrating gender equality into city planning - update October 2007. Internal report to CAWI Steering Committee.

........(2007-10-25). Integrating equality into city planning - an update and concerns. Internal report to CAWI Steering Committee.

........(2007-11-05). Letter to Kent Kirkpatrick re: Gender Equality Lens and Multifocal Lens. Letter from CAWI Coordinator on behalf of CAWI Steering Committee to City Manager.

........(2008-n.d.). Multi-Focal Lens Project Overview.

........(2008-02-06). Multi-focal Lens (Equity and Inclusion Lens) development.

........(2008-03-20). Letter to Steve Finnamore re: Multi-focal Lens. Letter from CAWI to the City of Ottawa Deputy City Manager, Business Transformation Services.

.......(2008-04-03). Draft - Division of responsibilities, Equity and Inclusion Lens.

........(2008-05-20). Multi Focal Lens discussion summary.

........(2008-05-27). Equity and Inclusion Lens Reference Group terms of references.

..(2008-05-28). Multi Focal Lens introduction: Integrating inclusion and equity into planning - A partnership project between the City of Ottawa and City for All Women Initiative / Initiative : une ville pour toutes les femmes.

.......(2008-05-29). Multi Focal Lens Planning Tool Reference Group terms of references.

........(2008-06-04). Advisory Committees - Multi Focal Lens.

..(2008-09-05). Reference Group meetings letter.

........(2009-02-06). Multi-Focal Lens development.

.......(2008-08-02). Learning from first consultation with Advisory Committees - Multi Focal Lens.

........(2008-08-18). Advisory Committees - Multi Focal Lens.

..(2008-09-25). Multi-Focal Lens - Sept 13 report. 
........(2008-11-27). Equity \& Inclusion Lens focus document (1 pager \& 6-8 pager) recent immigrants \& visible minorities.

.......(2008-12-01). Risks and mitigating factors: Ensuring success by addressing the risk.

........(2008-12-03). Equity and Inclusion Lens concept paper.

........(2009-01-29). Focus document outline.

........(2008-12-23). Snapshot questionnaire - Disabilities.

.......(2009-02-09). Equity \& Inclusion Lens - Presentation to Advisory Committees January-February 2009.

........(2009-03-06). Email comment from Advisory Committee member.

........(2009-04-07). Visible minority meeting\#1 notes. Meeting minutes.

........(2009-04-08). Equity and Inclusion Lens - Presentation to SMT April 2009.

...(2009-04-15). Recent immigrants meeting \#1. Meeting minutes.

........(2009-04-21). Visible minority meeting \#1 notes - audience. Meeting minutes.

........(2009-05-06). Visible minority meeting \#2. Meeting minutes.

........(2009-05-13a). People with disabilities meeting \#2. Meeting minutes.

........(2009-05-13b). Recent immigrants meeting \#2 full notes. Meeting minutes.

.......(2009-06). City Manager letter drafts 2009.

........(2009-06-07). Visible minority meeting\#3. Meeting minutes.

.......(2009-06-19). Immigration Ottawa Initiative. Written information provided by a City official to the Immigrants Snapshot Workgroup.

........(2009-06-30). Visible minority special meeting minutes. Meeting minutes.

.......(2009-07-16a). Visible minority meeting notes: common ground. Meeting minutes.

........(2009-07-16b). Visible minority meeting summary. Meeting minutes.

........(2009-07-16c). Visible minority meeting: common ground. Meeting minutes. 
City of Ottawa. (2006-08-21). Memo: Evaluation - Gender Equality Guide. Memo from Deputy City Manager to Community and Protective Services.

.(2008-01-21). Inquiry Response Letter - CAWI and Multi Focal Lens and Gender Equality Guide.

.......(2009b). City of Ottawa Management toolkit: Service Excellence overview.

Social Planning Council of Ottawa and City for All Women Initiative. (2005-06-16). Requesting support from Community Leaders: From CAWI \& Social Planning Council of Ottawa re: Incorporating equity into the City Corporate Plan, 20062009.

..(2005-07-17). Incorporating Gender and Equity into City of Ottawa Corporate Plan.

.......(2005-11-16). Equality Framework meeting, Nov 2005. Meeting minutes.

.......(2005-12-01). Equality Framework meeting, Second Discussion. Meeting Minutes.

........(2005-12-21). Community letter to Bob Hertzog. Letter from SPC and CAWI to the City of Ottawa Chief Corporate Planning and Performance Reporting Officer.

.......(2006a, January 16). Developing an Equality Framework for the City of Ottawa. Presentation given to Equity and Diversity Advisory Committee.

..(2006-01-25, January 25). Equality Planning Framework matrix. 


\section{Bibliography}

Accessibility for Ontarians with Disabilities Act. S.O. 2005, Chapter 11. Retrieved from http://www.e-laws.gov.on.ca/html/statutes/english/elaws_statutes_05a11_e.htm

AIDS Action Now. (n.d.) About AAN. Retrieved from http://www.aidsactionnow.org/ ?page_id $=21$

Aids Coalition to Unleash Power (ACT UP). ACT UP new york. Retrieved from http://www.actupny.org/

Amenta, Edwin, and Neal Caren. (2004). The legislative, organizational, and beneficiary consequences of state-oriented challengers. In The Blackwell Companion to Social Movements (pp. 461-488). Blackwell Publishing Ltd.

Amenta, Edwin, Neal Caren, Tina Fetner and Michael P. Young (2002). Challengers and states: Toward a political sociology of social movements. Sociological Views of Political Participation in the 21st Century, 10, 47-83.

Anheier, Helmut K. (2009). What kind of non-profit sector, what kind of society?:

Comparative policy reflections. American Behavioral Scientist, 52(7), 1082-1094.

AODA Alliance. (2007). AODA - Why has the Ontario Government's development of Accessibility Standards under the AODA been so ineffective so far? - Letter to Ellen Waxman, Assistant Deputy Minister, Accessibility Directorate of Ontario, and Scot Weeres, Director, Standards Development and Compliance Branch. Toronto, Ontario. Retrieved from http://www.aodaalliance.org/strong-effectiveaoda/10222007.asp

........(2008). AODA - Is the Ontario Government on schedule to making Ontario fully accessible for people with disabilities by 2025? - Letter to Ellen Waxman, Assistant Deputy Minister, Accessibility Directorate of Ontario. Toronto, Ontario. Retrieved from http://www.aodaalliance.org/strong-effective-aoda/10012008.asp

Arnold, Elisabeth. (2002). Partnership and the role of cities/municipalities. Conference presentation at First International Seminar on Women's Safety - Making the Links, Montréal, May 2002. Retrieved from http://www.femmesetvilles.org/ seminar/pdf_seminar/pres_en/arnol_en.pdf

Bakan, Abigail and Audrey Kobayashi. (2007a). Affirmative action and employment equity: Policy, ideology, and backlash in Canadian context. Studies in Political Economy, 79, 145-166. 
(2007b). The sky didn't fall: organizing to combat racism in the workplace: The case of the alliance for employment equity. In Randy Enomoto and Genevieve Fuji Johnson (Eds.), Race, racialization, and anti-racism in Canada and beyond (pp. 51-78). Toronto: University of Toronto Press.

Benford, Robert D. (2013). Master frame. In The Wiley-Blackwell Encyclopedia of Social and Political Movements, January 14, 2013. Retrieved from http://onlinelibrary.wiley.com/doi/10.1002/9780470674871.wbespm126/full

Benford, Robert D. and David. A. Snow. (2000). Framing processes and social movements: An overview and assessment, Annual Review of Sociology 26, 611639.

Boudreau, Julie-Anne, Roger Keil, and Douglas Young. (2009). Changing Toronto: Governing urban neoliberalism. Toronto: University of Toronto Press.

Bradford, Neil. (2003). Public-private partnership? Shifting paradigms of economic governance in Ontario. Canadian Journal of Political Science / Revue Canadienne de Science Politique, 36(5), 1005-1033.

Brown, Wendy. (2008). Regulating aversion: Tolerance in the age of identity and empire. Princeton: Princeton University Press.

CBC News. (2009a). Off-duty officer to be investigated for alleged assault on cabbie. May 13. Retrieved from http://www.cbc.ca/news/Canada/ottawa/story/2009/05/ 13/ottawa-police-officer-assault-investigation.html

.......(2009b). Ottawa Police officer charged with assaulting cabbie. June 24. Retrieved from http://www.cbc.ca/news/Canada/ottawa/story/2009/06/23/ottawapolice-cabbie-assault.html

Canadian Auto Workers Union. (n.d.) To our allies: Everything you ever wanted to know about lesbian, gay, bisexual, and trans issues... Well, maybe not everything... Retrieved from http://www.caw.ca/assets/pdf/glbt_booklet.pdf

Canadian Race Relations Foundation. (2007). CRRF's response to the concluding observations of the CERD. Retrieved from http://www.crr.ca/en/policy-aresearch/ position-papers/item/23514-crrfs-response-to-the-concludingobservations-of-the-cerd

CanWest News Service. (2007). UN calls Canada racist for 'visible minorities' tag. March 8. Retrieved from http://www.Canada.com/cityguides/fortstjohn/ story.html?id=f469b36e-c587-40e7-98e5-3aa50a371318\&k=23802

Centre for Addiction and Mental Health. (2011). Researching for LGBTQ health: TwoSpirit community. Retrieved from http://gbtqhealth.ca/community/two-spirit.php 
Church, Kathryn, Catherine Frazee, Melanie Panitch, Theresa Luciani, and Victoria Bowman. (2007). Doing disability at the bank: Discovering the work of learning/teaching done by disabled bank employees. Toronto: RBC Foundation Institute for Disability Studies, Ryerson University. Retrieved from http://www.rbc.com/diversity/pdf/Ryerson_Report_Oct-07.pdf

City for All Women Initiative. (2005, September 15). Deputation to HRSS: Community input into strategic plan of Community and Protective Services. Retrieved from http://www.cawi-ivtf.org/sites/all/files/pdf/past_actions/2005/DeputationCPS StrategicPlanSept2005.pdf

.(2007). How we make decisions - Steering Committee 2007. Retrieved from http://www.cawi-ivtf.org/sites/all/files/pdf/How_we_make_decisions.pdf

........(2007). Women's perspectives on inclusive municipal governance, A Peach Paper, June 2007. Retrieved from http://www.cawi-ivtf.org/sites/all/files/pdf/ past_actions/2007/Peach\%20Paper\%20-\%20FINALenglish.pdf

.......(2011a). Governance. Retrieved from http://www.cawi-ivtf.org/governance

.......(2011b). Our History. Retrieved from http://www.cawi-ivtf.org/history

........(2011c). Research. Retrieved from http://www.cawi-ivtf.org/research

City for All Women Initiative and City of Ottawa. (2008a). Gender Equality Lens Promoting equality and inclusion for the full diversity of women in the City of Ottawa. Retrieved from http://www.cawi-ivtf.org/sites/all/files/pdf/publications/ Gender EqualityLensGuide-08-en.pdf

........(2008b). Multi Focal Lens: Integrating Inclusion and Equality into Planning - A partnership project between the City of Ottawa and City for All Women Initiative. Presentation to Poverty Issues Advisory Committee. June 10. Retrieved from http://ottawa.ca/calendar/ottawa/citycouncil/a-piac/2008/06-10/Multi\%20 Focal\%20Lens\%20Eng\%20June\%202008.htm

..(2009a, February 4). City of Ottawa Equity and Inclusion Lens. Presentation to Seniors Advisory Committee. Retrieved from http://ottawa.ca/calendar/ottawa/ citycouncil/a-sac/2009/02-04/Ref\%203\%20-\%20EI\%20Lens\%20Dec\%20 2008\%20-\%20EN.htm

(2009b). Equity and Inclusion Lens - A User's Guide, Pilot version Fall '09. (Unpublished). ..(2010a). Equity and Inclusion Lens - A User's Guide, Version 2010. Retrieved From http://ottawa.ca/sites/ottawa.ca/files/attachments/ottpage/eil_user_Guide_ en.pdf 
.......(2010b). Diversity Snapshot: Aboriginal peoples: First Nations, Inuit, Métis, Version 2010. Retrieved from http:/ottawa.ca/sites/ottawa.ca/files/attachments/ ottpage/aboriginal_en.pdf

.......(2010c). Diversity Snapshot: Francophones, Version 2010. Retrieved from http://ottawa.ca/sites/ottawa.ca/files/attachments/ottpage/francophone_en.pdf .(2010d). Diversity Snapshot: GLBT (gay, lesbian, bisexual, trans), Version 2010. Retrieved from http://ottawa.ca/sites/ottawa.ca/files/attachments/ottpage/Gblt _en.pdf

..(2010e). Diversity Snapshot: Immigrants, Version 2010. Retrieved from http://ottawa.ca/sites/ottawa.ca/files/attachments/ottpage/immigrants_en.pdf

........(2010f). Diversity Snapshot: People living in poverty, Version 2010. Retrieved from http://ottawa.ca/sites/ottawa.ca/files/attachments/ottpage/poverty_en.pdf

........(2010g). Diversity Snapshot: People with disabilities, Version 2010. Retrieved from http://ottawa.ca/sites/ottawa.ca/files/attachments/ottpage/disabilities_en.pdf ..(2010h). Diversity Snapshot: Rural residents, Version 2010. Retrieved from http://ottawa.ca/sites/ottawa.ca/files/attachments/ottpage/rural_2010_en.pdf

.......(2010i). Diversity Snapshot: Seniors, Version 2010. Retrieved from http://ottawa.ca/sites/ottawa.ca/files/attachments/ottpage/seniors_en.pdf ..(2010j). Diversity Snapshot: Visible minorities, Version 2010. Retrieved from http://ottawa.ca/sites/ottawa.ca/files/attachments/ottpage/visible_minorities_2010 _en.pdf

.(2010k). Diversity Snapshot: Women, Version 2010. Retrieved from http:/ottawa.ca/sites/ottawa.ca/files/attachments/ottpage/women_2010_en.pdf

........(20101). Diversity Snapshot: Youth, Version 2010. Retrieved from http://ottawa.ca/sites/ottawa.ca/files/attachments/ottpage/youth_en.pdf

City of Ottawa (2003). The Ottawa 20/20, The Human Services Plan - Priority on people. Retrieved from http://ottawa.ca/cs/groups/content/@webottawa/ documents/pdf/mdaw/mdc4/ edisp/cap078814.pdf

.(2007a). City of Ottawa Municipal Accessibility Plan (COMAP). Submitted by the Accessibility Steering Committee in collaboration with the City of Ottawa Accessibility Advisory Committee. Retrieved from http://www.ottawa.ca/ calendar/ottawa/citycouncil/csedc/2007/01-6/Comap\%202007.htm 
........(2007b). City of Ottawa annual report 2006. Retrieved from http://ottawa.ca/cs/ groups/content/@webottawa/documents/pdf/mdaw/mdq1/ edisp/con022149.pdf

........(2009a). City of Ottawa annual report 2008. Retrieved from http://ottawa.ca/en/ city-hall/accountability-and-transparency/annual-report/2009-city-ottawa-annualreport

..(2010). City of Ottawa annual report 2009. Retrieved from http://ttawa.ca/en/ city-hall/accountability-and-transparency/annual-report/2009-city-ottawa-annualreport

..(2011a). City of Ottawa annual report 2010. Retrieved from http://ottawa.ca/en/ city-hall/accountability-and-transparency/annual-report/2010-city-ottawa-annualreport

........(2011b). City of Ottawa 2010 financial statement discussion and analysis. Retrieved from http://app06.ottawa.ca/cs/groups/content/@webottawa/documents/ $\mathrm{pdf} / \mathrm{mdaw} / \mathrm{mdgz} / \sim$ edisp/cap084604.pdf

........(2012a). City of Ottawa annual report 2011. Retrieved from https://ottawa.ca/ sites/ottawa.ca/files/migrated/files/cap214801.pdf

........(2013a). Your City government. Retrieved from http://ottawa.ca/en/city-hall/yourcity-government

..(2013b). City Manager profile - Kent Kirkpatrick. Retrieved from http://ottawa.ca /en/city-hall/city-manager-and-administration/city-manager/city-manager

.......(2013c). City of Ottawa annual report 2012. Retrieved from http://ottawa.ca/ sites/ottawa.ca/files/print_ready_2012_coo_annual_report_en_accessible_aug_28 2013.pdf

.........(n.d.a). Accessibility for Ontarians with Disabilities Act (AODA). Retrieved from http://ottawa.ca/en/city-hall/accessibility-services/municipal-accessibility-planand- policies/accessibility-ontarians

..(n.d.b). Mandate of the Aboriginal Working Committee. Retrieved from http://ottawa.ca/ en/city-hall/your-city-government/aboriginal-workingcommittee/aboriginal-working-committee

City of Ottawa Accessibility Advisory Committee (AAC). (2008, June 4). Accessibility Advisory Committee meeting 16. Meeting minutes. Retrieved from http://app06.ottawa.ca/calendar/ottawa/citycouncil/a-acac/2008/06-04/ minutes $16 . h$ tm 
City of Ottawa Equity and Diversity Policy. (2001). Retrieved from http://ottawa.ca/ en/city_hall/policiesadministration/policies/equity_diversity/

City of Ottawa Community and Protective Services Committee (CPSC). (2008). Report to Community and Protective Services Committee: Immigration Ottawa Initiative, submitted by Steve Kanellakos, Deputy City Manager. ACS2008-CPS-EFA-0001. June 11, 2008. Retrieved from https:/app06.ottawa.ca/calendar/ottawa/ citycouncil/occ/2008/07-09/cpsc/01\%20-\%20ACS2008-CPS-EFA-0001.htm

City of Ottawa Corporate Services and Economic Development Committee (CSEDC). (2006, October 25). Accessibility lens in the City of Ottawa. Disposition presented to CSEDC by Accessibility Advisory Committee. Retrieved from http://ottawa.ca/ calendar/ottawa/citycouncil/occ/2006/10-25/csedc/ACS2006-CCV-AAC0003.htm

........(2007, May 15). CSEDC minutes 9. Retrieved from http://app06.ottawa.ca/ calendar/ottawa/citycouncil/csedc/2007/05-15/minutes 9. htm

City of Ottawa Council. (2005, May 25). Council meeting minutes 34. Retrieved from http://app06.ottawa.ca/calendar/ottawa/citycouncil/occ/2005/05-25/minutes 34.htm

........(2006, October 25). Council meeting minutes 67. Retrieved from http://app06.ottawa.ca/calendar/ottawa/citycouncil/occ/2006/10-25/minutes 67.htm

.(2008a, May 14). Council meeting minutes 36. Retrieved from http://app06.ottawa.ca/calendar/ottawa/citycouncil/occ/2008/05-14/Minutes 36.htm

.(2008b, May 14). 2. Equity and Diversity Advisory Committee - 2007 annual report, 2008 workplan and revised terms of reference. Document presented at Council Meeting 36. Retrieved from http://app06.ottawa.ca/calendar/ottawa/ citycouncil/occ/2008/05-14/csedc/02-ACS2008-CCV-EQD-0001.htm

(2008c, July 9). Council meeting minutes 40. Retrieved from http://app06.ottawa.ca/calendar/ottawa/citycouncil/occ/2008/07-09/minutes 40.htm

City of Ottawa Equity and Diversity Advisory Committee (EDAC). (2006, January 16). EDAC meeting minutes 17. Retrieved from http://app06.ottawa.ca/calendar/ ottawa/citycouncil/a-edac/2006/01-16/minutes $17 . \mathrm{htm}$ 
........(2007a, April 17). Report to Corporate Services and Economic Development Committee and Council. ACS2007-CCV-EQD-0001. Submitted by Chair, Equity and Diversity Advisory Committee. Retrieved from http://app06.ottawa.ca/ calendar/ottawa/citycouncil/occ/2007/05-23/csedc/ACS2007-CCV-EQD0001.htm

..(2007b, May 14). EDAC meeting minutes. Retrieved from http://www.ottawa.ca/ calendar/ottawa/citycouncil/a-edac/2007/05-14/minutes4.htm

........(2007d, December 3). Budget considerations for the integration of equity and diversity norms within the City of Ottawa. Presented to Ottawa City Council by the Equity and Diversity Advisory Committee

........(2008a, March 25). Report to Corporate Services and Economic Development Committee and Council. Submitted by Essam Hamed, Chair, Equity and Diversity Advisory Committee. Retrieved from http://ottawa.ca/calendar/ottawa/ citycouncil/csede/2008/05-06/ACS2008-CCV-EQD-0001.htm

.......(2008b, April 1). EDAC Chair letter to Steve Finnamore re: multi-focal lens.

City of Ottawa Finance and Economic Development Committee (FEDCO) and Governance Renewal Subcommittee. (2012, September 12). Joint report 2: Advisory Committee renewal to support Council's term of council priorities. Retrieved from http://ottawa.ca/calendar/ottawa/citycouncil/occ/2012/0912/fedco/01\%20-20Advisory\%20Committee\%20Renewal\%20-\%20EN.pdf

City of Ottawa French Language Services Advisory Committee (FLSAC). (2008, June 5). FLSAC minutes 8 -English. Retrieved from http://app06.ottawa.ca/calendar/ ottawa/citycouncil/a-flsac/2008/06-05/minutes8eng.htm

City of Ottawa Health and Social Services Advisory Committee (HSSAC). (2005). HSSAC minutes 18. August 30. Retrieved from http://app06.ottawa.ca/calendar/ ottawa/citycouncil/a-hssac/2005/08-30/minutes $18 . \mathrm{htm}$

City of Ottawa Health, Recreation and Social Services Committee (HRSSC). (2005, April 28). Report to HRSSC and Council, submitted by Deputy City Manager CPS. Retrieved from http://app06.ottawa.ca/calendar/ottawa/citycouncil/hrssc/2005/0505/ACS2005-CPS-DCM-0002.htm

........(2005, May 5). HRSSC mnutes 21. Retrieved from http://app06.ottawa.ca/ calendar/ottawa/citycouncil/hrssc/2005/05-05/minutes21.htm

........(2005, June 16). Report to HRSSC: CPS three year strategic plan and 2006 departmental business plan, submitted by Deputy City Manager CPS. Retrieved from http://www.ottawa.ca/calendar/ottawa/citycouncil/a-hssac/2005/09-15/ ACS2005-CPS-DCM-0008.htm 
........(2005, May 25). HRSSC report $21 \mathrm{~A}$ to Council. Retrieved from http://app06.ottawa.ca/calendar/ottawa/citycouncil/occ/2005/05-25/hrss/ reportindex 21A.htm

City of Ottawa Poverty Issues Advisory Committee (PIAC). (2008). PIAC minutes 15. June 10. Retrieved from http://ottawa.ca/calendar/ottawa/citycouncil/a-piac/2008/ 06-10/minutes $15 . h t m$

City of Ottawa Rural Issues Advisory Committee (RIAC). (2008). RIAC minutes 13. June 17. Retrieved from http://app06.ottawa.ca/calendar/ottawa/citycouncil/riac/2008/ 06-17/minutes $13 . h t m$

City of Ottawa Seniors Advisory Committee (SAC). (2008, June 18). SAC minutes 14. Retrieved from http://app06.ottawa.ca/calendar/ottawa/citycouncil/a-sac/2008/0618/minutes $14 . h$ tm (2009, February 4). SAC minutes 19. Retrieved from http://ottawa.ca/calendar/ ottawa/citycouncil/a-sac/2009/02-04/minutes $19 . \mathrm{htm}$

City of Ottawa Labour Market Integration. (2007). Faces of Ottawa: A snapshot of immigrant labour market integration - Highlights. March 2007. Retrieved from http://app06.ottawa.ca/calendar/ottawa/citycouncil/cpsc/2007/04-05/faces_of_ immigration_highlights_en.pdf

Croteau, David and Lyndsi Hicks. (2003). Coalition framing and the challenge of a consonant frame pyramid: The case of a collaborative response to homelessness. Social Problems, 50, 251-72.

Dijk, Teun A. van. (1993). Elite discourse and racism. Newbury Park: Sage Publications.

Dua, Enakshi. (2009). On the effectiveness of anti-racist policies in Canadian universities: Issues of implementation of policies by senior administration. In Frances Henry and Carol Tator (Eds.), Racism in the Canadian university: Demanding social justice, inclusion and equity, (pp. 160-195). Toronto: University of Toronto Press.

Employment Equity Act. S.C. 1995, c. 44. Retrieved from http://laws-lois.justice.gc.ca/ eng/acts/E-5.401/page-1.html

Fagan, Noreen. (2010). Ottawa mayoral race: Jim Watson to the rescue? Daily Extra Beta. August 12. Retrieved from http://www.dailyxtra.com/ottawa/news/ottawamayoral-race-jim-watson-the-rescue?market $=210$

Ferree, Myra Marx. (2003). Resonance and radicalism: Feminist framing in the abortion debates of the United States and Germany. American Journal of Sociology, 109, 304-344. 
Fraser, Nancy. (2000). Rethinking recognition, New Left Review, (3), 107-120.

Gabriel, John. (1998). Whitewash: Racialized politics and the media. New York: Routledge.

Gamson, William. A. (1990[1975]). The strategy of social protest, (2nd ed.). Belmont, Calif:: Wadsworth Pub.

Guenther, Katja M. (2010). The strength of weak coalitions: transregional feminism in Eastern Germany since unification. In Nella van Dyke and Holly McCammon (Eds.), Strategic alliances: New studies of social movement coalitions (pp. 119142). Minneapolis: University of Minnesota Press.

Greater London Authority. (2009). Publications 2000-2008 - Equalities. London, UK. Retrieved from http://legacy.london.gov.uk/gla/publications/equalities.jsp

Hadibhai, Amyn. (2004). Surveying racial discrimination cases. Ontario Human Rights Commission race policy dialogue papers, December 2004. Retrieved from http://www.ohrc.on.ca/vi/node/8973

Harney, Stefano. (2002). State work: Public administration and mass intellectuality. Durham: Duke University Press.

Hayashi, Yuki. (1992). On Queer Nation. Xtra! June 26, 14. Toronto, Ontario.

Henry, Frances et al. (2005). The colour of democracy: Racism in Canadian society, (3nd ed.). Toronto: Thomson Nelson.

Hire Immigrants Ottawa (HIO). (2006). The HIO Initiative. Retrieved from http://www.hireimmigrantsottawa.ca/English/About\%20Us/initiative.php

........(2008). Employers guide to integrating immigrants into the workplace. Retrieved from http://www.hireimmigrantsottawa.ca/downloads/EmployersGuide-English/ EmpGuide_EN_2011.pdf

Immigration Watch Canada. (2010). Immigration Watch Canada. Retrieved from http://www.immigrationwatchcanada.org/

Jiwani, Yasmin. (2006). Discourses of denial: Mediations of race, gender, and violence. Vancouver: UBC Press.

Kepmthorne, Eric G. (2013). Claims making and policymaking in state anti-racism in Ontario: The case of the Ontario Anti-Racism Secretariat. Open Access Dissertations and Theses. Paper 7979. 
Kobayashi, Audrey. (1993). Representing ethnicity: Political statistexts. In Challenges of measuring an ethnic world, proceedings from the Joint Canada-United States Conference on the Measurement of Ethnicity, Statistics Canada and the U.S. Bureau of the Census, 513-525.

Lepofsky, M. David. (2004). The long, arduous road to a barrier-free Ontario for People with disabilities: The history of the Ontarians with Disabilities Act - the first chapter. National Journal of Constitutional Law, 15(2), 125-333.

Lo, Clarence Y. H. (1992). Communities of challengers in social movement theory. In Aldon Morris and Carol McClurg Mueller (Eds.), Frontiers in social movement theory (pp. 224-227). New Haven: Yale University Press.

MacKenzie, I. R. (1994). Racial harassment in the workplace: Evolving approaches. Canadian Labour and Employment Law Journal, 3, 287-311.

Macpherson, Crawford Brough. (1977). The life and times of liberal democracy. Oxford: Oxford University Press.

Mahon, Rianne. (1977). Canadian public policy: The unequal structure of representation. In Leo Panitch (Ed.), The Canadian state: Political economy and political power (pp. 165-198). Toronto: University of Toronto Press.

McCall, Leslie. (2005). The complexity of intersectionality. Signs, 30(3), 1771-1800.

McIntosh, Peggy. (1989). White privilege: Unpacking the invisible knapsack. Peace and Freedom Magazine, July/August,10-12. Philadelphia: Women's International League for Peace and Freedom.

Ministry of Community and Social Services, Government of Ontario. (2008). About the Accessibility for Ontarians with Disabilities Act, 2005 (AODA). Queen's Printer for Ontario. Retrieved from http://www.mcss.gov.on.ca/documents/en/mcss/ publications/accessibility/AboutAODAWeb20080311EN.pdf

Mock, Karen et al. (2006). Addressing hate crime in Ontario: Final report of the Hate Crimes Community Working Group to the Attorney General and the Minister of Community Safety and Correctional Services - Strategy recommendations priorities for action. Hate Crimes Community Working Group, Ministry of the Attorney General and Ministry of Community Safety and Correctional Services, Government of Ontario. Toronto: Ministry of the Attorney General. Retrieved from http://www.attorneygeneral.jus.gov.on.ca/english/about/pubs/hatecrimes/ HCCWG_full.pdf

Mohanty, Chandra Talpade. (1984). Under Western eyes: Feminist scholarship and colonial discourses. boundary 2, 12/13(3), 333-358. 
Moodley, Kogila A. (1985). Review of Equality Now: Report of the Special Committee on Visible minorities in Canadian society. Canadian Public Policy/Analyse de Politiques 11(2), 254-256.

National Post. (2007). Canada told not to use term 'visible minorities'. March 8. Retrieved from http://www.Canada.com/nationalpost/news/story.html ?id=99f7e1e1-4424-429c-908a-125822989a97

Okamoto, Dina G. (2010). Organizing across ethnic boundaries in the post-civil rights era: Asian American panethnic coalitions. In Van Dyke, Nella and Holly J. McCammon (Eds.), Strategic alliances - coalition building and social movements (pp. 143-169). Minneapolis: University of Minnesota Press.

Oliver, Pamela E. and Hank Johnston. (1999). What a good idea! Frames and ideologies in social movement research, draft originally prepared for the annual meeting of the American Sociological Association, August 8, 1999, 1-24. Retrieved from http://www3.nd.edu/ dmyers/cbsm/vol2/ideology.pdf

Ontario Human Rights Commission. (2013). OHRC seeks input on new Code grounds gender identity and gender expression. Toronto, April 24, 2013. Retrieved from http://www.ohrc.on.ca/en/news_centre/ohrc-seeks-input-new-code-groundsgender-identity-and-gender-expression

........(n.d.a) The Ontario Human Rights Code. Retrieved from http://www.ohrc.on.ca/ en/ontario-human-rights-code

.(n.d.b) Grounds of discrimination. Retrieved from http://www.ohrc.on.ca/en/ learning/ basic-rights-and-responsibilities/grounds-discrimination

Ontario Human Rights Code. R.S.O. 1990, Chapter H.19, Part I, Freedom from Discrimination. Retrieved from http://www.e-laws.gov.on.ca/html/statutes/ english/elaws_statutes_90h19_e.htm

Ontario Ministry of Community and Protective Services. (2008). About the Accessibility for Ontarians with Disabilities Act, 2005. Toronto: Queen's Printer for Ontario. Retrieved from http://www.mcss.gov.on.ca/documents/en/mcss/publications/ accessibility/AboutAODAWeb20080311EN.pdf

Ottawa Chamber of Commerce. (2008). Employer's guide to integrating immigrants into the workplace. Retrieved from http://www.ottawachamber.ca/global_experience _work/employers_guide_to_integrating_immigrants_into_the_workplace.aspx

Pilieci, Vito. (2013). Invest Ottawa puts city's high tech future in hands of six experts. Ottawa Citizen, July 30. 
Patwell, Beverley, Donna Gray, and Steve Kanellakos. (2012a). Discovering the magic of culture shifts: A case study in large scale culture transformation. $O D$ PRACTITIONER, 44(1), 11-17.

........(2012b). An innovative approach to fostering a culture of Service Excellence in the City of Ottawa. Queen's University IRC. Retrieved from jttp://irc.queensu.ca/ sites/default/files/articles/innovative-approach-to-fostering-culture-of-serviceexcellence-city-ottawa.pdf

........(2011). Fostering a culture of Service Excellence in the City of Ottawa. Conference presentation at ODNET Conference, Baltimore, Maryland. October 31, 2011. Retrieved from www.odnetwork.org/resource/resmgr/2011_conf_ppts/ city_of_ottawa-fostering_a_c.pdf

Prince, Michael J. (2009). Absent citizens: Disability politics and policy in Canada. Toronto: University of Toronto Press.

Said, Edward. (1994[1978]). Orientalism. New York: Vintage Books.

Saloojee, Anver. (2003). Social inclusion, anti-racism and democratic citizenship. Perspectives On Social Inclusion Working Paper Series. Toronto: The Laidlaw Foundation. Retrieved from http://www.offordcentre.com/VoicesWebsite/Library/ reports/documents/laidlaw/saloojee.pdf

Siemiatycki, Myer. (2011). The diversity gap: the electoral under representation of visible minorities. Ryerson Cenre for Immigration \& Settlement, Ryerson University. Commissioned by Diverse City: The Greater Toronto Leadership Project, as part of Diverse City Counts Research Series, led by Maytree and the Greater Toronto Civic Action Alliance. Retrieved from http://diversecitytoronto.ca/wp-content/ uploads/Final-Report.pdf

Snow, David A. and Robert D. Benford. (1992). Master frames and cycles of protest. In Aldon Morris and Carol McClurg Mueller (Eds.), Frontiers in social movement theory (pp. 133-155). New Haven: Yale University Press.

..(2000). Mobilization forum: Comment on Oliver and Johnston: Clarifying the relationship between framing and ideology. Mobilization: An International Journal, 5(1), 55-60. Retrieved from http://www.ssc.wisc.edu/ oliver/ Protests/ArticleCopies/SnowBenford2000ReplytoOliverJohnstonMoby.pdf

Social Planning Council of Ottawa and City for All Women Initiative. (2005). Together, promoting equity in our city - CPS strategic plan. Presented to City of Ottawa Health and Social Services Citizens Advisory. Committee. Retrieved from http://ottawa.ca/calendar/ottawa/citycouncil/a-hssac/2005/08-30/ gender\%20equality.htm 
Spivak, Gayatri Chakravorty. “Can the Subaltern Speak?” Cary Nelson and Lawrence Grossberg (Eds.), Marxism and the Interpretation of Culture (pp. 271-313). Urbana: U of Illinois P, 1988.

Statistics Canada. (2013). Visible minority and population group reference guide, National Household Survey, 2011. Catalogue No.99-010-XWE2011009. May 8, 2013. Retrieved from http://www12.statcan.gc.ca/nhs-enm/2011/ref/guides/99010-x/99-010-x2011009-eng.cfm

Status of Women Canada. (2009). Disclosure of grant and contribution awards - 20082009. Updated February 3. Retrieved from http://www.swc-cfc.gc.ca/accountresp/pd-dp/dgc-dsc/2008-2009/gc-sc-291-eng.html

.......(2013a). What is GBA+? Updated September 30. Retrieved from http://www.swccfc.gc.ca/gba-acs/intro-eng.html

.(2013b). A brief history of GBA+. Updated September 30. Retrieved from http://www.swc-cfc.gc.ca/gba-acs/history-histoire-eng.html

Tanakiwin. (2009). Tanakiwin - Negotiating team. Algonquin Treaty Negotiation Funding Trust. Retrieved from http://www.tanakiwin.com/treaty_team.htm

The Canadian Tribute to Human Rights. (2008). History - The artist: Melvin Charney. Retrieved from http://www.cthr-mcdp.com/history/artist.html

The Ottawa Citizen. (2009a). Ottawa taxi driver recounts horrific road rage incident. May. 14. Retrieved from http://www.ottawacitizen.com/news/Ottawa+taxi+ driver+recounts+horrific+road+rage+incident/1589817/story.htm

........(2009b). Officer charged with assaulting cab driver. Jun 24. Retrieved from http://www2.Canada.com/ottawacitizen/news/city/story.html?id=36dbe369-bd3046ec-bb37-adaf6e968076

The Ottawa Sun. (2009a). Cabbie assaulted at airport: Witness says attacker flashed police ID. May 12 Retrieved from http://www.ottawasun.com/news/ottawa/ 2009/05/12/9436236.html

........(2009b). Road rage attack leaves Ottawa cabbie with broken arm. May 13. Retrieved from http://www.nugget.ca/2009/05/13/road-rage-attack-leaves-ottawacabbie-with-broken-arm

.......(2009c). Police Chief maps out assault probe for cab driver: Off-duty officer under investigation in airport incident. May 15. Retrieved from http://www.ottawasun.com/news/ottawa/2009/05/15/9465336-sun.html 
The Queer Nation Manifesto. (1990). Queers read this: The Queer Nation Manifestpublished anonymously by Queers. Pamphlet originally distributed at the New York Gay Pride Day parade, 1990. Retrieved from http://www.actupny.org/ documents/QueersReadThis.pdf

U.N. Committee on the Elimination of Racial Discrimination. Report of the Committee on the Elimination of Racial Discrimination, Seventieth session (February19March 9 2007) and Seventy-first session (July 30 - August 17 2007). Supp. No. 18 (A/62/18). Official Record. Retrieved from http://www.internaldisplacement.org/8025708F004CE90B/\%28httpDocuments\%29/335171A8F3A2 AD5BC12574B90039508C/\$file/a_62_18_2007.pdf

U.N. General Assembly. International Convention on the Elimination of All Forms of Racial Discrimination, December 21, 1965, United Nations Treaty Series, vol. 660, p. 195, Part I, Article 1. Retrieved from http://www.ohchr.org/EN/ ProfessionalInterest/Pages/CERD.aspx

Van Dyke, Nella and Holly J. McCammon (Eds.), (2010). Strategic alliances - Coalition building and social movements. Minneapolis: University of Minnesota Press.

Warner, Tom. (2002). Never going back: A history of queer activism in Canada. Toronto: University of Toronto Press.

Wilde, Lawrence. (2007). The concept of solidarity: Emerging from the theoretical shadows? The British Journal of Politics and International Relations, 9(1), 171181.

Williams, Charmaine C. (2002). A rationale for an anti-racist entry point to antioppressive social work in mental health services. Critical Social Work, 3(1). Retrieved from http://www1.uwindsor.ca/criticalsocialwork/a-rationale-for-ananti-racist-entry-point-to-anti-oppressive-social-work-in-mental-health-services

Working Group on Women's Access to Municipal Services in Ottawa (WGWAMSO). (2001). Making the new City of Ottawa work for women: The results from focus groups on women's experiences accessing municipal services in OttawaAppendices. August 28. Retrieved from http://aix1.uottawa.ca/ candrew/ appendices.pdf

........(2002). Making the new city of ottawa work for women: Report on recommendations to City Council. January 2002. Retrieved from http://www.cawi-ivtf.org/sites/all/files/pdf/WomenAccessFinalReport.pdf 